DANIELLE MATSUMOTO

\title{
MODELAGEM E SIMULAÇÃO DE REATOR SOLAR USANDO FLUIDODINÂMICA COMPUTACIONAL
}


DANIELLE MATSUMOTO

MODELAGEM E SIMULAÇÃO DE REATOR SOLAR USANDO FLUIDODINÂMICA COMPUTACIONAL

São Paulo

2013 


\title{
MODELAGEM E SIMULAÇÃO DE REATOR SOLAR USANDO FLUIDODINÂMICA COMPUTACIONAL
}

\author{
Dissertação apresentada à Escola \\ Politécnica da Universidade de São Paulo \\ para obtenção do título de Mestre em \\ Engenharia Química. \\ Área de concentração: \\ Engenharia Química
}

Orientador:

Prof. Dr. José Luís de Paiva

São Paulo 
Este exemplar foi revisado e corrigido em relação à versão original, sob responsabilidade única do autor e com a anuência de seu orientador.

São Paulo, de julho de 2013.

Assinatura do autor

Assinatura do orientador

FICHA CATALOGRÁFICA

Matsumoto, Danielle

Modelagem e simulação de reator solar usando fluidodinâmica computacional / D. Matsumoto. - versão corr. -- São Paulo, 2013.

$152 \mathrm{p}$.

Dissertação (Mestrado) - Escola Politécnica da Universidade de São Paulo. Departamento de Engenharia Química.

1.Reator químico 2.Simulação 3.Radiação (Calor) 4.Fotoquímica I.Universidade de São Paulo. Escola Politécnica. Departamento de Engenharia Química II.t. 


\section{AGRADECIMENTOS}

Ao meu orientador, Prof. Dr. José Luís de Paiva, pela infinita dedicação, comprometimento, motivação nos momentos difíceis, conselhos, horas de conversas, amizade e, principalmente, por acreditar e confiar no meu trabalho. Enfim, sem a sua ajuda e orientação, finalizar esse mestrado não teria sido possível;

Aos meus pais, Newton e Márcia, por me motivarem a sempre buscar o meu melhor, apoiarem todas as minhas decisões e, com muito amor, me ajudarem a concretizar os meus sonhos;

Ao Dr. Adriano Ferreira de Mattos Silvares, pela inestimável ajuda com o código do PHOENICS e pelas valiosas sugestões na qualificação;

A Dra. Kátia Ribeiro, pelas conversas sobre reatores fotoquímicos e fornecimento dos dados experimentais para a validação dos modelos;

Ao Prof. Dr. Roberto Guardani, pelo incentivo, conselhos e pelas excelentes sugestões na qualificação;

Ao Prof. Dr. Antonio Carlos Silva Costa Teixeira, pelas valiosas conversas e esclarecimentos de dúvidas sobre fotoquímica;

A CHAM, pela assistência técnica prestada durante o mestrado;

Ao amigo Igor Ribeiro de Souza, pela preciosa ajuda com as automações e desenvolvimento de macros e pela amizade;

A Profa. Dra. Liria Matsumoto Sato, pelo incentivo, ajuda e, principalmente, pelo exemplo de como ser uma engenheira, pesquisadora e mãe;

Ao meu namorado, Vinicius, pela paciência, infinitas conversas, motivação, amor e carinho durante todo o período do mestrado;

Ao meu irmão Luis Gustavo, pelo apoio, carinho e motivação;

Aos amigos, Amanda, Adriana, Vilaça, Thiago Bueno, Thiago Trigo, Cris, Ju, Ciuffo, Carol, Bianca e Moni por me incentivarem e torcerem por mim, seja com uma frase, um auxílio-moradia ou um happy hour em algum bar;

Ao Dr. Valter Cesar de Souza, por me apresentar o incrível mundo do CFD, pelo mentorado e pelos conselhos;

A todos os amigos da Chemtech, especialmente ao Luiz Antonio Costa de Arruda Mello, pelo incentivo inicial e apoio durante todo período do mestrado;

Ao Alexander Zerwas, pela ajuda no tratamento dos dados nesta reta final;

A Silvia Martins Baeder, Alexandre Oliveira e a Maria do Carmo Neves, pela ajuda prestada com assuntos de TI e administrativos. 


\section{RESUMO}

Este estudo apresenta a modelagem fluidodinâmica de um reator solar utilizado para Processos Oxidativos Avançados (POA). Desenvolveu-se um modelo que considera a fluidodinâmica, o campo de radiação e cinética da reação de actinometria química (ferrioxalato), em regime transiente. Essa modelagem foi feita utilizando-se o código de fluidodinâmica computacional PHOENICS.

Para análise dos resultados de simulações com o modelo, consideraram-se os dados experimentais de actinometria química para um trecho do reator, constituído de dois tubos (hairpin), e de distribuição de tempos de residência (DTR), para o reator completo, constituído de dez tubos. Os dados experimentais foram obtidos por RIBEIRO (2009).

O resultado da análise da distribuição do tempo de residência do reator completo mostrou que o modelo baseado em escoamento laminar apresentou uma maior aderência aos dados experimentais de DTR.

Como os experimentos de actinometria foram realizados em trecho com dois tubos do reator, construiu-se a geometria do hairpin que apresentou uma DTR mais aderente aos modelos teóricos. Outra simplificação foi necessária para a modelagem do campo de radiação de forma mais precisa, adaptando-se o hairpin para um tubo reto simples.

A partir dos resultados de actinometria química foi possível estimar, pelo modelo, a taxa de fótons incidentes na parede do reator.

Palavras-chave: CFD, Reator Fotoquímico, Simulação, Modelagem, Actinometria, Fotoquímica, Radiação, Distribuição do Tempo de Residência. 


\begin{abstract}
This study consists of the fluid dynamic modeling of a solar reactor used in Advanced Oxidation Processes (AOP). The model was developed by considering fluid dynamics, radiation field and the kinetics of the chemical actinometry reaction (ferrioxalate) in transient regime. This modeling was developed using computational fluid dynamics (CFD) in PHOENICS.

Simulation results based on the model were analyzed by comparing them with a set of chemical actinometry experimental data obtained by RIBEIRO (2009). This considered a reactor section constituted by two pipes (hairpin), and the residence time distribution (RTD) of the complete reactor, composed of ten pipes.

Residence time distribution results showed that the laminar flow model presented a better fitting to experimental data.

Since the actinometry experiments were carried out in a reactor section with two pipes, a new geometry was designed, which resulted in a better fitting of RTD results with theoretical models. In order to obtain a more precise radiation field model, another simplification was necessary, which consisted of assuming a straight cylindrical pipe geometry.

The use of the chemical actinometry and the radiation field model enabled the estimation of the incident photons rate at reactor wall.
\end{abstract}

Keywords: CFD, Photochemical reactor, Simulation, Modeling, Actinometry, Radiation, Residence Time Distribution. 


\section{LISTA DE FIGURAS}

Figura 1.1 - Estrutura da metodologia de trabalho utilizada para desenvolver o presente estudo...

Figura 2.1 - Exemplo de malha utilizada no método dos volumes finitos. (MALISKA, 2004)

Figura 2.2 - Organização dos pontos no espaço para o caso de elementos hexaédricos. (Maliska, 2004).

Figura 2.3 - Tipos de malha: (a) estruturada cartesiana, (b) estrutura generalizada, (c) não estruturada e (d) híbrida. (MALISKA, 2004)

Figura 2.4 - Métodos para a determinações da distribuição do tempo de residência (FOGLER, 2002).

Figura 2.5 - Desvios em reatores reais: (a) DTR para um escoamento quase uniforme; (b) DTR para um CSTR de mistura quase perfeita; (c) DTR para um reator de leito de recheio com zonas mortas e canalizações; (d) reator de leito de recheio; (e) reator tanque com curto circuito no escoamento (desvio ou bypass); (f) CSTR com zona morta e bypass. (FOGLER, 2002).

Figura 2.6 - Abordagem teórica para a modelagem do LVREA. (ALFANO, 1986) ...18

Figura 2.7 - Características de modelos bidimensionais de incidência de radiação:

(a) Radial, (b) Parcialmente difusa e (c) Difusa. (ALFANO, 1986) 20

Figura 2.8 - Geometria básica de um reator CPC teórico. (ALFANO,2000) .23

Figura 3.1 - Reator CPC existente no CESQ que será modelado - Vista frontal do reator. (RIBEIRO, 2009)

Figura 3.2 - Esquema do reator CPC modelado e simulado no PHOENICS - Vista superior.

Figura 3.3 - Módulos de pré-processamento, solver e pós processamento existentes no software PHOENICS. (SPALDING, 2011)

Figura 3.4 - Ponto modelado de injeção do corante azul de metileno para as simulações de distribuição de tempo de residência no PHOENICS. 33

Figura 3.5 - Dados de input do tipo pulso, inseridos no PHOENICS. 34

Figura 3.6 - Comparação dos diferentes ajustes matemáticos feitos para o modelo cinético. 36

Figura 4.1 - Malha 1, com 55.278 elementos, usada para a seleção de malha........41

Figura 4.2 - Malha 2, com 280.860 elementos, usada para a seleção de malha......42

Figura 4.3 - Comparativo dos campos de velocidades e pressão obtidos na seleção de malhas para o escoamento laminar, no reator completo: (a) Malha 1 e (b) Malha 2.

Figura 4.4 - Comparativo das curvas de distribuição do tempo de residência para a seleção das malhas para o escoamento laminar, no reator completo. 
Figura 4.5 - Comparativo dos campos de velocidades e pressão obtidos na seleção de malhas para o escoamento turbulento $(\mathrm{K}-\varepsilon)$, no reator completo : (a) Malha 1 e (b) Malha 2.

Figura 4.6 - Comparativo das curvas de distribuição do tempo de residência para a seleção das malhas para o escoamento turbulento $(\mathrm{K}-\varepsilon)$, no reator completo.

Figura 4.7 - Resultados obtidos para o escoamento laminar, utilizando-se a malha 2 selecionada : (a) Campo de pressão, (b) Campo de velocidades e (c) Detalhe do campo de velocidade dos dois últimos trechos do reator.

Figura 4.8 - Resultados obtidos para o escoamento utilizando o modelo de turbulência k- $\varepsilon$ para a malha 2 : (a) Campo de pressão, (b) Campo de velocidades, (c) Detalhe do campo de velocidade dos dois últimos trechos do reator e (d) $\mathrm{Y}^{+} \ldots . .48$

Figura 4.9 - Comparativo das curvas de distribuição do tempo de residência obtidas para o escoamento Laminar, turbulento $(k-\varepsilon)$ e para a curva experimental. 49

Figura 4.10 - Comparativo das curvas de distribuição do tempo de residência obtidas para o reator completo, para diferentes passos de tempo simulados e para a curva experimental.

Figura 4.11 - Concentração do traçador em função do tempo para o escoamento laminar no reator completo e passo de tempo $\Delta \mathrm{t}=1 \mathrm{~s}$.

Figura 4.12 - Modelos teóricos de escoamento para a distribuição de tempo de residência em reatores tubulares. (Levenspiel, 2000)

Figura 4.13 - Concentração do traçador em função do tempo para uma secção do reator.

Figura 4.14 - Comparativo das curvas de distribuição do tempo de residência entre a curva experimental, modelos teóricos, modelos semi-teóricos e a curva selecionada do modelo.

Figura 4.15 - Domínio do hairpin utilizado em experimentos de actinometria em coordenadas cartesianas.

Figura 4.16 - Malha 1 usada para a seleção de malha no hairpin com 50799 elementos.

Figura 4.17 - Comparativo dos campos de velocidades e pressão obtidos na seleção de malhas para o escoamento laminar no hairpin : (a) Malha 1, (b) Malha 2 e (c) Malha 3

Figura 4.18 - Comparativo das curvas de distribuição do tempo de residência para seleção das malhas, para o escoamento laminar no hairpin.

Figura 4.19 - Comparativo dos campos de velocidades e pressão obtidos na seleção

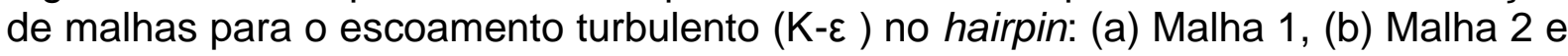
(c) Malha 3

Figura 4.20 - Comparativo das curvas de distribuição do tempo de residência para seleção das malhas, para o escoamento turbulento $(\mathrm{K}-\varepsilon)$ no hairpin. .57

Figura 4.21 - Malha selecionada para ser usada nas simulações do hairpin. .58 
Figura 4.22 - Resultados obtidos para o escoamento laminar, utilizando a malha 2 selecionada: (a) Campo de pressão, (b) Campo de velocidades e (c) Detalhe do campo de velocidade do último trecho do hairpin.

Figura 4.23 - Resultados obtidos para o escoamento utilizando o modelo de turbulência k- $\varepsilon$ para a malha 2 selecionada : (a) Campo de pressão, (b) Campo de velocidades, (c) Detalhe do campo de velocidade do último trecho do hairpin e (d) $\mathrm{Y}^{+}$.

Figura 4.24 - Comparativo das curvas de distribuição do tempo de residência para escoamento laminar no hairpin, para diferentes passos de tempo simulados.

Figura 4.25 - Comparativo das curvas de distribuição do tempo de residência para escoamento turbulento no hairpin, para diferentes passos de tempo simulados. .....62

Figura 4.26 - Concentração do traçador em função do tempo para o escoamento laminar no hairpin, para passo de tempo $\Delta \mathrm{t}=1 \mathrm{~s}$. .63

Figura 4.27 - Perfil de concentração do traçador em função do tempo para uma secção do hairpin. .64

Figura 4.28 - Comparação das curvas de distribuição do tempo de residência, para o escoamento laminar no hairpin: modelos teóricos e a curva selecionada do modelo.

Figura 4.29 - Concentração do traçador em função do tempo para o escoamento turbulento $(\mathrm{K}-\varepsilon)$ no hairpin para passo de tempo $\Delta \mathrm{t}=1 \mathrm{~s}$

Figura 4.30 - Comparação das curvas de distribuição do tempo de residência, para o escoamento turbulento $(\mathrm{K}-\varepsilon)$ no hairpin : modelo semi-teórico e a curva selecionada do modelo.

Figura 4.31 - Domínio do reator tubo reto cilíndrico 66

Figura 4.32 - Malha 2, com 600 elementos, selecionada para simulações do tubo reto cilíndrico.

Figura 4.33 - Comparativo dos campos de velocidades e pressão obtidos na seleção de malhas para o escoamento laminar no tubo reto cilíndrico: (a) Malha 1, (b) Malha 2 e (c) Malha 3. .68

Figura 4.34 - Comparação das curvas de distribuição do tempo de residência para a seleção das malhas, para o escoamento laminar no tubo reto cilíndrico. 68

Figura 4.35 - Comparativo dos campos de velocidades e pressão obtidos na seleção de malhas para o escoamento turbulento $(\mathrm{K}-\varepsilon$ ) no tubo reto cilíndrico: (a) Malha 1, (b) Malha 2 e (c) Malha 3.

Figura 4.36 - Comparação das curvas de distribuição do tempo de residência para a seleção das malhas, para o escoamento turbulento $(\mathrm{K}-\varepsilon)$ no tubo reto cilíndrico.....69

Figura 4.37 - Comparativo das curvas de distribuição do tempo de residência para escoamento laminar no tubo reto cilíndrico para diferentes passos de tempo simulados.

Figura 4.38 - Comparativo das curvas de distribuição do tempo de residência para escoamento turbulento no tubo reto cilíndrico para diferentes passos de tempo simulados. 
Figura 4.39 - Resultados obtidos para o escoamento laminarem tubo reto cilíndrico, utilizando a malha 2, para vazão de 0,845 L. $\min ^{-1}$ : (a) Campo de pressão, (b) Campo de velocidades.

Figura 4.40 - Campo de velocidades obtido para o escoamento turbulento (k- $-\varepsilon$ ), vazão de 8 L. $\mathrm{min}^{-1}$, utilizando a malha 2, para o tubo reto cilíndrico.

Figura 4.41 - Campo de velocidades obtido para o escoamento laminar, vazão de 8 L. $\mathrm{min}^{-1}$, utilizando a malha 2, para o tubo reto cilíndrico.

Figura 4.42 - Campo de velocidades para o escoamento plug-flow, vazão de 8 L. $\min ^{-1}$, utilizando a malha 2 selecionada, para o tubo reto cilíndrico.

Figura 4.43 - Campo de velocidades para o escoamento turbulento $(k-\varepsilon)$, vazão de 4 L. $\mathrm{min}^{-1}$, utilizando a malha 2 , para o tubo reto cilíndrico.

Figura 4.44 - Campo de velocidades para o escoamento turbulento $(k-\varepsilon)$, vazão de 12 L. min $^{-1}$, utilizando a malha 2 , para o tubo reto cilíndrico. .75

Figura 4.45 - Comparativo das curvas de distribuição do tempo de residência obtidas para escoamento laminar no tubo reto cilíndrico, para diferentes comprimentos do domínio, e a curva selecionada para o hairpin. .76

Figura 4.46 - Comparativo das curvas de distribuição do tempo de residência obtidas para escoamento turbulento $(k-\varepsilon)$ no tubo reto cilíndrico, para diferentes comprimentos do domínio, e a curva selecionada para o hairpin.

Figura 4.47 - Comparativo das curvas de distribuição do tempo de residência para o escoamento laminar no tubo reto cilíndrico: modelos teóricos e a curva selecionada do modelo.

Figura 4.48 - Comparativo das curvas de distribuição do tempo de residência para o escoamento turbulento $(K-\varepsilon)$ no tubo reto cilíndrico entre a curva do modelo semiteórico e a curva selecionada do modelo.

Figura 4.49 - Comparativo das curvas de distribuição do tempo de residência para o escoamento laminar no tubo reto cilíndrico e no hairpin. .80

Figura 4.50 - Comparativo das curvas de distribuição do tempo de residência para o escoamento turbulento $(\mathrm{k}-\varepsilon)$ no tubo reto cilíndrico e no hairpin.

Figura 5.1 - Curva obtida experimentalmente por RIBEIRO et al 2009, mostrando a concentração de $\mathrm{Fe}^{2+}$ em função do tempo. 82

Figura 5.2 - Campo de radiação para o modelo de incidência radial, para $G v=$ $6,0509 \cdot 10^{-4}$ einstein. $\mathrm{s}^{-1} \cdot \mathrm{m}^{-2}$, sem absorção da radiação.

Figura 5.3 - Comparativo do campo de radiação para o: (a) Modelo cinético de 1a ordem e (b) Modelo cinético exponencial.

Figura 5.4 - Comparação dos erros do balanço de massa para os diferentes modelos cinéticos ajustados.

Figura 5.5 - Comparativo das curvas de concentração de $\mathrm{Fe}^{+2}$ em função do tempo, mostrando resultados experimental e calculados para diferentes valores de $G_{v} \ldots \ldots . .87$

Figura 5.6 - Campo de radiação obtido para $G v=6,0509 \cdot 10^{-4}$ einstein $\cdot \mathrm{s}^{-1} \cdot \mathrm{m}^{-2}$, no instante $\mathrm{t}=1800 \mathrm{~s}$ 
Figura 5.7 - Concentração de $C 3=F e 3+$ e $C 4=F e 2+$ para $G v=6,0509.10^{-4}$ einstein. $s^{-1} \cdot m^{-2}$, nos instantes: (a) $t=30$ s e (b) $t=1800$ s

Figura 5.8 - Campo de radiação obtido para $G v=3,1054 \cdot 10^{-4}$ einstein. $\mathrm{s}^{-1} \cdot \mathrm{m}^{-2}$, no instante $\mathrm{t}=1800 \mathrm{~s}$.

Figura 5.9 - Concentração de $C 3=F e 3+$ e $C 4=F e 2+$ para $G v=3,1054.10^{-4}$ einstein. $s^{-1} \cdot m^{-2}$, nos instantes: (a) $t=30$ s e (b) $t=1800 s$

Figura 5.10 - Comparação das curvas de concentração $\mathrm{Fe}^{+2}$ em função do tempo para: os resultados experimentais e os calculados para diferentes valores $\alpha$.

Figura 5.11 - Comparação do campo de radiação para $G v=3,1054.10^{-4}$ einstein.s ${ }^{1} \cdot \mathrm{m}^{-2}$ e $\mathrm{t}=1800 \mathrm{~s}$, para diferentes valores de $\alpha$ : (a) $\alpha=5,17 \cdot 10^{4} \mathrm{~m}^{2} \cdot \mathrm{kmol}^{-1}$, (b) $10 . \alpha=$ $5,17 \cdot 10^{5} \mathrm{~m}^{2} \cdot \mathrm{kmol}^{-1} \mathrm{e}(\mathrm{c}) \alpha 10=5,17 \cdot 10^{3} \mathrm{~m}^{2} \cdot \mathrm{kmol}^{-1}$

Figura 5.12 - Comparação das concentrações de $\mathrm{C} 3=\mathrm{Fe} 3+$ e $\mathrm{C} 4=\mathrm{Fe} 2+$, para $G v=3,1054 \cdot 10^{-4}$ einstein $\cdot \mathrm{s}^{-1} \cdot \mathrm{m}^{-2} \mathrm{e} \mathrm{t}=1800 \mathrm{~s}$ : (a) $\alpha=5,17 \cdot 10^{4} \mathrm{~m}^{2} \cdot \mathrm{kmol}^{-1}$, (b) $10 . \alpha$ $=5,17 \cdot 10^{5} \mathrm{~m}^{2} \cdot \mathrm{kmol}^{-1} \mathrm{e}(\mathrm{c}) \alpha 10=5,17 \cdot 10^{3} \mathrm{~m}^{2} \cdot \mathrm{kmol}^{-1}$.

Figura 5.13 - Comparação das curvas de concentração $\mathrm{Fe}^{+2}$ em função do tempo para modelos de incidência de radiação.

Figura 5.14 - Comparação do campo de radiação para $G v=3,1054.10^{-4}$ einstein.s ${ }^{1}$. $\mathrm{m}^{-2}$ e $\mathrm{t}=1800 \mathrm{~s}$ : (a) Modelo de Incidência Radial e (b) Modelo de Incidência Difusa.

Figura 5.15 - Comparação das concentrações de $\mathrm{C} 3=\mathrm{Fe} 3+\mathrm{e} C 4=\mathrm{Fe} 2+$, para $G v=3,1054 \cdot 10^{-4}$ einstein. $s^{-1} \cdot \mathrm{m}^{-2}$ e t=1800s: (a) Modelo de Incidência Radial e (b) Modelo de Incidência Difusa.

Figura 5.16 - Campo de radiação para $G v=3,1054 \cdot 10^{-4}$ einstein. $\mathrm{s}^{-1} \cdot \mathrm{m}^{-2}, \alpha 10=5,17 \mathrm{x}$ $10^{3} \mathrm{~m}^{2} \cdot \mathrm{kmol}^{-1}$ e t $=1800 \mathrm{~s}$ : (a) Modelo de Incidência Radial e (b) Modelo de Incidência Difusa.

Figura 5.17 - Comparação das concentrações de $\mathrm{C} 3=\mathrm{Fe} 3+$ e $\mathrm{C} 4=\mathrm{Fe} 2+$, para $G v=3,1054 \cdot 10^{-4}$ einstein. $\mathrm{s}^{-1} \cdot \mathrm{m}^{-2}, \alpha 10=5,17 \times 10^{3} \mathrm{~m}^{2} \cdot \mathrm{kmol}^{-1} \mathrm{e} \mathrm{t}=1800 \mathrm{~s}$ : (a) Modelo de Incidência Radial e (b) Modelo de Incidência Difusa.

Figura 5.18 - Comparação das curvas de concentração $\mathrm{Fe}^{+2}$ em função do tempo para análise da influência de diferentes modelos de escoamento.

Figura 5.19 - Comparação do campo de radiação, para $G v=3,1054.10^{-4}$ einstein.s ${ }^{1} . \mathrm{m}^{-2}$ e t $=1800 \mathrm{~s}$ : (a) Plug Flow, (b) Turbulento (k-ع) e (c) Laminar.

Figura 5.20 - Comparação das concentrações de $\mathrm{C} 3=\mathrm{Fe} 3+$ e $\mathrm{C} 4=\mathrm{Fe} 2+$, para $G v=3,1054.10^{-4}$ einstein. $s^{-1} \cdot \mathrm{m}^{-2}$ e $\mathrm{t}=1800 \mathrm{~s}$ : (a) Plug Flow, (b) Turbulento $(\mathrm{k}-\varepsilon$ ) e (c) Laminar. 100

Figura 5.21 - Comparação das curvas de concentração $\mathrm{Fe}^{+2}$ em função do tempo para análise da influência de diferentes vazões. 102

Figura 5.22 - Comparação do campo de radiação para $G v=3,1054.10^{-4}$ e $\mathrm{t}=1800 \mathrm{~s}$, para: (a) Vazão = 8 L.min ${ }^{-1}$, (b) Vazão = 12 L. $\min ^{-1}$ e (c) Vazão = 4 L. $\min ^{-1} \ldots \ldots \ldots . . .102$

Figura 5.23 - Comparação das concentrações de $\mathrm{C} 3=\mathrm{Fe} 3+$ e $\mathrm{C} 4=\mathrm{Fe} 2+$, para $G v=3,1054 \cdot 10^{-4}$ einstein. $\mathrm{s}^{-1} \cdot \mathrm{m}^{-2}$ e $\mathrm{t}=1800 \mathrm{~s}$ : (a) Vazão $=4 \mathrm{~L} \cdot \mathrm{min}^{-1}$, (b) Vazão $=$ 8 L. $\min ^{-1} \mathrm{e}(\mathrm{c})$ Vazão $=12$ L. $\mathrm{min}^{-1}$ 


\section{LISTA DE TABELAS}

Tabela 2-1 - Termos da equação de transporte generalizada. (MALISKA, 2004) ......4

Tabela 2-2 - Variáveis da equação diferencial de transporte. (MALISKA, 2004) ........5

Tabela 2-3 - Modelos de turbulência utilizados no software PHOENICS (SPALDING, 2011).

Tabela 2-4 - Principais modelos desenvolvidos para reatores fotoquímicos, grupos de pesquisa e período de publicação. (ALFANO, 1986)

Tabela 2-5 - Definições das principais propriedades utilizadas nos estudos de radiação. (CASSANO, 1995)

Tabela 2-6 - Classificação utilizada para os principais modelos de radiação.

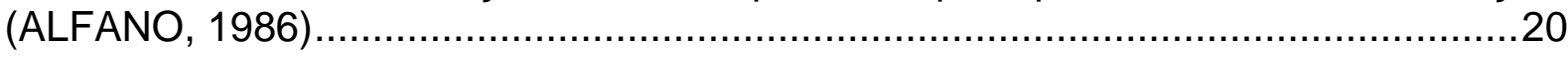

Tabela 2-7 - Tipos de actinômetros existentes. (SILVARES, 2006) ........................25

Tabela 2-8 - Rendimento quântico médio e o coeficiente neperiano de absorção médio do ferrioxalato de potássio. (ZALAZAR, 2005)

Tabela 4-1 - Malhas testadas no software PHOENICS para seleção de malha no reator completo. 41

Tabela 4-2 - Resumo das simulações realizadas para o reator completo.

Tabela 4-3 - Comparação dos tempos médios obtidos para o experimento e diferentes modelos de escoamento.

Tabela 4-4 - Comparação dos tempos médios obtidos para o experimento e diferentes passos de tempo simulados para o reator completo.

Tabela 4-5 - Malhas testadas no software PHOENICS para seleção de malha no Hairpin. .55

Tabela 4-6 - Resumo das simulações realizadas para o Hairpin. .58

Tabela 4-7 - Comparação dos tempos médios obtidos para o escoamento laminar no hairpin para diferentes passos de tempo simulados.

Tabela 4-8 - Comparação dos tempos médios obtidos para o escoamento turbulento para o hairpin., para diferentes passos de tempo.

Tabela 4-9 - Malhas testadas no software PHOENICS para seleção de malha no tubo reto cilíndrico.

Tabela 4-10 - Resumo das simulações realizadas para o tubo reto cilíndrico.

Tabela 4-11 - Comparação dos tempos médios obtidos para o escoamento laminar para o experimento e diferentes passos de tempo simulados no tubo reto cilíndrico.

Tabela 4-12 - Comparação dos tempos médios obtidos para o escoamento turbulento para o experimento e diferentes passos de tempo simulados no tubo reto cilíndrico. 
Tabela 4-13 - Resumo das simulações realizadas para o tubo reto cilíndrico para comparação de diferentes modelos de escoamento.

Tabela 4-14 - Resumo das simulações realizadas para o tubo reto cilíndrico visando comparar diferentes comprimentos do domínio.

Tabela 5-1 - Dados experimentais utilizados no modelo implementado no PHOENICS.(RIBEIRO , 2009).

Tabela 5-2 - Condições de contorno e dados de entrada das simulações do modelo cinético

Tabela 5-3 - Condições de contorno e dados de entrada das simulações para determinação do $G v$.

Tabela 5-4 - Condições de contorno e dados de entrada das simulações para a análise da influência do coeficiente neperiano de absorção molar.

Tabela 5-5 - Simulações realizadas para a análise da influência do coeficiente neperiano de absorção molar

Tabela 5-6 - Condições de contorno e dados de entrada das simulações para a análise da influência do tipo de modelo de radiação.

Tabela 5-7 - Condições de contorno e dados de entrada das simulações para a análise do tipo de escoamento.

Tabela 5-8 - Condições de contorno e dados de entrada das simulações para a análise da influência da vazão. 


\section{LISTA DE SÍMBOLOS}

\begin{tabular}{|c|c|c|}
\hline Símbolo & Descrição & Unidade \\
\hline$A$ & Área & $\mathrm{m}^{2}$ \\
\hline$[A]$ & Concentração de um Componente A & $\mathrm{kmol} \cdot \mathrm{m}^{-3}$ \\
\hline$\alpha$ & Coeficiente Neperiano de Absorção & $\mathrm{m}^{2} \cdot \mathrm{kmol}^{-1}$ \\
\hline$\beta$ & Coeficiente de Extinção Volumétrico & $m^{-1}$ \\
\hline$c$ & Velocidade da Luz & $\mathrm{m} \cdot \mathrm{s}^{-1}$ \\
\hline$C_{p}$ & Calor Específico & kcal. $\mathrm{kg}^{-1} \cdot{ }^{\circ} \mathrm{C}^{-1}$ \\
\hline$D$ & Diâmetro & $\mathrm{m}$ \\
\hline$D_{A c, \lambda}$ & $\begin{array}{l}\text { Absorbância da Solução Contendo o Actinômetro } \\
\text { para o Comprimento } \lambda\end{array}$ & - \\
\hline$D_{i}$ & Difusividade do Componente i & $\mathrm{m}^{2} \cdot \mathrm{s}^{-1}$ \\
\hline $\mathrm{e}_{v}^{\mathrm{a}}$ & Energia Local Absorvida Volumétrica & einstein. $\mathrm{m}^{-3} \cdot \mathrm{s}^{-1}$ \\
\hline$E_{v}$ & Energia Radiante & $J$ \\
\hline$E$ & $\begin{array}{l}\text { Taxa de Dissipação de Energia Cinética de } \\
\text { Turbulência }\end{array}$ & J.kg $\mathrm{kg}^{-1} \cdot \mathrm{s}^{-1}$ \\
\hline$G_{v}$ & Radiação Incidente & einstein. $\mathrm{m}^{2}$ \\
\hline$h$ & Constante de Planck & J.s \\
\hline$I_{v}$ & Intensidade Específica & $\mathrm{W} \cdot \mathrm{m}^{-2} \cdot \mathrm{sr}^{-1}$ \\
\hline $\boldsymbol{k}$ & Coeficiente de Transferência de Energia & $\mathrm{W} \cdot \mathrm{m}^{-2} \cdot \mathrm{K}^{-1}$ \\
\hline$k$ & Energia Cinética de Turbulência & $J \mathrm{~kg}^{-1}$ \\
\hline$k_{v}$ & Coeficiente de Absorção Volumétrico & $\mathrm{m}^{-1}$ \\
\hline$\lambda$ & Comprimento de Onda & $\mathrm{m}$ \\
\hline$L_{s, \lambda}$ & Distribuição Espectral da Irradiância Solar & $\mathrm{W} \cdot \mathrm{m}^{-2} \cdot \mathrm{nm}^{-1}$ \\
\hline$l$ & Caminho Ótico Percorrido & $\mathrm{m}$ \\
\hline$M_{A}$ & Massa Molar de um Componente A & $\mathrm{kg} \cdot \mathrm{kmol}^{-1}$ \\
\hline$n_{A}$ & Número de Moléculas de $A$ & kmol \\
\hline$n_{\Omega, v}$ & $\begin{array}{l}\text { Número de Fótons por Ângulo Sólido e por } \\
\text { Unidade de Intervalo de Frequência }\end{array}$ & fótons. $\mathrm{m}^{-3} \cdot \mathrm{s}^{-1}$ \\
\hline $\boldsymbol{n}$ & Versor Normal a Área & - \\
\hline$n_{\Omega, v}^{a}$ & Taxa de Absorção de Fótons & fótons.s ${ }^{-1}$ \\
\hline$n_{\Omega, v}^{e}$ & Taxa de Emissão de Fótons & fótons.s ${ }^{-1}$ \\
\hline
\end{tabular}




\begin{tabular}{|c|c|c|}
\hline$n^{s-i n} \Omega, v$ & $\begin{array}{l}\text { Taxa de Ganho de Fótons devido à Entrada por } \\
\text { Espalhamento }\end{array}$ & fótons. $s^{-1}$ \\
\hline$n^{s-o u t}{ }_{\Omega, v}$ & $\begin{array}{l}\text { Taxa de Perda de Fótons devido à Saída por } \\
\text { Espalhamento }\end{array}$ & fótons. $s^{-1}$ \\
\hline$\widetilde{N}$ & Número de Avogadro & $\mathrm{mol}^{-1}$ \\
\hline $\mathrm{Nt}$ & Número de Tanques & - \\
\hline$\Omega$ & Ângulo Sólido & $\mathrm{sr}$ \\
\hline $\mathbf{\Omega}$ & Versor de Direção de Propagação da Radiação & - \\
\hline$\varnothing$ & Variável Genérica & - \\
\hline$\phi$ & Ângulo & $\underline{0}$ \\
\hline$\phi$ & Diâmetro & $\mathrm{m}$ \\
\hline$\Phi_{A c}$ & Rendimento Quântico & kmol.einstein $^{-1}$ \\
\hline$P$ & Taxa de Fótons & Fótons \\
\hline$\rho$ & Densidade & $\mathrm{kg} \cdot \mathrm{m}^{-3}$ \\
\hline$P$ & Pressão & $\mathrm{Pa}$ \\
\hline$P_{v}$ & Potência de Radiação & W \\
\hline$\dot{q}$ & Vazão Volumétrica & $\mathrm{m}^{3} \cdot \mathrm{s}^{-1}$ \\
\hline $\boldsymbol{q}_{v}^{R}$ & Vetor de Fluxo Radiante & $\mathrm{W} \cdot \mathrm{m}^{-2}$ \\
\hline$R$ & Taxa de Reação & $\mathrm{kmol} \cdot \mathrm{m}^{-3} \cdot \mathrm{s}^{-1}$ \\
\hline$r$ & Coordenada Radial & $\mathrm{m}$ \\
\hline Re & Número de Reynolds & - \\
\hline$\sigma$ & Coeficiente de Espalhamento Volumétrico & $\mathrm{m}^{-1}$ \\
\hline$S^{\emptyset}$ & Termo Fonte & - \\
\hline$\theta$ & Ângulo & $\underline{0}$ \\
\hline $\mathrm{T}$ & Temperatura & $\stackrel{\circ}{ } \mathrm{C}$ \\
\hline$t$ & Tempo & s \\
\hline$T_{\lambda}$ & Transmitância da Parede de Vidro & - \\
\hline$T$ & Fração de Energia Transmitida & - \\
\hline V & Volume & $\mathrm{m}^{3}$ \\
\hline$v_{b}$ & Velocidade Média & $\mathrm{m} \cdot \mathrm{s}^{-1}$ \\
\hline$\vec{v}$ & Vetor Velocidade & $m \cdot s^{-1}$ \\
\hline$v$ & Velocidade em y & $\mathrm{m} \cdot \mathrm{s}^{-1}$ \\
\hline
\end{tabular}




$\begin{array}{cll}\mu & \text { Viscosidade } & \text { Pa.s } \\ u & \text { Velocidade em x } & \mathrm{m} . \mathrm{s}^{-1} \\ u_{v}^{R} & \text { Densidade de Energia Radiante } & \mathrm{J} . \mathrm{m}^{-3} \\ w & \text { Velocidade em z } & \mathrm{m} . \mathrm{s}^{-1} \\ y & \text { Coordenada em y } & \mathrm{m} \\ x & \text { Coordenada em x } & \mathrm{m} \\ \boldsymbol{x}_{A} & \text { Fração Mássica de um Componente A } & - \\ z & \text { Coordenada em z } & \mathrm{m}\end{array}$




\section{LISTA DE ÍNDICES}

$\begin{array}{cl}0 & \text { Incidente } \\ A b s & \text { Absorvidos } \\ A c & \text { Actinômetro } \\ B & \text { Bulk: Média } \\ C m & \text { Azul de Metileno } \\ E & \text { Elemento ao Leste } \\ H & \text { Elemento Acima } \\ \text { I } & \text { Componente i } \\ J & \text { Componente j } \\ L & \text { Elemento Abaixo } \\ \lambda & \text { Comprimento de Onda } \\ N & \text { Elemento ao Norte } \\ p & \text { Pressão Constante } \\ P & \text { Elemento Central } \\ S & \text { Elemento ao Sul } \\ T & \text { Transmitida } \\ W & \text { Elemento ao Oeste }\end{array}$




\section{LISTA DE ABREVIATURAS}

$\begin{array}{ll}\text { CAD } & \text { Computer Aided Design } \\ \text { CESQ } & \text { Centro de Estudos de Sistemas Químicos } \\ \text { CFSTR } & \text { Reator de Mistura em Tanque Contínuo } \\ \text { CFD } & \text { Computational Fluid Dynamics } \\ \text { CHAM } & \text { Concentration, Heat and Momentum } \\ \text { CONAMA } & \text { Conselho Nacional do Meio Ambiente } \\ \text { CPC } & \text { Coletores parabólicos compostos } \\ \text { DTR } & \text { Distribuição de Tempo de Residência } \\ \text { EGWF } & \text { Earth Generated Wall Functions } \\ \text { LSCP } & \text { Laboratório de Simulação e Controle de Processos } \\ \text { LVREA } & \text { Local Volumetric Rate of Energy Absorption } \\ \text { MVF } & \text { Método de Volumes Finitos } \\ \text { PHOENICS } & \text { Parabolic Hyperbolic Or Elliptic Numerical Integration } \\ \text { PIL } & \text { Code Series } \\ \text { POA } & \text { PHOENICS Input Language } \\ \text { PTC } & \text { Processos Oxidativos Avançados } \\ \text { TFFBR } & \text { Reator com Coletor Cilíndrico Parabólico } \\ \text { UV } & \text { Reator de Filme Fino Descendente } \\ & \text { Radiação Ultravioleta }\end{array}$




\section{SUMÁRIO}

1. INTRODUÇÃO

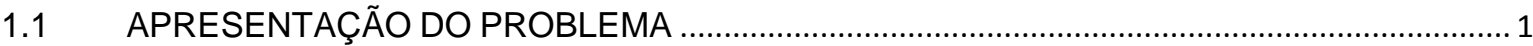

1.2 OBJETIVOS GERAIS E ESPECÍFICOS …........................................................................ 2

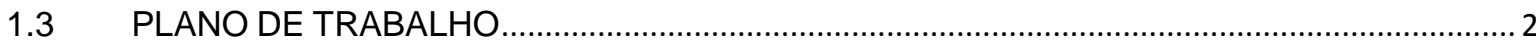

$1.4 \quad$ ESTRUTURA DA DISSERTAÇÃO

2. REVISÃO BIBLIOGRÁFICA.......................................................................

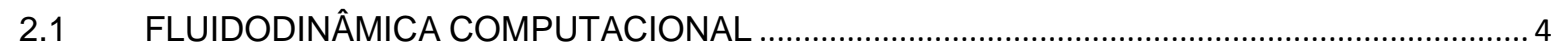

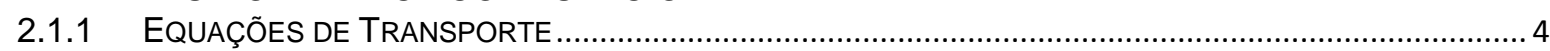

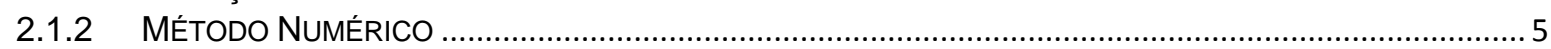

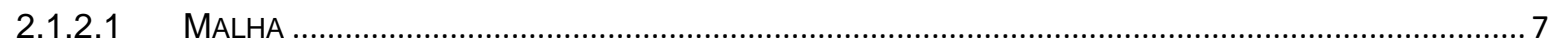

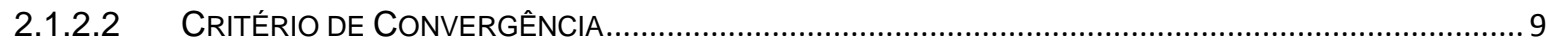

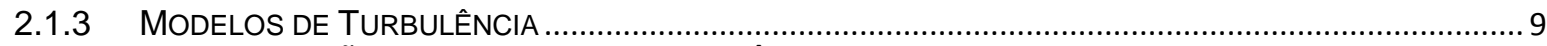

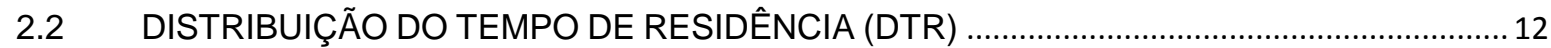

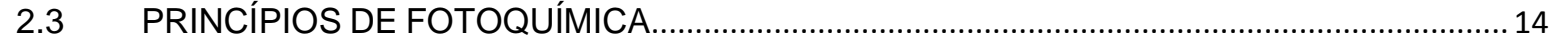

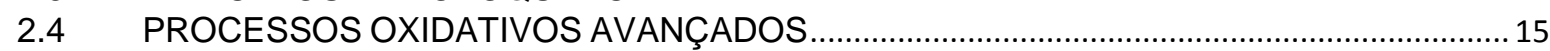

2.5 MODELOS MATEMÁTICOS PARA DESCRIÇÃO DO TRANSPORTE DE RADIAÇÃO ........ 16

2.5 .1 INTRODUÇÃO

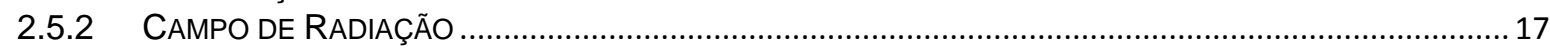

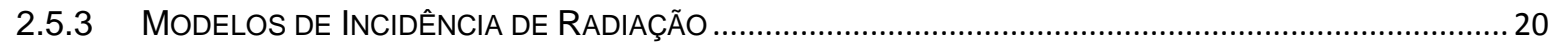

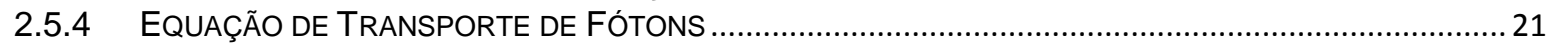

2.6 REATOR SOLAR COM COLETOR PARABÓLICO COMPOSTO (CPC) ................................23

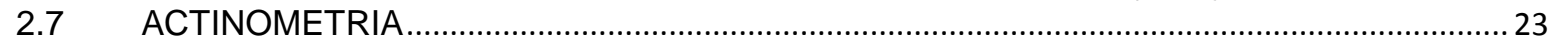

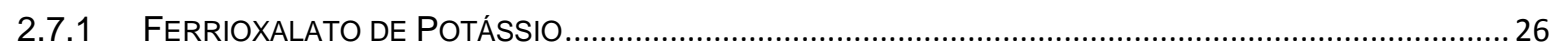

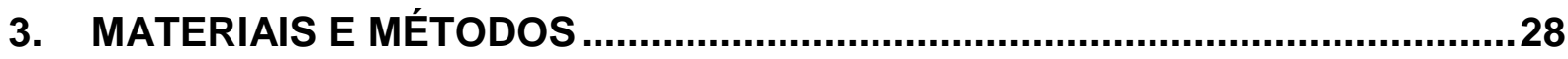

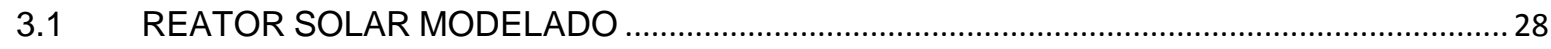

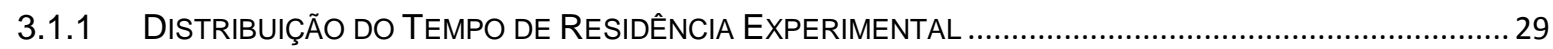

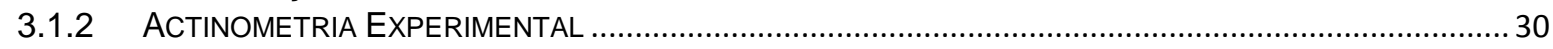

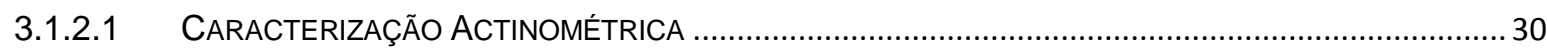

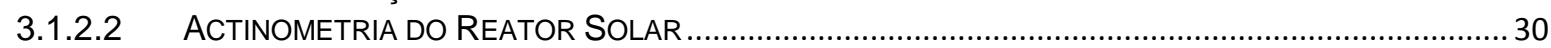

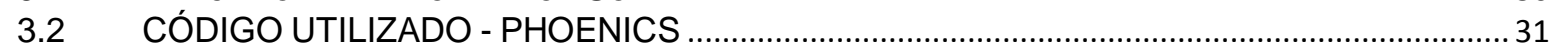

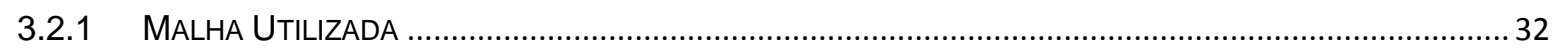

3.3 MODELAGEM DA DISTRIBUIÇÃO DO TEMPO DE RESIDÊNCIA - DTR ................................ 33

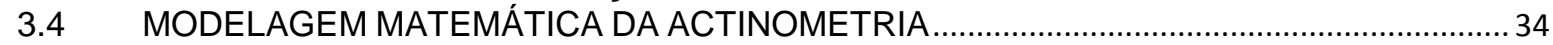

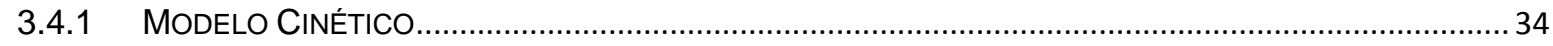

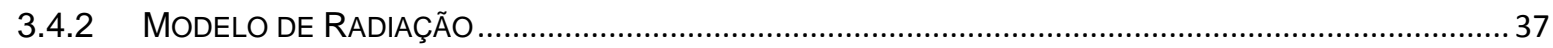

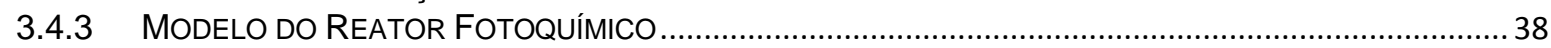

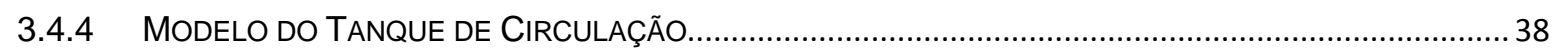

4. RESULTADOS DO ESTUDO DO ESCOAMENTO ..........................................40

4.1 REATOR SOLAR COMPLETO

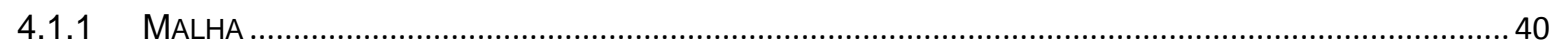

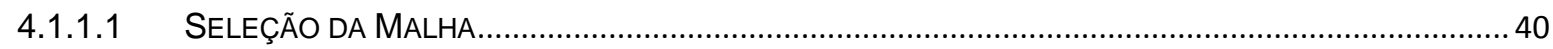

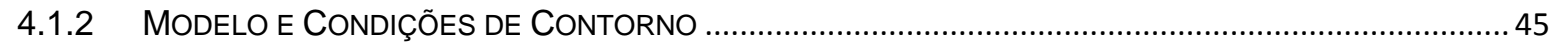

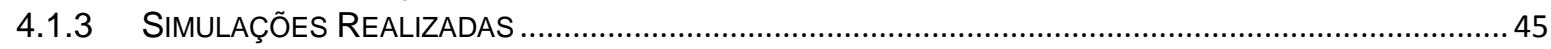

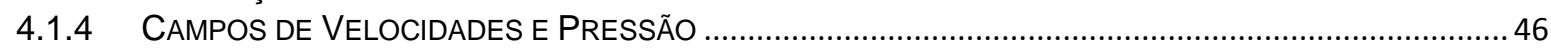

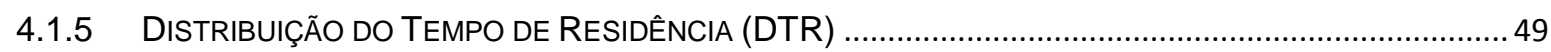

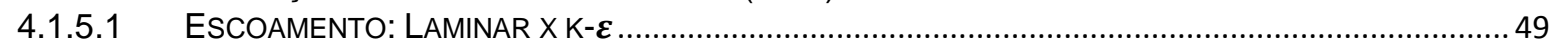




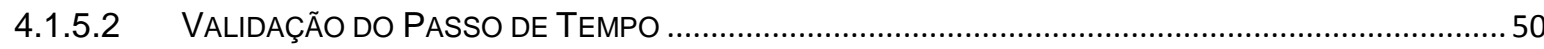

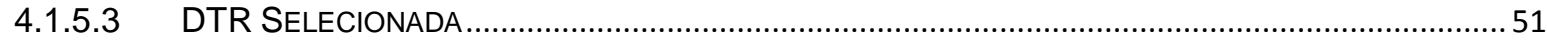

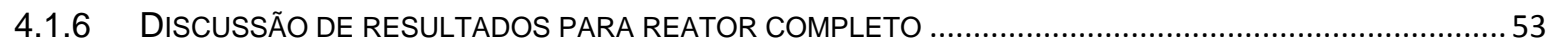

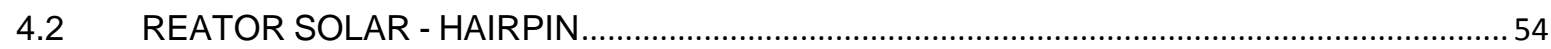

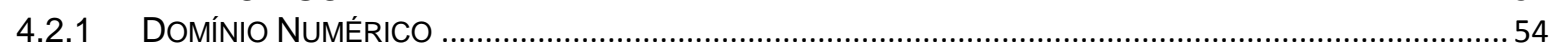

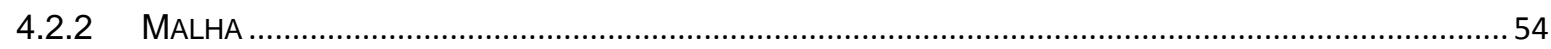

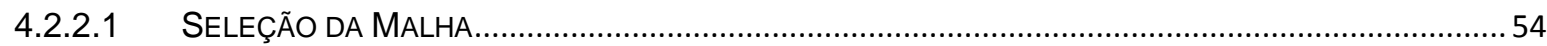

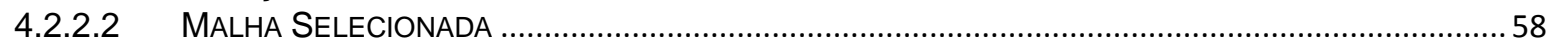

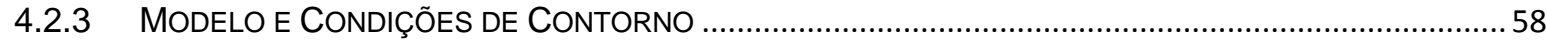

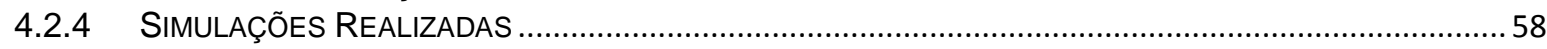

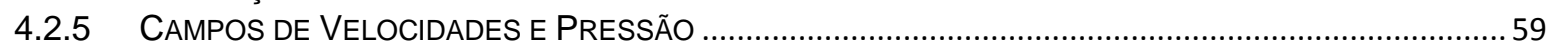

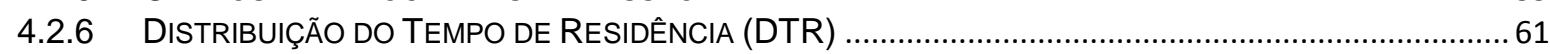

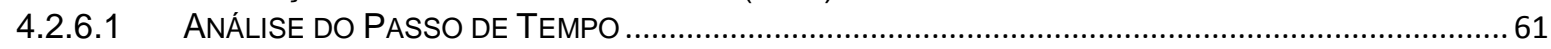

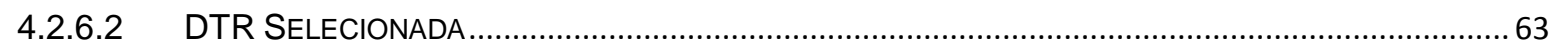

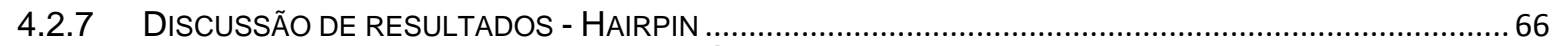

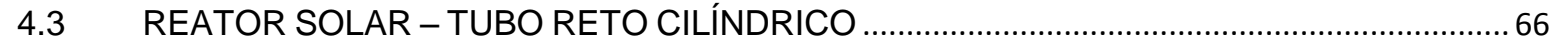

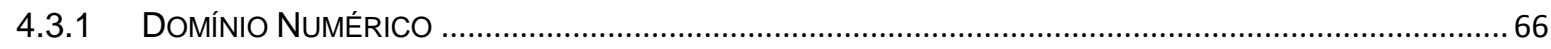

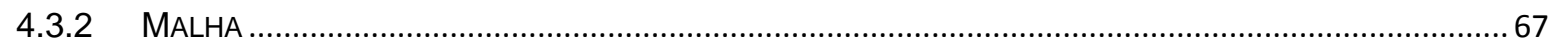

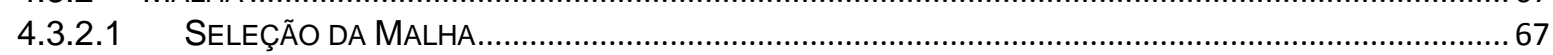

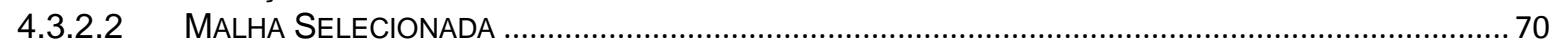

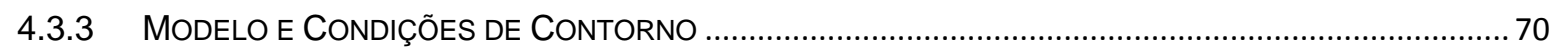

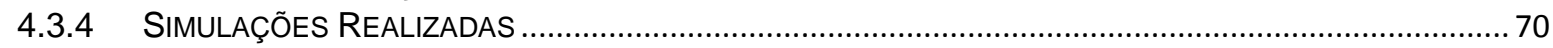

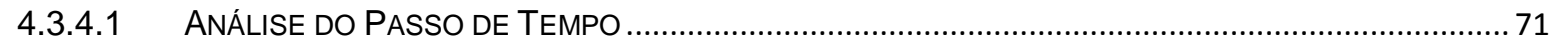

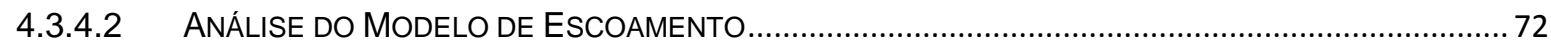

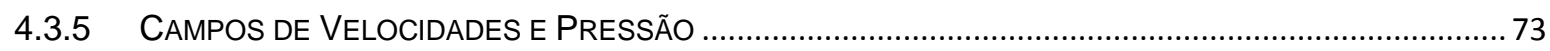

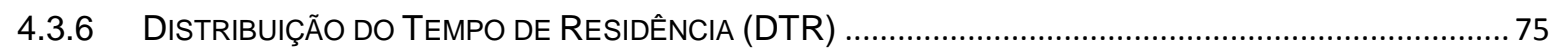

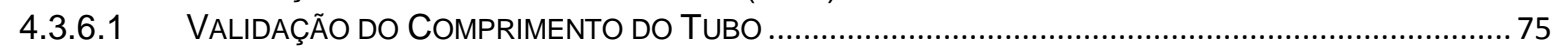

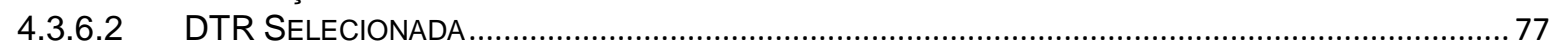

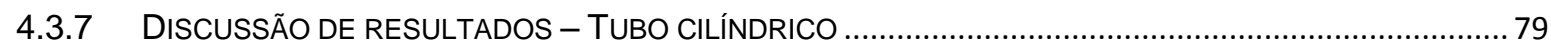

5. RESULTADOS DA MODELAGEM MATEMÁTICA DO REATOR FOTOQUÍMICO - ACTINOMETRIA ................................................................82

5.1 MODELO CINÉTICO

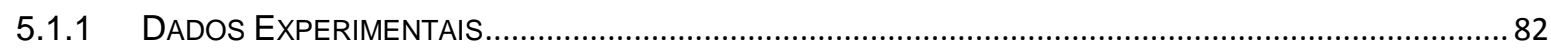

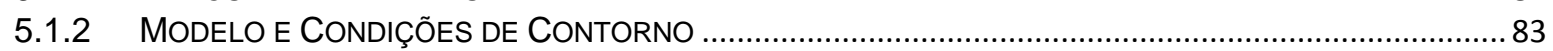

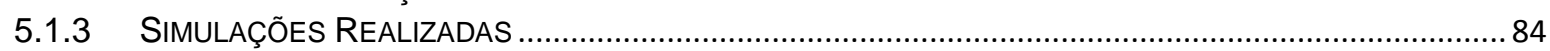

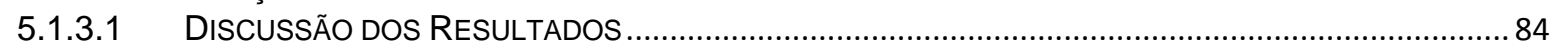

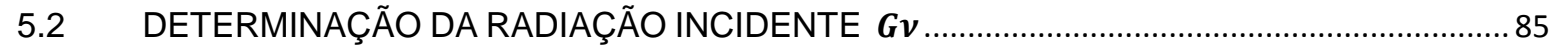

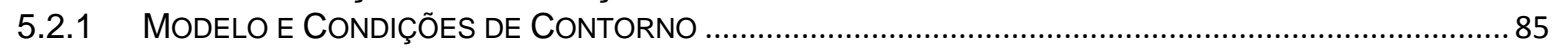

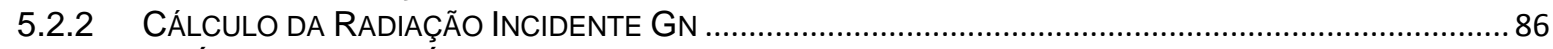

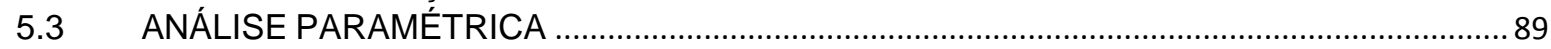

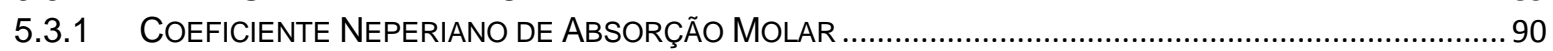

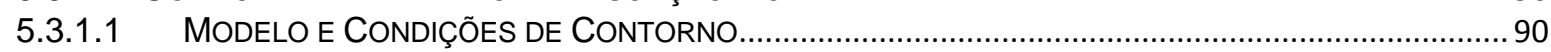

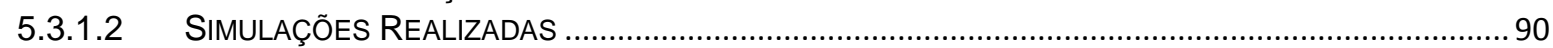

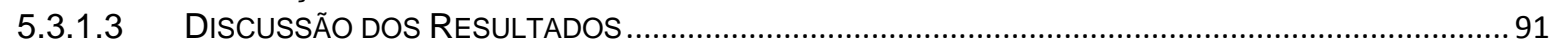

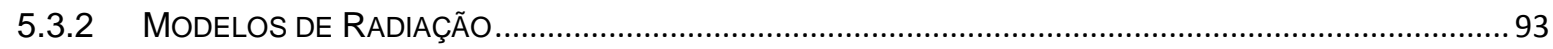

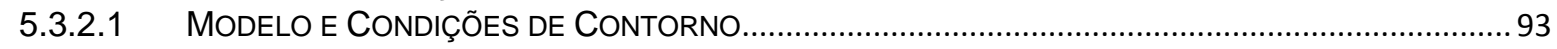

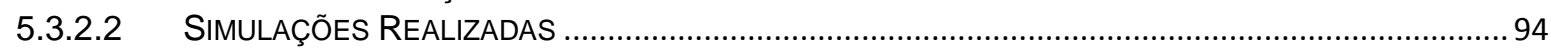

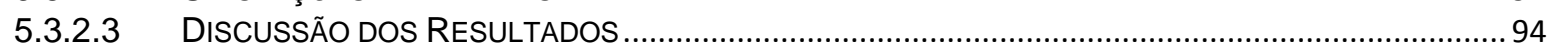

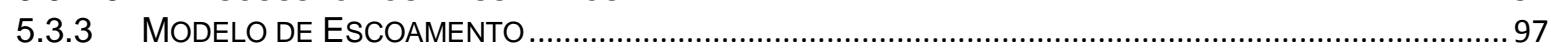

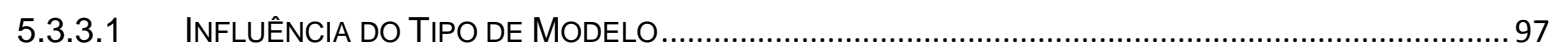

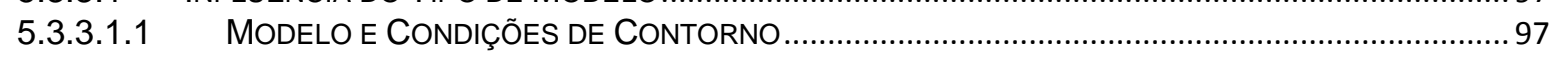

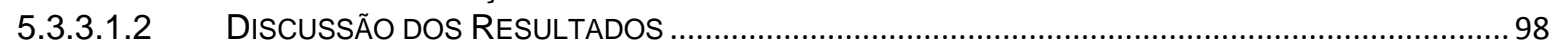

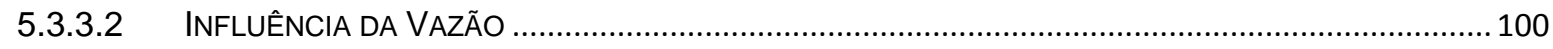

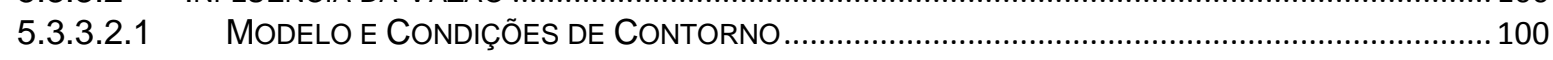




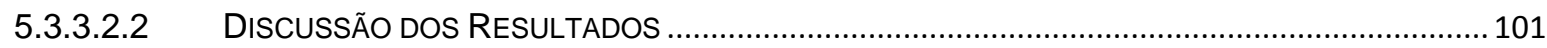

6. CONSIDERAÇÕES FINAIS ...................................................................... 104

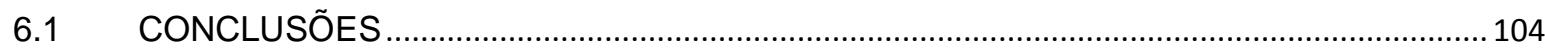

6.2 SUGESTÕES DE CONTINUIDADE

7. REFERÊNCIAS BIBLIOGRÁFICAS........................................................106

APÊNDICE A - Q1 ................................................................................. 109

APÊNDICE B - GROUND ....................................................................113

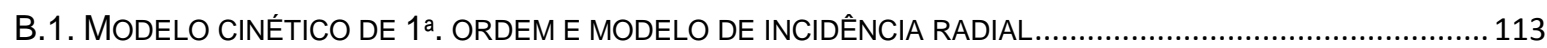

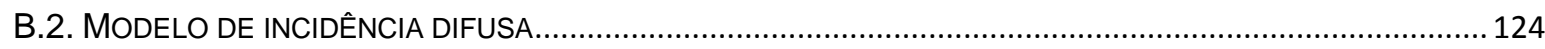

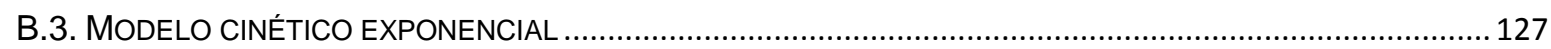

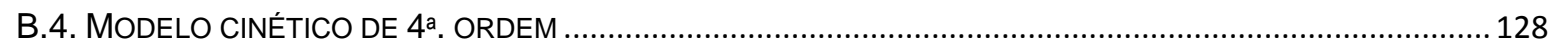

APÊNDICE C - GXMONI DA SIMULAÇÃO DO GvESCOLHIDO.........................130 


\section{INTRODUÇÃO}

\subsection{APRESENTAÇÃO DO PROBLEMA}

Atualmente, existe um grande interesse no estudo e desenvolvimento de processos fotoquímicos, denominados de Processos Oxidativos Avançados (POA). Estes processos possuem uma ampla variedade de aplicações industriais, como reações de cloração e nitração, síntese de fármacos e eliminação de poluentes.

Nesse sentido, a utilização de POA's vem se mostrando uma alternativa muito interessante para o tratamento de efluentes devido à sua capacidade de oxidar e mineralizar praticamente qualquer contaminante. No entanto, o desenvolvimento teórico e a implantação de processos fotoquímicos para tratamento de efluentes em escala piloto e industrial é um desafio para a engenharia química, pois esses processos são altamente não lineares e os modelos muito complexos.

Os métodos convencionais de análise de um equipamento proporcionam uma visão global, não permitindo análises locais do interior do reator. Para uma análise mais rigorosa e detalhada, modelos microscópicos, baseados nos fenômenos de transporte devem ser empregados, e uma importante ferramenta é a Fluidodinâmica Computacional (CFD).

Visando contribuir para o conhecimento destas técnicas, o presente trabalho consiste em um estudo de aplicação de processos fotoquímicos, no qual foram modelados o escoamento, o campo de radiação e a cinética da reação de actinometria química (ferrioxalato), em um reator solar operando em regime transiente.

Para esse estudo, empregou-se o código de fluidodinâmica computacional PHOENICS (versão 2000).

A presente dissertação insere-se na linha de pesquisa em Processos Oxidativos Avançados (POAs), desenvolvida no CESQ - Centro de Engenharia de Sistemas Químicos, do Departamento de Engenharia Química da Escola Politécnica da USP. 


\subsection{OBJETIVOS GERAIS E ESPECÍFICOS}

O principal objetivo deste estudo é a modelagem matemática de um reator solar para análise do escoamento reativo e os processos fotoquímicos.

Dentre os objetivos específicos, destacam-se:

- Desenvolver uma modelagem fluidodinâmica para o reator solar, considerando-se o escoamento reativo e processos fotoquímicos, com o apoio de CFD.

- Validar o modelo fluidodinâmico com dados experimentais.

\subsection{PLANO DE TRABALHO}

O plano de trabalho foi dividido em algumas etapas, conforme ilustrado na Figura 1.1.

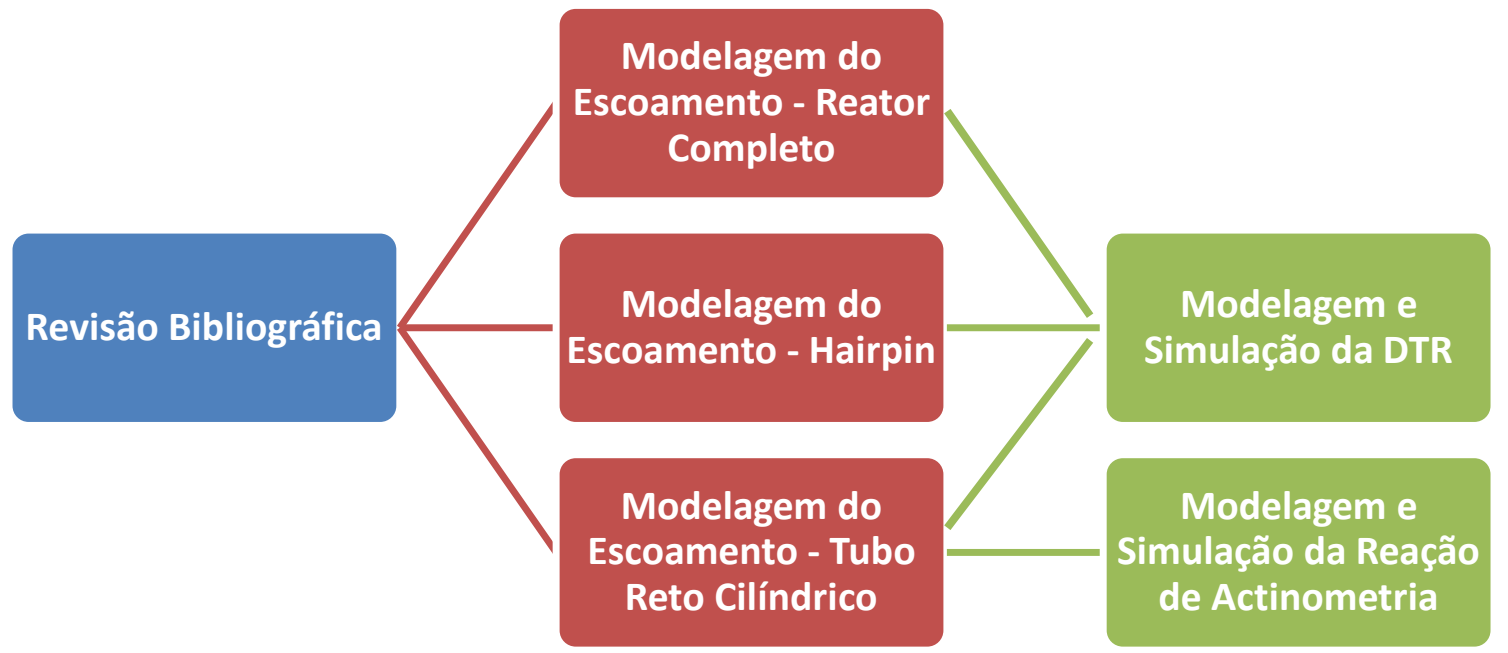

Figura 1.1 - Estrutura da metodologia de trabalho utilizada para desenvolver o presente estudo.

Para cada uma das etapas de modelagem mostradas acima, foi necessário fazer uma etapa de análise dos resultados e validação.

\subsection{ESTRUTURA DA DISSERTAÇÃO}

A dissertação está estruturada da seguinte forma:

- O capítulo 2 apresenta a revisão bibliográfica, que consiste essencialmente de: princípios básicos de fluidodinâmica computacional, 
breve discussão sobre distribuição de tempo de residência, introdução aos processos oxidativos avançados, modelos de radiação para reatores fotoquímicos e actinometria.

- O capítulo 3 trata da descrição dos sistemas e processos modelados, especificamente a distribuição de tempo de residência e a actinometria química do reator solar. Apresenta-se, também, a modelagem dos processos estudados e o programa computacional utilizado.

- O capítulo 4 apresenta os resultados e discussões do escoamento no reator completo, hairpin e no tubo cilíndrico reto. Como resultado do estudo do escoamento, obtiveram-se os campos de pressão e velocidade e a distribuição de tempo de residência para as diversas configurações.

- O capítulo 5 apresenta os resultados da modelagem da actinometria para o reator solar, em uma comparação com dados experimentais e uma análise paramétrica do modelo.

- O capítulo 6 finaliza o presente trabalho com as conclusões e principais recomendações para trabalhos futuros. 


\section{REVISÃO BIBLIOGRÁFICA}

\subsection{FLUIDODINÂMICA COMPUTACIONAL}

Neste capítulo apresenta-se uma breve introdução à fluidodinâmica computacional (CFD), considerando-se a abordagem de volumes finitos. Iniciando-se com as equações de transporte, passando pelos modelos de turbulência e, por fim, apresentando-se o método numérico a ser empregado.

\subsubsection{Equações de Transporte}

Todas as equações resolvidas por CFD apresentam-se sob uma forma generalizada, como pode ser vista na (Equação 2.1). (MALISKA, 2004)

$$
\begin{aligned}
\frac{\partial}{\partial t}(\rho \emptyset)+\frac{\partial}{\partial x} & (\rho u \emptyset)+\frac{\partial}{\partial y}(\rho v \emptyset)+\frac{\partial}{\partial z}(\rho w \emptyset) \\
& =\frac{\partial}{\partial x}\left(\Gamma^{\varnothing} \frac{\partial \emptyset}{\partial x}\right)+\frac{\partial}{\partial y}\left(\Gamma^{\varnothing} \frac{\partial \emptyset}{\partial y}\right)+\frac{\partial}{\partial z}\left(\Gamma^{\varnothing} \frac{\partial \emptyset}{\partial z}\right)+S^{\varnothing}
\end{aligned}
$$

(Equação 2.1)

A Tabela 2-1 mostra o significado de cada termo da equação generalizada. (MALISKA, 2004)

Tabela 2-1 - Termos da equação de transporte generalizada. (MALISKA, 2004)

\begin{tabular}{cc}
\hline Expressão & Termo \\
\hline$\frac{\partial}{\partial t}(\rho \emptyset)$ & Temporal \\
$\frac{\partial}{\partial x}(\rho u \emptyset)+\frac{\partial}{\partial y}(\rho v \emptyset)+\frac{\partial}{\partial z}(\rho w \emptyset)$ & Convectivo \\
$\frac{\partial}{\partial x}\left(\Gamma^{\varnothing} \frac{\partial \emptyset}{\partial x}\right)+\frac{\partial}{\partial y}\left(\Gamma^{\varnothing} \frac{\partial \emptyset}{\partial y}\right)+\frac{\partial}{\partial z}\left(\Gamma^{\varnothing} \frac{\partial \emptyset}{\partial z}\right)$ & Difusivo \\
$S^{\varnothing}$ & Fonte \\
\hline
\end{tabular}


Todas as equações de conservação podem ser representadas nesta forma generalizada, modificando-se somente os respectivos termos temporais, difusivos, convectivos, fontes e a variável correspondente. A Tabela 2-2 mostra a expressão associada às variáveis pertencentes à equação diferencial. (MALISKA, 2004)

Tabela 2-2 - Variáveis da equação diferencial de transporte. (MALISKA, 2004)

\begin{tabular}{ccccc}
\hline $\begin{array}{c}\text { Equação de } \\
\text { Conservação }\end{array}$ & $\emptyset$ & $\Gamma^{\varnothing}$ & $\boldsymbol{S}^{\varnothing}$ \\
\hline Continuidade & 1 & 0 & 0 \\
Movimento em x & $u$ & $\mu$ & $B_{x}+\frac{\partial}{\partial x}\left(\mu \frac{\partial u}{\partial x}-\frac{2}{3} \mu \nabla \cdot \bar{V}\right)+\frac{\partial}{\partial y}\left(\mu \frac{\partial v}{\partial x}\right)+\frac{\partial}{\partial z}\left(\mu \frac{\partial w}{\partial x}\right)-\frac{\partial P}{\partial x}$ \\
Movimento em y & $v$ & $\mu$ & $B_{y}+\frac{\partial}{\partial y}\left(\mu \frac{\partial v}{\partial y}-\frac{2}{3} \mu \nabla \cdot \bar{V}\right)+\frac{\partial}{\partial x}\left(\mu \frac{\partial u}{\partial y}\right)+\frac{\partial}{\partial z}\left(\mu \frac{\partial w}{\partial y}\right)-\frac{\partial P}{\partial y}$ \\
Movimento em z & $w$ & $\mu$ & $B_{z}+\frac{\partial}{\partial z}\left(\mu \frac{\partial w}{\partial z}-\frac{2}{3} \mu \nabla \cdot \bar{V}\right)+\frac{\partial}{\partial x}\left(\mu \frac{\partial u}{\partial z}\right)+\frac{\partial}{\partial y}\left(\mu \frac{\partial v}{\partial z}\right)-\frac{\partial P}{\partial z}$ \\
Energia & $T$ & $\frac{k}{C_{p}}$ & \\
$\begin{array}{c}\text { Massa de um } \\
\text { componente i }\end{array}$ & $C$ & $\rho D i$ & $\frac{1}{C_{p}} \frac{D P}{D t}+\frac{\mu}{C_{P}} \Phi$ \\
\hline
\end{tabular}

\subsubsection{Método Numérico}

Devido à necessidade de se obter soluções numéricas paras as equações diferenciais apresentadas no item 2.1.1, tem-se a necessidade de discretizar essas equações no espaço, implementando-se uma malha contendo pequenas células (elementos de volume), e no tempo $(\Delta t)$. Quanto menor o tamanho da célula da malha computacional, mais os resultados tendem a se aproximar do real (da equação diferencial). Entretanto, quando o número de elementos de volume aumenta, o tempo de simulação também aumenta podendo levar horas ou até mesmo dias para resolução do problema. (MALISKA, 2004) 
Para a resolução de um problema via simulação CFD, podem-se utilizar diversos métodos de discretização, sendo o mais utilizado o Método de Volumes Finitos (MVF). (MALISKA, 2004) Esta técnica parte da integração formal das equações de transporte que regem o escoamento do fluido em todos os volumes de controle obtidos pela discretização do domínio. A Figura 2.1 mostra um exemplo de malha utilizada no método dos volumes finitos.

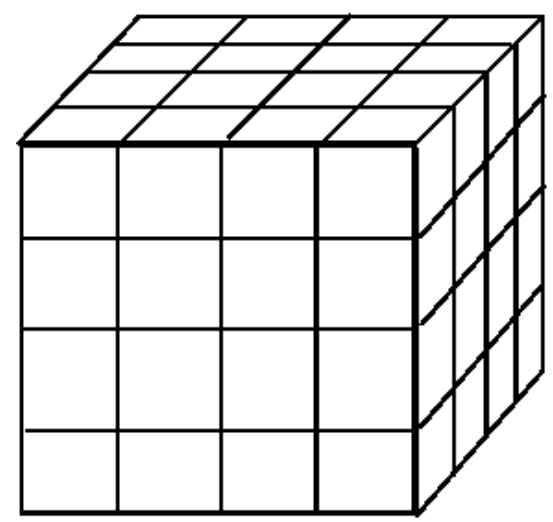

Figura 2.1 - Exemplo de malha utilizada no método dos volumes finitos. (MALISKA, 2004)

Nesta integração, a forma conservativa de cada equação é usada para que seja possível transformar as integrais em volume dos divergentes dos fluxos advectivos e difusivos em integrais em área dos fluxos normais à superfície dos volumes de controle, através da aplicação do teorema da divergência. Embora esta operação seja exata, a completa discretização destes termos e das outras integrais no volume necessita do uso de técnicas numéricas para aproximar os campos das variáveis conservadas, $\phi$, que utilizam funções de interpolação ou aproximações funcionais. A acurácia destas aproximações e da representação obtida para os fluxos através das superfícies dos volumes de controle é o aspecto mais importante no método de volumes finitos. Como os outros métodos, as equações finais levam a um sistema algébrico de equações. A solução das equações de conservação via MVF requer uma relação do ponto a ser calculado com as suas vizinhanças. A Figura 2.2 mostra a organização do ponto e seus vizinhos para o caso de elementos de volume hexaédricos e a equação seguinte mostra a relação de um ponto da malha com suas vizinhanças. (MALISKA, 2004) 


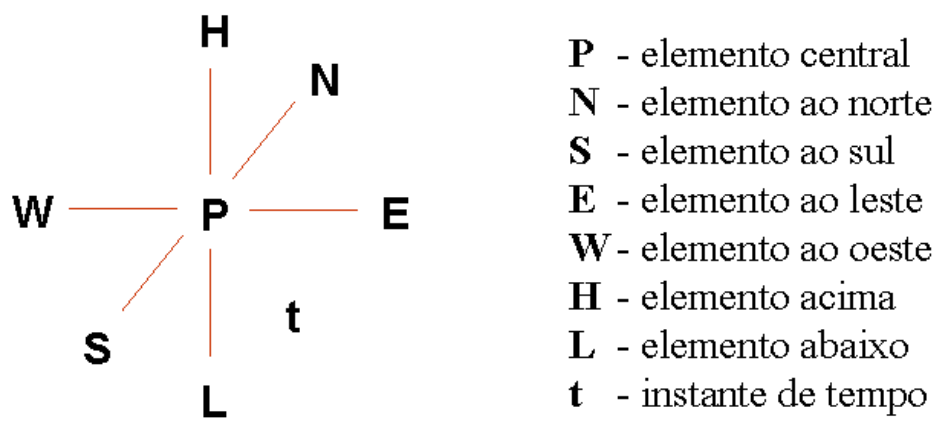

Figura 2.2 - Organização dos pontos no espaço para o caso de elementos hexaédricos. (Maliska, 2004)

$$
A_{P} \emptyset_{P}=A_{N} \emptyset_{N}+A_{S} \emptyset_{S}+A_{E} \emptyset_{E}+A_{W} \emptyset_{W}+A_{H} \emptyset_{H}+A_{L} \emptyset_{L}+A_{t} \emptyset_{t}+\text { fontes }
$$

(Equação 2.2)

Uma vez discretizadas, as equações devem ser resolvidas. A metodologia de solução envolve a solução de um sistema de equações algébricas (Equação 2.2) representado sob a forma $F \emptyset=a$, onde $F$ é a matriz de coeficientes, $\phi$ é o vetor da variável de interesse e a é o vetor que contém as informações dos termos fontes associados. (MALISKA, 2004)

Para a montagem da matriz de coeficientes do sistema linear de equações, podem-se utilizar métodos diretos ou iterativos. Os métodos diretos são aqueles que necessitam da inversão da matriz completa, incluindo os elementos não nulos. Esses são recomendados quando o número de equações do sistema não é muito alto. (MALISKA, 2004)

Os métodos iterativos podem se classificar de acordo com o esquema de solução: ponto a ponto, linha a linha, plano a plano ou todos os elementos da matriz a serem resolvidos simultaneamente. Os três primeiros são utilizados pelo código PHOENICS (SPALDING et al., 2011).

\subsubsection{Malha}

Conforme mostrado anteriormente, o método dos volumes finitos discretiza o domínio de um problema em uma malha para resolver as equações de conservação para cada volume finito. Podem-se empregar diferentes tipos de malhas, conforme pode ser visto na Figura 2.3. 


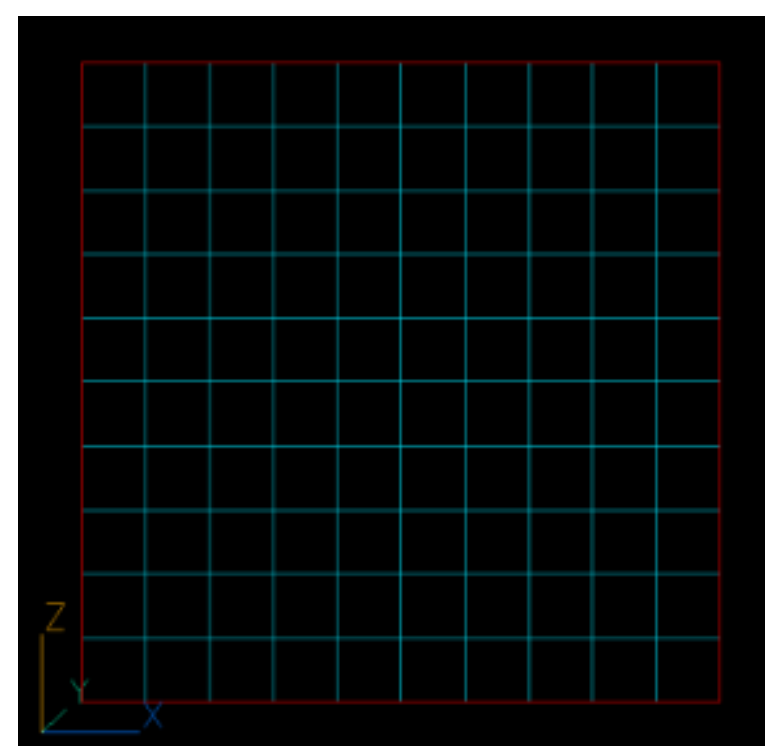

(a)

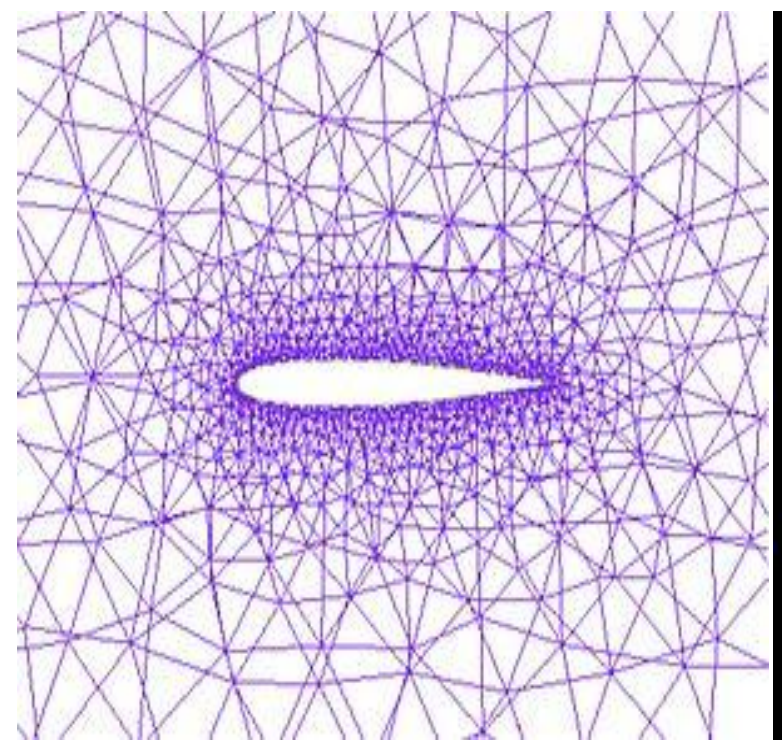

(c)

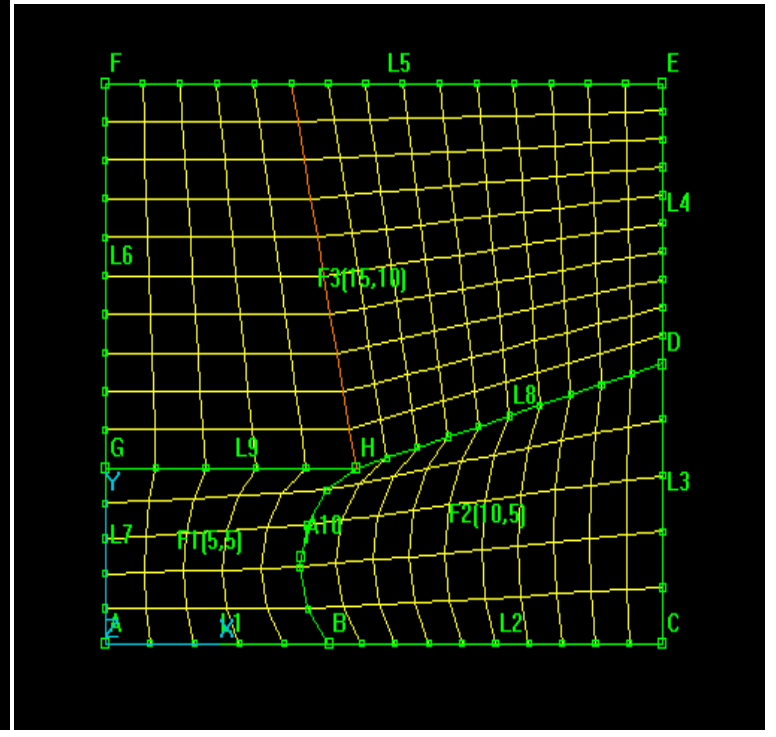

(b)

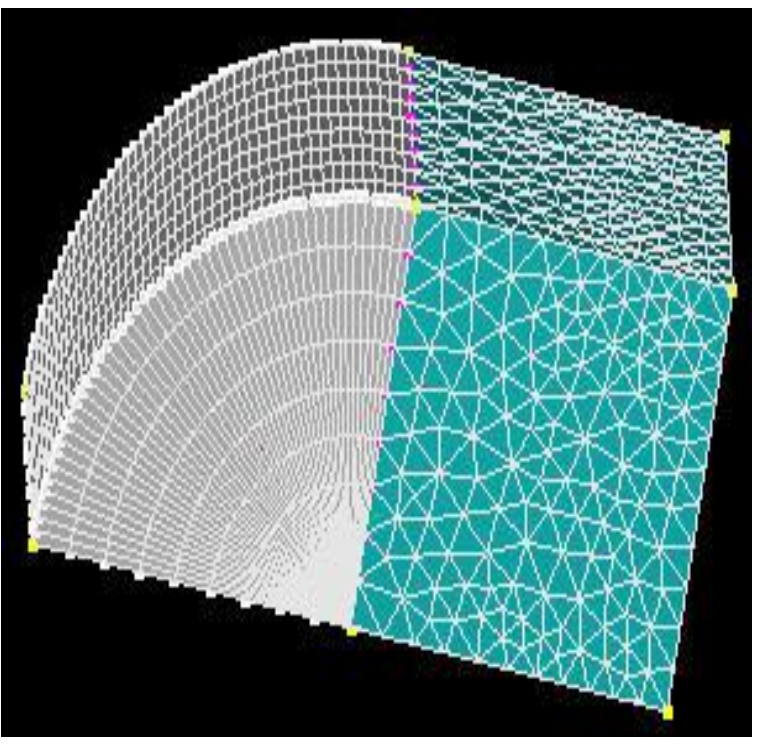

(d)

Figura 2.3 - Tipos de malha: (a) estruturada cartesiana, (b) estrutura generalizada, (c) não estruturada e (d) híbrida. (MALISKA, 2004)

Quando os volumes de controle são obtidos de uma discretização que segue um sistema de coordenadas globais, conforme a Figura 2.3 (a) e a Figura 2.3 (b), denomina-se a malha de estruturada, pois cada volume interno possui o mesmo número de vizinhos, seguindo uma determinada lei de construção. A estrutura das malhas facilita na ordenação dos sistemas de equações, de forma a obter matrizes diagonais que permitem a utilização de solvers. (MALISKA, 2004) 
No entanto, para muitos problemas reais, em função da complexidade das geometrias, recomenda-se o emprego de malhas não estruturadas, conforme ilustrado na Figura 2.3 (c) e na Figura 2.3 (d). Essas malhas possuem maior versatilidade e são mais aptas para discretizar geometrias irregulares. A maior desvantagem de malhas não estruturadas é que elas apresentam grande dificuldade de ordenação, dando origem a matrizes não diagonais. (MALISKA, 2004)

No código PHOENICS, utilizado para este trabalho, as malhas comumente geradas são estruturadas cartesianas ou polares.

\subsubsection{Critério de Convergência}

Conforme visto anteriormente, o método dos volumes finitos, utiliza sistemas de equações não-lineares, resolvidas em geral de forma sequencial, em que acoplamentos delicados estão presentes, que dificulta que a aproximação numérica seja estável e convergente.

Para uma aproximação numérica ser dita consistente, ela deve reproduzir a equação diferencial quando os tamanhos da malha espacial e temporal tendam a zero. Com isso, os erros de truncamento devem tender a zero quando a malha tender a um número infinito de pontos. Todo modelo numérico desenvolvido a partir das equações de conservação usando volumes finitos é considerado consistente.

Outro aspecto importante, é que a solução numérica, das equações diferenciais, tenha estabilidade. Portanto, consistência e estabilidade são condições necessárias e suficientes para a convergência. (MALISKA, 2004)

\subsubsection{Modelos de Turbulência}

Escoamentos turbulentos são comumente encontrados em aplicações práticas de engenharia, pois seus comportamentos são os mais usuais. A transição do regime laminar para o turbulento é causada pela presença de turbilhões de diferentes tamanhos, orientações e velocidades de rotação. Estes turbilhões surgem espontaneamente como consequência da instabilidade do escoamento e da geometria do domínio. (PATANKAR, 1980)

Para o escoamento turbulento, o balanço de quantidade de movimento deve ser aprimorado de modo a incluir as equações de Reynolds. (KAYS,1993) As equações de conservação apresentam um número de variáveis maior do que o 
número de equações. A solução para esse problema é a utilização de modelos de turbulência. Para um modelo de turbulência ser eficaz, em um código de CFD, deve ter uma ampla aplicabilidade, ser preciso, simples e de fácil processamento. (VERSTEEG, 1995) O código PHOENICS possui diversos modelos de turbulência implementados, classificados em grupos, que estão apresentados na Tabela 2-3.

Tabela 2-3 - Modelos de turbulência utilizados no software PHOENICS (SPALDING, 2011).

\begin{tabular}{|c|c|}
\hline Grupo & Modelo \\
\hline \multirow{13}{*}{ Hipótese da Viscosidade Efetiva } & Viscosidade Efetiva Preescrita \\
\hline & LVEL \\
\hline & Comprimento de Mistura de Prandt| \\
\hline & Van-Driest \\
\hline & Energia de Prandtl \\
\hline & Duas Camadas KE-EP \\
\hline & $\mathrm{k}-\varepsilon$ \\
\hline & CHEN-KIM KE-EP \\
\hline & RNG-derivado KE-EP \\
\hline & LAM-BREMHORST \\
\hline & Saffman-Spalding KE-VO \\
\hline & Kolmogorov-Wilcox KE-OMEGA \\
\hline & Duas Escalas KE-EP \\
\hline \multirow[t]{2}{*}{$\begin{array}{l}\text { Não emprega a Hipótese de } \\
\text { Viscosidade Efetiva }\end{array}$} & Reynolds Stress \\
\hline & Smagorinsky \\
\hline \multirow[t]{2}{*}{ Mista } & Bifásico \\
\hline & Multifásico \\
\hline
\end{tabular}

Neste item será apresentado, brevemente, o modelo "k-£ padrão", proposto por Launder e Spalding em 1974, que foi utilizado na modelagem e simulação do escoamento do reator estudado, no caso de regime turbulento. 
O modelo $k-\varepsilon$ pertence à categoria de modelos de turbulência de duas equações, na qual equações de transporte são resolvidas para dois parâmetros, no caso, $k$, energia cinética de turbulência, e, $\varepsilon$, taxa de dissipação de energia cinética de turbulência. Trata-se do modelo mais empregado e incorporado em códigos de fluidodinâmica computacional. A energia cinética de turbulência, $k$, é expressa pela seguinte equação de transporte de $\mathrm{k}$ :

$$
\frac{\partial(\rho k)}{\partial t}+\operatorname{div}(\rho k \vec{v})=\operatorname{div}\left(\frac{\mu_{T}}{\sigma_{k}} \operatorname{gr} a d k\right)+\mu_{t} S^{2}-\rho \varepsilon
$$

(Equação 2.3)

onde $S$ é a função dissipação, e é expressa a partir dos gradientes de velocidade local média:

$$
S^{2}=\left(\frac{\partial \bar{v}_{i}}{\partial x_{j}}+\frac{\partial \bar{v}_{j}}{\partial x_{i}}\right) \frac{\partial \bar{v}_{i}}{\partial x_{j}}
$$

(Equação 2.4)

Para a taxa de dissipação de energia cinética de turbulência, tem-se a (Equação 2.5):

$$
\frac{\partial(\rho \varepsilon)}{\partial t}+\operatorname{div}(\rho \vec{v})=\operatorname{div}\left(\frac{\mu_{T}}{\sigma_{\varepsilon}} \operatorname{gr} a d \varepsilon\right)+C_{1 \varepsilon} \frac{\varepsilon}{k} \mu_{t} S^{2}-C_{2 \varepsilon} \frac{\varepsilon^{2}}{k} \rho
$$

(Equação 2.5)

Os parâmetros $\mathrm{k}$ e $\varepsilon$ são relacionados à viscosidade turbulenta (efetiva) por:

$$
\mu_{T}=\rho C_{\mu} \frac{k^{2}}{\varepsilon}
$$

(Equação 2.6)

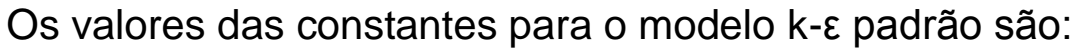

$$
C_{\mu}=0,09 ; C_{1 \varepsilon}=1,44 ; C_{2 \varepsilon}=1,92 ; \sigma_{k}=1,00 ; \sigma_{\varepsilon}=1,30 .
$$

(VERSTEEG, 1995)

Para altos números de Reynolds, o modelo padrão k-E não se aplica próximo à parede, sendo necessário e emprego de modelo expresso pela "lei de parede", nessa região, expresso pela (Equação 2.8), definida no seguinte intervalo:

$$
30<y^{+}<500
$$

(Equação 2.7)

Satisfazendo a lei logarítmica de parede:

$$
u^{+}=\frac{1}{k} \ln y^{+}+B=\frac{1}{k} \ln \left(E y^{+}\right)
$$

(Equação 2.8) 


\subsection{DISTRIBUIÇÃO DO TEMPO DE RESIDÊNCIA (DTR)}

Numa abordagem mais simples, o estudo do escoamento em reatores químicos parte dos modelos denominados de reatores ideais, como reator batelada de mistura perfeita, o reator tubular ("plug flow") de escoamento uniforme e o reator de mistura em tanque contínuo ("CFSTR"). No entanto, de fato, observam-se comportamentos muito diferentes dos idealizados, como o surgimento de zonas de volume morto e correntes de by-pass.

Existem três conceitos muito utilizados para caracterizar reatores não ideais:

- Distribuição do tempo de residência (DTR) em um sistema;

- Qualidade da Mistura;

- Modelo usado para descrever o sistema. (FOGLER, 2002)

No presente trabalho, abordar-se-á o conceito de distribuição de tempo de residência (DTR). A técnica para determinação da DTR é bastante conhecida e está descrita na literatura. (FOGLER, 2002) Em resumo, esta determinação é realizada experimentalmente, injetando-se uma substância química inerte, molécula ou átomo, chamada de traçador, no reator, no tempo $t=0$, e, então se medindo a concentração do traçador, $[T]$, no efluente do reator em função do tempo. Além de ser uma espécie não reativa e facilmente detectável, o traçador deve ter propriedades físicas semelhantes àquelas da mistura reagente, ser completamente solúvel e não ser adsorvido nas paredes do reator ou em outras superfícies. Os dois métodos de injeção mais usados são o de entrada de tipo pulso e de entrada de tipo degrau, conforme mostrado na Figura 2.4. (FOGLER, 2002) 

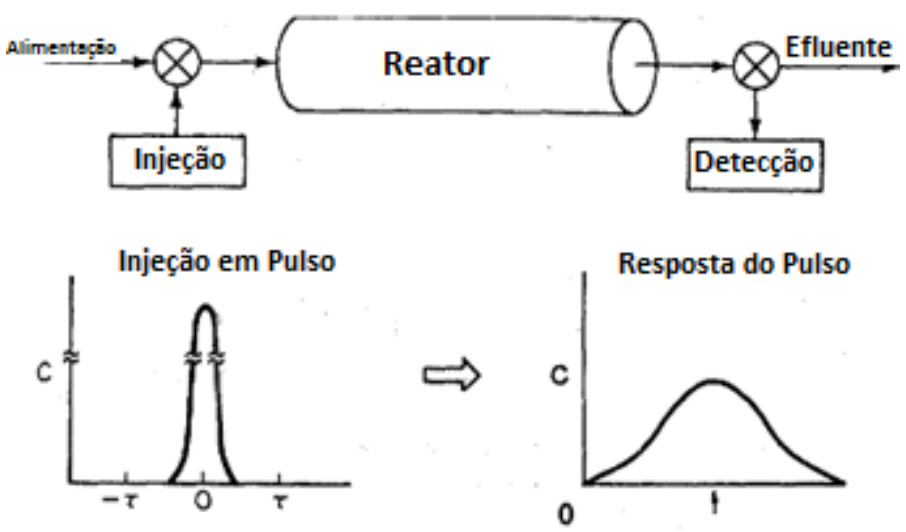

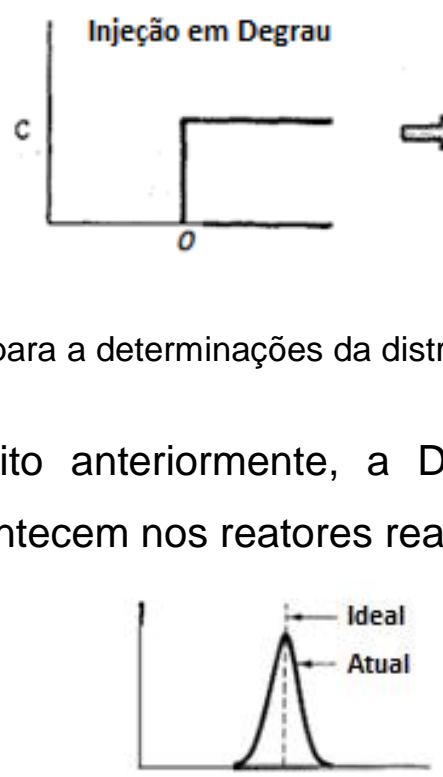

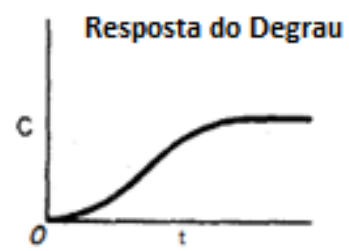

Figura 2.4 - Métodos para a determinações da distribuição do tempo de residência (FOGLER, 2002).

Conforme dito anteriormente, a DTR pode mostrar diversos desvios da idealidade que acontecem nos reatores reais, como ilustrado na Figura 2.5.

(o)

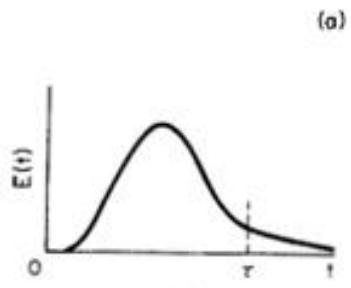

(c)

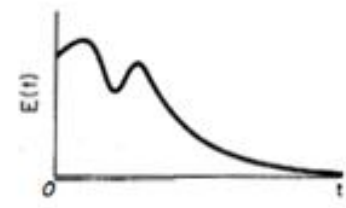

(e)

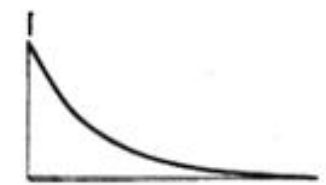

(b)

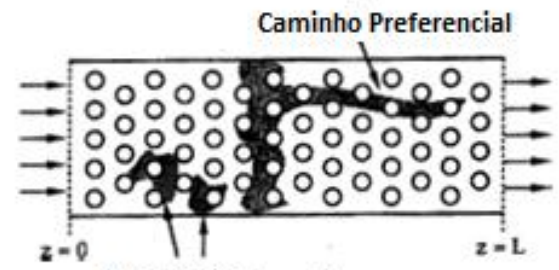

Zonas Mortas (d)

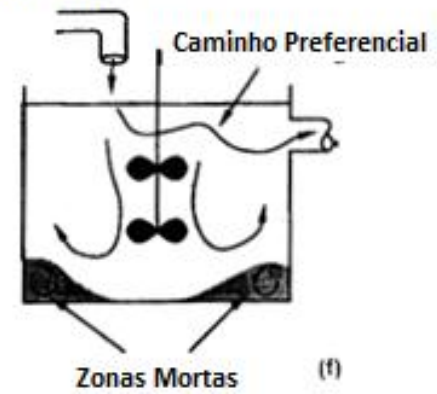

Figura 2.5 - Desvios em reatores reais: (a) DTR para um escoamento quase uniforme; (b) DTR para um CSTR de mistura quase perfeita; (c) DTR para um reator de leito de recheio com zonas mortas e canalizações; (d) reator de leito de recheio; (e) reator tanque com curto circuito no escoamento (desvio ou bypass); (f) CSTR com zona morta e bypass. (FOGLER, 2002). 
Particularmente, no caso de escoamentos laminares em tubos longos, alguns modelos para obtenção teórica da DTR foram desenvolvidos e apresentam soluções analíticas, dependendo do regime de escoamento, da geometria do tubo e da difusividade mássica. Dentre estes modelos, tem-se, o modelo de dispersão de Taylor, o de Aris e o modelo laminar segregado (LEVENSPIEL, 2000).

Esses modelos e os respectivos equacionamentos estão disponíveis na literatura nos textos de LEVENSPIEL (2000) e SHERWOOD (1975).

\subsection{PRINCÍPIOS DE FOTOQUÍMICA}

A fotoquímica é uma área da química que estuda interações de átomos e pequenas moléculas com a radiação eletromagnética ou com a luz. Atualmente, existem diversos processos importantes relacionados a este ramo da química, entre eles fotossíntese, fotólise e fotofosforilação. A primeira lei da fotoquímica, conhecida como lei de Grotthuss-Draper, estabelece que a luz deve ser absorvida por uma substância química para produzir uma reação fotoquímica. (MUKHERJEE, 1991)

A lei de Beer-Lambert estabelece que há uma relação exponencial entre a fração de radiação absorvida por uma substância e a concentração da substância, e que esta fração de radiação absorvida é independente da intensidade da radiação incidente. (SILVARES, 2006)

A segunda lei da fotoquímica, a lei de Stark-Einstein, estabelece que para cada fóton absorvido por um sistema químico, somente uma molécula é ativada em uma reação fotoquímica. Isto é também conhecido como a lei de fotoequivalência e foi derivada por Albert Einstein no tempo em que a teoria quântica (dos fótons) estava sendo desenvolvida.

A absorção de um fóton pela molécula de reagente resulta em um estado cuja energia é maior do que a energia inicial, conhecido como estado excitado. A perda do excesso de energia absorvida pode ocorrer por emissão do estado excitado singlete (fluorescência), por emissão do estado excitado triplete (fosforescência), por um processo de relaxação não radiativo ou por uma reação química. (TURRO, 1991)

A eficiência dos vários processos mencionados acima pode ser medida através de rendimentos quânticos ou eficiências quânticas, que descrevem a fração 
de moléculas retidas em cada etapa em relação ao total de fótons absorvidos. (MUKHERJEE, 1991) A soma dos rendimentos quânticos é 1.

Adicionalmente, a absorção do fóton pode permitir que ocorra uma reação não apenas fornecendo a energia de ativação necessária, mas também alterando a simetria da configuração eletrônica molecular e permitindo um caminho de reação outrora inacessível, conforme descrito pelas regras de seleção de WoodwardHoffmann. (WOODWARD e HOFFMANN, 1970)

Reações fotoquímicas envolvem a reorganização eletrônica iniciada pela radiação eletromagnética e são muitas ordens de magnitude mais rápidas que as

reações térmicas. Frequentemente são observadas reações da ordem de $10^{-9}$ segundo e processos na faixa de 10-15 segundos.

A reação fotoquímica normalmente está relacionada com uma reação em que ocorre a absorção, por uma molécula, de radiação eletromagnética de comprimento de onda adequada. (BRAUN, 1991) Portanto, essas reações são seletivas, reagindo somente moléculas que absorveram a radiação no comprimento de onda emitido. Estas moléculas podem se transformar quimicamente em um produto final ou em reagentes intermediários para outras reações.

\subsection{PROCESSOS OXIDATIVOS AVANÇADOS}

O sistema de reação fotocatalítico é classificado como um Processo Oxidativo Avançado (POA), pois há a produção de radical hidroxila, $\mathrm{OH} \bullet$, espécie altamente oxidante e não seletiva. (TÔRRES, 2007) Estes processos podem ser homogêneos ou heterogêneos e usarem ou não a radiação eletromagnética. O radical hidroxila possui um alto potencial de oxidação, sendo capaz de oxidar quase todos compostos orgânicos a $\mathrm{CO}_{2}$ e água. (RIBEIRO, 2009)

O mecanismo de reação dos radicais $\mathrm{OH}^{\bullet}$ é a reação do hidrogênio que forma de radicais orgânicos que reagem com o oxigênio molecular gerando radicais peroxila. Os radicais peroxila iniciam reações de degradação oxidativas produzindo compostos intermediários e finais, podendo chegar a $\mathrm{CO}_{2}$ e água. (RIBEIRO, 2009)

As reações podem ser visualizadas na (Equação 2.9), a seguir:

$$
\mathrm{HO}^{\bullet}+\mathrm{RH} \rightarrow \mathrm{R}^{\bullet}+\mathrm{H}_{2} \mathrm{O}
$$




$$
\mathrm{R}^{\bullet}+\mathrm{O}_{2} \rightarrow \mathrm{RO}_{2}^{\bullet}+\mathrm{H}_{2} \mathrm{O}
$$

(Equação 2.9)

As vantagens desta reação são indiscutíveis, nos seguintes aspectos: não há consumo de produtos químicos; não é necessário transformar o oxigênio do ar (como na ozonização); e não existe a necessidade de separar subprodutos ao final da reação (exceto no caso de se utilizar reatores de lama ou suspensão). Uma desvantagem deste processo é o alto custo. (PERETTI, 2008)

Os Processos Oxidativos Avançados (POAs) têm sido usados como um dos mais eficientes processos de remoção de poluentes de soluções aquosas contendo compostos orgânicos solúveis, que são tóxicos ou recalcitrantes. (RIBEIRO, 2009)

\subsection{MODELOS MATEMÁTICOS PARA DESCRIÇÃO DO TRANSPORTE DE RADIAÇÃO}

\subsubsection{Introdução}

Para a aplicação dos POAs ao tratamento de efluentes, diferentes reatores fotoquímicos foram estudados, analisados e projetados. Diversas modelagens para esses reatores fotoquímicos foram estudadas por muitos grupos de pesquisa. A Tabela 2-4, apresentada por Alfano (1986), apresenta os principais estudos e modelos desenvolvidos. 
Tabela 2-4 - Principais modelos desenvolvidos para reatores fotoquímicos, grupos de pesquisa e período de publicação. (ALFANO, 1986)

\begin{tabular}{|c|c|c|}
\hline Grupo de Pesquisa & Modelo & Período \\
\hline $\begin{array}{l}\text { Faraboschi, Santarelli e co- } \\
\text { autores }\end{array}$ & $\begin{array}{l}\text { Fonte extensa com emissão superficial } \\
\text { Fonte linear com emissão esférica } \\
\text { Fonte linear com emissão em planos paralelos } \\
\text { Incidência parcialmente difusa }\end{array}$ & $1959-1983$ \\
\hline Smith e co-autores & $\begin{array}{c}\text { Incidência difusa bidimensional } \\
\text { Incidência radial }\end{array}$ & $1965-1974$ \\
\hline Hill e co-autores & Incidência radial e paralela & $1965-1978$ \\
\hline Dranof e co-autores & $\begin{array}{l}\text { Fonte linear com emissão esférica } \\
\text { Fonte linear com emissão em planos paralelos }\end{array}$ & $1965-1978$ \\
\hline Sugawara e co-autores & $\begin{array}{c}\text { Fonte extensa com emissão superficial difusa } \\
\text { Fonte linear de emissão } \\
\text { Incidência paralela } \\
\text { Incidência difusa tridimensional }\end{array}$ & $1969-1981$ \\
\hline Williams e co-autores & $\begin{array}{c}\text { Incidência difusa bidimensional } \\
\text { Incidência radial } \\
\text { Incidência difusa bidimensional }\end{array}$ & $1970-1978$ \\
\hline Akehata e co-autores & $\begin{array}{l}\text { Fonte linear com emissão difusa } \\
\text { Fonte linear com emissão esférica } \\
\text { Fonte linear com emissão em planos paralelos }\end{array}$ & $1971-1973$ \\
\hline Shirotsuka e co-autores & $\begin{array}{l}\text { Fonte extensa de emissão } \\
\text { Incidência radial e paralela }\end{array}$ & $1971-1979$ \\
\hline Costa e co-autores & $\begin{array}{c}\text { Fonte extensa com emissão volumétrica } \\
\text { Fonte linear de emissão } \\
\text { Incidência radial e difusa bidimensional } \\
\text { Fonte extensa com emissão volumétrica }\end{array}$ & $1972-1980$ \\
\hline Cassano e co-autores & $\begin{array}{l}\text { Fonte extensa com emissão superficial difusa } \\
\text { Fonte linear com emissão esférica } \\
\text { Fonte linear com emissão em planos paralelos }\end{array}$ & $\begin{array}{l}1972-1978 \\
1982-1984\end{array}$ \\
\hline Thiele e co-autores & $\begin{array}{c}\text { Incidência paralela } \\
\text { Fonte linear de emissão }\end{array}$ & $1975-1980$ \\
\hline Yokota e co-autores & $\begin{array}{l}\text { Fonte extensa com emissão superficial difusa } \\
\text { Fonte linear com emissão difusa } \\
\text { Fonte linear com emissão esférica }\end{array}$ & $1976-1983$ \\
\hline Villermaux e co-autores & Incidência difusa & $1979-1983$ \\
\hline Andre e co-autores & $\begin{array}{l}\text { Fonte linear com emissão esférica } \\
\text { Fonte linear com emissão em planos paralelos }\end{array}$ & $1981-1983$ \\
\hline
\end{tabular}

\subsubsection{Campo de Radiação}

Diversos modelos foram propostos para descrever o campo de radiação, que é empregado na determinação da taxa volumétrica local de energia absorvida (Local volumetric rate of energy absorption - LVREA), a característica fundamental para análise e projeto de um reator fotoquímico. (ALFANO et al, 1986) 
Para a modelagem correta do reator, há a necessidade de se considerar a distribuição do campo de radiação, as propriedades físicas e as características geométricas do reator, a homogeneidade do sistema e estabelecer os balanços de massa, quantidade de movimento e energia, conforme esquema da Figura 2.6.

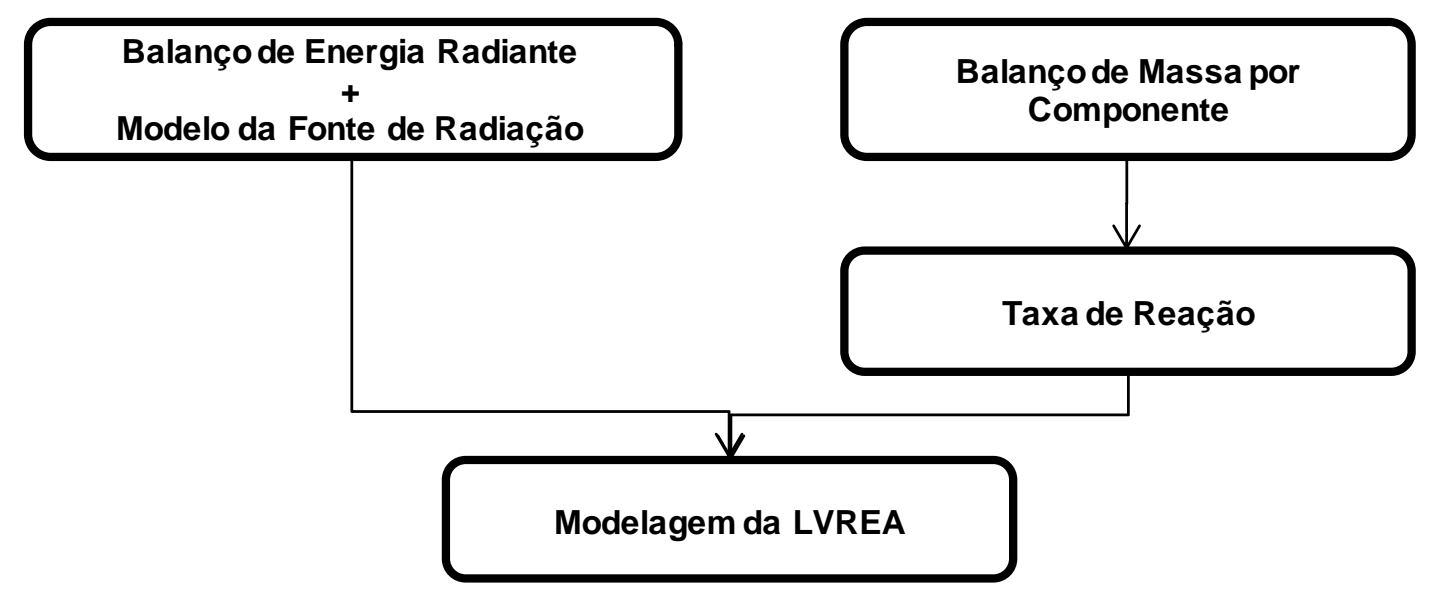

Figura 2.6 - Abordagem teórica para a modelagem do LVREA. (ALFANO, 1986)

O LVREA $\left(e_{v}^{a}\right)$ representa a quantidade de fótons (em unidades de energia por um intervalo de frequência) que é absorvida por unidade de tempo e unidade de volume de reação. O valor do LVREA é definido para uma radiação monocromática, mas pode ser estendido para campos policromáticos através da integração para os comprimentos de onda de interesse. (CASSANO, 1995)

A taxa de reação ativada pela radiação é proporcional à taxa de energia absorvida (a local volumetric rate of energy absorption). A constante de proporcionalidade é chamada de rendimento quântico $\left(\Phi_{A c}, \lambda\right)$ e tem unidade kmol.einstein ${ }^{-1}$ :

$$
R=\Phi_{A c, \lambda} \cdot \mathrm{e}_{v}^{\mathrm{a}}(x, t)
$$

(Equação 2.10)

A transferência de radiação em um meio participante é um tema bem estabelecido nos campos de ciências físicas e engenharias. No entanto, quando o assunto é agregado a um meio reativo, existem diferentes abordagens, cada uma com suas unidades, simbologias e definições. Em Cassano et al (1995), foi utilizada uma abordagem aderida a ideias existentes na engenharia. As principais propriedades podem ser vistas na Tabela 2-5. 
Tabela 2-5 - Definições das principais propriedades utilizadas nos estudos de radiação. (CASSANO, 1995)

\begin{tabular}{|c|c|c|c|c|}
\hline Propriedade & Nome & Definição & Símbolo & Unidade \\
\hline Energia & Energia Radiante & & $E_{v}$ & $\mathrm{~J}$ \\
\hline Energia por tempo & $\begin{array}{l}\text { Potência de } \\
\text { Radiação }\end{array}$ & $d E_{v} / d t$ & $P_{v}$ & W \\
\hline $\begin{array}{l}\text { Energia por tempo, } \\
\text { área e ângulo sólido } \\
\text { sobre a direção de } \\
\text { propagação }\end{array}$ & $\begin{array}{l}\text { Intensidade } \\
\text { Específica }\end{array}$ & $d E_{v} /[(d A \cos \theta) d t d \Omega]$ & $I_{v}$ & $\mathrm{~W} /\left(\mathrm{m}^{2} \mathrm{sr}\right)$ \\
\hline Energia por volume & $\begin{array}{l}\text { Densidade de } \\
\text { Energia Radiante }\end{array}$ & $(1 / c) \int_{\Omega} I_{v} d \Omega$ & $u_{v}^{R}$ & $\mathrm{~J} / \mathrm{m}^{3}$ \\
\hline $\begin{array}{l}\text { Energia por tempo e } \\
\text { área }\end{array}$ & $\begin{array}{l}\text { Vetor de Fluxo } \\
\text { Radiante }\end{array}$ & $\int_{\Omega} I_{v} \Omega d \Omega$ & $\boldsymbol{q}_{v}^{R}$ & $\mathrm{~W} / \mathrm{m}^{2}$ \\
\hline $\begin{array}{l}\text { Energia por tempo e } \\
\text { área para todas as } \\
\text { direções }\end{array}$ & Radiação Incidente & $\int_{\Omega} I_{v} d \Omega$ & $G_{v}$ & $\mathrm{~W} / \mathrm{m}^{2}$ \\
\hline
\end{tabular}

Para complementar a Tabela 2-5, tem-se que:

- $\quad c$ : velocidade da luz $\left(\mathrm{m} . \mathrm{s}^{-1}\right)$;

- $\Omega$ : ângulo sólido (sr);

- $\boldsymbol{\Omega}$ : versor de direção de propagação da radiação (Adimensional) (SILVARES, 2006).

Para radiações policromáticas, uma integração sobre todo o intervalo de frequência de interesse deve ser realizada, obtendo-se a (Equação 2.11). (CASSANO, 1995)

$$
G=\int_{\nu_{1}}^{v_{2}} \int_{\theta_{1}}^{\theta_{2}} \int_{\phi_{1}}^{\phi_{2}} I_{\nu} \sin \theta d \phi d \theta d v
$$

(Equação 2.11)

Em um volume elementar onde acontece a absorção da radiação, se um único fóton é absorvido, a energia absorvida segue a (Equação 2.12).

$$
\mathrm{e}_{v}^{\mathrm{a}}(x, t)=k_{v}(x, t) \cdot G_{v}(x, t)
$$

(Equação 2.12)

Sendo:

$\mathrm{e}_{v}^{\mathrm{a}}(x, t)$ : LVREA espectral (einstein. $\left.\mathrm{m}^{-3} \cdot \mathrm{s}^{-1}\right)$;

$k_{v}(x, t)$ : Coeficiente molar de absorção $\left(\mathrm{m}^{3} \cdot \mathrm{mol}^{-1} \cdot \mathrm{cm}^{-1}\right)$. (SILVARES, 2006)

Para um sistema homogêneo e bem diluído, pode-se utilizar a conhecida aproximação de Beer. Para radiação policromática, obtêm-se a (Equação 2.13) e a (Equação 2.14). 


$$
\begin{gathered}
e^{a}=\int_{v_{1}}^{v_{2}} k_{v} \cdot G_{v} d v \\
e^{a}=\int_{v_{1}}^{v_{2}} \int_{\theta_{1}}^{\theta_{2}} \int_{\phi_{1}}^{\phi_{2}} k_{v} I_{v} \sin \theta d \boldsymbol{\phi} d \theta d v
\end{gathered}
$$

(Equação 2.13)

(Equação 2.14)

Portanto, para obter o LVREA, a intensidade espectral específica deve ser conhecida em cada ponto do reator. Esse valor pode ser obtido através da equação de transporte de fótons.

\subsubsection{Modelos de Incidência de Radiação}

Os principais modelos de reatores fotoquímicos podem ser classificados em modelos de incidência e de emissão, conforme a Tabela 2-6.

Tabela 2-6 - Classificação utilizada para os principais modelos de radiação. (ALFANO, 1986)

\begin{tabular}{lcc}
\hline Tipo & Característica & Nome \\
\hline \multirow{3}{*}{ Modelos de Incidência } & Bidimensional & Radial \\
& & Parcialmente Difusa \\
& Tridimensional & Difusa \\
& Fonte Linear & Emissão em Planos Paralelos \\
& & Emissão Esférica \\
Modelos de Emissão & & Emissão Difusa \\
& Fonte Extensa & Emissão Volumétrica \\
& & Emissão Superficial Esférica \\
& & Emissão Superficial Difusa \\
\hline
\end{tabular}

Nesta seção, serão apresentados apenas os modelos de incidência utilizados neste trabalho: bidimensional radial e bidimensional difusa. A Figura 2.7 mostra o diagrama de cada modelo de incidência bidimensional.

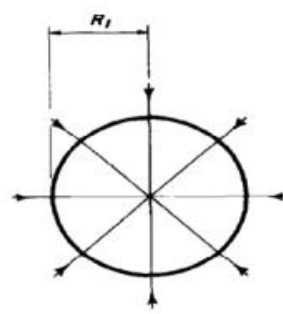

(a)

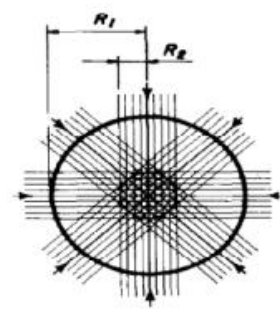

(b)

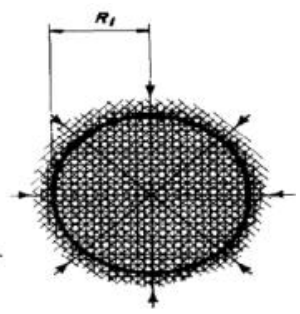

(c)

Figura 2.7 - Características de modelos bidimensionais de incidência de radiação: (a) Radial, (b) Parcialmente difusa e (c) Difusa. (ALFANO, 1986) 
Os raios incidentes estão em um plano normal ao eixo do reator e a circunferência representa a parede do reator para cada caso. O modelo parcialmente difuso assume que um feixe de raios paralelos, de largura $2 R_{2}$, incide em qualquer direção no reator com a mesma probabilidade. Assumindo que $R_{2}$ tenda a zero, obtêm-se o modelo de incidência radial. Ao considerar que a largura do feixe é próxima do valor do diâmetro do reator, obtêm-se o modelo difuso. (ALFANO, 1986)

O modelo de incidência radial não apresenta dependência radial ou axial em sua formulação e prevê uma densidade de fluxo de energia infinita na linha de centro do reator. Já para o modelo de incidência difusa, é observado, para meios com baixa absortividade, que existirá uma densidade de fluxo constante ao longo da coordenada radial. (ALFANO, 1986)

\subsubsection{Equação de Transporte de Fótons}

A transferência de radiação em um meio reativo participante é resultado da interação do material multicomponente contínuo com uma fase de fótons imaterial. Ambas as fases coexistem em uma dada região e interagem entre elas de acordo com as equações constitutivas de cada meio. A equação de transporte de fótons é dada pela (Equação 2.15). (SILVARES, 2006)

$$
\begin{aligned}
\frac{\partial}{\partial t} \int_{\forall} n_{\boldsymbol{\Omega}, v} d V & +\int_{A} n_{\boldsymbol{\Omega}, v}(c \boldsymbol{\Omega}) \cdot \boldsymbol{n} d A \\
& =-\int_{\forall} n^{a}{ }_{\boldsymbol{\Omega}, v} d V+\int_{\forall} n_{\boldsymbol{\Omega}, v}^{e} d V+\int_{\forall} n^{s-i n}{ }_{\boldsymbol{\Omega}, v} d V-\int_{\forall} n^{s-o u t} \boldsymbol{\Omega}, v
\end{aligned}
$$

(Equação 2.15)

Sendo:

$n_{\Omega, v}$ : Número de fótons por unidade de ângulo sólido e por unidade de intervalo de frequência;

$\boldsymbol{n}$ : Versor normal a área;

$n_{\Omega, v}^{a}$ : Taxa de absorção de fótons;

$n_{\Omega, v}^{e}$ : Taxa de emissão de fótons; 
$n^{s-i n}{ }_{\Omega, v}$ : Taxa de ganho de fótons devido à entrada por espalhamento;

$n^{s-o u t}{ }_{\Omega, v}:$ Taxa de perda de fótons devido à saída por espalhamento.

Considerando-se que:

- O termo fonte de emissão é desprezível;

- A taxa de entrada e saída de fótons devido ao espalhamento é desprezível para sistemas homogêneos;

- O sistema de coordenadas utilizado são as coordenadas cilíndricas;

- As componentes $\theta$ e $z$ do vetor de fluxo radioativo são inexistentes;

- Vetor de fluxo radioativo aproximado à radiação incidente $G_{v}$;

obtêm-se a (Equação 2.16). (SILVARES, 2006)

$$
\frac{1}{r} \frac{\partial r G_{v}(r)}{\partial r}=-\beta G_{v}
$$

(Equação 2.16)

Por definição, tem-se que:

$$
\beta=k_{v}+\sigma
$$

(Equação 2.17)

Sendo:

$\beta$ : Coeficiente de extinção volumétrico $\left(\mathrm{m}^{-1}\right)$;

$k_{v}$ : Coeficiente de absorção volumétrico $\left(\mathrm{m}^{-1}\right)$;

$\sigma$ : Coeficiente de espalhamento volumétrico $\left(\mathrm{m}^{-1}\right)$.

Para baixas concentrações, a aproximação de Beer pode ser aplicada:

$$
k_{v}=\alpha \cdot[A c]
$$

(Equação 2.18)

Sendo:

$\alpha$ : Coeficiente Neperiano de Absorção $\left(\mathrm{m}^{2} \cdot \mathrm{kmol}^{-1}\right)$;

$[A c]$ : Concentração de Actinomêtro $\left(\mathrm{kmol}^{\mathrm{m}} \mathrm{m}^{-3}\right)$.

Finalmente, obtendo-se a (Equação 2.19).

$$
\frac{1}{r} \frac{\partial r G_{v}(r)}{\partial r}=-\alpha \cdot[A c] \cdot G_{v}
$$

(Equação 2.19) 


\subsection{REATOR SOLAR COM COLETOR PARABÓLICO COMPOSTO (CPC)}

Existem diversos tipos de reatores solares, como o com coletor cilíndrico parabólico (PTC), o de filme fino descendente (TFFBR) e o de lâmina de camada dupla. (SILVA, 2012) No presente estudo, o reator com coletor parabólico composto (CPC) foi utilizado. O reator CPC é bastante empregado para aplicações fotoquímicas. A forma de um refletor $\mathrm{CPC}$ consiste de dois meio cilindros de perfil parabólico posicionados lado a lado, com o tubo transparente disposto na linha de conexão dos dois perfis parabólicos, conforme ilustrado na Figura 2.8. (ALFANO, 2000)

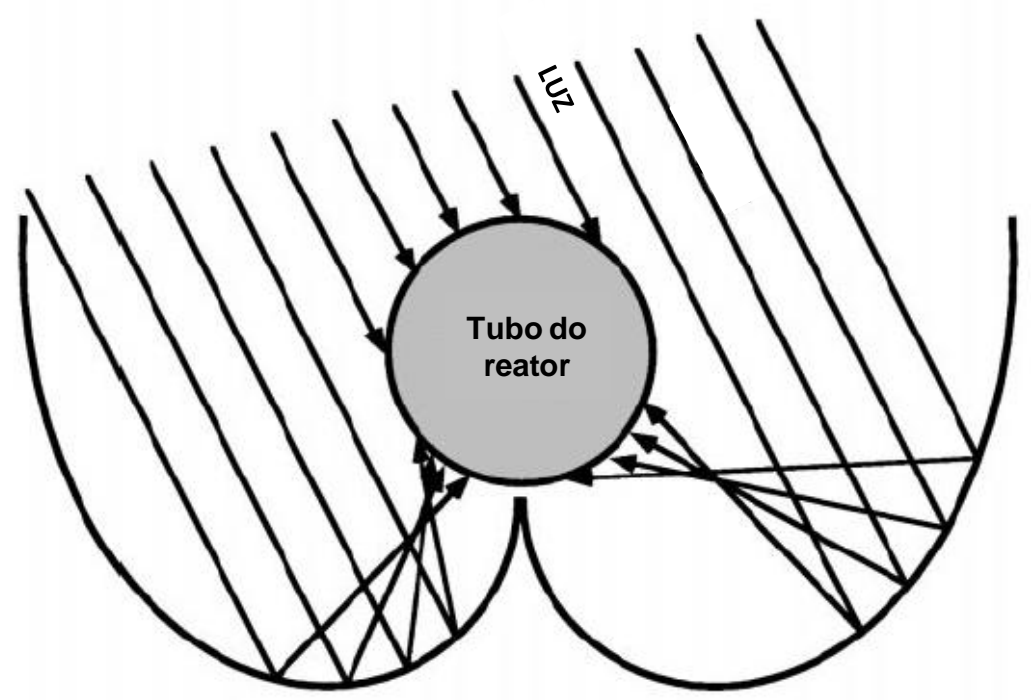

Figura 2.8 - Geometria básica de um reator CPC teórico. (ALFANO,2000)

Essa geometria permite que a luz incidente em todas as direções seja refletida no eixo focal do coletor, captando tanto a radiação direta como grande parte da difusa. (SILVA,2012)

\subsection{ACTINOMETRIA}

A análise de actinometria química é um tipo de análise realizada para se obter uma medida da taxa de fótons incidentes na parede de um reator fotoquímico de geometria especifica, com uma distribuição espectral luminosa bem definida. (BRAUN, 1991) Um actinômetro químico pode ser qualquer substância que reaja 
fotoquimicamente com um rendimento quântico conhecido $\left(\Phi_{A c, \lambda}\right)$. No entanto, um bom actinômetro deve ser capaz de sofrer uma transformação fotoquímica com um rendimento químico que seja pouco sensível a variações de comprimento de onda, de concentração e de temperatura. As análises de determinação da conversão do actinômetro devem ser simples e precisas. (SILVARES, 2006)

Nos experimentos de actinometria é essencial que se determine o número de moléculas de actinômetro $\left(\Delta n_{A c}\right)$ que reagem durante um dado período de irradiação $\Delta t$. O número de fótons $\left(P_{a b s, \lambda}\right)$ absorvidos, de dado comprimento de onda $\lambda$, durante o mesmo período, pode ser calculado através de $\Delta n_{A c}$ e do rendimento quântico $\left(\Phi_{A c, \lambda}\right)$ do actinômetro, para o mesmo comprimento de onda, através da (Equação 2.20).

$$
\frac{\Delta n_{A c}}{\Delta t}=\Phi_{A c, \lambda} P_{a b s, \lambda}
$$

(Equação 2.20)

Considerando-se que a reação do actinômetro é uma reação elementar do tipo $A c \rightarrow B$ e o actinômetro é a única espécie que absorve radiação de comprimento de onda $\lambda$ emitido pela fonte, pode-se aplicar a lei de Lambert-Beer.

$$
P_{a b s, \lambda}=P_{0, \lambda}\left(1-10^{-D_{A c, \lambda}}\right)
$$

(Equação 2.21)

Sendo:

$P_{a b s, \lambda}=$ taxa de absorção de fótons de comprimento de onda $\lambda$ pelo actinômetro;

$P_{0, \lambda}=$ taxa de fótons incidentes de comprimento de onda $\lambda$;

$D_{A c, \lambda}=$ absorbância da solução contendo o actinômetro para o comprimento $\lambda$. Considerando-se que a solução contendo o actinômetro irá absorver totalmente a radiação, obtém-se:

$$
P_{a b s, \lambda}=P_{0, \lambda}
$$

(Equação 2.22)

Substituindo-se a (Equação 2.22) na (Equação 2.20), resulta:

$$
\frac{\Delta n_{A c}}{\Delta t}=\Phi_{A c, \lambda} P_{0, \lambda}
$$




$$
n_{A c, f}=\Phi_{A c, \lambda} P_{0, \lambda} \Delta t+n_{A c, 0}
$$

(Equação 2.24)

As concentrações iniciais e finais do actinômetro podem ser obtidas experimentalmente, para condições reais de irradiação e geometria dos reatores. Conhecendo-se o rendimento quântico do actinômetro para o comprimento de onda específico, pode-se obter a taxa de fótons incidente $\left(P_{0}, \lambda\right)$, a partir do qual se pode obter a radiação incidente $\left(G_{v}\right)$.

Atualmente existe uma diversidade muito grande de actinômetros no mercado. Alguns tipos empregados podem ser vistos na Tabela 2-7.

Tabela 2-7 - Tipos de actinômetros existentes. (SILVARES, 2006)

\begin{tabular}{lcc}
\hline \multicolumn{1}{c}{ Actinômetros } & $\begin{array}{c}\text { Faixa de Comprimentos de } \\
\text { onda de excitação (nm) }\end{array}$ & $\boldsymbol{\Phi}_{\boldsymbol{A c}, \boldsymbol{\lambda}}$ \\
\hline Actinômetros para fase gasosa & $250-320$ & 1,0 \\
Acetona, 50 torr, $125^{\circ} \mathrm{C}$ & $365-635$ & 2,0 \\
HOCl & $254-436$ & $0,58-0,49$ \\
Actinômetros para solução & $250-436$ & $\sim 1,24$ \\
Oxalato de uranila & $250-330$ & $\sim 1,0$ \\
Ferrioxalato de potássio & 254 & 0,31 \\
Verde Malacheta & 366 & 0,69 \\
Ácido cloro acético, 25ㄷ & $400-580$ & 0,016 \\
Benzofenona & $310-370$ & 0,20 \\
Heterocoerdiantrona (em & $436-546$ & $0,076-0,047$ \\
tolueno) & 500 & 0,026 \\
Abercromo 540 & 540 & 0,058 \\
Abercromo 999P & & \\
\hline
\end{tabular}

Para o espectro de radiação solar, que é contínuo em todo o intervalo de comprimento de onda, tem-se: (RIBEIRO et al., 2009)

$$
\left(\frac{\Delta n_{A c}}{\Delta t}\right)_{\text {teo }}=\frac{A}{\widetilde{N} h c} \int_{\lambda_{\min }}^{\lambda_{\text {máx }}} \lambda L_{s, \lambda} \Phi_{A c, \lambda}\left(1-10^{-D_{A c, \lambda}}\right) T_{\lambda} d \lambda
$$

(Equação 2.25)

Sendo:

$A$ : Área da superfície irradiada $\left(\mathrm{m}^{2}\right)$

$\widetilde{N}$ : Número de Avogadro

$h$ : Constante de Planck

$\lambda$ : Comprimento de onda $(\mathrm{m})$

$L_{s, \lambda}$ : Distribuição espectral da irradiância solar $\left(W \cdot m^{-2} \cdot n m^{-1}\right)$

$T_{\lambda}$ : Transmitância da parede de vidro. 


\subsubsection{Ferrioxalato de Potássio}

Nos trabalhos desenvolvidos no CESQ, para a medida de actinometria, temse utilizado o ferrioxalato de potássio como actinômetro para determinar a taxa de radiação solar incidente. Este é apropriado para UV visível de $250 \mathrm{~nm}$ a $550 \mathrm{~nm}$. Sob irradiação, os íons férricos $\left(\mathrm{Fe}^{3+}\right)$ presentes na solução aquosa do ferrioxalato se reduzem a íons ferrosos $\left(\mathrm{Fe}^{2+}\right)$, de acordo com as (Equação 2.26) e (Equação 2.27).

$$
\begin{aligned}
& \mathrm{Fe}^{3+}+\mathrm{C}_{2} \mathrm{O}_{4}^{2-} \stackrel{h v}{\rightarrow} \mathrm{Fe}^{2+}+\mathrm{C}_{2} \mathrm{O}_{4}^{--} \\
& \mathrm{C}_{2} \mathrm{O}_{4}^{--}+\mathrm{Fe}^{3+} \rightarrow \mathrm{Fe}^{2+}+2 \mathrm{CO}_{2}
\end{aligned}
$$

(Equação 2.26)

(Equação 2.27)

Considerando-se que a reação dada pela (Equação 2.27) ocorre instantaneamente, a cinética global de reação de redução dos íons férricos pelos íons ferrosos pode ser dada pela (Equação 2.28).

$$
2 \mathrm{Fe}^{3+}+\mathrm{C}_{2} \mathrm{O}_{4}^{2-} \stackrel{h v}{\rightarrow} 2 \mathrm{Fe}^{2+}+2 \mathrm{CO}_{2}
$$

(Equação 2.28)

As concentrações dos íons ferrosos produzidos pelas reações fotoquímicas $\left(\mathrm{Fe}^{2+}\right)$ são determinadas por espectrofotometria. A partir das amostras retiradas do experimento, adicionam-se soluções de 1,10-fenantrolina. (SILVARES, 2006) Esse composto complexará tanto os íons férricos quanto os íons ferrosos. (BRAUN, 1991) Portanto, pode-se medir a absorbância da amostra retirada do reator solar e complexada em uma cubeta de $1 \mathrm{~cm}$ de largura e, para o cálculo de $\mathrm{Fe}^{2+}$, empregase uma curva de calibração obtida previamente a partir de soluções de $\mathrm{FeSO}_{4} \cdot 7 \mathrm{H}_{2} \mathrm{O}$. (RIBEIRO, 2009)

Os valores do rendimento quântico $\left(\Phi_{A c}, \lambda\right)$ e do coeficiente neperiano de absorção molar $\left(\alpha_{\lambda}\right)$, em função de $\lambda$, foram obtidos a partir de dados da literatura. (ZALAZAR, 2005) No presente trabalho, consideraram-se os valores médios de rendimento quântico $\left(\Phi_{A c}, \lambda\right)$ e do coeficiente neperiano de absorção $\left(\alpha_{\lambda}\right)$, calculados a partir da (Equação 2.29) e da (Equação 2.30), integrando-se seus valores no intervalo de $\lambda$ de interesse, e considerando-se a transmissividade do vidro, ou seja, a transmissão é feita a partir da parede de vidro. 


$$
\begin{gathered}
\Phi_{A c, \lambda}=\frac{\int_{\lambda_{\text {min }}}^{\lambda_{\text {máx }}} \lambda \cdot L_{s, \lambda} \cdot \Phi_{A c, \lambda} \cdot T_{\lambda} d \lambda}{\int_{\lambda_{\text {man }}}^{\lambda_{\text {máx }}} \lambda \cdot L_{s, \lambda} \cdot T_{\lambda} d \lambda} \\
\alpha_{\lambda}=\frac{\int_{\lambda_{\text {man }}}^{\lambda_{\text {máx }}} \lambda \cdot L_{s, \lambda} \cdot \alpha_{\lambda} \cdot T_{\lambda} d \lambda}{\int_{\lambda_{\text {max }}}^{\lambda_{\text {máx }}} \lambda \cdot L_{s, \lambda} \cdot T_{\lambda} d \lambda}
\end{gathered}
$$

(Equação 2.29)

(Equação 2.30)

Onde,

$\lambda$ : Comprimento de onda $(\mathrm{m})$

$L_{s, \lambda}$ : Distribuição espectral da irradiância solar $\left(W \cdot \mathrm{m}^{-2} \cdot \mathrm{nm}^{-1}\right)$

$T_{\lambda}$ : Transmitância da parede de vidro.

Os valores médios obtidos podem ser vistos na Tabela 2-8.

Tabela 2-8 - Rendimento quântico médio e o coeficiente neperiano de absorção médio do ferrioxalato de potássio. (ZALAZAR, 2005)

\begin{tabular}{ccc}
\hline Parâmetro & Valor & Unidade \\
\hline$\Phi_{A c}$ & $1,04 \times 10^{-4}$ & $\mathrm{kmol}^{-}$einstein \\
$\alpha$ & $5,17 \times 10^{4}$ & $\mathrm{~m}^{2} . \mathrm{kmol}^{-1}$ \\
\hline
\end{tabular}




\section{MATERIAIS E MÉTODOS}

O presente capítulo tem como objetivo apresentar o modelo para cálculo da DTR do reator e o modelo de reator fotoquímico, para reação de actinometria.

Os procedimentos experimentais relatados referem-se aos trabalhos de RIBEIRO (2009), cujos resultados experimentais foram utilizados para análise e validação dos modelos desenvolvidos no presente trabalho.

\subsection{REATOR SOLAR MODELADO}

O reator solar estudado é provido de coletores parabólicos compostos (CPC), e está mostrado na Figura 3.1. (RIBEIRO, 2009) Este reator tem sido utilizado em experimentos realizados no CESQ - Centro de Engenharia de Sistemas Químicos, do Departamento de Engenharia Química da Universidade de São Paulo.

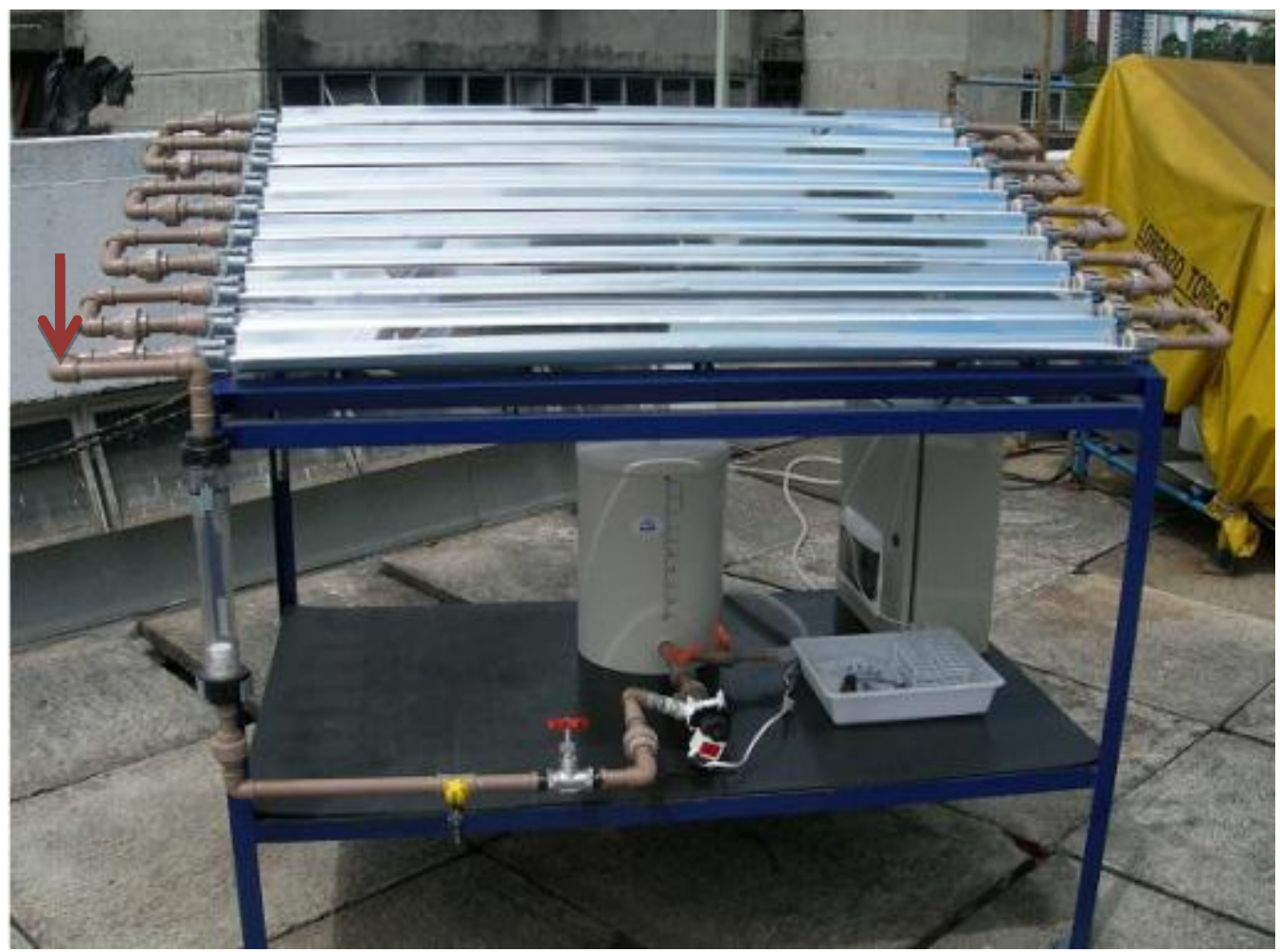

Figura 3.1 - Reator CPC existente no CESQ que será modelado - Vista frontal do reator. (RIBEIRO, 2009) 
O reator é composto de 10 tubos de vidro paralelos (diâmetro interno 29,2 mm e externo $32 \mathrm{~mm}$ ) posicionados sobre os coletores solares de alumínio. As outras dimensões do reator podem ser vistas no esquema apresentado na Figura 3.2.

No caso dos ensaios de actinometria, empregou-se um trecho de apenas dois tubos irradiados - hairpin -, sendo o reator acoplado a um tanque de circulação de volume 5 litros, com operação em regime transiente.

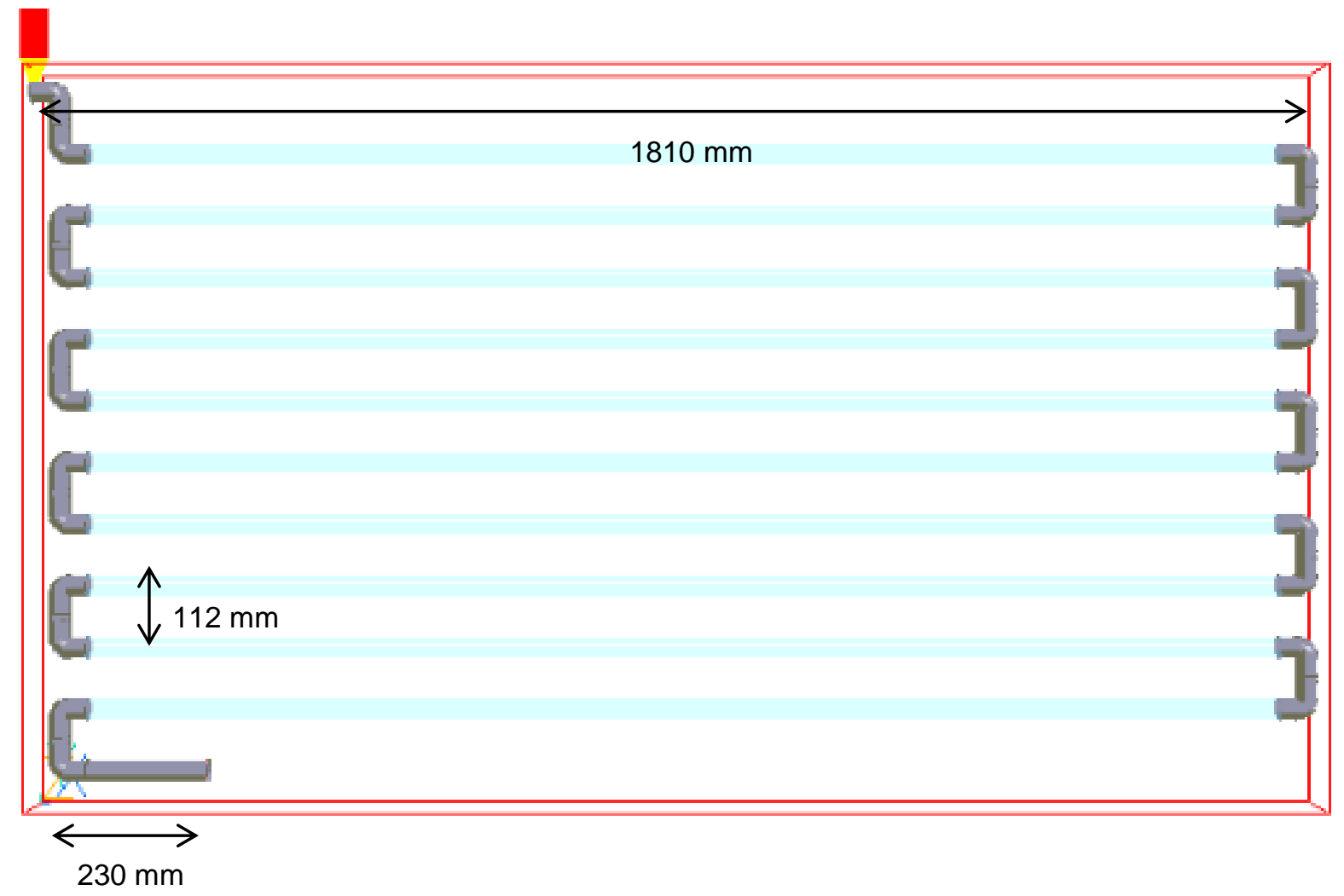

Figura 3.2 - Esquema do reator CPC modelado e simulado no PHOENICS - Vista superior.

\subsubsection{Distribuição do Tempo de Residência Experimental}

Conforme visto no item 2.2, uma forma de caracterizar um reator não ideal é através da determinação da sua distribuição de tempo de residência (DTR). Neste estudo, foram consideradas as medidas experimentais de DTR no reator solar obtidas por RIBEIRO (2009), no CESQ - LSCP, empregando-se a através da seguinte metodologia:

1. Operação contínua do reator, ajustando-se inicialmente a vazão de água através de uma válvula e um rotâmetro. 
2. Injeção do corante azul de metileno ( $\mathrm{V}=0,5 \mathrm{ml})$, de forma praticamente instantânea e com o acionamento de um cronômetro, no local indicado na Figura 3.1.

3. Observação da dispersão do traçador, à medida que escoa no reator, tomando-se amostras na saída deste em tempos pré-determinados.

4. Determinação da concentração de traçador nas amostras, por meio de medidas de absorbância utilizando-se espectrofotômetro. (RIBEIRO, 2009)

\subsubsection{Actinometria Experimental}

\subsubsection{Caracterização Actinométrica}

Inicialmente, a solução do actinômetro é transferida para o reator e recircula por 10 minutos antes de ser irradiada. Nesta etapa, a solução circula sob a atmosfera de nitrogênio. Em sala escura, prepara-se a solução aquosa contendo ácido oxálico $\left(\mathrm{H}_{2} \mathrm{C}_{2} \mathrm{O}_{4} \cdot 2 \mathrm{H}_{2} \mathrm{O}\right) \quad 0,75 \mathrm{~mol} \cdot \mathrm{L}^{-1}$ e íons de $F e^{3+} \quad 0,15 \mathrm{~mol} . \mathrm{L}^{-1}$ $\left(\mathrm{Fe}_{2}\left(\mathrm{SO}_{4}\right)_{3} \cdot 5 \mathrm{H}_{2} \mathrm{O}\right)$.

Inicia-se o experimento quando os coletores solares parabólicos são expostos ao sol. As amostras de 0,25 mL são coletadas a cada 2 minutos e transferidas para frascos âmbar encapados com papel alumínio contendo $24,75 \mathrm{~mL}$ de solução complexante. $\mathrm{O}$ experimento tem duração de 30 minutos, e as soluções são agitadas vigorosamente e deixadas em repouso por 90 minutos. Então, mede-se a absorbância de cada amostra para comprimento de onda de $510 \mathrm{~nm}$ no espectrofotômetro UV visível. (RIBEIRO, 2009)

\subsubsection{Actinometria do Reator Solar}

O reator $\mathrm{CPC}$ foi operado em dia ensolarado para obtenção dos dados de actinometria. O volume de solução actinométrica utilizado no experimento foi de 5,0 litros, com o reator solar operando com dois tubos irradiados. A vazão de circulação que escoa pelo reator foi fixada em 8 L.min ${ }^{-1}$. (RIBEIRO, 2009) 


\subsection{CÓDIGO UTILIZADO - PHOENICS}

Neste trabalho será utilizado 0 método dos volumes finitos para a discretização das equações de conservação, conforme procedimento apresentado e empregado no código PHOENICS (Parabolic Hyperbolic Or Elliptic Numerical Integration Code Series), desenvolvido pelo professor Spalding (2011) e comercializado pela empresa britânica CHAM (Concentration, Heat and Momentum). O PHOENICS surgiu em 1981, como o primeiro software de aplicação geral em Fluidodinâmica Computacional. No presente trabalho, empregou-se a versão de 2010. O PHOENICS é divido em três módulos básicos:

- Pré-processador: O usuário define qual problema será resolvido, quais serão os modelos e as condições de contorno. Este módulo pode ser chamado de SATELLITE e engloba o VR-viewer.

- Solver: Neste módulo tem-se a discretização e resolução das equações necessárias. Também chamado de Earth.

- Pós-processador: Trata os resultados da simulação através de gráficos, tabelas, etc. Podendo-se utilizar os seguintes recursos: PHOTON, AUTOPLOT e Vr-Viewer. (SPALDING, 2011)

Um esquema simplificado da relação entre os módulos pode ser visualizado na Figura 3.3.

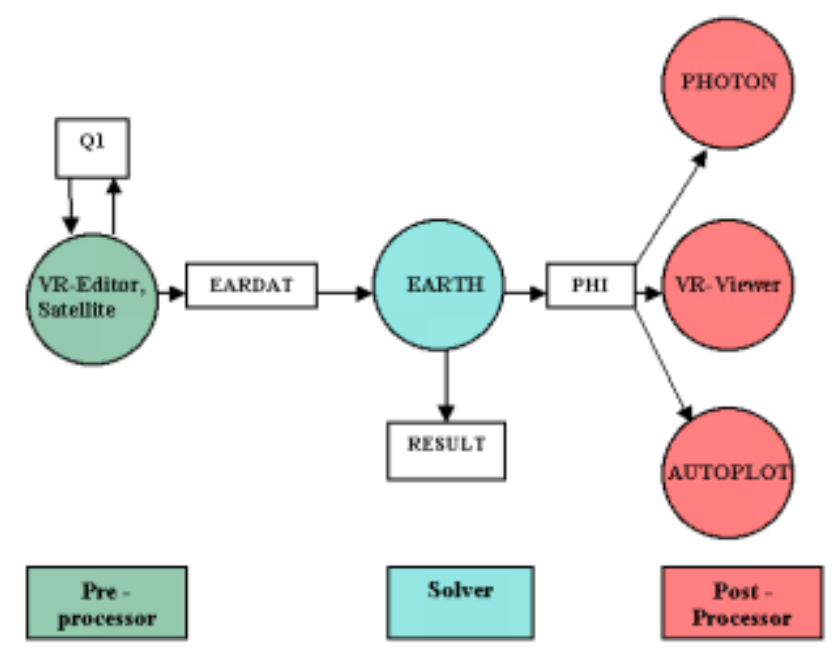

Figura 3.3 - Módulos de pré-processamento, solver e pós processamento existentes no software PHOENICS. (SPALDING, 2011) 
Empregaram-se os seguintes computadores no desenvolvimento deste trabalho:

- Windows 7, Processador Intel $₫$ Xeon $\AA$ X550 RAM 12GB

- Windows 7, Processador Intel $\AA$ i7 RAM 8GB

O PHOENICS dispõe de códigos específicos, como, por exemplo, o In-Form e o GROUND. O In-Form é um suplemento ao PIL (PHOENICS Input Language) que facilita a inserção de dados de definição do problema a ser resolvido. O GROUND é um suplemento em Fortran que permite a inserção de modelos no solver do PHOENICS. Eles permitem ao usuário expressar seus requisitos do problema estudado através de fórmulas algébricas sendo muito usado para:

- Discretização no espaço e no tempo

- Propriedades do material

- Condições iniciais

- Fontes

- Condições de Contorno

- Formatos e Geometria complexas e com movimento

- Formas especiais de imprimir os resultados.

\subsubsection{Malha Utilizada}

O PHOENICS pode empregar três diferentes tipos de malhas:

1. Cartesiana: é um tipo de malha estruturada, composta por células formadas pela intersecção de três planos paralelos perpendiculares entre si. Os espaços entre os planos podem sofrer variações de acordo com a necessidade do problema.

2. Cilíndrica-Polar: também é uma malha estruturada, composta por células formadas pela intersecção de planos constantes em z (perpendicular ao eixo de rotação), planos constantes em x (ângulos em radianos) e por superfícies cilíndricas concêntricas (coordenada radial y).

3. Curvilínea, também chamada de body-fitted: é uma malha estruturada, onde todas as células vizinhas se mantêm, porém suas formas são alteradas consideravelmente. (SPALDING, 2011) 


\subsection{MODELAGEM DA DISTRIBUIÇÃO DO TEMPO DE RESIDÊNCIA - DTR}

A modelagem da DTR é feita através da resolução do balanço de massa por componente, expresso pela (Equação 3.2), no caso, para o traçador azul de metileno. A conservação de massa pode ser expressa tanto em função da fração mássica como da concentração, respeitando-se a seguinte relação:

$$
\begin{gathered}
{[\mathrm{Cm}]=\frac{\rho \cdot \boldsymbol{x}_{C m}}{M_{C m}}} \\
\frac{\partial[\mathrm{Cm}]}{\partial t}+\overrightarrow{d \imath v}(\vec{v}[\mathrm{Cm}])=\overrightarrow{d \imath v}\left(D_{C m} \overrightarrow{\operatorname{grad}}[\mathrm{Cm}]\right)
\end{gathered}
$$

(Equação 3.1)

(Equação 3.2)

Sendo:

$[\mathrm{Cm}]$ : Concentração de Azul de Metileno $\left(\mathrm{mol} \cdot \mathrm{m}^{-3}\right)$

$\rho$ : Densidade da Solução $\left(\mathrm{kg} \cdot \mathrm{m}^{-3}\right)$

$\boldsymbol{x}_{C m}$ : Fração Mássica de Azul de Metileno

$M_{C m}$ : Massa Molar do Azul de Metileno $\left(\mathrm{kg} \cdot \mathrm{mol}^{-1}\right.$ )

$t$ : Tempo (s)

$\vec{v}$ : Vetor Velocidade $\left(\mathrm{m} \cdot \mathrm{s}^{-1}\right)$

$D_{C m}$ : Difusividade do Azul de Metileno em Água $\left(\mathrm{m}^{2} \cdot \mathrm{s}^{-1}\right)$

No PHOENICS, a modelagem da DTR foi feita através da inserção de uma condição de contorno adicional (objeto) do tipo inlet. Este objeto não pode ser inserido exatamente no mesmo local do experimento, devido às limitações do software e da malha. Inseriu-se, então, no local indicado na Figura 3.4.

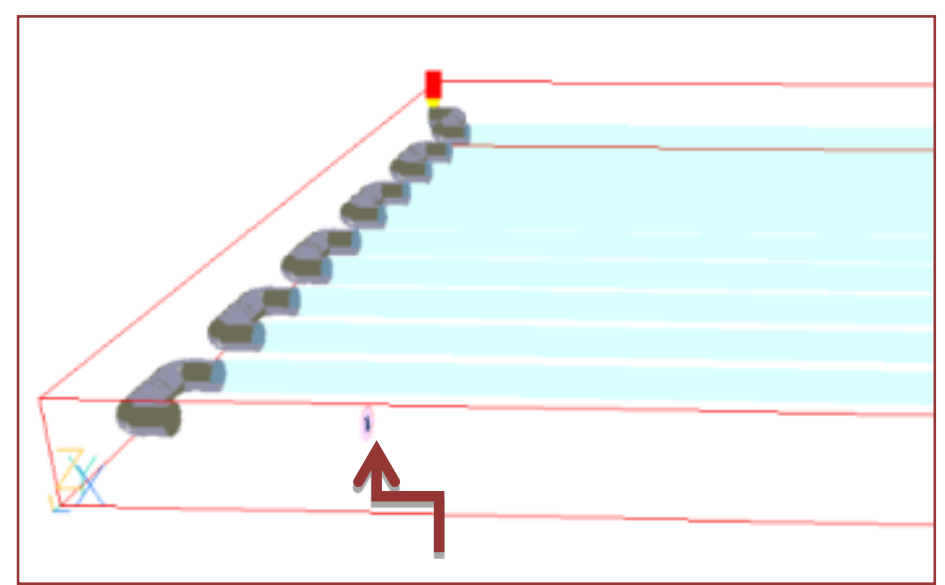

Figura 3.4 - Ponto modelado de injeção do corante azul de metileno para as simulações de distribuição de tempo de residência no PHOENICS. 
Realizou-se uma simulação em regime transiente, com uma nova variável, $\mathrm{C} 1$, inserida no programa para representar o traçador. As condições de contorno para a alimentação do traçador (C1) podem ser vistas na Figura 3.5, e foram inseridas como um pulso de volume $0,5 \mathrm{~mL}$.

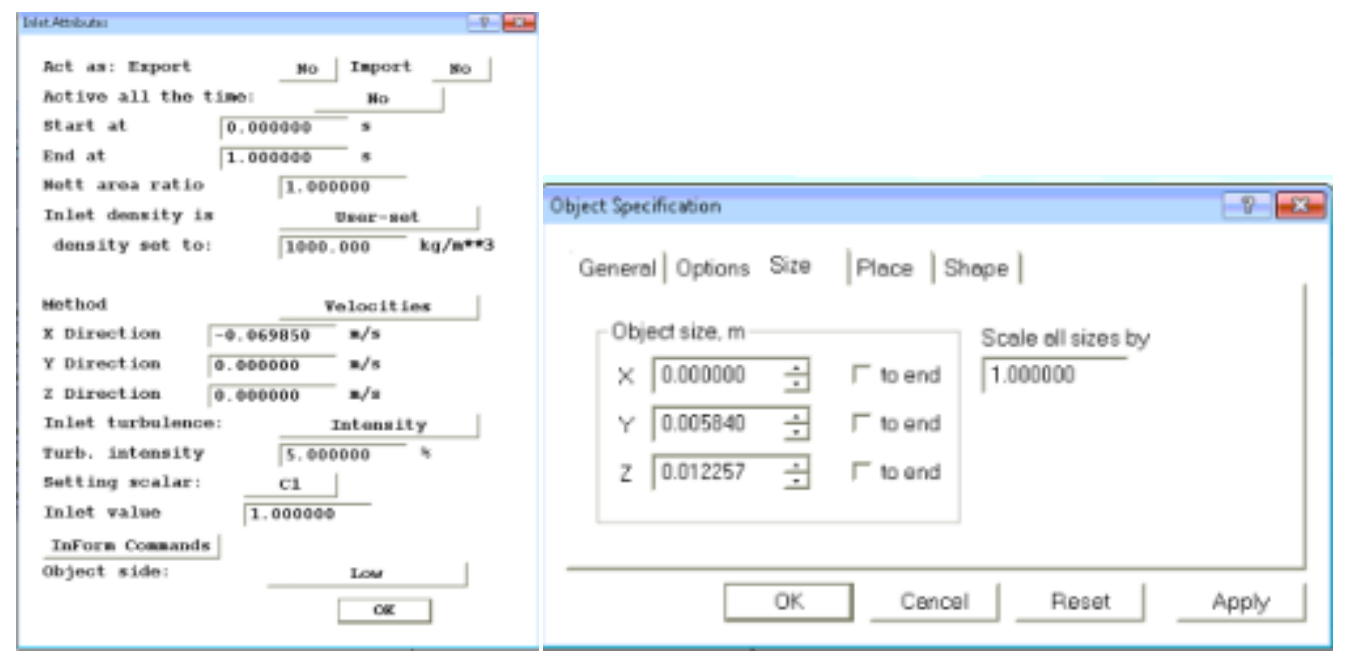

Figura 3.5 - Dados de input do tipo pulso, inseridos no PHOENICS.

Para a difusividade do material, alterou-se a propriedade Prandtl, da variável $\mathrm{C} 1$, como sendo igual a $\mathrm{D}_{\mathrm{Azul} \text { de Metileno,H2O }}=-7,9 \times 10^{-10} \mathrm{~m}^{2} \cdot \mathrm{s}^{-1}$ (LEAIST, 1988). O sinal negativo utilizado na frente da difusividade é uma regra do PHOENICS para entendimento de que esse valor refere-se à difusividade de $\mathrm{C} 1$. As medidas de concentração foram obtidas a partir da saída do reator, como no experimento.

\subsection{MODELAGEM MATEMÁTICA DA ACTINOMETRIA}

O desenvolvimento dos modelos cinético e de radiação, assim como a implementação no PHOENICS, que serão apresentados neste item, foram baseados essencialmente nos trabalhos de SILVARES (2001 e 2006).

\subsubsection{Modelo Cinético}

A partir de Cassano (1995) e Silvares (2006), obteve-se a seguinte expressão para a reação de consumo de íons férricos, em função do fluxo de radiação, que pode ser aplicada a cada elemento de volume:

$$
R_{F e^{3+}}=-\Phi_{F e^{3+}} G_{v}{ }^{a b s} \cdot \frac{1}{l}
$$


Sendo:

$R_{\mathrm{Fe}^{3+}}$ : Taxa de consumo de íons férricos $\left(\mathrm{kmol} . \mathrm{m}^{-3} \cdot \mathrm{s}^{-1}\right)$;

$\Phi_{\mathrm{Fe}^{3+}}$ : Rendimento quântico da reação fotoquímica do íon férrico (kmol. einstein $\left.{ }^{-1}\right)$;

$G_{v}{ }^{a b s}$ : Radiação Absorvida no elemento de volume (einstein. $\mathrm{m}^{-2} \cdot \mathrm{s}^{-1}$ )

$l$ : Caminho Ótico do elemento de volume $(\mathrm{m})$

Pela Lei de Beer, a fração de energia transmitida é dado por:

$$
T=\frac{G_{v}^{T}}{G_{v}}=e^{-\alpha . l .\left[F e^{3+}\right]}
$$

(Equação 3.4)

Sendo:

$T$ :Fração de Energia Transmitida

$G_{v}^{T}:$ Radiação Transmitida (einstein. $\mathrm{m}^{-2} \cdot \mathrm{s}^{-1}$ )

$G_{v}:$ Radiação Incidente (einstein. $\mathrm{m}^{-2} \cdot \mathrm{s}^{-1}$ )

$\left[\mathrm{Fe}^{3+}\right]$ : Concentração de ĺons Férricos $\left(\mathrm{kmol} \cdot \mathrm{m}^{-3}\right)$

$\mathrm{Na}$ ausência de espalhamento, têm-se:

$$
G_{v}=G_{v}^{T}+G_{v}^{a b s}
$$

(Equação 3.5)

Então, substituindo-se a (Equação 3.5) na (Equação 3.4), têm-se:

$$
\begin{gathered}
\frac{G_{v}-G_{v}{ }^{a b s}}{G_{v}}=e^{-\alpha . l .\left[F e^{3+}\right]} \\
G_{v}{ }^{a b s}=G_{v}\left(1-e^{-\alpha . l .\left[F e^{3+}\right]}\right)
\end{gathered}
$$

(Equação 3.6)

(Equação 3.7)

Substituindo-se esse termo na (Equação 3.3), obtêm-se a equação para a cinética de consumo de íons férricos:

$$
R_{F e^{3+}}=-\Phi_{F e^{3+} .} G_{v}\left(1-e^{-\alpha . l .\left[F e^{3+}\right]}\right) \cdot \frac{1}{l}
$$

(Equação 3.8)

Analogamente, obtêm-se a equação da cinética de produção dos íons ferrosos:

$$
R_{F e^{2+}}=\Phi_{F e^{3+} .} G_{v}\left(1-e^{-\alpha . l . l\left[F e^{3+}\right]}\right) \cdot \frac{1}{l}
$$


Constataram-se dificuldades numéricas (altos resíduos e baixa velocidade de convergência) na implementação do modelo cinético na sua forma original, conforme a (Equação 3.5). Face à isto, optou-se pelo emprego de modelos matemáticos mais simples, que, no entanto, apresentam desvios em relação ao valor exato. Estudaram-se dois ajustes diferentes para o termo $1-e^{-\alpha . l .\left[F e^{3+}\right]}$, que foram simulados, com valor de $\alpha$ da Tabela 2-8: aproximação de 1a. Ordem ((Equação 3.10) e (Equação 3.11)) e de 4⿳亠丷a . ordem ((Equação 3.12) e (Equação 3.13)).

$$
\begin{aligned}
& 1-e^{-\alpha . l .\left[F e^{3+}\right]}=0,8 \cdot \alpha \cdot l \cdot\left[F^{3+}\right] \\
& R_{F e^{3+}}=-0,8 \cdot \Phi_{F e^{3+}} \cdot G_{v} \alpha \cdot\left[F e^{3+}\right] \\
& 1-e^{-\alpha . l .\left[F e^{3+}\right]}=\alpha . l \cdot\left[F e^{3+}\right]-\frac{\left(\alpha . l \cdot\left[F e^{3+}\right]\right)^{2}}{2}+\frac{\left(\alpha \cdot l \cdot\left[F e^{3+}\right]\right)^{3}}{6}-\frac{\left(\alpha \cdot l \cdot\left[F e^{3+}\right]\right)^{4}}{24} \\
& R_{F e^{3+}}=-\Phi_{F e^{3+}} \cdot G_{v}\left(\alpha \cdot l \cdot\left[F e^{3+}\right]-\frac{\left(\alpha \cdot l \cdot\left[F e^{3+}\right]\right)^{2}}{2}+\frac{\left(\alpha \cdot l \cdot\left[F e^{3+}\right]\right)^{3}}{6}-\frac{\left(\alpha \cdot l \cdot\left[F e^{3+}\right]\right)^{4}}{24}\right) \cdot \frac{1}{l}
\end{aligned}
$$

(Equação 3.13)

A Figura 3.6 apresenta a comparação dos dois ajustes matemáticos, obtidos por expansão em séries, testados numericamente na simulação e o modelo rigoroso (exponencial). Constata-se que a qualidade do ajuste está intrinsicamente associada à dimensão da malha considerada, no caso expressa por $y$, como pode ser observado na Figura 3.6.

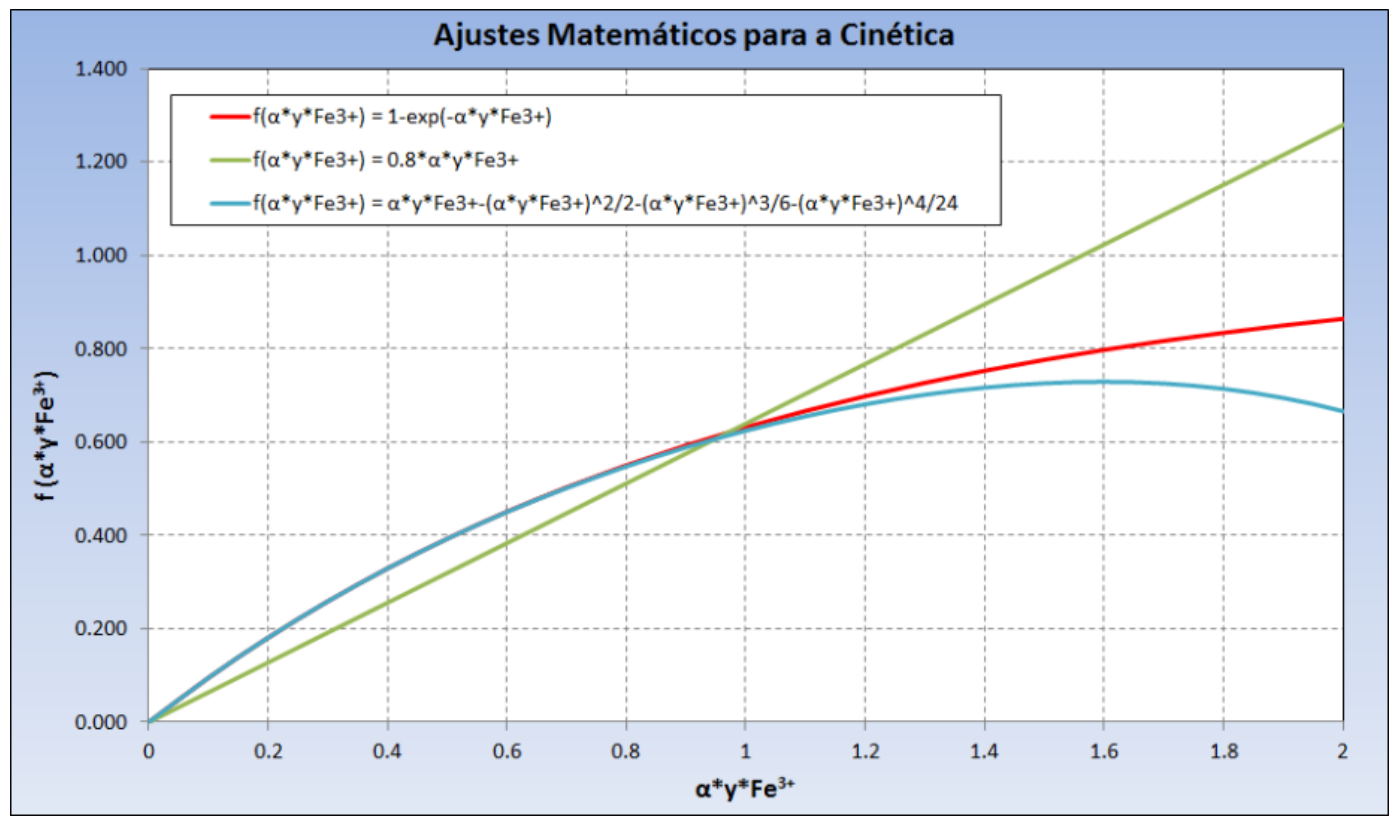

Figura 3.6 - Comparação dos diferentes ajustes matemáticos feitos para o modelo cinético. 


\subsubsection{Modelo de Radiação}

A partir da equação de transporte de fótons, (Equação 2.19), tem-se para o modelo de radiação:

$$
\frac{1}{r} \frac{d}{d r}\left[r G_{v}(r)\right]=-\alpha \cdot\left[F e^{3+}\right] \cdot G_{v}
$$

(Equação 2.19)

Aplicando-se o modelo de incidência radial e integrando-se para um elemento de raio, obtém-se:

$$
\begin{gathered}
\frac{1}{r}\left(r \frac{d G_{v}(r)}{d r}+G_{v}(r)\right)=-\alpha \cdot\left[F e^{3+}\right] \cdot G_{v}(r) \\
\frac{d G_{v}(r)}{d r}=-G_{v}(r)\left(\alpha \cdot\left[F e^{3+}\right]+\frac{1}{r}\right) \\
\int_{G_{v, \text { ext }}}^{G_{v, \text { int }}} \frac{d G_{v}(r)}{G_{v}(r)}=-\int_{r_{\text {ext }}}^{r_{\text {int }}}\left(\alpha \cdot\left[F e^{3+}\right]+\frac{1}{r}\right) d r \\
\frac{G_{v_{\text {,int }}}}{G_{v, \text { ext }}}=e^{\left(-\alpha \cdot\left[F e^{3+}\right] \cdot\left(r_{i n t}-r_{\text {ext }}\right)+\ln \left(\frac{r_{\text {ext }}}{r_{\text {int }}}\right)\right)} \\
G_{v, \text { int }}=G_{v, \text { ext }}\left(\frac{r_{\text {ext }}}{r_{\text {int }}}\right) \cdot e^{\left(-\alpha \cdot\left[F e^{3+}\right] \cdot\left(r_{\text {int }}-r_{\text {ext }}\right)\right)}
\end{gathered}
$$

(Equação 3.15)

(Equação 3.16)

(Equação 3.17)

(Equação 3.18)

Para o modelo de incidência difusa, considerou-se um campo de radiação uniforme atenuado apenas pela absorção, expresso pelas seguintes equações:

$$
\begin{gathered}
\frac{d G_{v}(r)}{d r}=-\alpha \cdot\left[F e^{3+}\right] \cdot G_{v}(r) \\
\int_{G_{v, \text { ext }}}^{G_{v, \text { int }}} \frac{d G_{v}(r)}{G_{v}(r)}=-\left(\alpha \cdot\left[F e^{3+}\right]\right) \int_{r_{\text {ext }}}^{r_{\text {int }}} 1 d r \\
\frac{G_{v_{\text {,int }}}}{G_{v_{\text {,ext }}}}=e^{\left(-\alpha \cdot\left[F e^{3+}\right] \cdot\left(r_{\text {int }}-r_{\text {ext }}\right)\right)}
\end{gathered}
$$

(Equação 3.19)

(Equação 3.20)

(Equação 3.21) 


$$
G_{v, \text { int }}=G_{v, \text { ext }} \cdot e^{\left(-\alpha \cdot\left[F e^{3+}\right] \cdot\left(r_{i n t}-r_{e x t}\right)\right)}
$$

(Equação 3.22)

No PHOENICS, esse modelo de radiação pode ser inserido no solver do software através da rotinha chamada GROUND, que pode ser visto detalhadamente no APÊNDICE B - GROUND, Group 19. Essa rotina faz com que o campo de radiação seja calculado em cada célula do domínio.

\subsubsection{Modelo do Reator Fotoquímico}

A modelagem do reator fotoquímico é feita através da resolução do balanço de massa por componente, expresso pela (Equação 3.23), no caso, para o actinômetro.

$$
\frac{\partial[A]}{\partial t}+\overrightarrow{d \imath v}(\vec{v}[A])=\overrightarrow{d \imath v}\left(D_{A} \overrightarrow{\operatorname{grad}}[A]\right)+R_{A}
$$

(Equação 3.23)

Sendo:

$[A]$ : Concentração de Actinômetro $\left(\mathrm{mol} . \mathrm{m}^{-3}\right)$

$\rho$ : Densidade da Solução $\left(\mathrm{kg} \cdot \mathrm{m}^{-3}\right)$

$t$ : Tempo (s)

$\vec{v}$ : Vetor Velocidade $\left(\mathrm{m} \cdot \mathrm{s}^{-1}\right)$

$D_{A}$ : Difusividade do Actinômetro $\left(\mathrm{m}^{2} \cdot \mathrm{s}^{-1}\right)$

$R_{A}$ : Termo de reação (kmol. $\left.\mathrm{m}^{-3} \cdot \mathrm{s}^{-1}\right)$

No PHOENICS, esse modelo de reação pode ser inserido no solver do software através da rotinha chamada GROUND, que pode ser visto detalhadamente no APÊNDICE B - GROUND, Group 13. Essa rotina faz com que o termo fonte do balanço de massa seja calculado de uma forma específica.

\subsubsection{Modelo do Tanque de Circulação}

No tanque de circulação, que está acoplado ao reator, não há reação química e o balanço de massa por componente para os íons férricos é expresso por:

$$
V_{\text {Tanque }} \frac{d\left[\mathrm{Fe}^{3+}\right]_{\text {Tanque }}}{d t}=\dot{q} \cdot\left(\left[\mathrm{Fe}^{3+}\right]_{\text {Reator }, z=L}-\left[\mathrm{Fe}^{3+}\right]_{\text {Tanque }}\right)
$$


Sendo:

$V_{\text {Tanque }}$ : Volume do tanque $\left(\mathrm{m}^{3}\right)$

$\dot{q}$ : Vazão do sistema $\left(\mathrm{m}^{3} \cdot \mathrm{s}^{-1}\right)$

$t$ : Tempo (s)

$\left[\mathrm{Fe}^{3+}\right]_{\text {Reator }, \mathrm{z}=L}$ : Concentração de $\mathrm{Fe}^{3+}$ na entrada do tanque (saída do reator) $\left(\mathrm{kmol} . \mathrm{m}^{-3}\right)$

$\left[\mathrm{Fe}^{3+}\right]_{\text {Tanque }}$ : Concentração de $\mathrm{Fe}^{3+}$ na saída do tanque (entrada do reator) $\left(\mathrm{kmol} . \mathrm{m}^{-3}\right)$

Considerando que não há reação no tanque de mistura e que ele atua como uma célula a mais no domínio, obtêm-se, a seguinte equação discretizada no tempo:

$$
V_{\text {Tanque }} \frac{\left[\mathrm{Fe}^{3+}\right]_{\text {Tanque }_{t+d t}}-\left[\mathrm{Fe}^{3+}\right]_{\text {Tanque }_{t}}}{d t}=\dot{q} \cdot\left[\mathrm{Fe}^{3+}\right]_{\text {Reator }, \mathrm{Z}=L}-\dot{q} \cdot\left[\mathrm{Fe}^{3+}\right]_{\text {Tanque }_{t+d t}}
$$

(Equação 3.25)

$$
\left[\mathrm{Fe}^{3+}\right]_{\text {Tanque }_{t+d t}}=\frac{\dot{q} \cdot\left[\mathrm{Fe}^{3+}\right]_{\text {Reator }, z=L} \cdot d t+V_{\text {Tanque }}\left[\mathrm{Fe}^{3+}\right]_{\text {Tanque }_{t}}}{V+\dot{q} \cdot d t}
$$

(Equação 3.26)

Essa equação foi implementada no GROUND como uma célula adicional colocada na sequência do reator, representando um tanque de mistura perfeita, conforme a (Equação 3.26). 


\section{RESULTADOS DO ESTUDO DO ESCOAMENTO}

Neste capítulo são apresentados os resultados das simulações do escoamento e da distribuição dos tempos de residência para três configurações de reatores, a saber:

- Reator solar completo

- Hairpin

- Tubo reto cilíndrico

Ressalta-se que o modelo turbulento foi estudado mesmo em alguns cenários com número de Reynolds característico de regime laminar. Este procedimento foi considerado em decorrência da geometria do reator que impõe mudanças bruscas de direção e pode induzir escoamentos turbulentos.

\subsection{REATOR SOLAR COMPLETO}

\subsubsection{Malha}

No caso das simulações para o escoamento do reator completo, utilizou-se o domínio mostrado na Figura 3.2, de dimensões de 1,818 m x $1 \mathrm{~m}$ × 0,0100 m, empregando-se coordenadas cartesianas.

\subsubsection{Seleção da Malha}

Para obter a melhor malha para a análise do escoamento no reator, o método utilizado foi o de escolher uma malha grosseira e simulá-la. Após isso, diminuiu-se o tamanho da malha até que os campos de velocidade, pressão e a curva de DTR não se modificassem com a malha e que o tempo de processamento não fosse alto. Utilizando-se esses dois critérios, foram simuladas as duas malhas presentes na Tabela 4-1, para os modelos laminar e turbulento. 
Tabela 4-1 - Malhas testadas no software PHOENICS para seleção de malha no reator completo.

\begin{tabular}{ccc}
\hline Parâmetros & Malha 1 & Malha 2 \\
\hline Células em x & 111 & 93 \\
Células em y & 83 & 151 \\
Células em z & 6 & 20 \\
Número de Volumes Total & 55278 & 280860 \\
Tempo de Simulação - Laminar* & $2 \mathrm{~h} 32$ & $13 \mathrm{~h} 38$ \\
Tempo de Simulação - K- $\varepsilon^{*}$ & $3 \mathrm{~h} 52$ & $22 \mathrm{~h} 00$ \\
Passo de Tempo & $30 \mathrm{~s}$ & $30 \mathrm{~s}$
\end{tabular}

* Simuladas em Windows 7, Processador Intel $\circledast$ Xeon ${ }^{\circledR}$ X550 RAM 12GB

As malhas simuladas podem ser visualizadas nas Figura 4.1 e Figura 4.2.

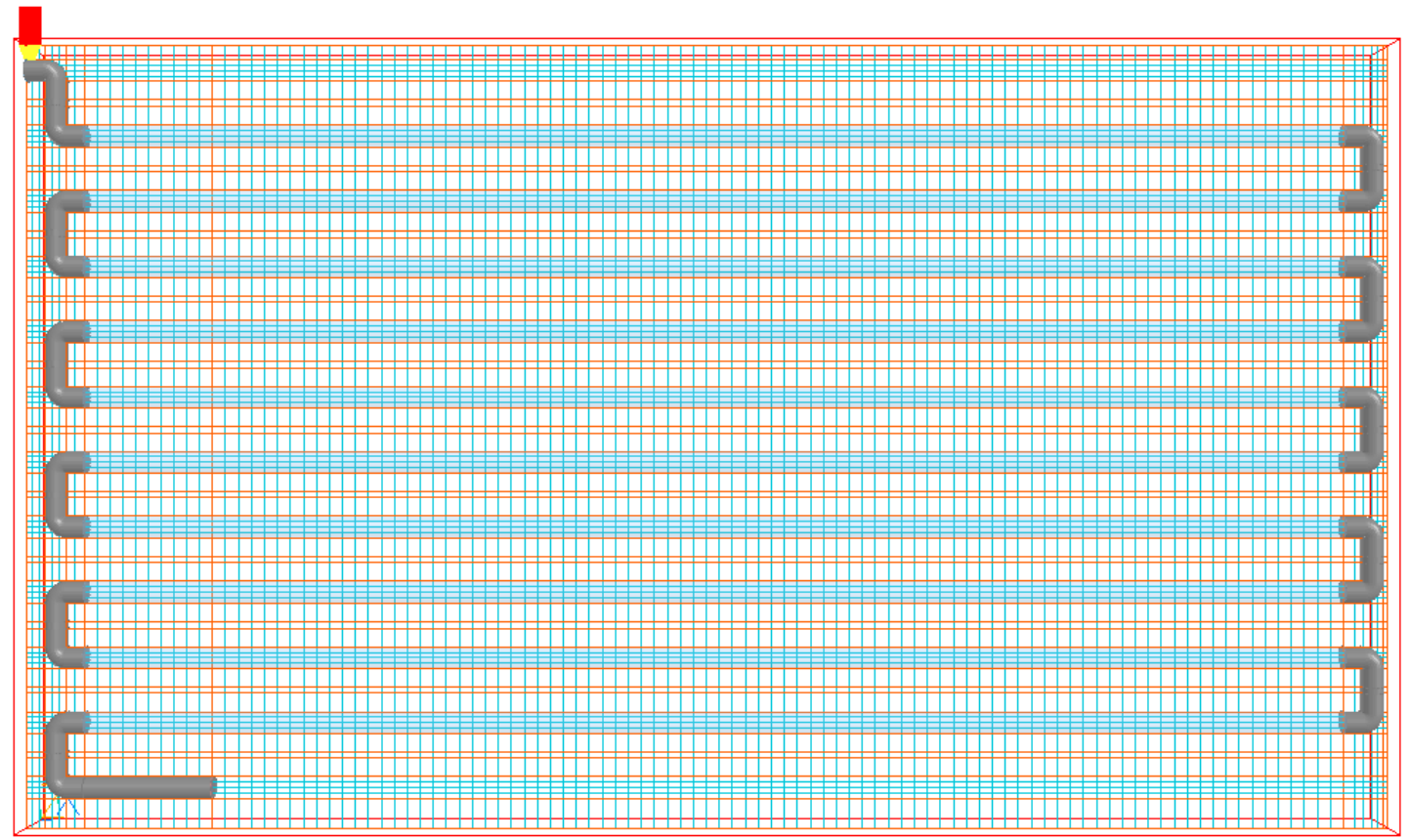

Figura 4.1 - Malha 1, com 55.278 elementos, usada para a seleção de malha. 


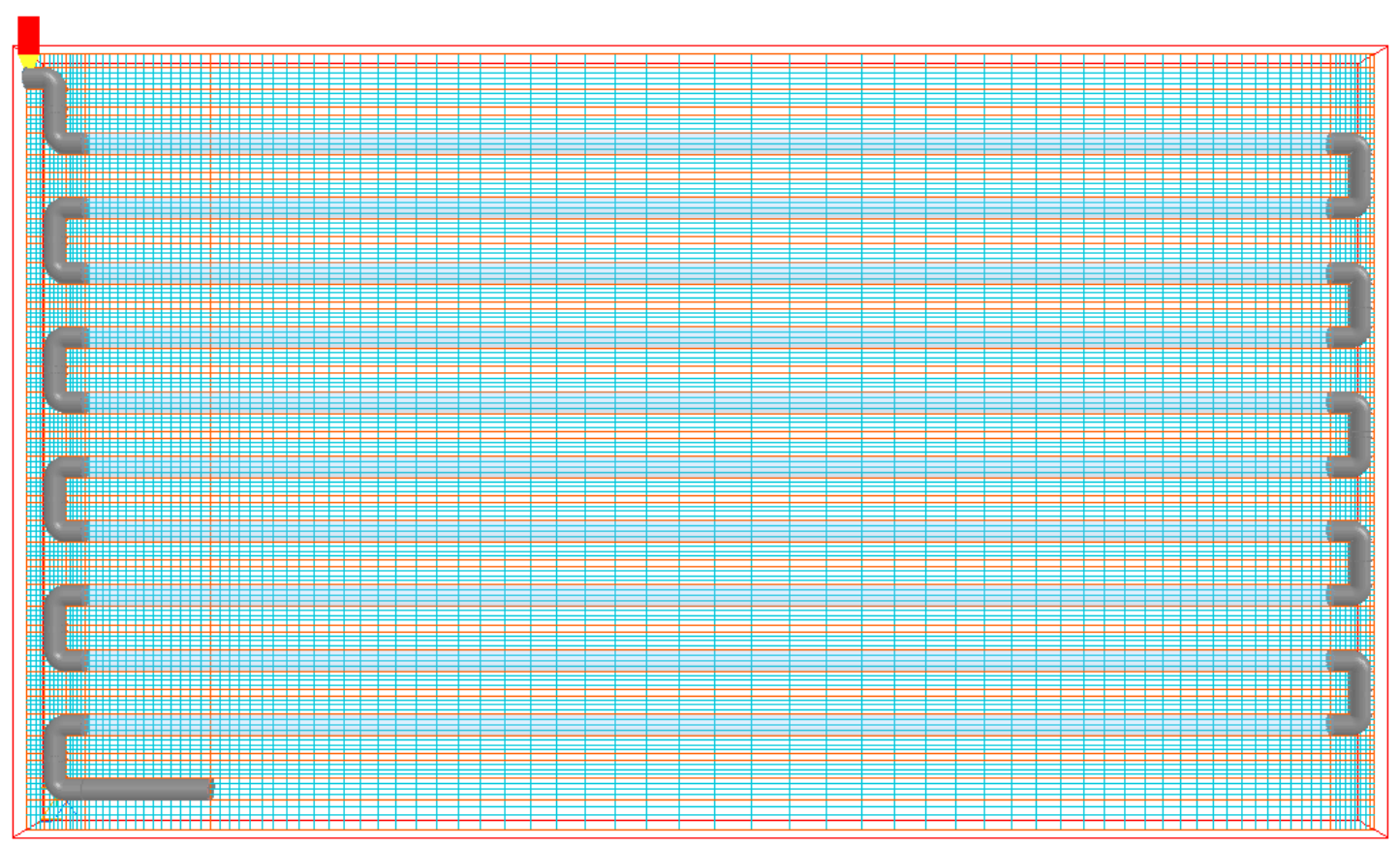

Figura 4.2 - Malha 2, com 280.860 elementos, usada para a seleção de malha.

Os campos de velocidades e pressão, obtidos para cada malha, estão ilustrados na Figura 4.3, para o escoamento laminar, e na Figura 4.5, para o escoamento turbulento, ambos para a mesma condição.

Constata-se que há uma diferença nos campos de pressões previstos pelo modelo laminar e o turbulento. No entanto, as curvas de distribuição de tempo de residência, apresentadas nas Figura 4.4 e Figura 4.6, indicam comportamentos bastante similares para os dois modelos.

Optou-se, portanto, pelo modelo laminar para a sequencia do estudo, no caso deste escoamento. 


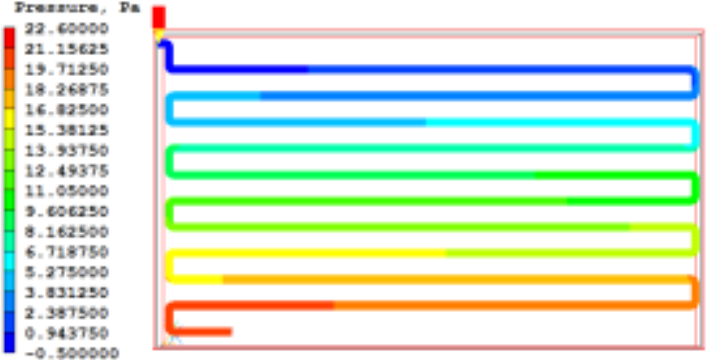

Pressure, P

22.60000

21.15625
19.71250

19.71250
18.26875

16.82500

15. 38125

13. 93750

12. 49375

11.05000

.606250

a. 162500

6.718750

5.275000

.

943750

. .943750
-0.500000

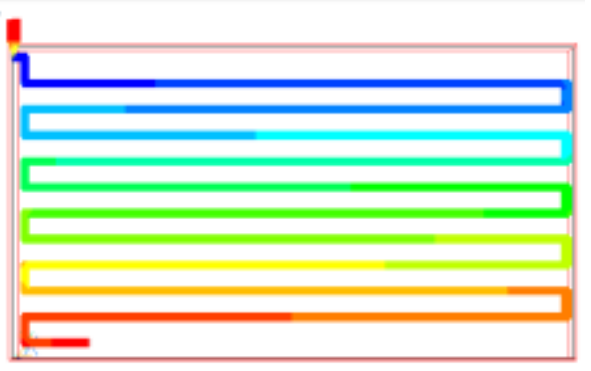

(a)

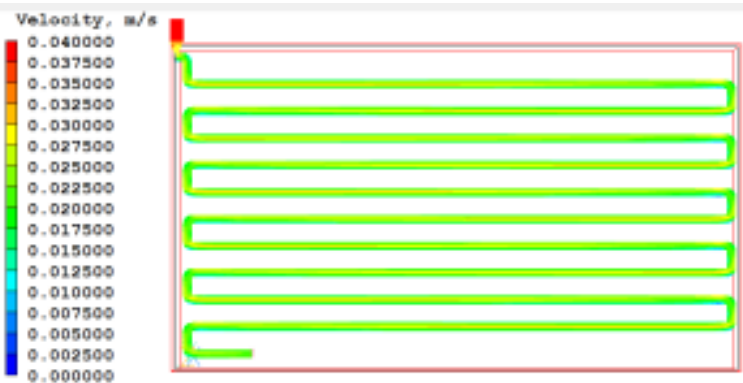

a)

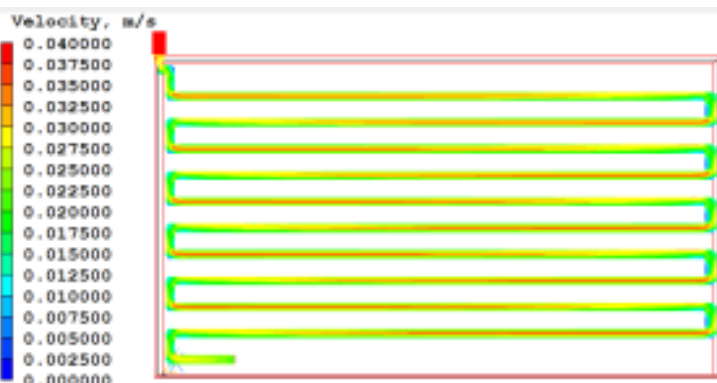

(b)

Figura 4.3 - Comparativo dos campos de velocidades e pressão obtidos na seleção de malhas para o escoamento laminar, no reator completo: (a) Malha 1 e (b) Malha 2.

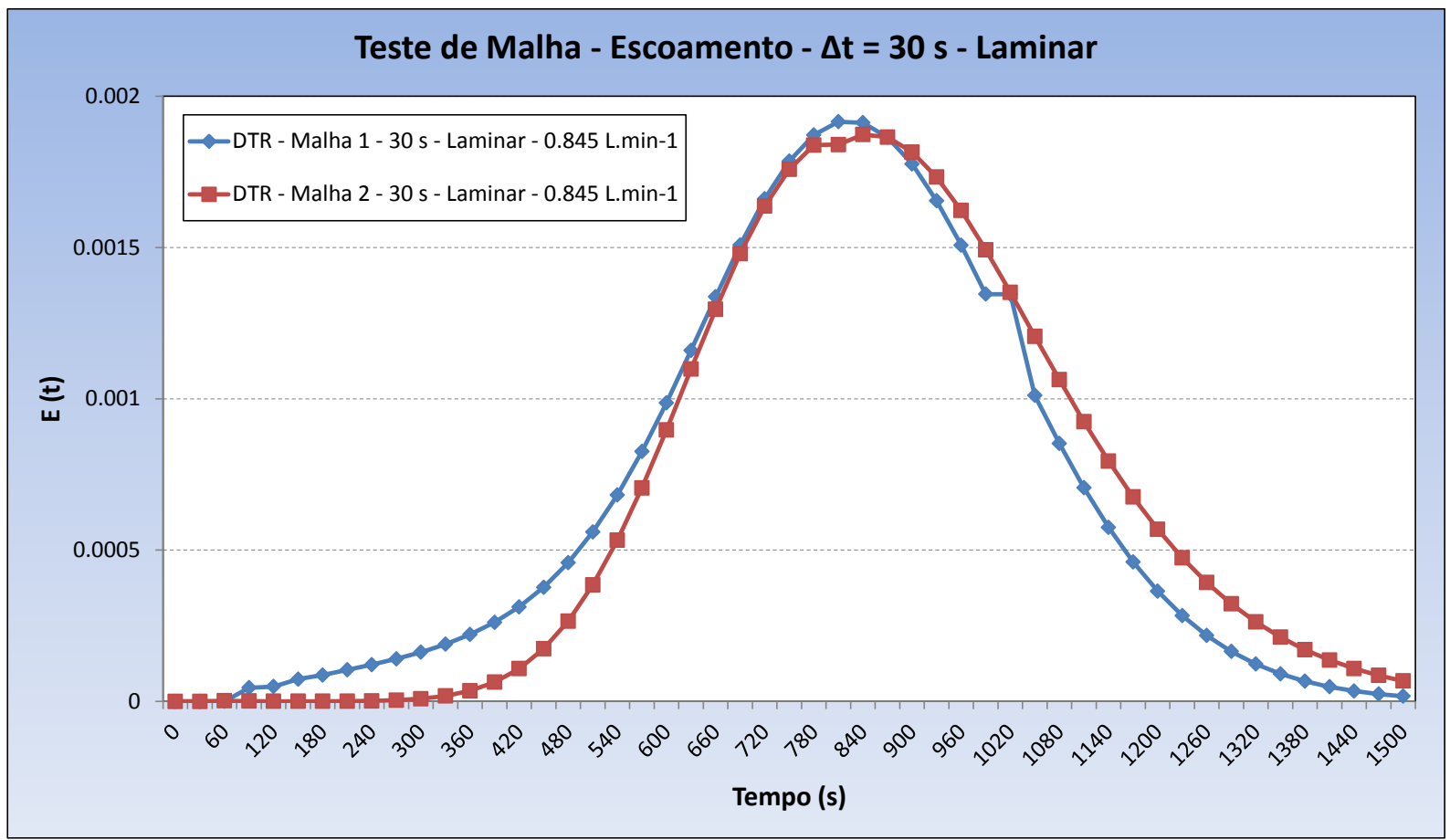

Figura 4.4 - Comparativo das curvas de distribuição do tempo de residência para a seleção das malhas para o escoamento laminar, no reator completo. 

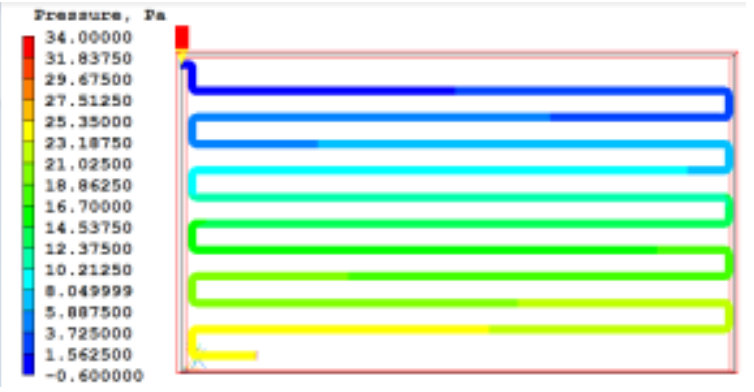

(a)

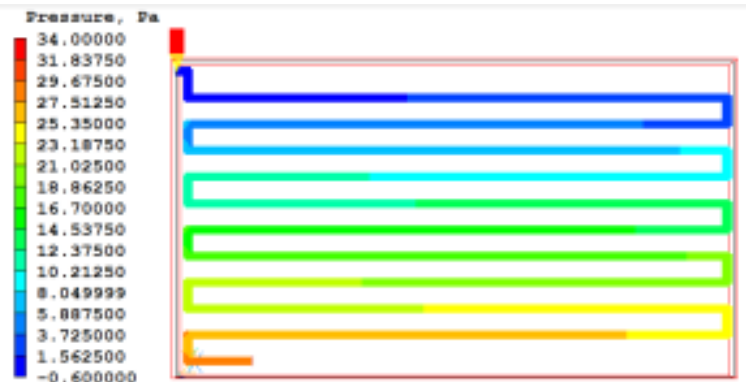

)
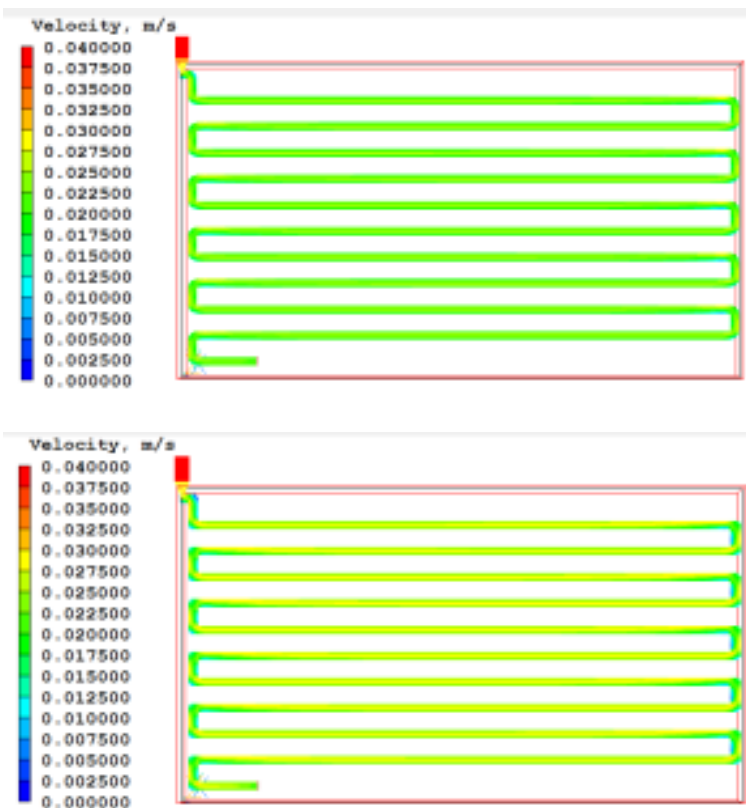

(b)

Figura 4.5 - Comparativo dos campos de velocidades e pressão obtidos na seleção de malhas para

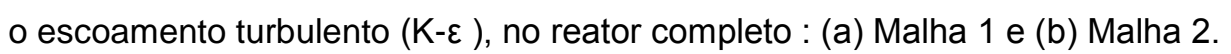

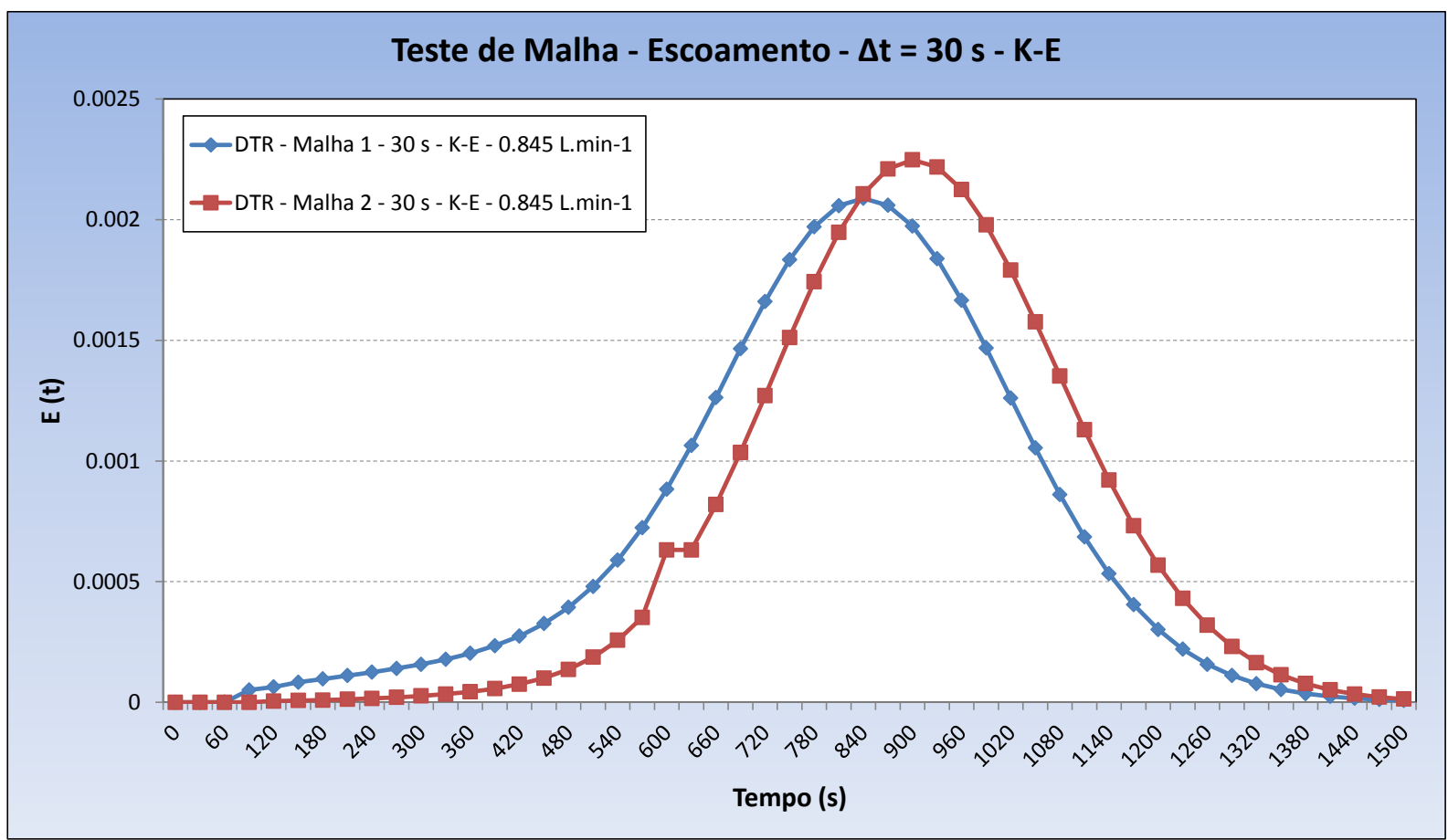

Figura 4.6 - Comparativo das curvas de distribuição do tempo de residência para a seleção das malhas para o escoamento turbulento $(\mathrm{K}-\varepsilon)$, no reator completo.

Considerando-se que os resultados obtidos pelas duas malhas apresentam algumas diferenças, optou-se pela malha mais refinada, a malha 2 , com quantidade de células do domínio de 93 × 151 × 20, num total de 280.860 volumes. A 
investigação de malhas mais refinadas foi descartada, face ao excessivo tempo de processamento necessário.

\subsubsection{Modelo e Condições de Contorno}

Para o domínio apresentado na Figura 3.2, definiu-se o vidro como o material e, sendo a água, a $20^{\circ} \mathrm{C}$, o fluido considerado para o escoamento no interior dos tubos e das curvas. A geometria foi construída no programa AutoCAD ${ }^{\circledR}$ e posteriormente foi importada para o PHOENICS através do assistente de importação do software.

Para as condições de contorno, no caso do escoamento, considerou-se velocidade nula na parede. $E$ no caso do modelo de turbulência, $k-\varepsilon$, adotou-se a lei de parede gerada automaticamente pela função do PHOENICS Earth Generated Wall Functions (EGWF). A condição na entrada do tubo foi definida por um objeto do tipo inlet, na qual o campo de velocidades foi considerado uniforme $\left(v_{y}=v_{z}=0\right)$, e no caso do modelo turbulento, com intensidade de turbulência de $5 \%$. Para a condição de contorno na saída do domínio, considerou-se um objeto do tipo outlet, com pressão de referência, nula, fixa.

\subsubsection{Simulações Realizadas}

Para o escoamento do reator solar CPC, foram simulados dois casos, um para o escoamento laminar e outro para o escoamento utilizando modelo de turbulência k- $\varepsilon$. Como já comentado, apesar do número de Reynolds, no caso, ser indicativo de um escoamento laminar, utilizou-se o modelo k- $\varepsilon$ para uma análise da influência das curvas do reator no escoamento.

Para o modelo laminar, foram simuladas várias variações da malha temporal, para cálculo da distribuição de tempo de residência. Os passos de tempo escolhidos para simulação foram de $30 \mathrm{~s}, 10 \mathrm{~s}, 5 \mathrm{~s}, 2 \mathrm{~s}$ e $1 \mathrm{~s}$. As condições simuladas nessa etapa são mostradas na Tabela 4-2. 
Tabela 4-2 - Resumo das simulações realizadas para o reator completo.

\begin{tabular}{ccccccc}
\hline Dado & $\mathbf{1}$ & $\mathbf{2}$ & $\mathbf{3}$ & $\mathbf{4}$ & $\mathbf{5}$ & $\mathbf{6}$ \\
\hline Vazão $\left(\mathrm{L} \cdot \mathrm{min}^{-1}\right)$ & 0,85 & 0,85 & 0,85 & 0,85 & 0,85 & 0,85 \\
Densidade $\left(\mathrm{kg} \cdot \mathrm{m}^{-1}\right)$ & 1000 & 1000 & 1000 & 1000 & 1000 & 1000 \\
Diâmetro dos tubos $(\mathrm{m})$ & 0,0292 & 0,0292 & 0,0292 & 0,0292 & 0,0292 & 0,0292 \\
Viscosidade $(\mathrm{Pa} . \mathrm{s})$ & 0,001 & 0,001 & 0,001 & 0,001 & 0,001 & 0,001 \\
Vazão $\left(\mathrm{m}^{3} \cdot \mathrm{s}^{-1}\right)$ & $1,41 \mathrm{E}-05$ & $1,41 \mathrm{E}-05$ & $1,41 \mathrm{E}-05$ & $1,41 \mathrm{E}-05$ & $1,41 \mathrm{E}-05$ & $1,41 \mathrm{E}-05$ \\
Velocidade $\left(\mathrm{m}^{-1} \mathrm{~s}^{-1}\right)$ & 0,0210 & 0,0210 & 0,0210 & 0,0210 & 0,0210 & 0,0210 \\
Número de Reynolds & 614 & 614 & 614 & 614 & 614 & 614 \\
Modelo de Escoamento & Laminar & $\mathrm{k}-\varepsilon$ & Laminar & Laminar & Laminar & Laminar \\
Passo de Tempo & $30 \mathrm{~s}$ & $30 \mathrm{~s}$ & $10 \mathrm{~s}$ & $5 \mathrm{~s}$ & $2 \mathrm{~s}$ & $1 \mathrm{~s}$ \\
\hline
\end{tabular}

\subsubsection{Campos de Velocidades e Pressão}

Os campos de velocidades e pressão para o escoamento laminar, na condição de regime permanente, estão apresentados na Figura 4.7. 


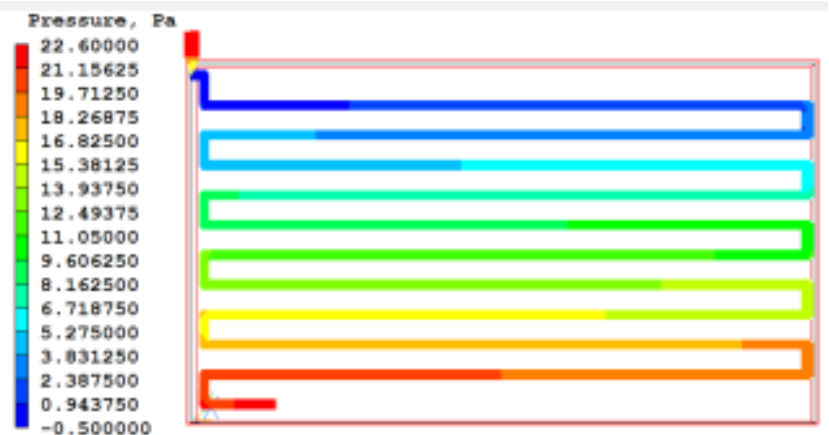

(a)

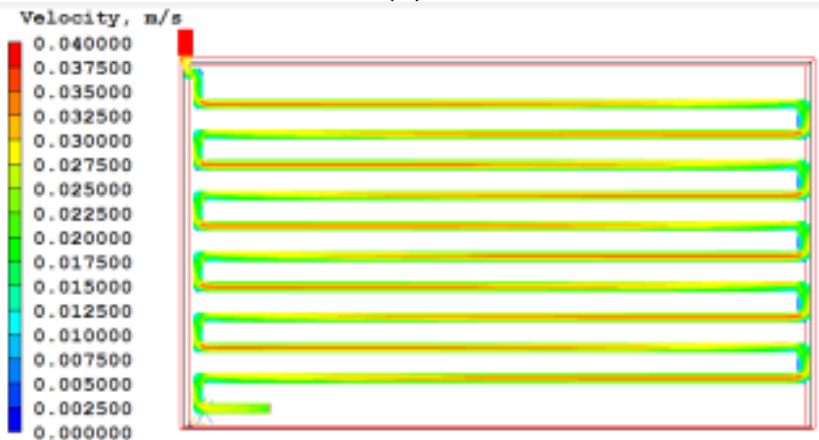

(b)
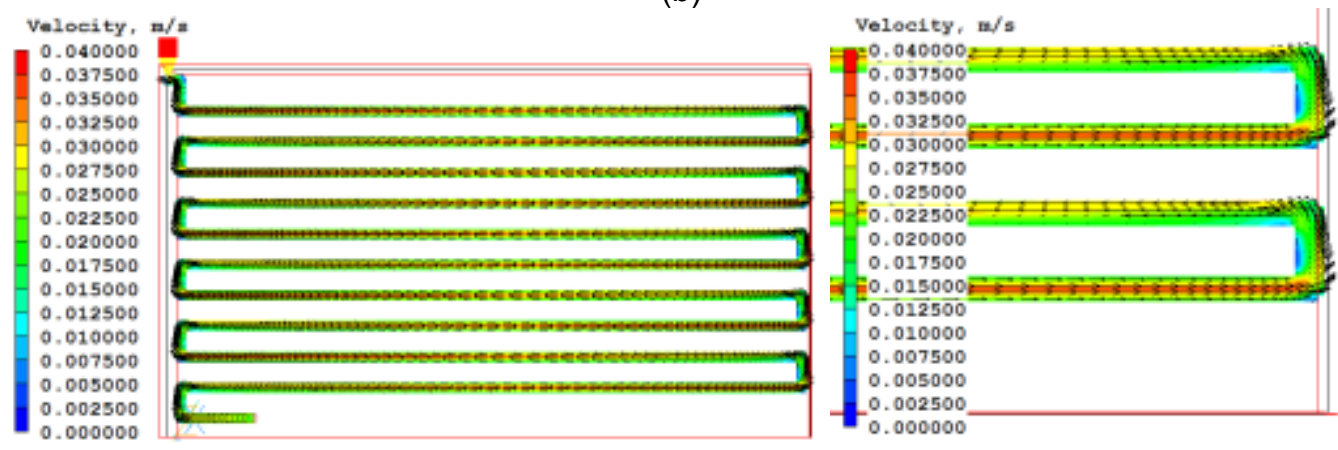

(c)

Figura 4.7 - Resultados obtidos para o escoamento laminar, utilizando-se a malha 2 selecionada : (a) Campo de pressão, (b) Campo de velocidades e (c) Detalhe do campo de velocidade dos dois últimos trechos do reator.

Os campos de velocidade, pressão e os valores de $\mathrm{Y}^{+}$, para o modelo de turbulência $k-\varepsilon$, na condição de regime permanente, estão os apresentados na Figura 4.8. 


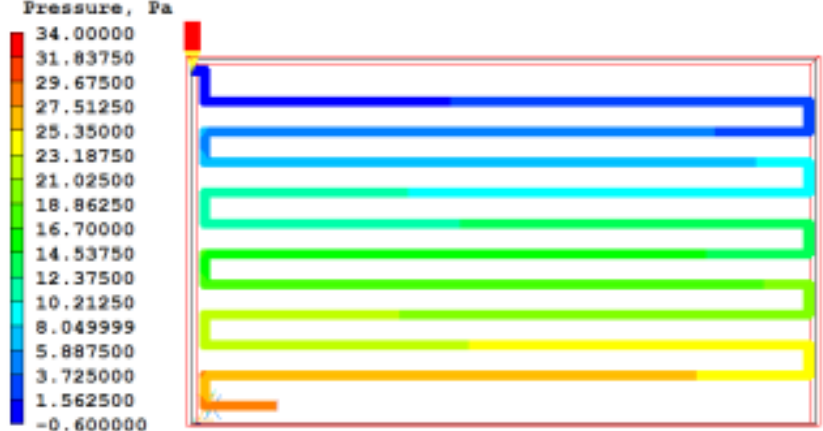

(a)

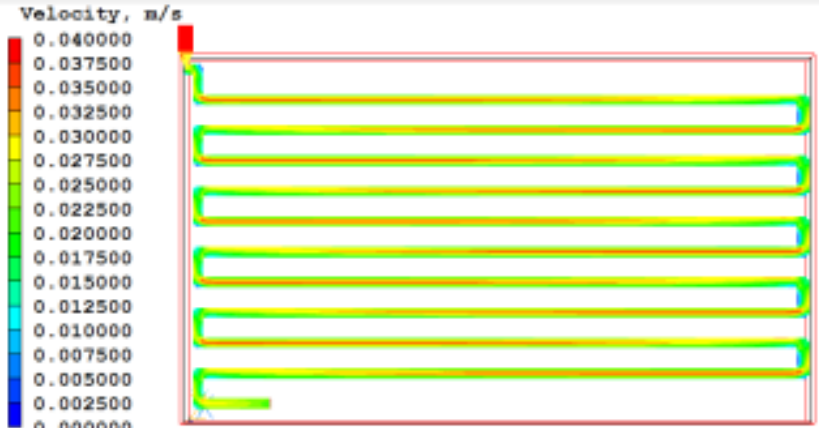

(b)
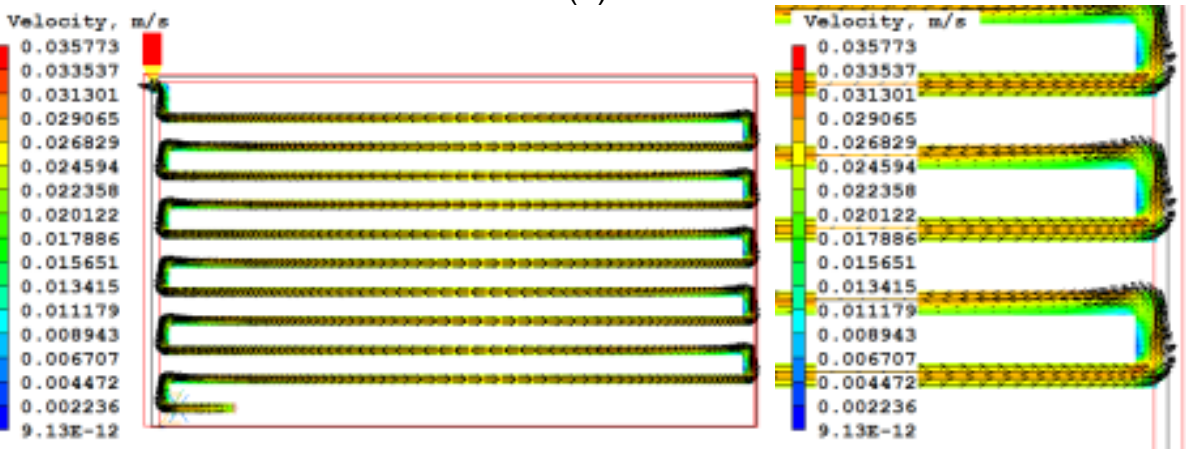

(c)

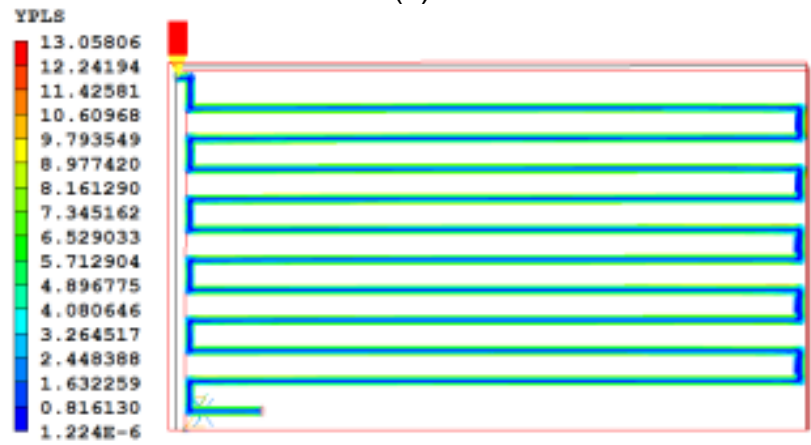

(d)

Figura 4.8 - Resultados obtidos para o escoamento utilizando o modelo de turbulência k- $\varepsilon$ para a malha 2 : (a) Campo de pressão, (b) Campo de velocidades, (c) Detalhe do campo de velocidade dos dois últimos trechos do reator e (d) $\mathrm{Y}^{+}$. 


\subsubsection{Distribuição do Tempo de Residência (DTR)}

Para cada uma das simulações realizadas citadas no item 4.1.3, estudou-se, também, a distribuição do tempo de residência para comparação com os dados experimentais. Para tanto, realizaram-se simulações em regime transiente, com passo de integração de $30 \mathrm{~s}$. Considerou-se a injeção de um pulso de traçador na entrada do reator. $O$ traçador empregado foi o azul de metileno, cuja difusividade mássica é $7,9 \cdot 10^{-11} \mathrm{~m}^{2} \cdot \mathrm{s}^{-1}$.

\subsubsection{Escoamento: Laminar $x k-\varepsilon$}

As curvas de distribuição de tempo de residência para cada um dos modelos e a curva experimental (RIBEIRO, 2009) podem ser vistas na Figura 4.9.

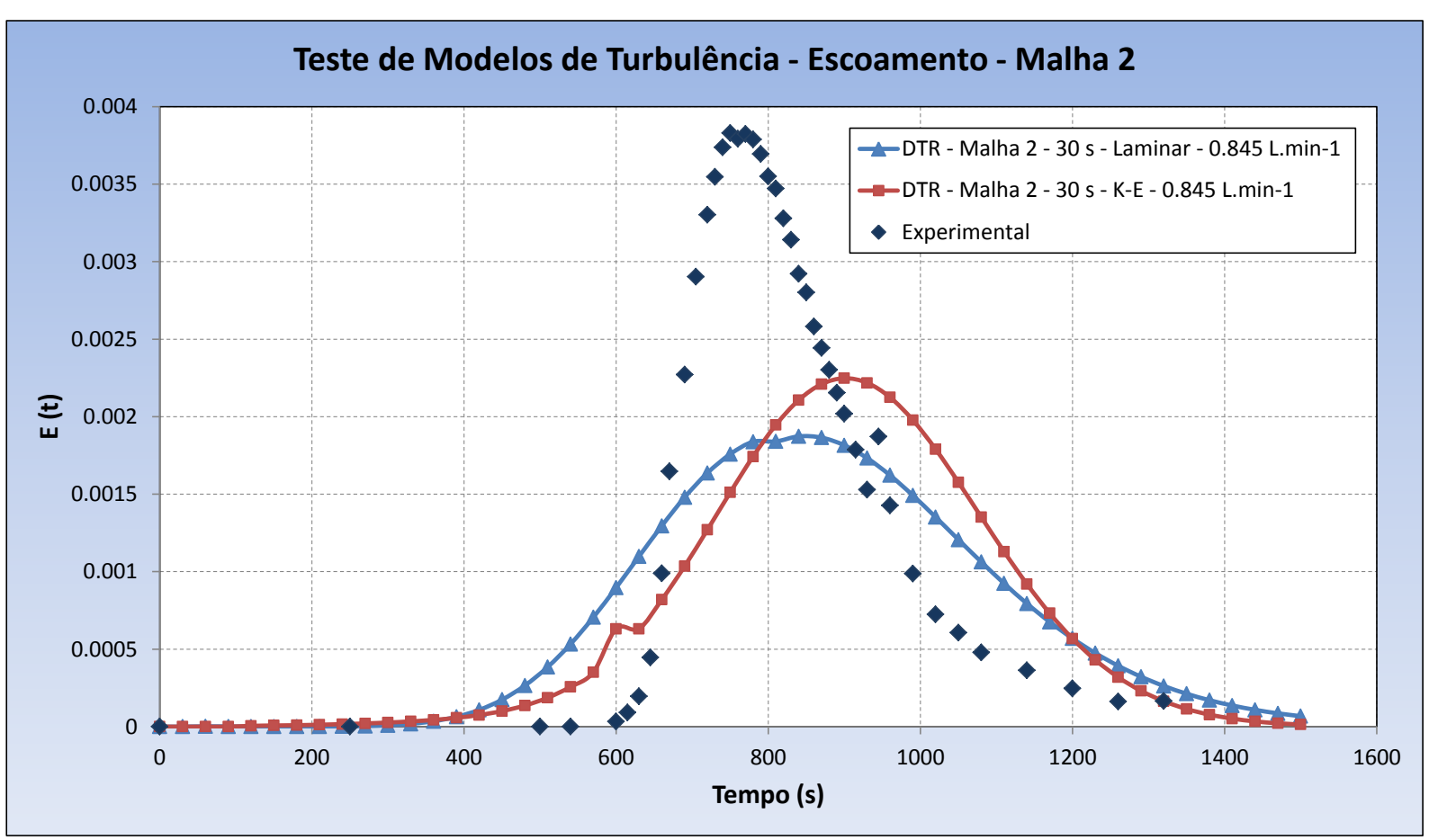

Figura 4.9 - Comparativo das curvas de distribuição do tempo de residência obtidas para o escoamento Laminar, turbulento $(k-\varepsilon)$ e para a curva experimental.

Os tempos médios simulados e o experimental obtidos são apresentados na Tabela 4-3.

Tabela 4-3 - Comparação dos tempos médios obtidos para o experimento e diferentes modelos de escoamento.

\begin{tabular}{cc}
\hline Caso & Tempo Médio (s) \\
\hline Experimental & 827 \\
PHOENICS_KE & 917 \\
PHOENICS_LAM & 893 \\
\hline
\end{tabular}


Analisando-se as curvas de distribuição do tempo de residência (DTR), constata-se que os modelos não representam bem os resultados experimentais. Para refinamento dos modelos, simularam-se passos de tempo menores para a integração.

Adotou-se o modelo de escoamento laminar para a continuidade das simulações. Considerando-se a maior proximidade do tempo médio (de residência) calculado pelo modelo laminar e o resultado experimental e, também, da inadequação dos resultados de $\mathrm{Y}^{+}$, no caso do modelo turbulento.

\subsubsection{Validação do Passo de Tempo}

Utilizando-se o modelo de escoamento laminar, simularam-se diferentes passos de tempo para a integração. Os passos de tempo estudados foram: $30 \mathrm{~s}, 10 \mathrm{~s}$, $5 \mathrm{~s}, 2 \mathrm{~s}$ e $1 \mathrm{~s}$. As curvas de DTR obtidas e a experimental podem ser vistas na Figura 4.10.

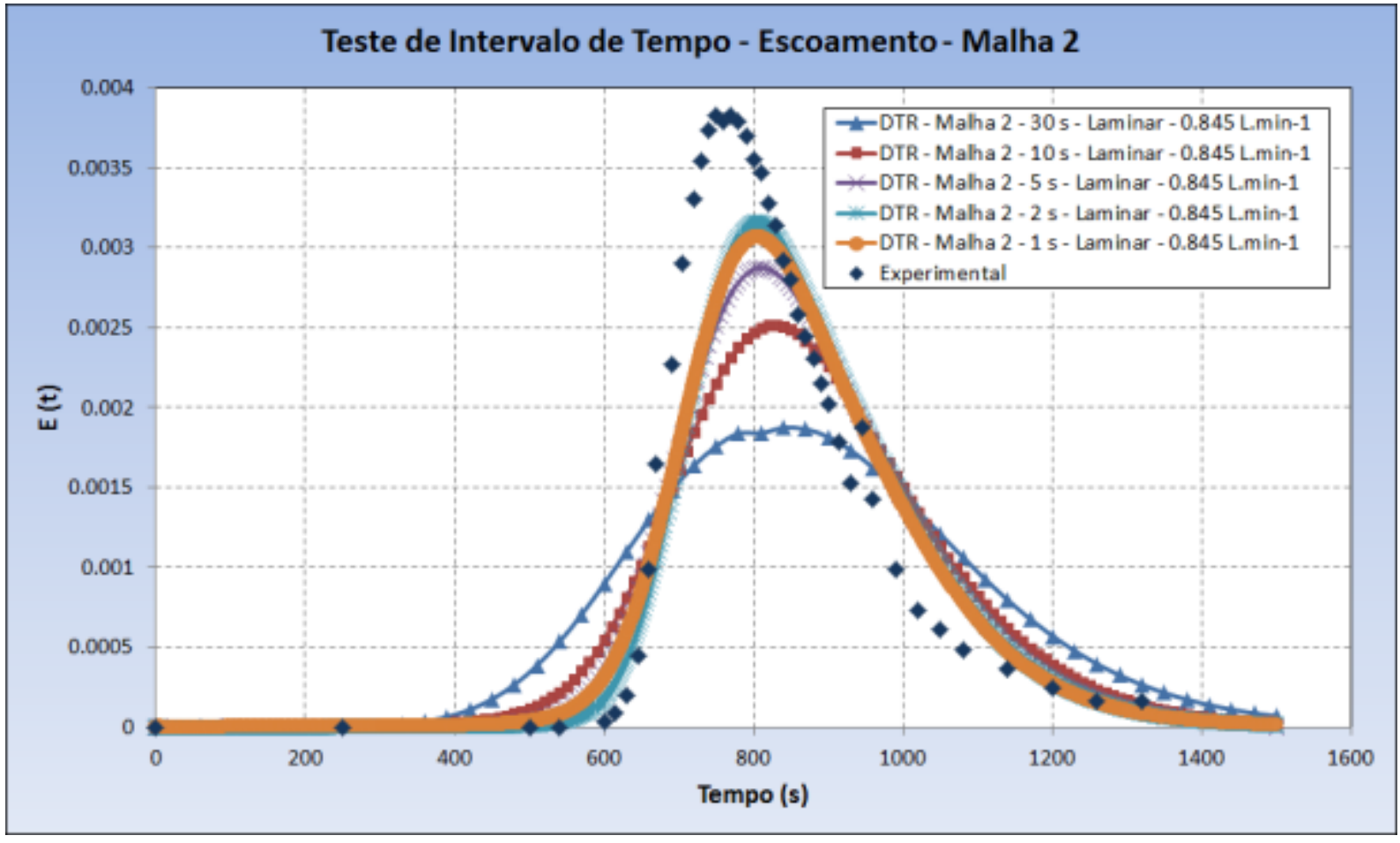

Figura 4.10 - Comparativo das curvas de distribuição do tempo de residência obtidas para o reator completo, para diferentes passos de tempo simulados e para a curva experimental.

Os tempos médios obtidos podem ser vistos na Tabela 4-4. 
Tabela 4-4 - Comparação dos tempos médios obtidos para o experimento e diferentes passos de tempo simulados para o reator completo.

\begin{tabular}{cc}
\hline Caso & Tempo Médio (s) \\
\hline Experimental & 827 \\
$\Delta t=30 \mathrm{~s}$ & 893 \\
$\Delta t=10 \mathrm{~s}$ & 878 \\
$\Delta t=5 \mathrm{~s}$ & 870 \\
$\Delta t=2 \mathrm{~s}$ & 873 \\
$\Delta t=1 \mathrm{~s}$ & 865 \\
\hline
\end{tabular}

Baseando-se na Figura 4.10 e na Tabela 4-4, a DTR que mais se ajustou à DTR experimental foi a com intervalo de tempo de $2 \mathrm{~s}$.

\subsubsection{DTR Selecionada}

A curva de distribuição de residência selecionada foi a com a malha 2, modelo laminar e $\Delta t=2 \mathrm{~s}$. Apresentam-se na Figura 4.11 a concentração do traçador em diferentes instantes, em uma secção passando pelo centro dos tubos.

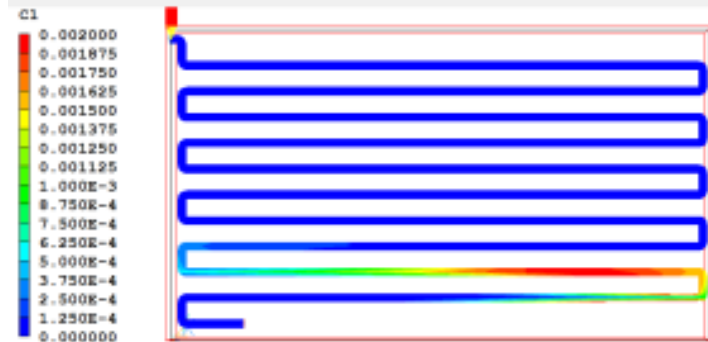

$t=100 s$

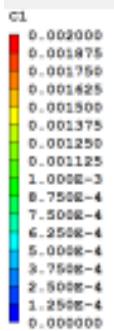

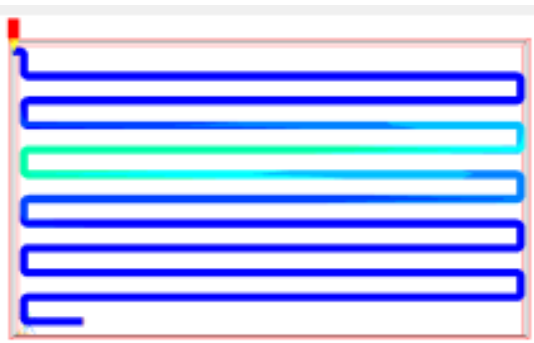

$\mathrm{t}=500 \mathrm{~s}$
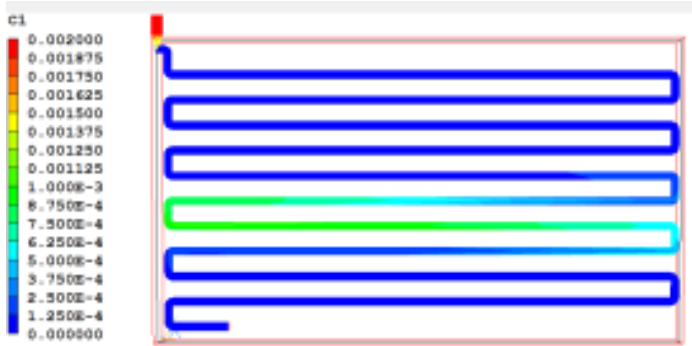

$t=300 s$

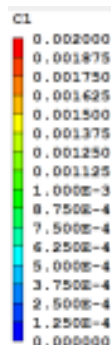

$2,5060-4$
$1.250 \pi-4$
0.006000
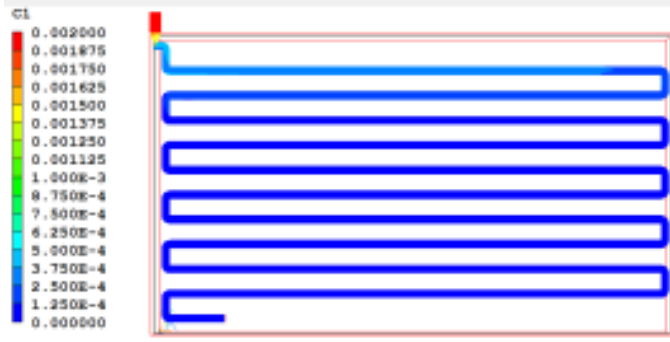

$t=900 s$

Figura 4.11 - Concentração do traçador em função do tempo para o escoamento laminar no reator completo e passo de tempo $\Delta \mathrm{t}=1 \mathrm{~s}$. 
A curva selecionada e a curva experimental foram comparadas (vide Figura 4.14.) com dois modelos teóricos de distribuição de tempo de residência para reatores tubulares, em escoamento laminar, citados apresentados no item 2.2: o modelo de dispersão de Taylor e o modelo de escoamento laminar (segregado). No entanto, o regime de escoamento e o processo difusivo configuram uma situação que está fora dos limites dos dois modelos citados, conforme pode ser observado na Figura 4.12.

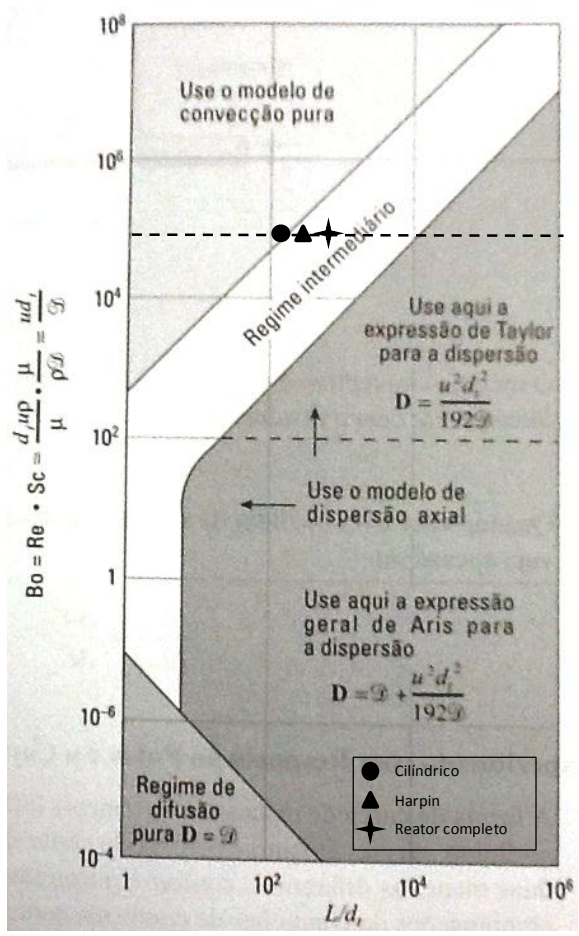

Figura 4.12 - Modelos teóricos de escoamento para a distribuição de tempo de residência em reatores tubulares. (Levenspiel, 2000)

Deve se observar também que, nestes modelos, outra limitação é a hipótese de que não há praticamente variação de concentração na direção radial. No entanto, conforme pode ser visto na Figura 4.13, na qual são apresentados cortes radiais no terceiro tubo em quatro instantes de tempo, isso não é verificado.
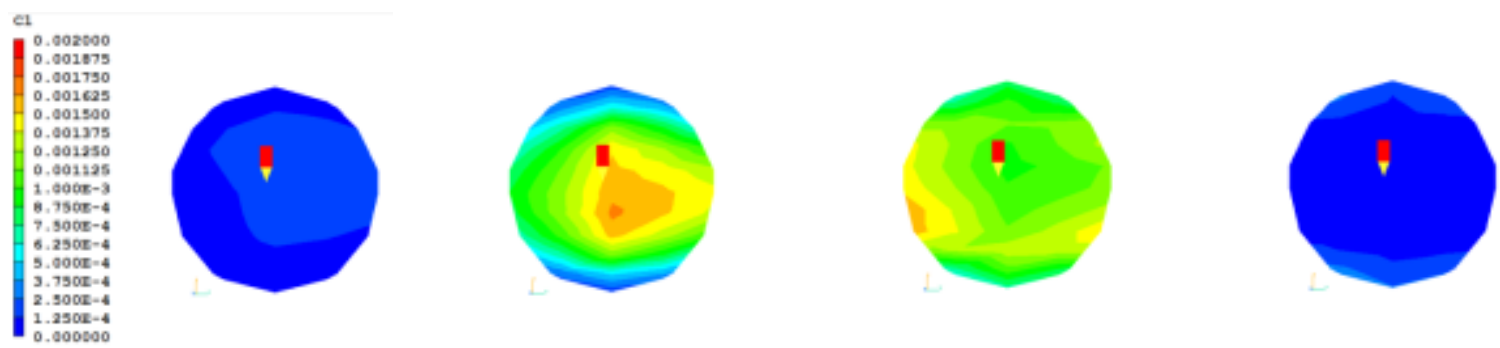

$\mathrm{t}=50 \mathrm{~s}$

$t=100 s$

$t=150$ s

$t=300 s$

Figura 4.13 - Concentração do traçador em função do tempo para uma secção do reator. 
A curva experimental também foi ajustada para outro modelo semi-teórico, com parâmetros ajustados, o modelo de tanques em série (Levenspiel, 2000), obtendo-se: $N t=57,4$ e $\tau=816,18 \mathrm{~s}$. Esse ajuste pode ser visto na Figura 4.14.

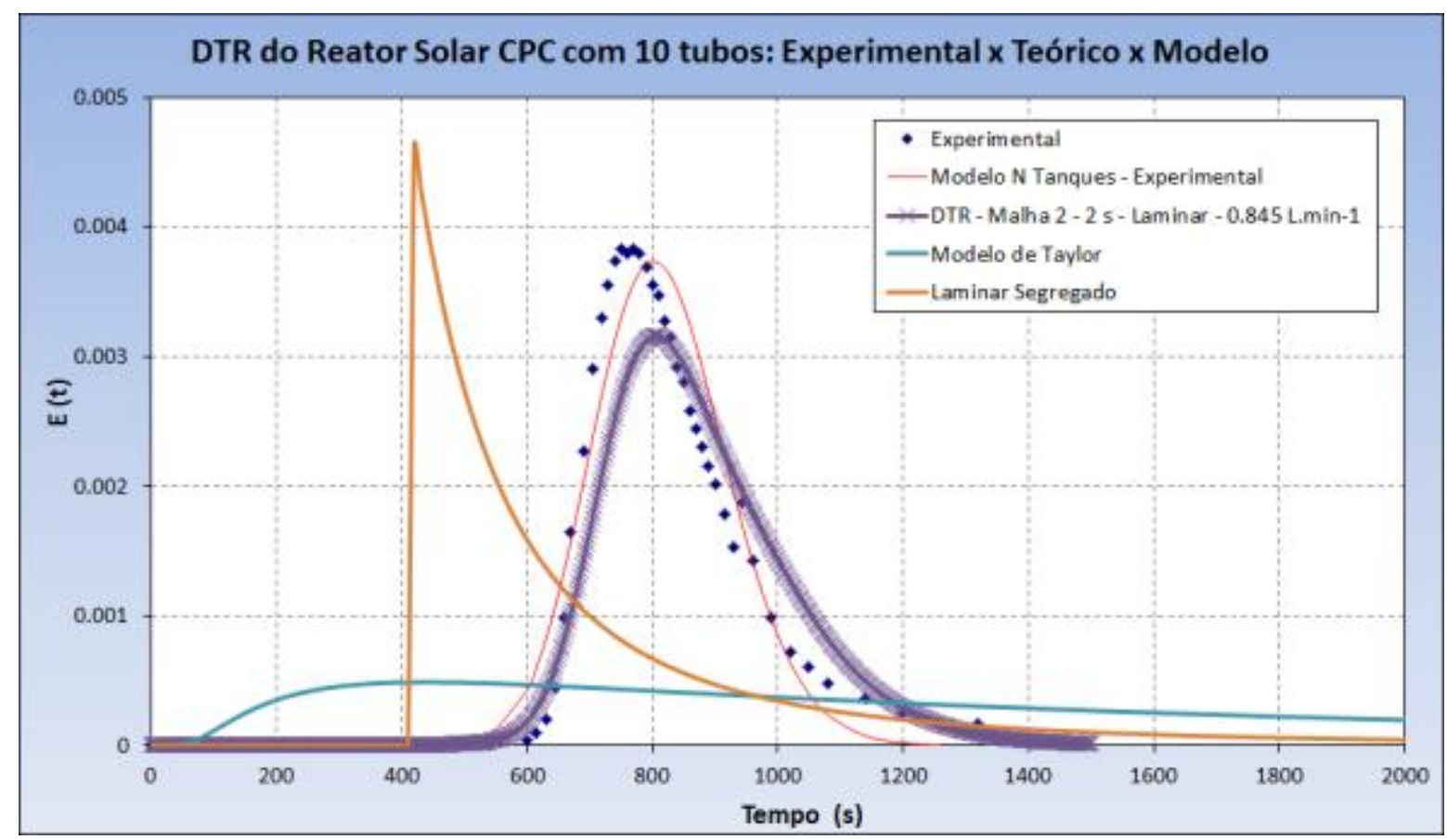

Figura 4.14 - Comparativo das curvas de distribuição do tempo de residência entre a curva experimental, modelos teóricos, modelos semi-teóricos e a curva selecionada do modelo.

\subsubsection{Discussão de resultados para reator completo}

A partir dos resultados dos campos de velocidades e pressão, pode-se avaliar o escoamento do reator. O campo de velocidades indica que a hipótese de escoamento pistonado, usual no caso de reatores fotoquímicos, não deve ser adotada. Para o escoamento analisado, adotou-se o modelo laminar, devido à maior aderência aos dados experimentais de DTR.

As curvas de distribuição de tempo de residência mostraram um desvio entre os valores simulados em relação ao experimental e em relação aos modelos teóricos. Sendo, portanto, necessária a solução numérica dos modelos de escoamento com difusão, no caso das condições aqui consideradas.

Nota-se pela DTR obtida pela simulação, que a dispersão axial do reator é ligeiramente diferente da obtida experimentalmente (Figura 4.14). Pode-se justificar esta diferença em função das aproximações feitas pela qualidade das malhas 
adotadas, que por ser cartesiana, não se molda exatamente ao sólido. Outros aspectos que poderiam justificar as diferenças observadas são: as aproximações feitas para a alocação do ponto de injeção e diferenças entre a geometria das curvas do reator implementadas no programa e as reais.

\subsection{REATOR SOLAR - HAIRPIN}

O hairpin foi simulado para reproduzir os experimentos de actinometria realizados no reator solar. Durante estes experimentos, empregou-se apenas um hairpin (Figura 4.15), conectado a um tanque de recirculação, conforme descrito no item 3.1.2 e não foi realizado um experimento de distribuição de tempo de residência, em decorrência de dificuldades experimentais. Os dois tubos foram simulados e analisados para que uma comparação possa ser estabelecida com a geometria simplificada a ser discutida no item 4.3.

\subsubsection{Domínio Numérico}

Nestas simulações, utilizou-se o domínio mostrado na Figura 4.15, sendo que as dimensões do domínio utilizado foram de 1,836 m x 0,03 m x 0,01 m.

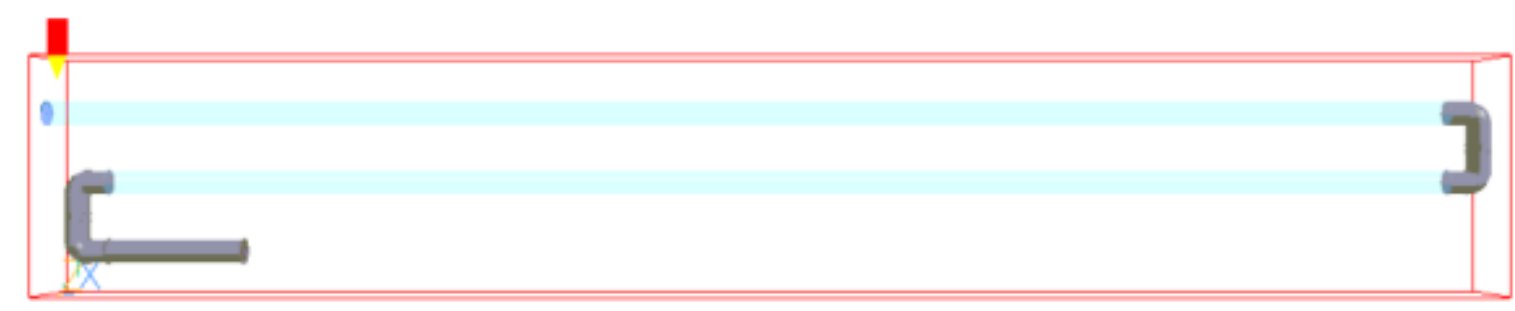

Figura 4.15 - Domínio do hairpin utilizado em experimentos de actinometria em coordenadas cartesianas.

\subsubsection{Malha}

\subsubsection{Seleção da Malha}

Para a obtenção de uma malha adequada para a análise do escoamento no hairpin, simularam-se três malhas cartesianas diferentes, fixando-se o passo de tempo. As condições das simulações estão apresentadas na Tabela 4-5. 
Tabela 4-5 - Malhas testadas no software PHOENICS para seleção de malha no Hairpin.

\begin{tabular}{|c|c|c|c|}
\hline Parâmetros & Malha 1 & Malha 2 & Malha 3 \\
\hline Células em $\mathrm{x}$ & 177 & 177 & 177 \\
\hline Células em y & 41 & 80 & 123 \\
\hline Células em z & 7 & 12 & 17 \\
\hline Número de Volumes Total & 50.799 & 169.920 & 370.107 \\
\hline Tempo de Simulação - Laminar* & $4 \mathrm{~h} 13$ & $19 \mathrm{~h} 26$ & $46 h 26$ \\
\hline Passo de Tempo - Laminar & $10 \mathrm{~s}$ & $10 \mathrm{~s}$ & $10 \mathrm{~s}$ \\
\hline Tempo de Simulação $-\mathrm{k}-\varepsilon^{*}$ & $68 \mathrm{~h} 23$ & $164 \mathrm{~h}$ & $500 \mathrm{~h}$ \\
\hline Passo de Tempo - k- $\varepsilon$ & $1 \mathrm{~s}$ & $1 \mathrm{~s}$ & $1 \mathrm{~s}$ \\
\hline
\end{tabular}

A malha 1 está ilustrada na Figura 4.16. As malhas 2 e 3 são refinamentos da malha 1.

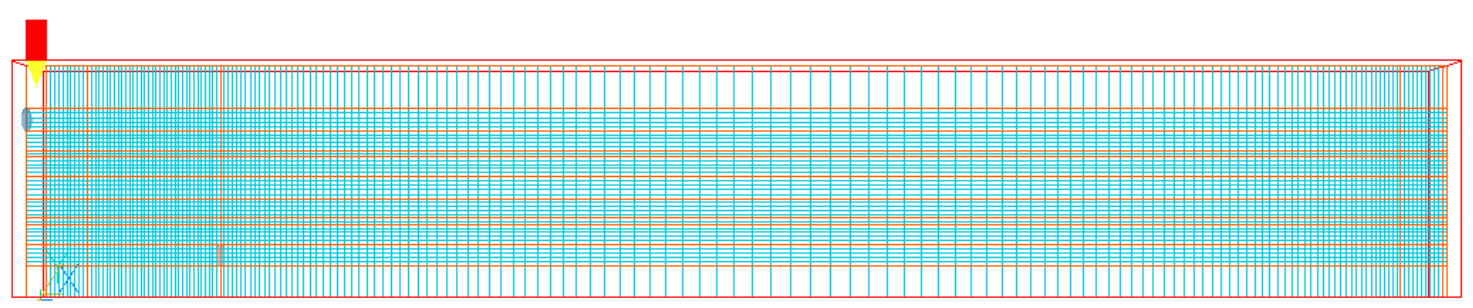

Figura 4.16 - Malha 1 usada para a seleção de malha no hairpin com 50799 elementos.

Para o hairpin, foram simuladas duas vazões diferentes: 0,845 L. $\min ^{-1}$ e 8 L. $\min ^{-1}$, com os respectivos modelos de escoamento: laminar e turbulento - K- $\varepsilon$.

Os campos de velocidades e pressão obtidos para cada malha e vazão podem ser vistos nas Figura 4.17 e Figura 4.19. As curvas de distribuição de tempo de residência estão ilustradas nas Figura 4.18 e Figura 4.20. 

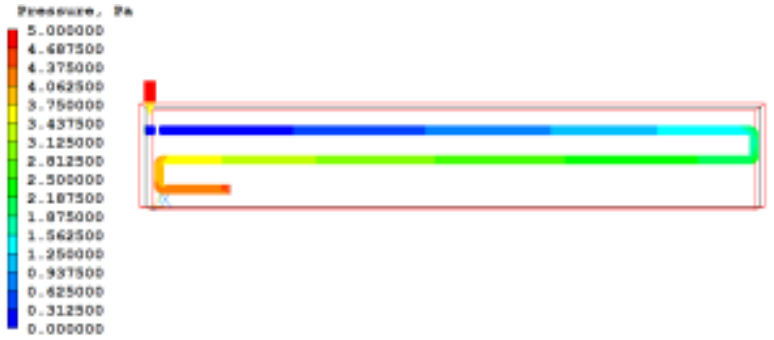

waloolty, w/

.

.

. 036563

0.039750

0.090938

0.023125

. 039687

.016875
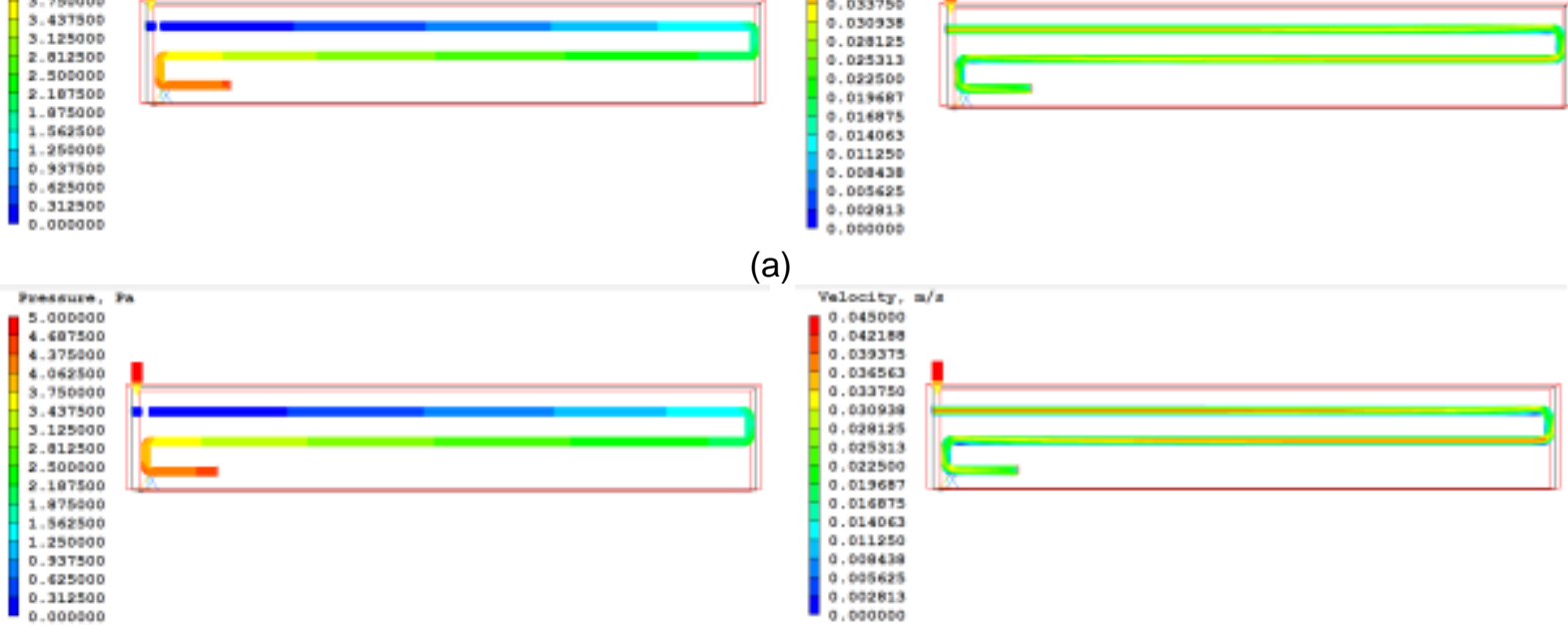

(a)

.004438

0.005625

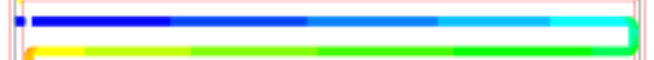

Veloetey, $=/ a$
0.045000

0.045060

0.033373

0.033750

0.030939

0,629125

0.625313
0.022500
0.02007

0.013687

0.016879

0.01406

0.049438

0.6096623
0.002613

(b)

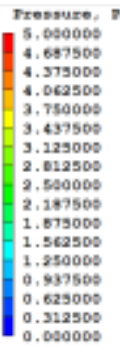
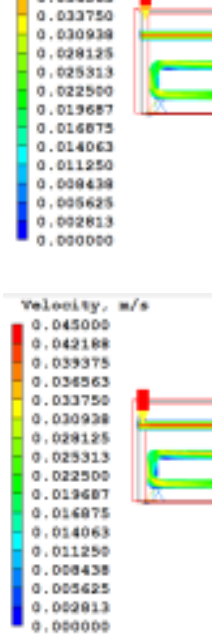

(c)

Figura 4.17 - Comparativo dos campos de velocidades e pressão obtidos na seleção de malhas para o escoamento laminar no hairpin: (a) Malha 1, (b) Malha 2 e (c) Malha 3.

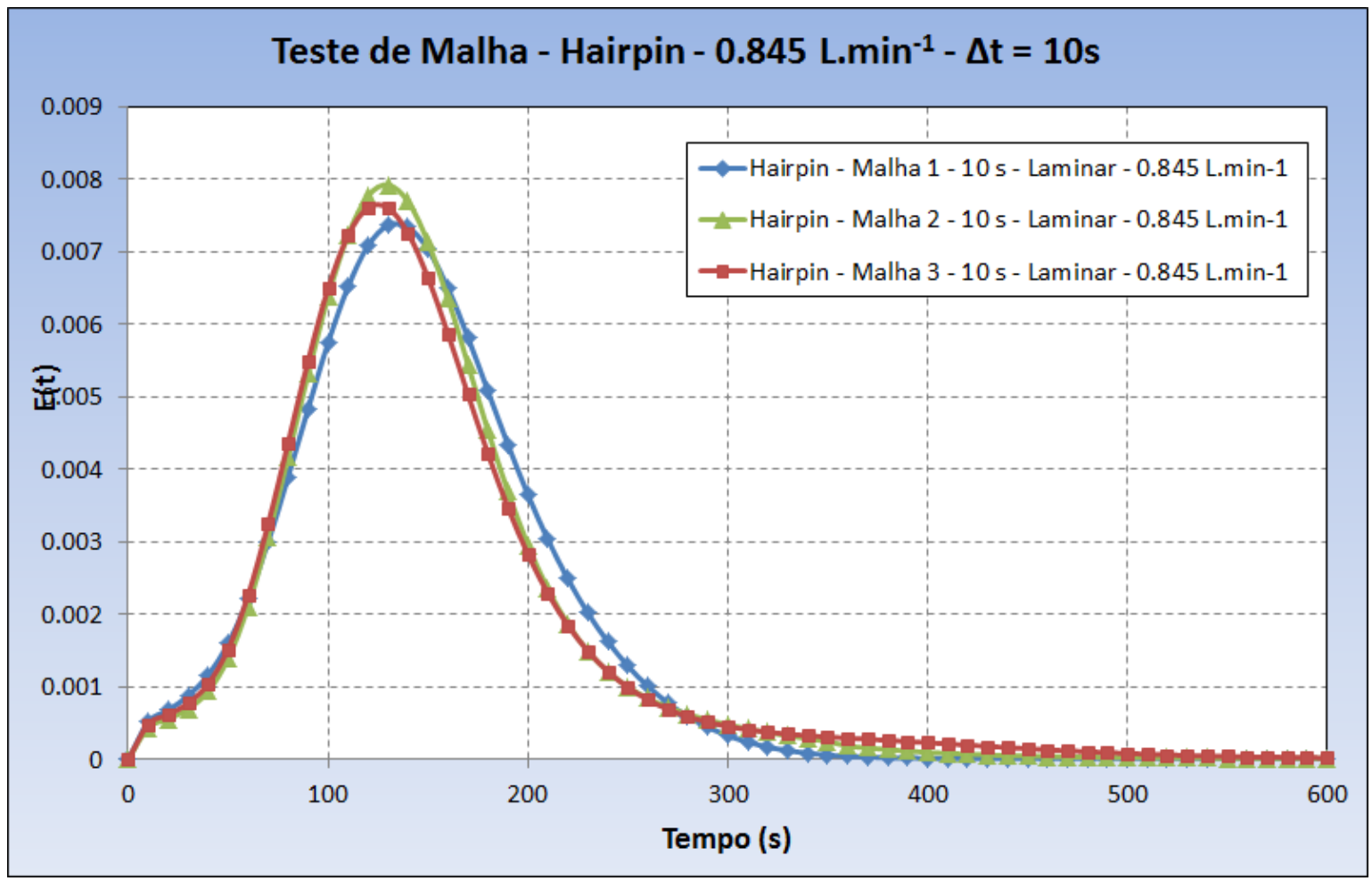

Figura 4.18 - Comparativo das curvas de distribuição do tempo de residência para seleção das malhas, para o escoamento laminar no hairpin. 

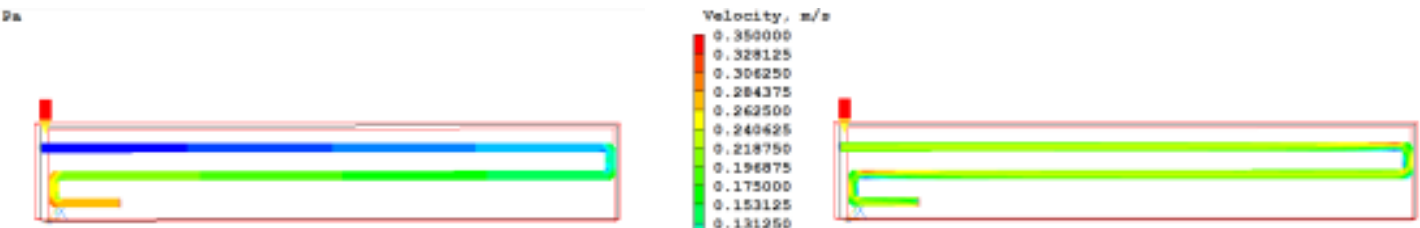

(a)
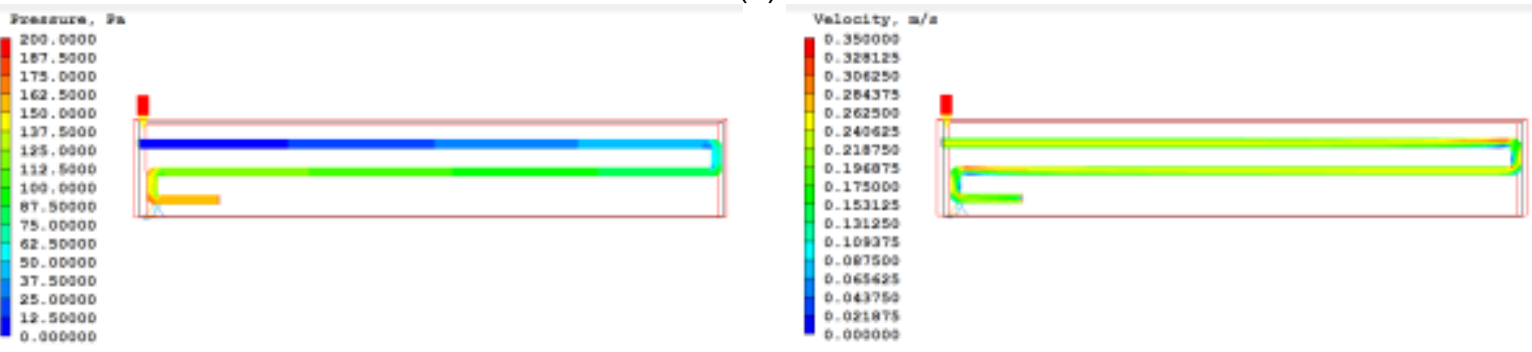

(b)
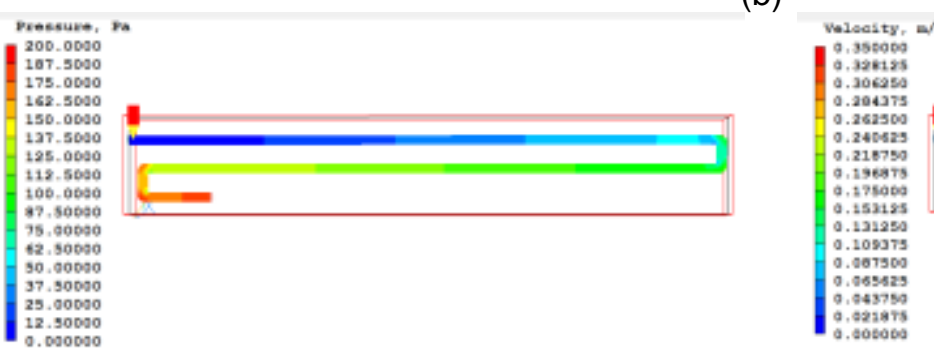

(c)

Figura 4.19 - Comparativo dos campos de velocidades e pressão obtidos na seleção de malhas para

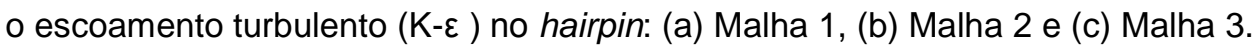

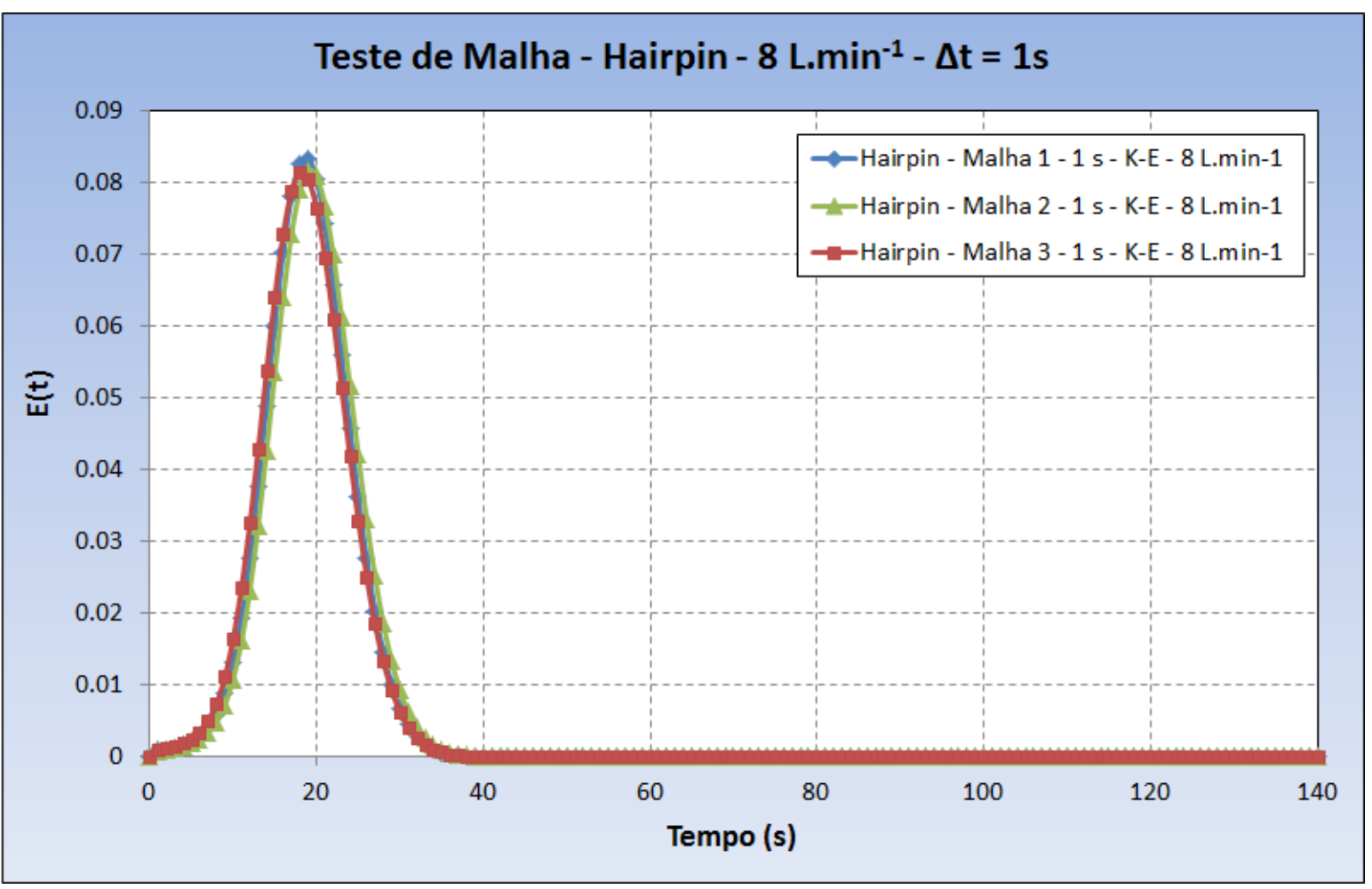

Figura 4.20 - Comparativo das curvas de distribuição do tempo de residência para seleção das malhas, para o escoamento turbulento $(\mathrm{K}-\varepsilon)$ no hairpin. 


\subsubsection{Malha Selecionada}

Com base nos resultados obtidos, optou-se pela malha cartesiana 2, mostrada na Figura 4.21, onde a quantidade de células do domínio é de 177 x 80 x 12 , num total de 169.920 volumes.

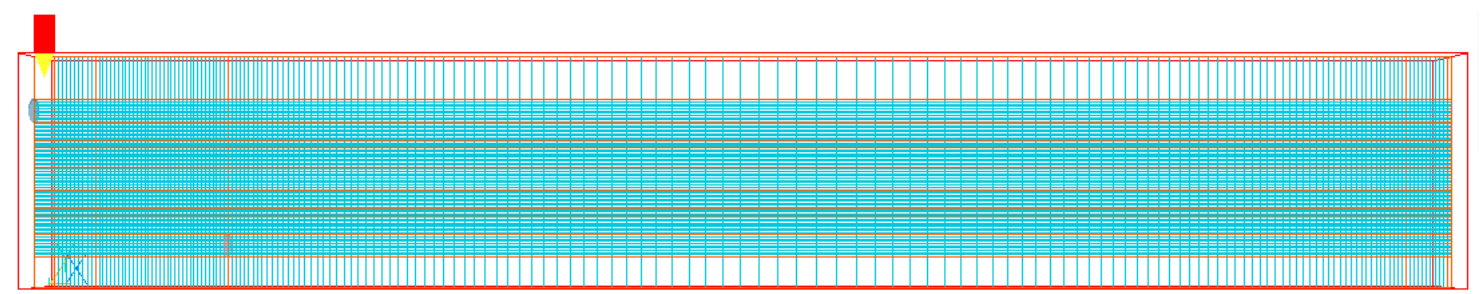

Figura 4.21 - Malha selecionada para ser usada nas simulações do hairpin.

\subsubsection{Modelo e Condições de Contorno}

Os modelos e as condições de contorno são as mesmas adotadas no item 4.1.2, adequadas para o domínio apresentado na Figura 4.21 e a malha 2.

\subsubsection{Simulações Realizadas}

Para o estudo do escoamento do hairpin, foram simuladas duas vazões diferentes: 0,845 L. $\min ^{-1}$ e 8 L. $\mathrm{min}^{-1}$, com os respectivos modelos de escoamento: Laminar e turbulento $(k-\varepsilon)$. Simularam-se diferentes passos de tempo para a integração. Os passos de tempo estudados foram: $30 \mathrm{~s}, 10 \mathrm{~s}, 5 \mathrm{~s}, 2 \mathrm{~s}$ e $1 \mathrm{~s}$. As condições simuladas nessa etapa do trabalho são as mostradas na Tabela 4-6.

Tabela 4-6 - Resumo das simulações realizadas para o Hairpin.

\begin{tabular}{cccccc}
\hline Dado & $\mathbf{1}$ & $\mathbf{2}$ & $\mathbf{3}$ & $\mathbf{4}$ & $\mathbf{5}$ \\
\hline Vazão $\left(\mathrm{L} \cdot \mathrm{min}^{-1}\right)$ & 0,85 & 8,00 & 0,85 & 8,00 & 0,85 \\
Densidade $\left(\mathrm{kg} \cdot \mathrm{m}^{-1}\right)$ & 1000 & 1000 & 1000 & 1000 & 1000 \\
Diâmetro dos tubos $(\mathrm{m})$ & 0,0292 & 0,0292 & 0,0292 & 0,0292 & 0,0292 \\
Viscosidade $(\mathrm{Pa} . \mathrm{s})$ & 0,001 & 0,001 & 0,001 & 0,001 & 0,001 \\
Vazão $\left(\mathrm{m}^{3} \mathrm{~s}^{-1}\right)$ & $1,41 \mathrm{E}-05$ & $1,33 \mathrm{E}-04$ & $1,41 \mathrm{E}-05$ & $1,33 \mathrm{E}-04$ & $1,41 \mathrm{E}-05$ \\
Velocidade $\left(\mathrm{m}^{-1} \mathrm{~s}^{-1}\right)$ & 0,0210 & 0,1991 & 0,0210 & 0,1991 & 0,0210 \\
Número de Reynolds & 614 & 5814 & 614 & 5814 & 614 \\
Modelo de Escoamento & Laminar & $\mathrm{k}-\varepsilon$ & Laminar & $\mathrm{k}-\varepsilon$ & Laminar \\
Passo de Tempo & $30 \mathrm{~s}$ & $30 \mathrm{~s}$ & $10 \mathrm{~s}$ & $10 \mathrm{~s}$ & $5 \mathrm{~s}$ \\
\hline
\end{tabular}




\begin{tabular}{cccccc}
\hline Dado & $\mathbf{6}$ & $\mathbf{7}$ & $\mathbf{8}$ & $\mathbf{9}$ & $\mathbf{1 0}$ \\
\hline Vazão $\left(\mathrm{L} \cdot \mathrm{min}^{-1}\right)$ & 8,00 & 0,85 & 8,00 & 0,85 & 8,00 \\
Densidade $\left(\mathrm{kg} \cdot \mathrm{m}^{-1}\right)$ & 1000 & 1000 & 1000 & 1000 & 1000 \\
Diâmetro dos tubos $(\mathrm{m})$ & 0,0292 & 0,0292 & 0,0292 & 0,0292 & 0,0292 \\
Viscosidade $(\mathrm{Pa} \cdot \mathrm{s})$ & 0,001 & 0,001 & 0,001 & 0,001 & 0,001 \\
Vazão $\left(\mathrm{m}^{3} \cdot \mathrm{s}^{-1}\right)$ & $1,33 \mathrm{E}-04$ & $1,41 \mathrm{E}-05$ & $1,33 \mathrm{E}-04$ & $1,41 \mathrm{E}-05$ & $1,33 \mathrm{E}-04$ \\
Velocidade $\left(\mathrm{m}^{-1} \mathrm{~s}^{-1}\right)$ & 0,1991 & 0,0210 & 0,1991 & 0,0210 & 0,1991 \\
Número de Reynolds & 5814 & 614 & 5814 & 614 & 5814 \\
Modelo de Escoamento & $\mathrm{k}-\varepsilon$ & Laminar & $\mathrm{k}-\varepsilon$ & Laminar & $\mathrm{k}-\varepsilon$ \\
Passo de Tempo & $5 \mathrm{~s}$ & $2 \mathrm{~s}$ & $2 \mathrm{~s}$ & $1 \mathrm{~s}$ & $1 \mathrm{~s}$ \\
\hline
\end{tabular}

\subsubsection{Campos de Velocidades e Pressão}

Os campos de velocidades e pressão, para o escoamento laminar, na condição de regime permanente, estão apresentados na Figura 4.22.

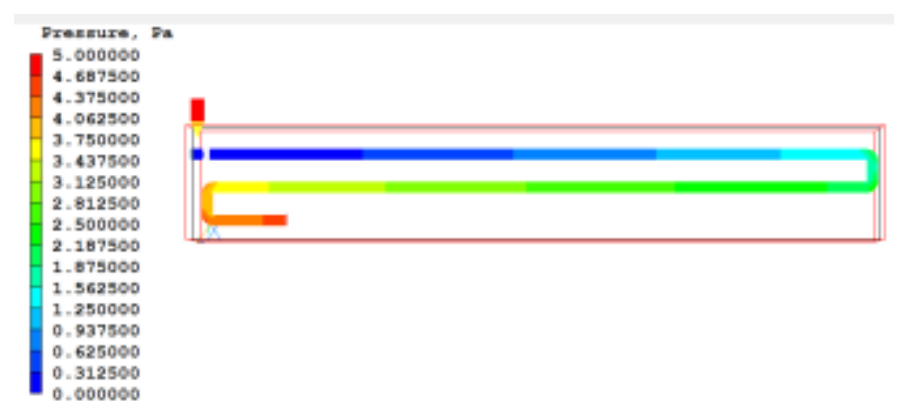

(a)
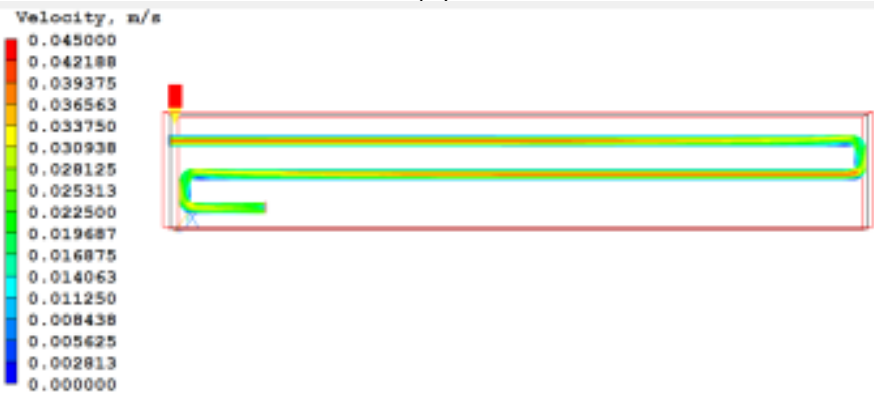

(b)
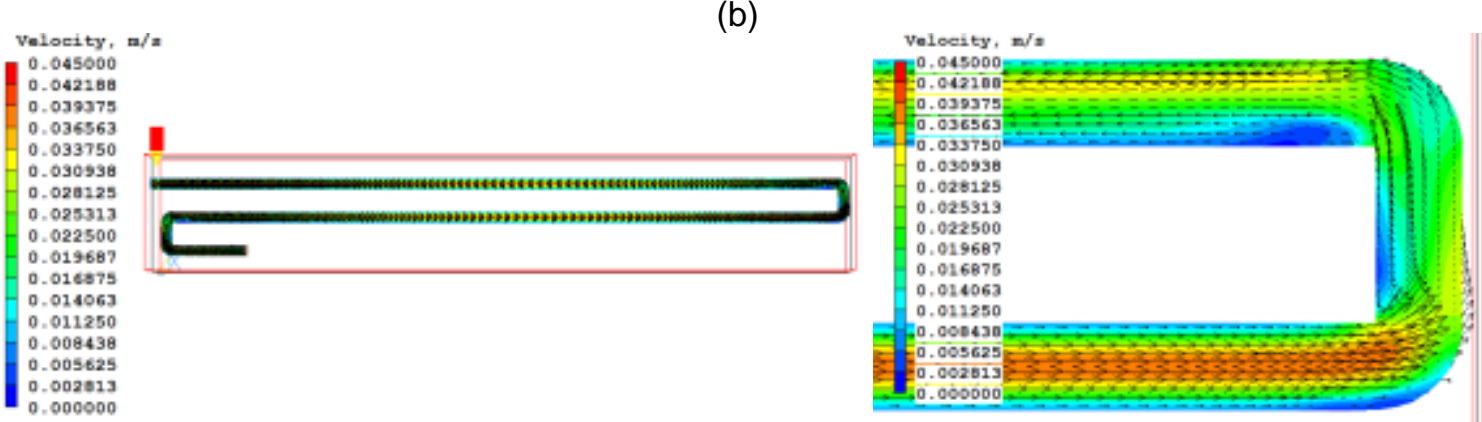

(c)

Figura 4.22 - Resultados obtidos para o escoamento laminar, utilizando a malha 2 selecionada: (a) Campo de pressão, (b) Campo de velocidades e (c) Detalhe do campo de velocidade do último trecho do hairpin. 
Os campos de velocidade, pressão e de $\mathrm{Y}^{+}$, para o modelo de turbulência $\mathrm{k}-\varepsilon$, na condiçãode regime permanente, estão apresentados na Figura 4.23.

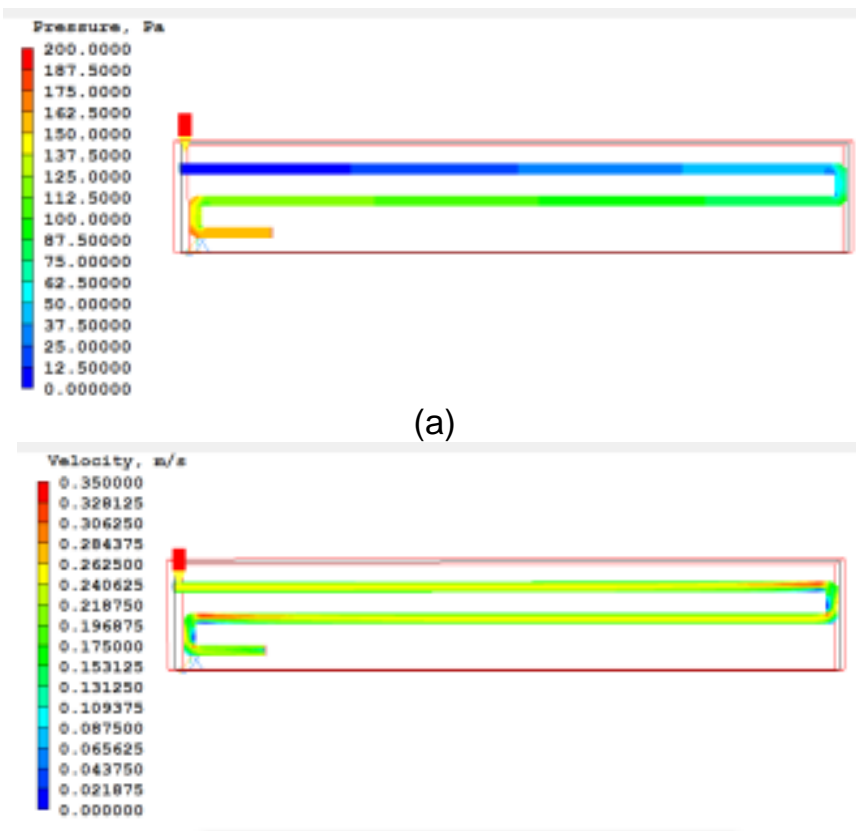

(b)

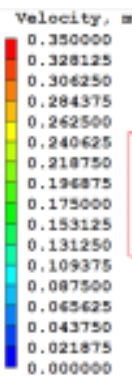

$$
a / 2
$$
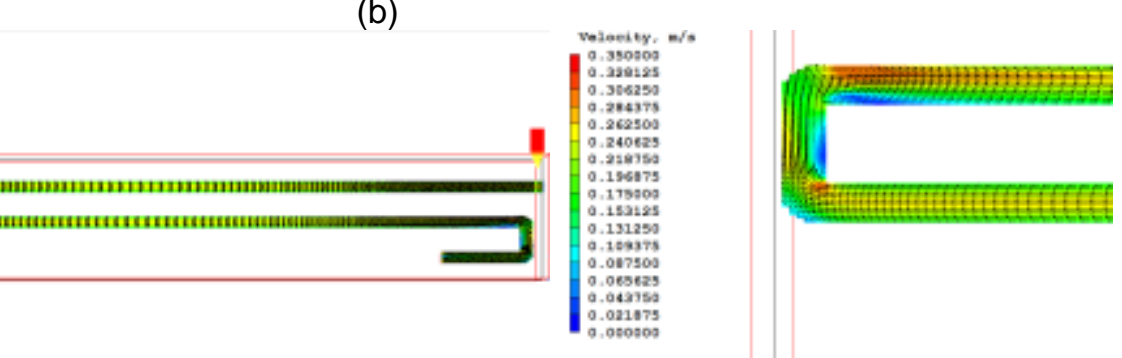

(c)

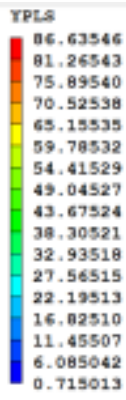

(d)

Figura 4.23 - Resultados obtidos para o escoamento utilizando o modelo de turbulência k- $\varepsilon$ para a malha 2 selecionada : (a) Campo de pressão, (b) Campo de velocidades, (c) Detalhe do campo de velocidade do último trecho do hairpin e (d) $\mathrm{Y}^{+}$. 


\subsubsection{Distribuição do Tempo de Residência (DTR)}

Para a análise da DTR para o escoamento no hairpin, realizaram-se simulações em regime transiente, para escoamentos em regime laminar (vazão de 0,845 L. $\mathrm{min}^{-1}$ ) e turbulento (vazão de 8,0 L.min ${ }^{-1}$ ). Considerou-se a injeção de um pulso de traçador (azul de metileno) na entrada do reator.

\subsubsection{Análise do Passo de Tempo}

Para o escoamento laminar, variaram-se os passos de tempo de integração. Os passos de tempo utilizados foram: 30s, 10s, $5 \mathrm{~s}, 2 \mathrm{~s}$ e $1 \mathrm{~s}$. As curvas de DTR resultantes podem ser vistas na Figura 4.24, e os tempos médios obtidos, na Tabela 4-7.

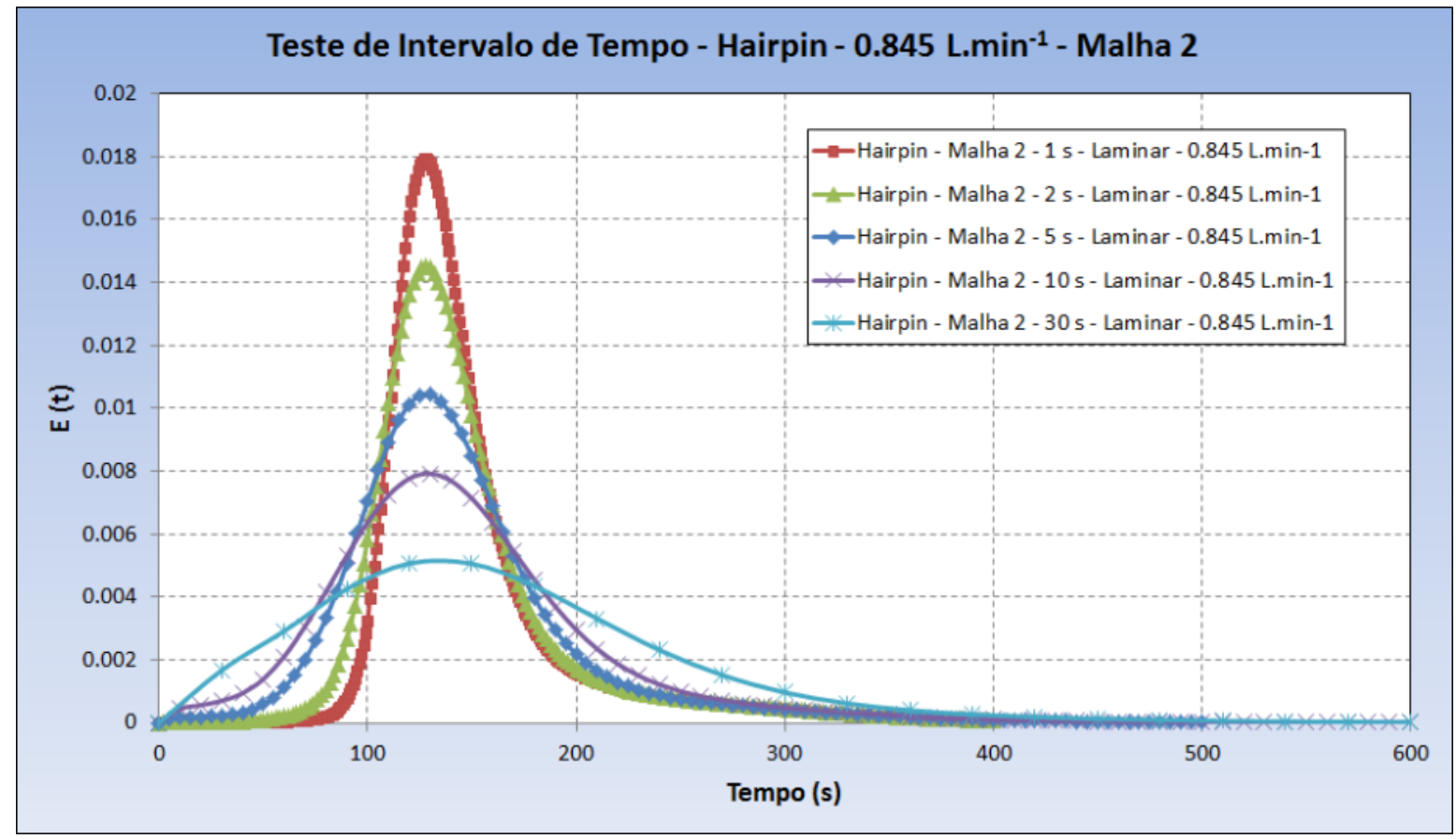

Figura 4.24 - Comparativo das curvas de distribuição do tempo de residência para escoamento laminar no hairpin, para diferentes passos de tempo simulados.

Tabela 4-7 - Comparação dos tempos médios obtidos para o escoamento laminar no hairpin para diferentes passos de tempo simulados.

\begin{tabular}{cc}
\hline Caso & Tempo Médio (s) \\
\hline$\Delta t=30 s$ & 179,11 \\
$\Delta t=10 s$ & 151,98 \\
$\Delta t=5 s$ & 147,91 \\
$\Delta t=2 s$ & 148,30 \\
$\Delta t=1 s$ & 149,59
\end{tabular}


Baseando-se na Figura 4.24 e na Tabela 4-7, a DTR do escoamento laminar escolhida para ser comparada com a DTR da simplificação para um único tubo cilíndrico, foi a de passo de tempo de 1s. Passos de tempo inferiores não foram investigados, devido ao excessivo tempo computacional.

Para o escoamento turbulento, consideraram-se os mesmos passos de tempo do caso laminar. As curvas de DTR resultantes podem ser vistas na Figura 4.25 e os tempos médios obtidos, na Tabela 4-8.

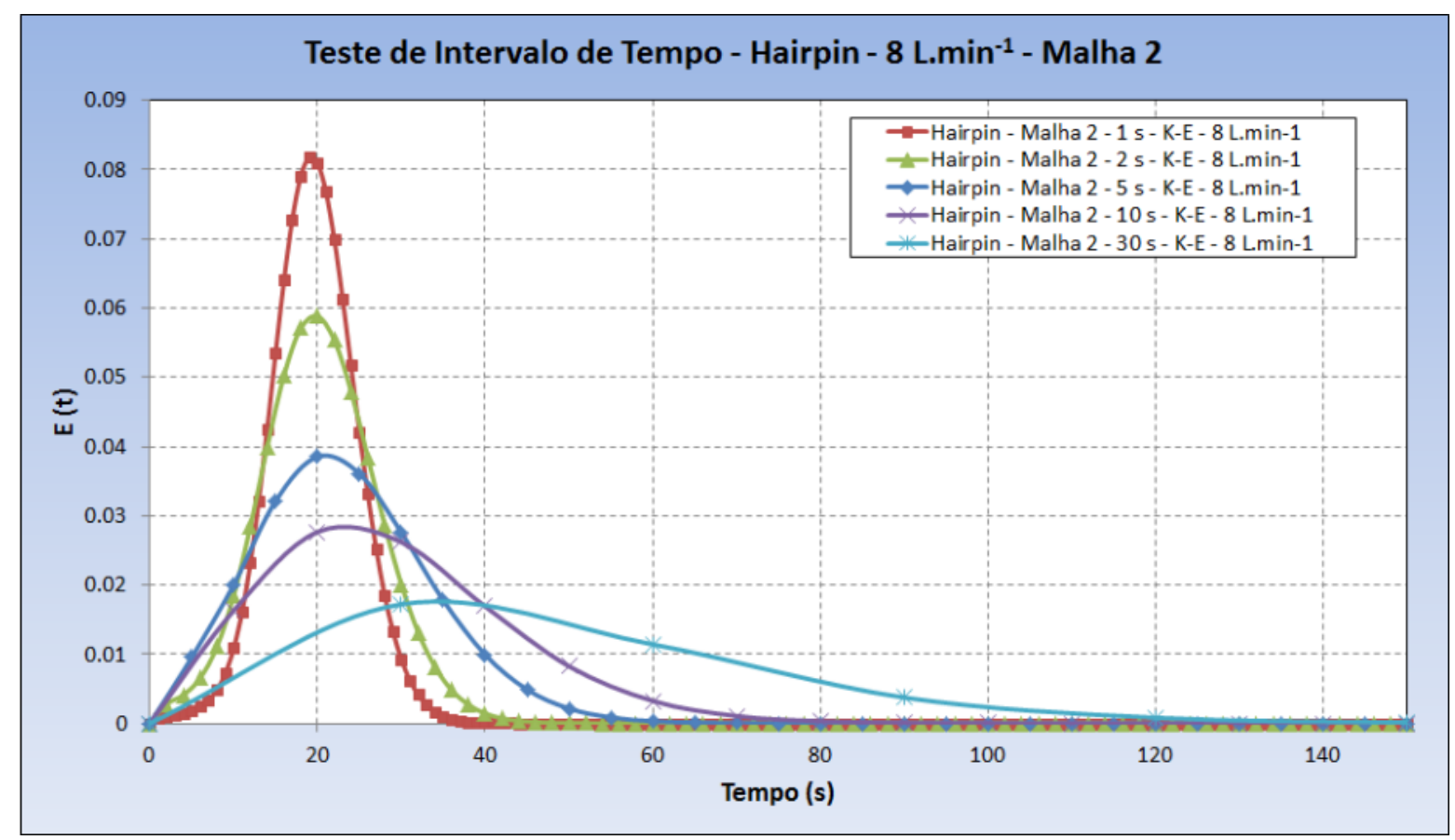

Figura 4.25 - Comparativo das curvas de distribuição do tempo de residência para escoamento turbulento no hairpin, para diferentes passos de tempo simulados.

Tabela 4-8 - Comparação dos tempos médios obtidos para o escoamento turbulento para o hairpin., para diferentes passos de tempo.

\begin{tabular}{cc}
\hline Caso & Tempo Médio (s) \\
\hline$\Delta t=30 s$ & 64,79 \\
$\Delta t=10 s$ & 33,95 \\
$\Delta t=5 s$ & 25,79 \\
$\Delta t=2 s$ & 21,25 \\
$\Delta t=1 s$ & 20,06 \\
\hline
\end{tabular}

Baseando-se na Figura 4.25 e na Tabela 4-8, a DTR do escoamento turbulento escolhida para ser comparada com a DTR da simplificação para um único 
tubo cilíndrico foi a de passo de tempo de 1s. Passos de tempo inferiores não foram investigados, também, devido ao excessivo tempo computacional.

\subsubsection{DTR Selecionada}

Conforme exposto no item 4.2.6.1, a curva de DTR selecionada para o modelo laminar foi a referente à malha 2 e $\Delta t=1 \mathrm{~s}$. Para esta condição, a Figura 4.26 apresenta a concentração do traçador ao longo do hairpin, em diferentes instantes em uma secção passando pelo centro do tubo.
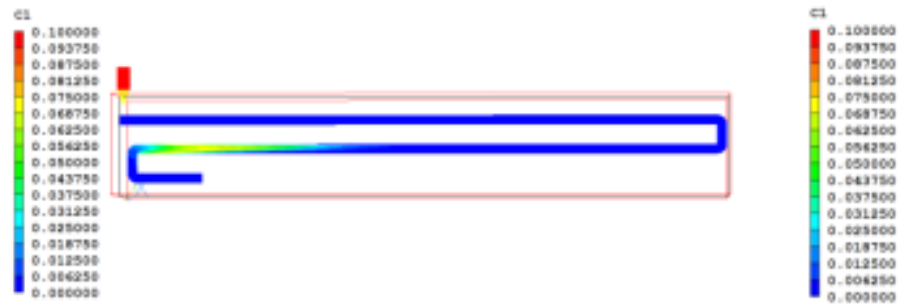

$t=20 s$

$t=40 s$

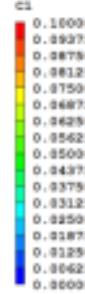

-

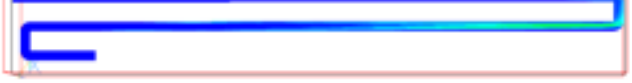

$t=60 s$

Figura 4.26 - Concentração do traçador em função do tempo para o escoamento laminar no hairpin, para passo de tempo $\Delta \mathrm{t}=1 \mathrm{~s}$.

A mesma análise apresentada no item 4.1.5.3 foi feita para o escoamento laminar no hairpin. A curva selecionada foi comparada com dois modelos teóricos de distribuição de tempo de residência: o modelo de dispersão de Taylor e o modelo de escoamento laminar (segregado). No entanto, também neste caso, o regime de escoamento e o processo difusivo configuram uma situação que está fora dos limites dos dois modelos citados, conforme pode ser observado na Figura 4.12.

Deve-se notar, também, a variação de concentração na direção radial, como pode ser visto na Figura 4.27. 


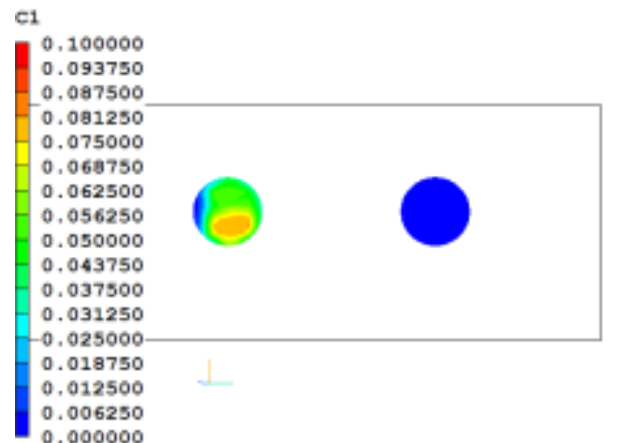

$t=20 s$ c1

0.100000
0.093750
0.087500
0.081250
0.075000
0.068750
0.062500
0.056250
0.050000
0.043750
0.037500
0.031250
0.025000
0.018750
0.012500
0.006250
0.000000

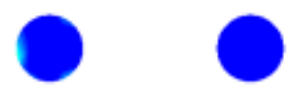

Figura 4.27 - Perfil de concentração do traçador em função do tempo para uma secção do hairpin.

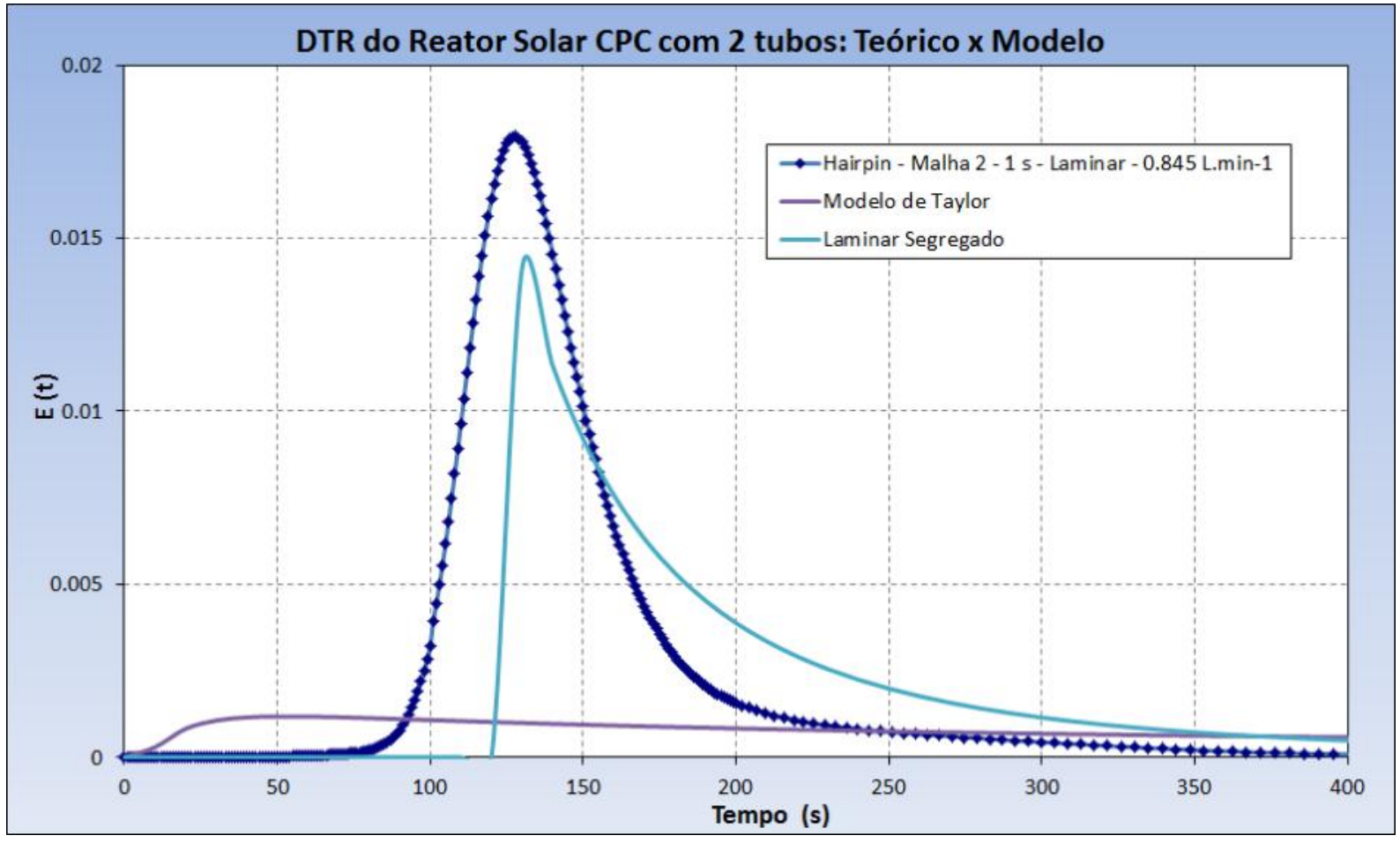

Figura 4.28 - Comparação das curvas de distribuição do tempo de residência, para o escoamento laminar no hairpin: modelos teóricos e a curva selecionada do modelo.

A curva de distribuição de residência selecionada para o modelo turbulento foi com a malha 2 e $\Delta t=1 \mathrm{~s}$. A Figura 4.29 apresenta a concentração do traçador ao longo do hairpin. 

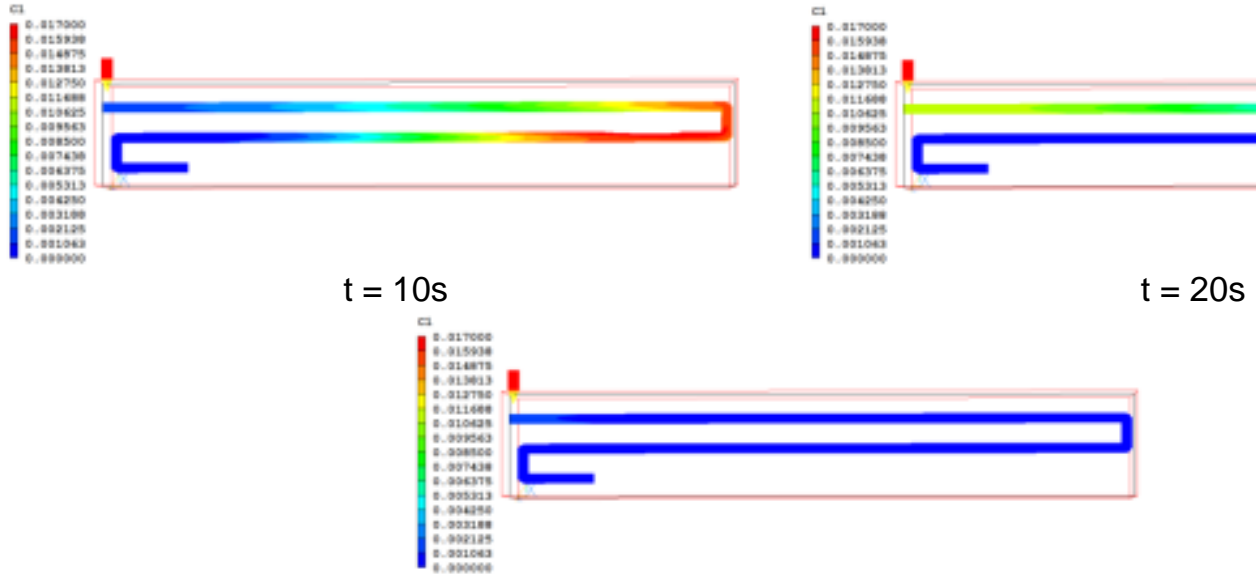

1

$t=30 s$

Figura 4.29 - Concentração do traçador em função do tempo para o escoamento turbulento $(\mathrm{K}-\varepsilon)$ no hairpin para passo de tempo $\Delta \mathrm{t}=1 \mathrm{~s}$.

A curva experimental foi ajustada para um modelo semi-teórico, com parâmetros ajustados. Pelo modelo de tanques em série (Levenspiel, 2000), obtiveram-se: $\mathrm{Nt}=17,5$ e $\tau=20,06$ s. A comparação dos resultados calculados pela simulação e pelo modelo de tanques em série está ilustrada na Figura 4.30.

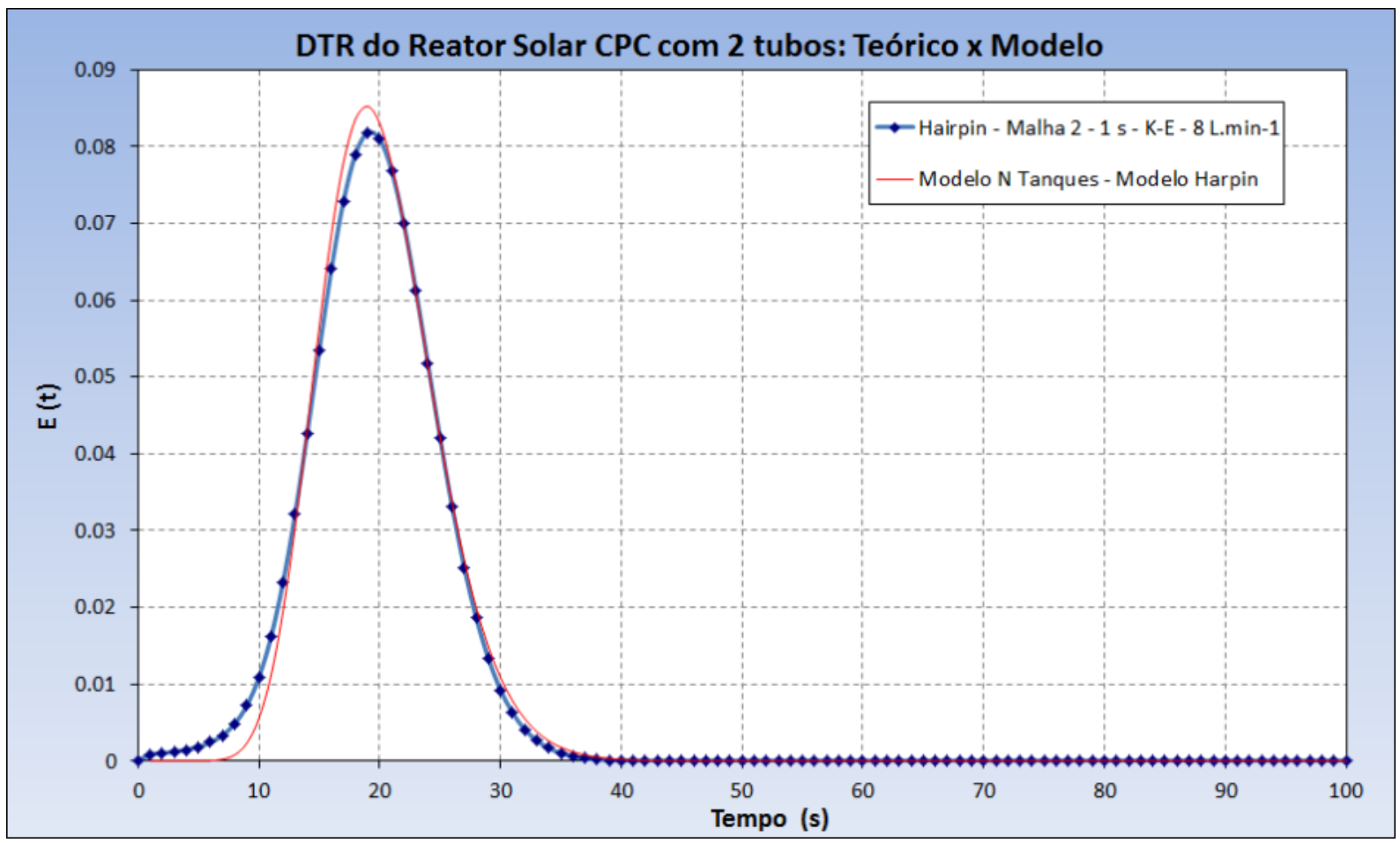

Figura 4.30 - Comparação das curvas de distribuição do tempo de residência, para o escoamento turbulento $(\mathrm{K}-\varepsilon)$ no hairpin : modelo semi-teórico e a curva selecionada do modelo. 


\subsubsection{Discussão de resultados - Hairpin}

A DTR do escoamento laminar mostra um desvio dos modelos teóricos, pois, conforme a Figura 4.12, o regime de escoamento e o processo difusivo configuram uma situação que está fora dos limites dos dois modelos citados.

Para a DTR do escoamento turbulento obteve-se um bom ajuste com o modelo de $\mathrm{N}$ tanques em série.

Essas duas curvas de distribuição de tempo de residência serão usadas como critério para uma simplificação da geometria, como será visto no item 4.3.

\subsection{REATOR SOLAR - TUBO RETO CILÍNDRICO}

Para possibilitar o desenvolvimento do modelo da reação de actinometria, descrito no item 3.4, foi necessário fazer uma simplificação do Hairpin (2 tubos) para um tubo reto simples, que possibilita o emprego de coordenadas cilíndricas, e consequentemente uma modelagem do campo de radiação mais precisa.

\subsubsection{Domínio Numérico}

As coordenadas cilíndricas foram usadas para simplificar a geometria e possibilitar a modelagem e simulação do campo de radiação e a reação de actinometria. O domínio considerado pode ser visualizado na Figura 4.31, sendo $\phi=0,0292 \mathrm{~m} \mathrm{e} \mathrm{L}=4,098 \mathrm{~m}$, de forma que o volume deste tubo é o mesmo que o do hairpin mostrado no item 4.2 .

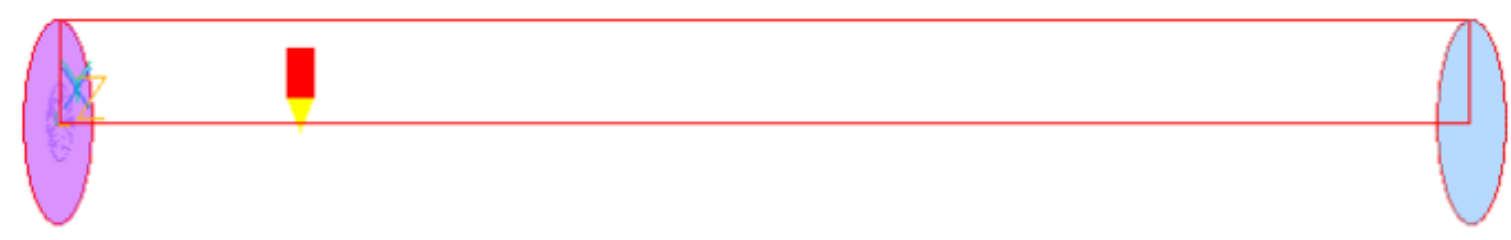

Figura 4.31 - Domínio do reator tubo reto cilíndrico . 


\subsubsection{Malha}

\subsubsection{Seleção da Malha}

Para obter a melhor malha para a análise do escoamento no cilindro, o mesmo método do item 4.1.1.1 foi utilizado. Foram simuladas as três malhas descritas na Tabela 4-9. A malha 2 está ilustrada na Figura 4.32.

Tabela 4-9 - Malhas testadas no software PHOENICS para seleção de malha no tubo reto cilíndrico.

\begin{tabular}{|c|c|c|c|}
\hline Parâmetros & Malha 1 & Malha 2 & Malha 3 \\
\hline Células em $x$ & 1 & 1 & 177 \\
\hline Células em y & 3 & 5 & 12 \\
\hline Células em z & 50 & 120 & 362 \\
\hline Número de Volumes Total & 150 & 600 & 4344 \\
\hline Tempo de Simulação - Laminar* & 7h19 & $28 \mathrm{~h} 50$ & $56 h 10$ \\
\hline Passo de Tempo - Laminar & $10 \mathrm{~s}$ & $10 \mathrm{~s}$ & $10 \mathrm{~s}$ \\
\hline Tempo de Simulação $-\mathrm{K}-\varepsilon^{*}$ & $13 \mathrm{~h} 45$ & 30h05 & $89 \mathrm{~h} 20$ \\
\hline Passo de Tempo - K- $\varepsilon$ & $1 \mathrm{~s}$ & $1 \mathrm{~s}$ & $1 \mathrm{~s}$ \\
\hline
\end{tabular}

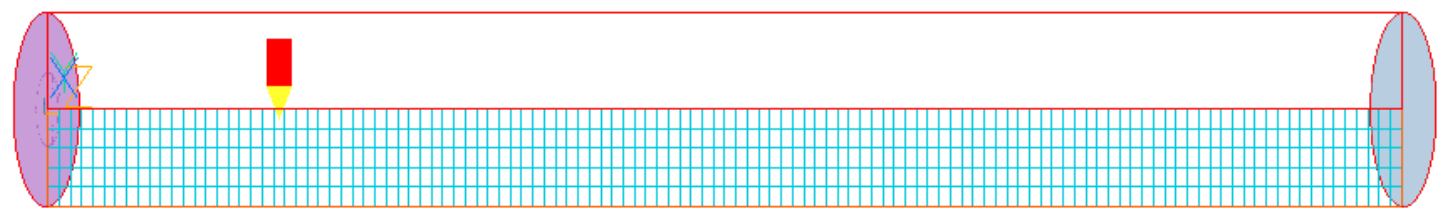

Figura 4.32 - Malha 2, com 600 elementos, selecionada para simulações do tubo reto cilíndrico.

Estudaram-se duas vazões diferentes: 0,845 L. $\mathrm{min}^{-1}$ e 8 L.min ${ }^{-1}$, com os respectivos modelos de escoamento: Laminar e Turbulento $(K-\varepsilon)$.

Os campos de velocidades e pressão obtidos para cada malha e vazão podem ser vistos nas Figura 4.33 e Figura 4.35. As curvas de distribuição de tempo de residência são apresentadas na Figura 4.34 e na Figura 4.36. 

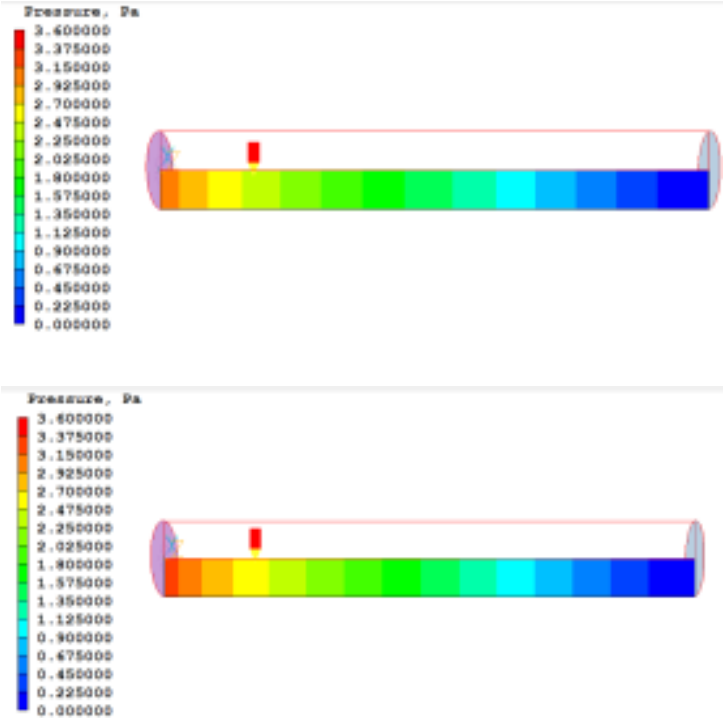

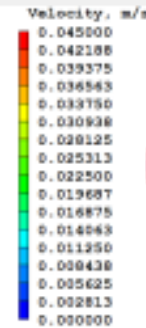

(a)

(b)

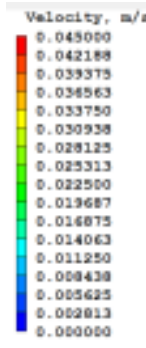

$$
\text { A }
$$

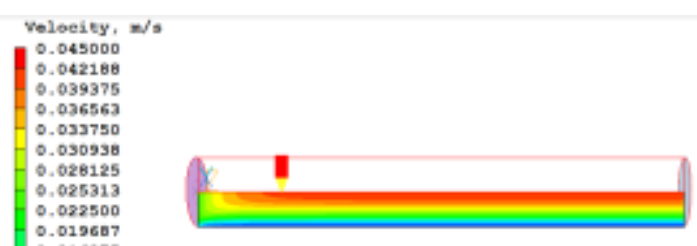

(c)

Figura 4.33 - Comparativo dos campos de velocidades e pressão obtidos na seleção de malhas para o escoamento laminar no tubo reto cilíndrico: (a) Malha 1, (b) Malha 2 e (c) Malha 3.

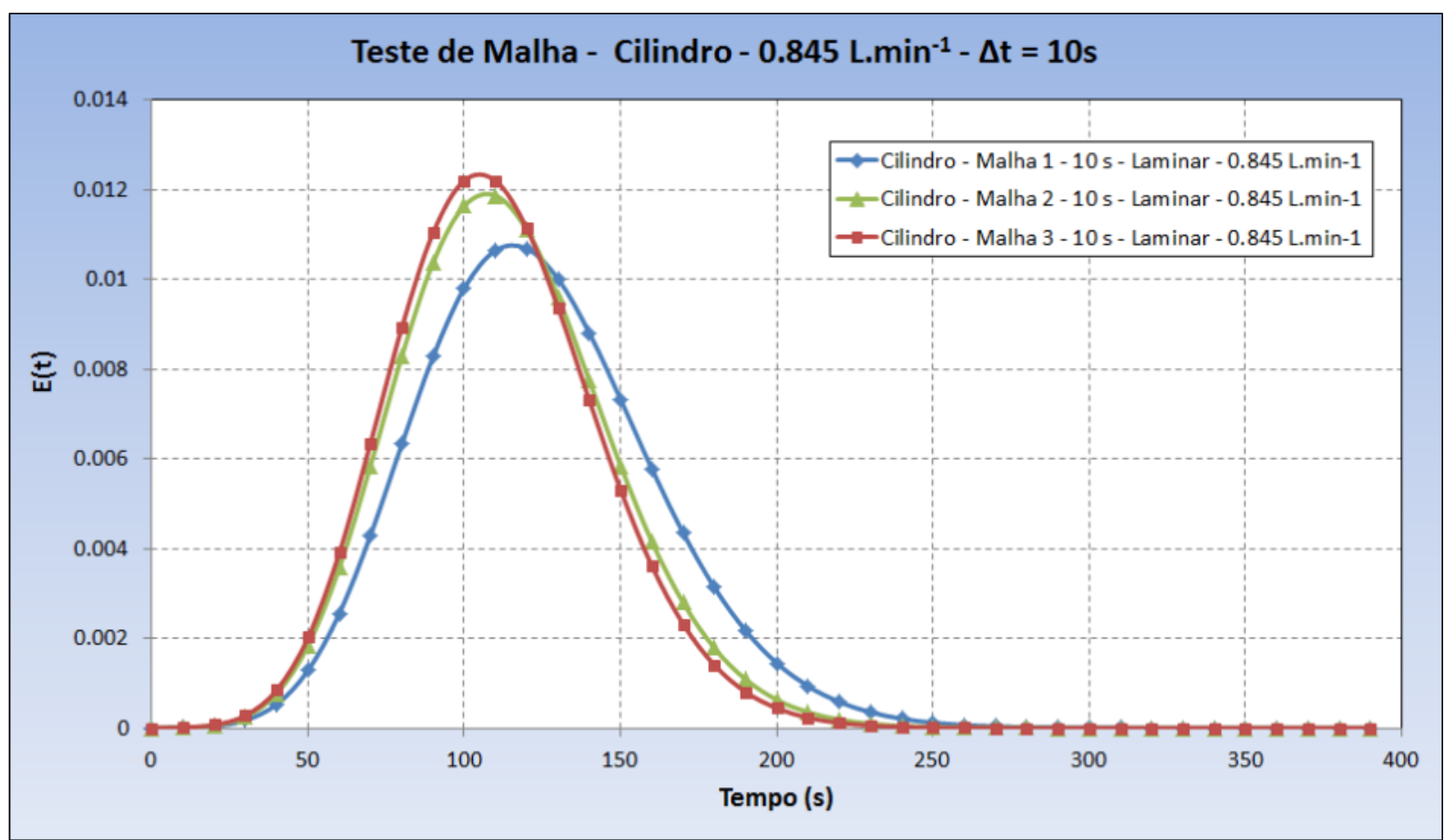

Figura 4.34 - Comparação das curvas de distribuição do tempo de residência para a seleção das malhas, para o escoamento laminar no tubo reto cilíndrico. 

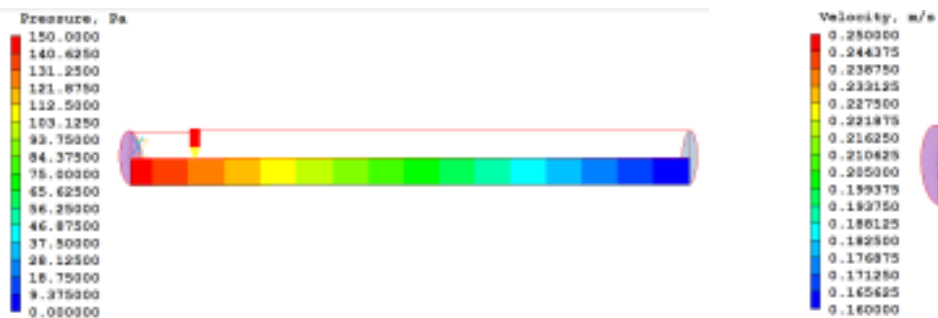

(a)
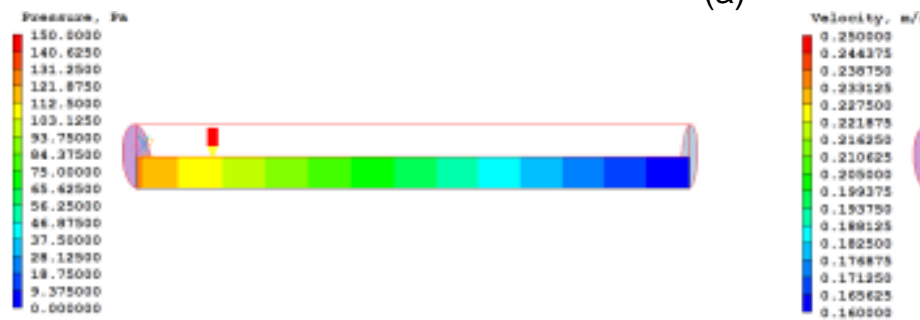

.

(b)
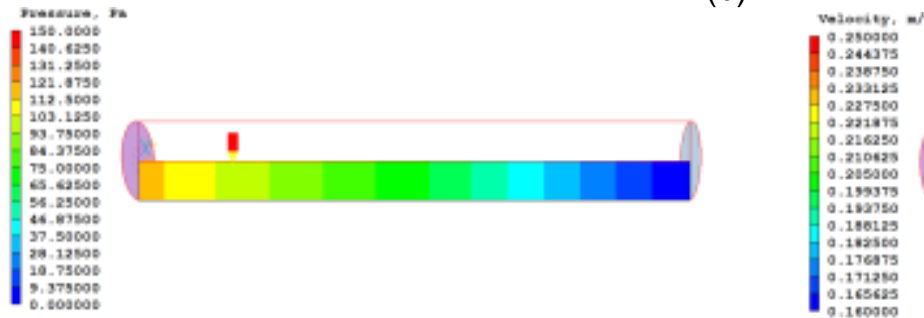

【

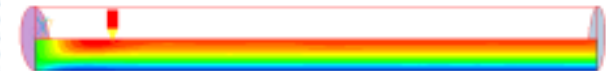

(c)

Figura 4.35 - Comparativo dos campos de velocidades e pressão obtidos na seleção de malhas para o escoamento turbulento (K- $\varepsilon$ ) no tubo reto cilíndrico: (a) Malha 1, (b) Malha 2 e (c) Malha 3.

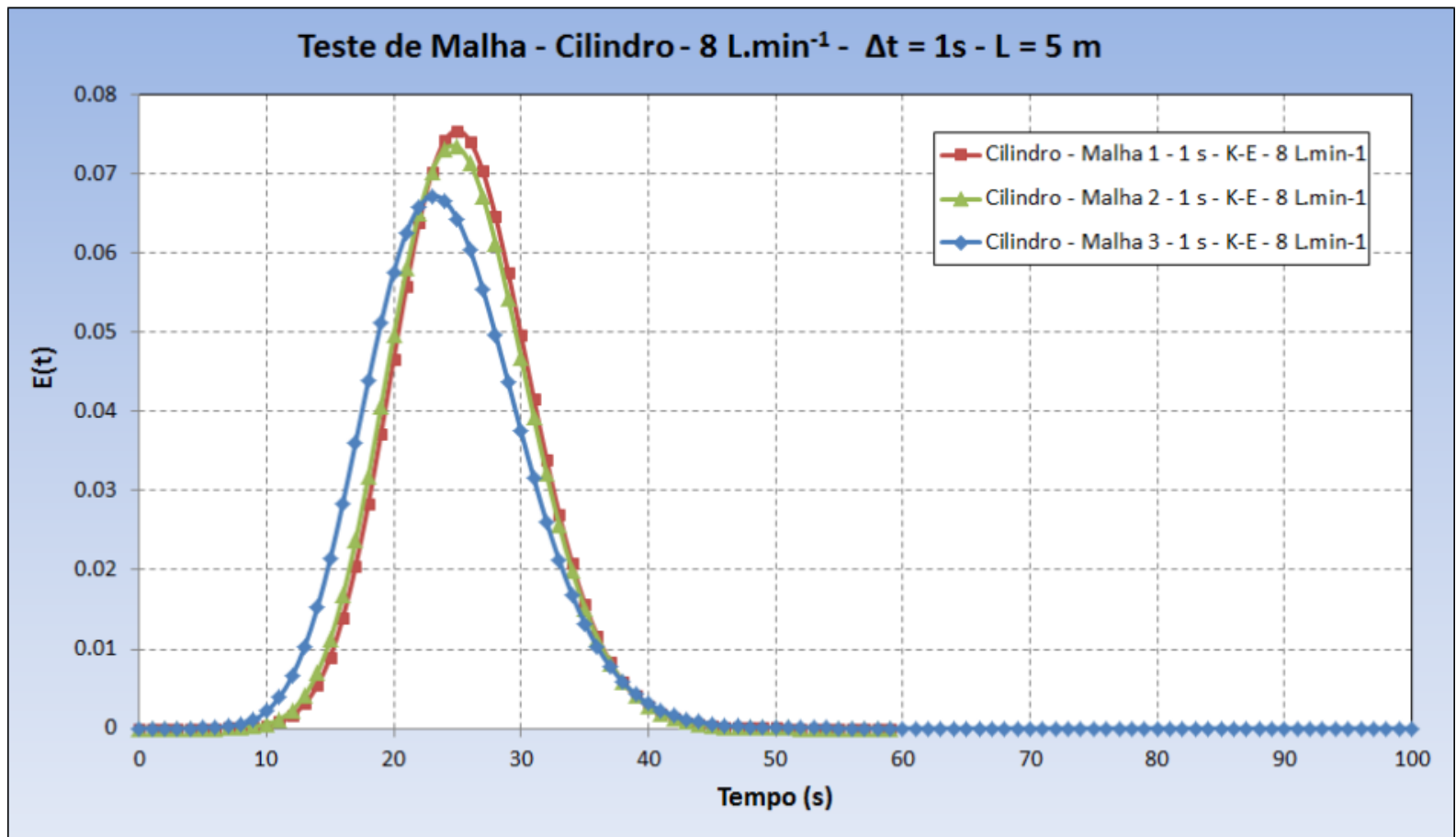

Figura 4.36 - Comparação das curvas de distribuição do tempo de residência para a seleção das malhas, para o escoamento turbulento $(\mathrm{K}-\varepsilon)$ no tubo reto cilíndrico. 


\subsubsection{Malha Selecionada}

Com base nos resultados obtidos, tanto para o caso laminar quanto turbulento, optou-se pela malha 2, mostrada na Figura 4.32, com a seguinte quantidade de células do domínio: 1 × 5 × 120, num total de 600 volumes.

\subsubsection{Modelo e Condições de Contorno}

Os modelos e as condições de contorno são as mesmas adotadas no item 4.1.2, adequadas para o domínio apresentado na Figura 4.32 e a malha 2.

\subsubsection{Simulações Realizadas}

Para o estudo do escoamento no tubo reto cilíndrico, foram simuladas duas vazões diferentes: 0,845 L. $\mathrm{min}^{-1}$ e 8 L. $\mathrm{min}^{-1}$, com os respectivos modelos de escoamento: laminar e turbulento $(k-\varepsilon)$. Simularam-se diferentes passos de tempo, a saber: $30 \mathrm{~s}, 10 \mathrm{~s}, 5 \mathrm{~s}, 2 \mathrm{~s}$ e $1 \mathrm{~s}$. As condições simuladas nessa etapa do trabalho são mostradas na Tabela 4-10.

Tabela 4-10 - Resumo das simulações realizadas para o tubo reto cilíndrico.

\begin{tabular}{|c|c|c|c|c|c|}
\hline Dado & 1 & 2 & 3 & 4 & 5 \\
\hline Vazão (L.min $\left.{ }^{-1}\right)$ & 0,85 & 8,00 & 0,85 & 8,00 & 0,85 \\
\hline Densidade $\left(\mathrm{kg} \cdot \mathrm{m}^{-1}\right)$ & 1000 & 1000 & 1000 & 1000 & 1000 \\
\hline Diâmetro dos tubos (m) & 0,0292 & 0,0292 & 0,0292 & 0,0292 & 0,0292 \\
\hline Viscosidade (Pa.s) & 0,001 & 0,001 & 0,001 & 0,001 & 0,001 \\
\hline Vazão $\left(m^{3} \cdot s^{-1}\right)$ & 1,41E-05 & $1,33 \mathrm{E}-04$ & 1,41E-05 & 1,33E-04 & 1,41E-05 \\
\hline Velocidade $\left(\mathrm{m} . \mathrm{s}^{-1}\right)$ & 0,0210 & 0,1991 & 0,0210 & 0,1991 & 0,0210 \\
\hline Número de Reynolds & 614 & 5814 & 614 & 5814 & 614 \\
\hline Modelo de Escoamento & Laminar & $\mathrm{k}-\varepsilon$ & Laminar & $\mathrm{k}-\varepsilon$ & Laminar \\
\hline Passo de Tempo & $30 \mathrm{~s}$ & $30 \mathrm{~s}$ & $10 \mathrm{~s}$ & $10 \mathrm{~s}$ & $5 s$ \\
\hline Dado & 6 & 7 & 8 & 9 & 10 \\
\hline Vazão $\left(\right.$ L. $\left.\min ^{-1}\right)$ & 8,00 & 0,85 & 8,00 & 0,85 & 8,00 \\
\hline Densidade $\left(\mathrm{kg} \cdot \mathrm{m}^{-1}\right)$ & 1000 & 1000 & 1000 & 1000 & 1000 \\
\hline Diâmetro dos tubos (m) & 0,0292 & 0,0292 & 0,0292 & 0,0292 & 0,0292 \\
\hline Viscosidade (Pa.s) & 0,001 & 0,001 & 0,001 & 0,001 & 0,001 \\
\hline $\operatorname{Vazão}\left(\mathrm{m}^{3} \cdot \mathrm{s}^{-1}\right)$ & $1,33 E-04$ & 1,41E-05 & $1,33 \mathrm{E}-04$ & $1,41 \mathrm{E}-05$ & $1,33 \mathrm{E}-04$ \\
\hline Velocidade $\left(\mathrm{m} . \mathrm{s}^{-1}\right)$ & 0,1991 & 0,0210 & 0,1991 & 0,0210 & 0,1991 \\
\hline Número de Reynolds & 5814 & 614 & 5814 & 614 & 5814 \\
\hline Modelo de Escoamento & $\mathrm{k}-\varepsilon$ & Laminar & $\mathrm{k}-\varepsilon$ & Laminar & $\mathrm{k}-\varepsilon$ \\
\hline Passo de Tempo & $5 s$ & $2 s$ & $2 s$ & $1 \mathrm{~s}$ & 1s \\
\hline
\end{tabular}




\subsubsection{Análise do Passo de Tempo}

As curvas de DTR, para o escoamento laminar, podem ser vistas na Figura 4.37, e, os tempos médios obtidos, na Tabela 4-11.

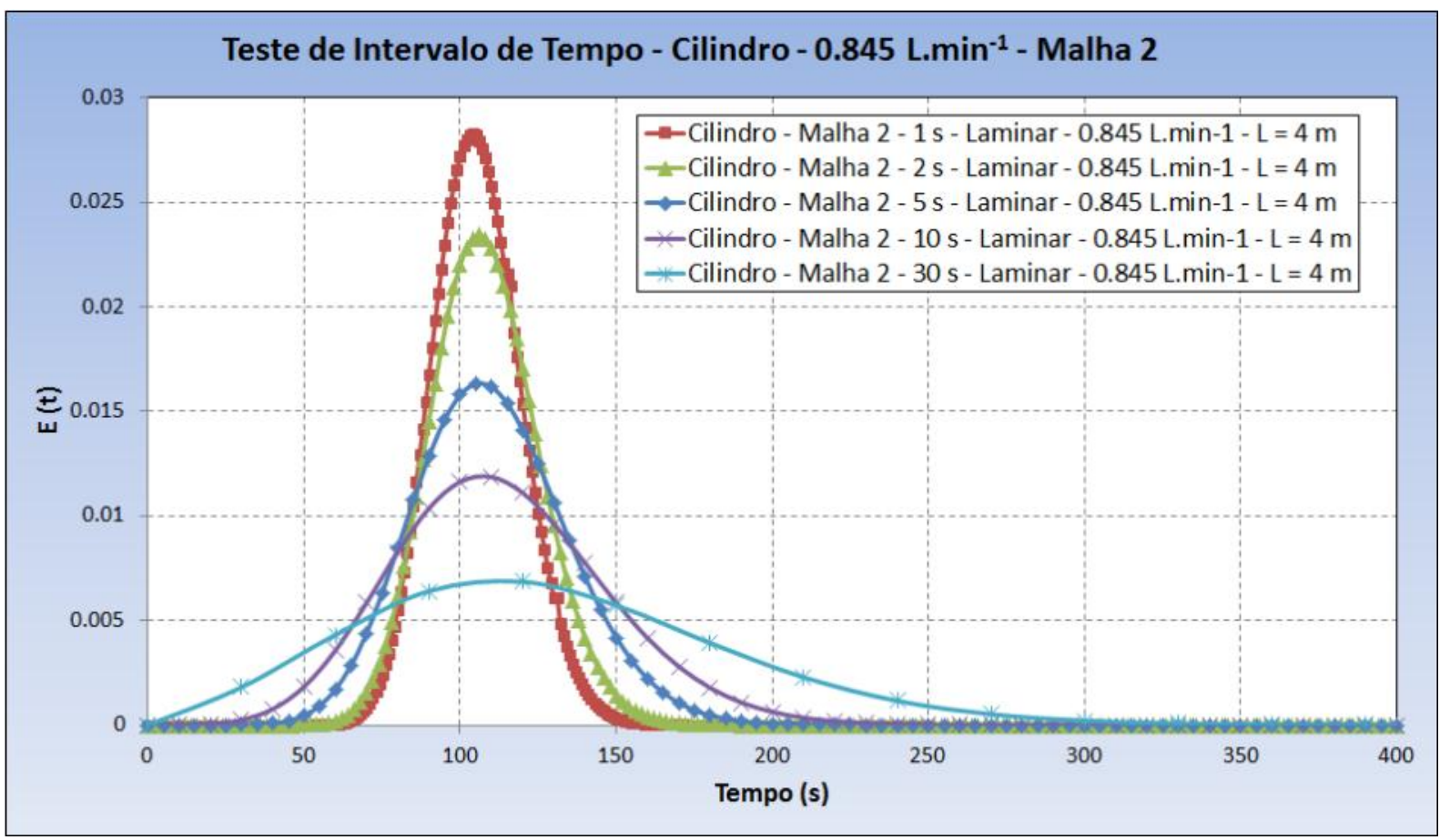

Figura 4.37 - Comparativo das curvas de distribuição do tempo de residência para escoamento laminar no tubo reto cilíndrico para diferentes passos de tempo simulados.

Tabela 4-11 - Comparação dos tempos médios obtidos para o escoamento laminar para o experimento e diferentes passos de tempo simulados no tubo reto cilíndrico.

\begin{tabular}{cc}
\hline Caso & Tempo Médio (s) \\
\hline$\Delta t=30 s$ & 143,38 \\
$\Delta t=10 s$ & 118,17 \\
$\Delta t=5 s$ & 112,51 \\
$\Delta t=2 s$ & 109,02 \\
$\Delta t=1 \mathrm{~s}$ & 105,85 \\
\hline
\end{tabular}

Baseando-se na Figura 4.37 e na Tabela 4-11, a DTR do escoamento laminar escolhida foi a de passo de tempo de 1s.

Para o escoamento turbulento, as curvas de DTR podem ser vistas na Figura 4.38, e, os tempos médios obtidos na Tabela 4-12. 


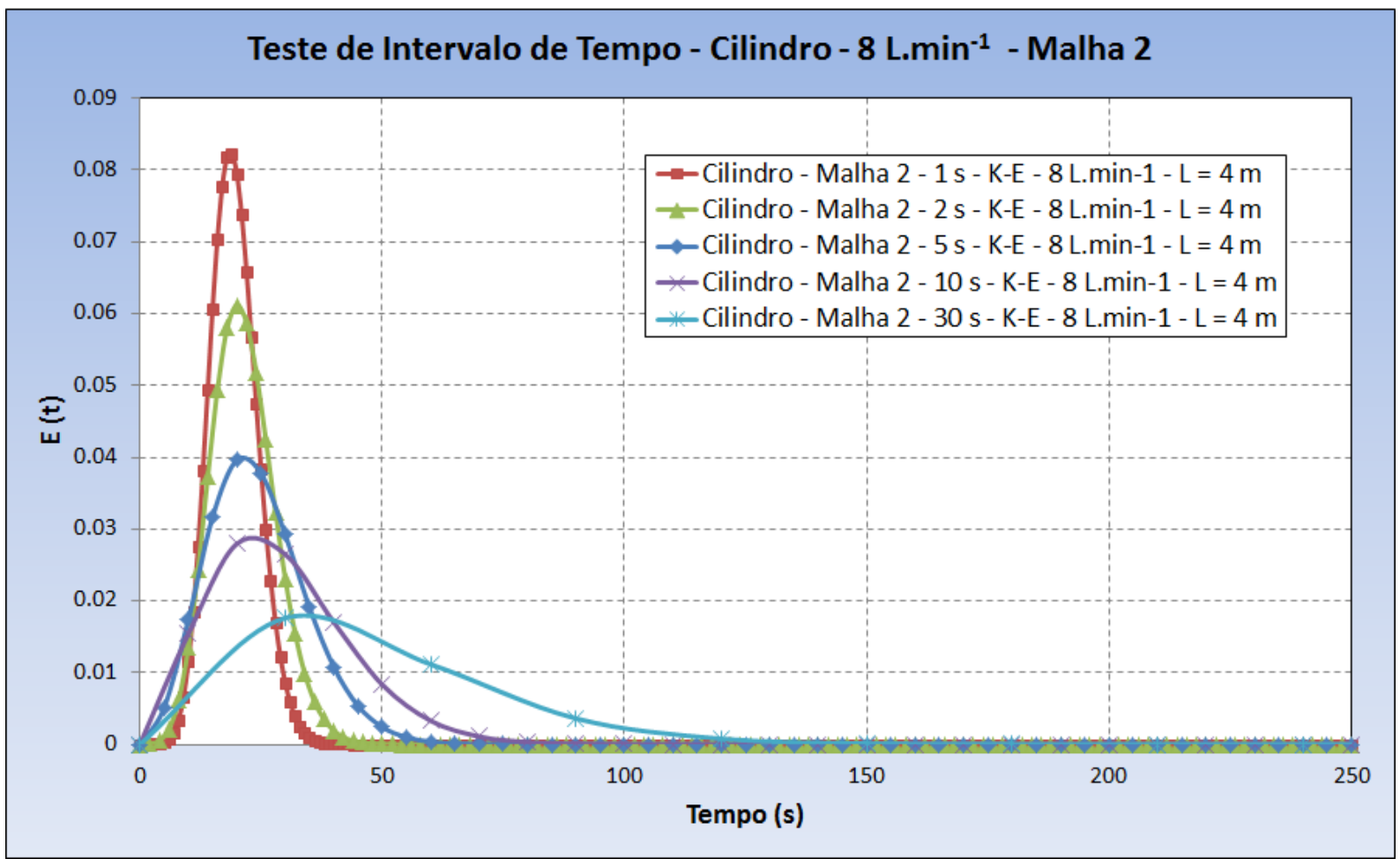

Figura 4.38 - Comparativo das curvas de distribuição do tempo de residência para escoamento turbulento no tubo reto cilíndrico para diferentes passos de tempo simulados.

Tabela 4-12 - Comparação dos tempos médios obtidos para o escoamento turbulento para o experimento e diferentes passos de tempo simulados no tubo reto cilíndrico.

\begin{tabular}{cc}
\hline Caso & Tempo Médio (s) \\
\hline$\Delta t=30 s$ & 64,24 \\
$\Delta t=10 s$ & 34,15 \\
$\Delta t=5 s$ & 26,70 \\
$\Delta t=2 s$ & 22,32 \\
$\Delta t=1 s$ & 19,86 \\
\hline
\end{tabular}

Baseando-se na Figura 4.38 e na Tabela 4-12, a DTR do escoamento turbulento escolhida para ser comparada com a DTR da simplificação para um único cilindro foi a de passo de tempo de $1 \mathrm{~s}$.

\subsubsection{Análise do Modelo de Escoamento}

Além das simulações para estudo da DTR, simularam-se algumas condições diferentes de escoamento importantes para análise da influência dos modelos de escoamento na reação de actinometria. As condições simuladas são mostradas na Tabela 4-13. 
Tabela 4-13 - Resumo das simulações realizadas para o tubo reto cilíndrico para comparação de diferentes modelos de escoamento.

\begin{tabular}{ccccc}
\hline Dado & Laminar & Plug Flow & 0,5.Vazão & $\mathbf{1 , 5 . V a z a ̃ o ~}$ \\
\hline Vazão $\left(\mathrm{L} \cdot \mathrm{min}^{-1}\right)$ & 8,00 & 8,00 & 4,00 & 12,00 \\
Densidade $\left(\mathrm{kg} \cdot \mathrm{m}^{-1}\right)$ & 1000 & 1000 & 1000 & 1000 \\
Diâmetro dos tubos $(\mathrm{m})$ & 0,0292 & 0,0292 & 0,0292 & 0,0292 \\
Viscosidade $(\mathrm{Pa} . \mathrm{s})$ & 0,001 & 0,001 & 0,001 & 0,001 \\
Vazão $\left(\mathrm{m}^{3} \cdot \mathrm{s}^{-1}\right)$ & $1,33 \mathrm{E}-04$ & $1,33 \mathrm{E}-04$ & $6.67 \mathrm{E}-05$ & $2,00 \mathrm{E}-04$ \\
Velocidade $\left(\mathrm{m} \cdot \mathrm{s}^{-1}\right)$ & 0,1991 & 0,1991 & 0,0996 & 0,2987 \\
Número de Reynolds & 5814 & 5814 & 2907 & 8721 \\
Modelo de Escoamento & Laminar & $\mathrm{k}-\varepsilon$ & $\mathrm{k}-\varepsilon$ & $\mathrm{k}-\varepsilon$ \\
Passo de Tempo & $30 \mathrm{~s}$ & $30 \mathrm{~s}$ & $30 \mathrm{~s}$ & $30 \mathrm{~s}$ \\
\hline
\end{tabular}

\subsubsection{Campos de Velocidades e Pressão}

Os campos de velocidades e pressão para o escoamento laminar, com vazão de 0,845 L. $\mathrm{min}^{-1}$, na condição de regime permanente, são os apresentados na Figura 4.39.

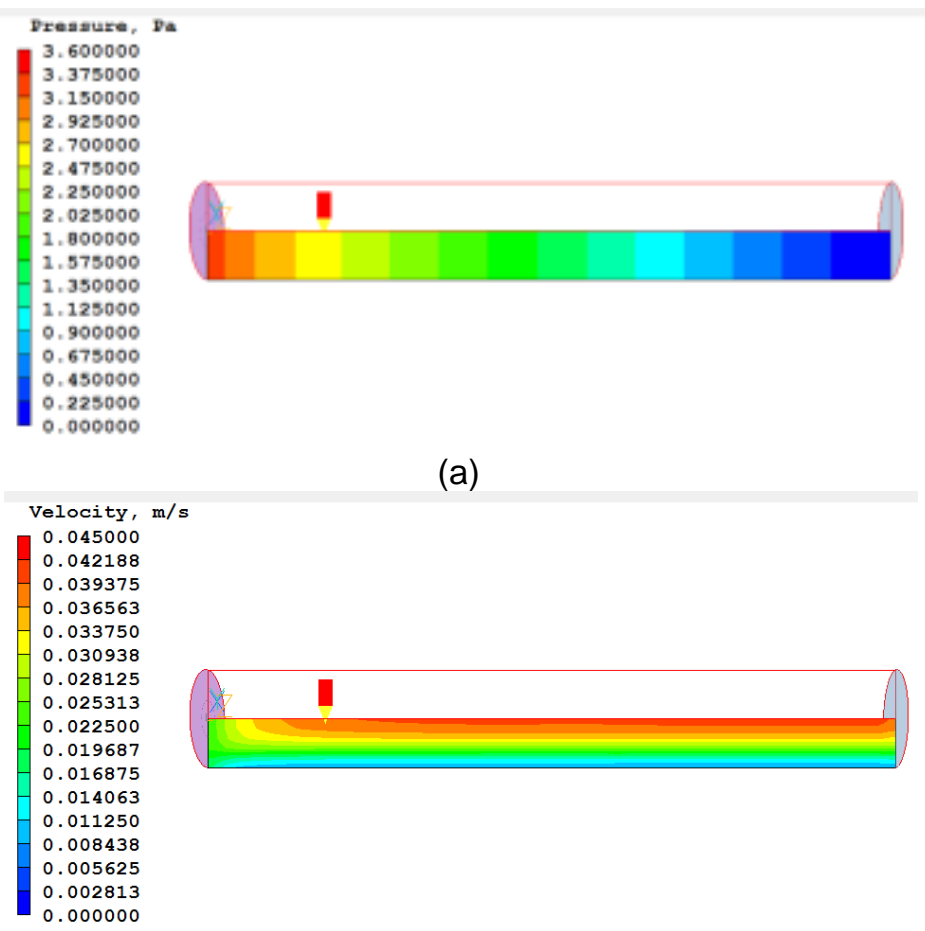

(b)

Figura 4.39 - Resultados obtidos para o escoamento laminarem tubo reto cilíndrico, utilizando a malha 2, para vazão de 0,845 L.min ${ }^{-1}$ : (a) Campo de pressão, (b) Campo de velocidades.

Para a vazão de 8 L. $\min ^{-1}$, modelo de turbulência k- $\varepsilon$, o campo de velocidade, na condição de regime permanente, é apresentado na Figura 4.40. 


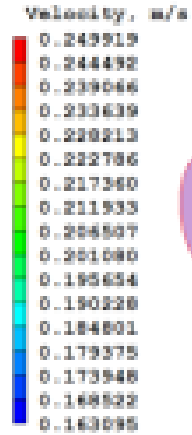

Figura 4.40 - Campo de velocidades obtido para o escoamento turbulento $(\mathrm{k}-\varepsilon)$, vazão de 8 L.min ${ }^{-1}$, utilizando a malha 2, para o tubo reto cilíndrico.

Para a vazão de 8 L. $\min ^{-1}$, modelo laminar, o campo de velocidade, na condição de regime permanente, é apresentado na Figura 4.41.

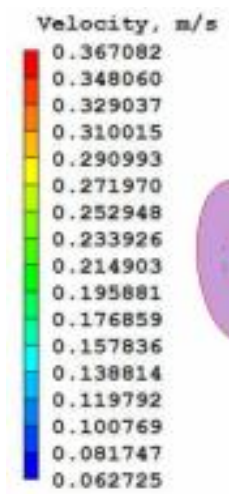

Figura 4.41 - Campo de velocidades obtido para o escoamento laminar, vazão de 8 L.min ${ }^{-1}$, utilizando a malha 2, para o tubo reto cilíndrico.

Para a vazão de 8 L.min ${ }^{-1}$, do modelo plug flow, o campo de velocidades, na condição de regime permanente, é apresentado na Figura 4.42.

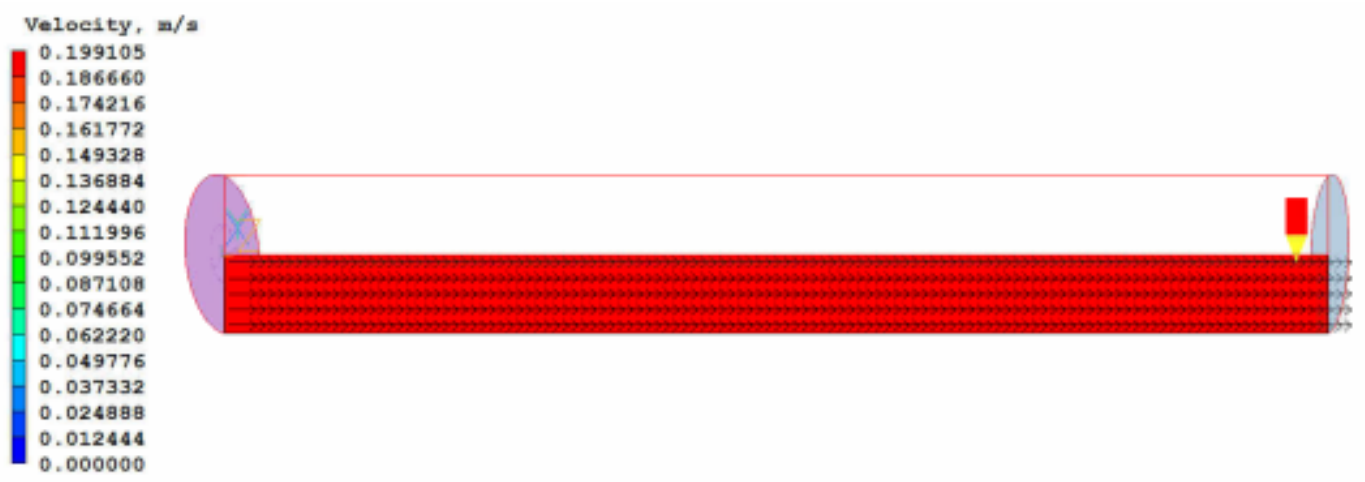

Figura 4.42 - Campo de velocidades para o escoamento plug-flow, vazão de 8 L. $\mathrm{min}^{-1}$, utilizando a malha 2 selecionada, para o tubo reto cilíndrico. 
Para a vazão de 4 L.min ${ }^{-1}$, no caso do modelo de turbulência k- $\varepsilon$, o campo de velocidades, na condição de regime permanente, é apresentado na Figura 4.43.

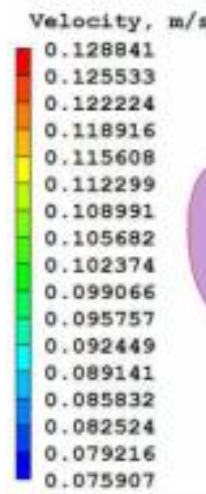

Figura 4.43 - Campo de velocidades para o escoamento turbulento $(k-\varepsilon)$, vazão de 4 L. $\min ^{-1}$, utilizando a malha 2 , para o tubo reto cilíndrico.

Para a vazão de 12 L.min ${ }^{-1}$, no caso modelo de turbulência $k-\varepsilon$, o campo de velocidades, na condição de regime permanente, é apresentado na Figura 4.44.

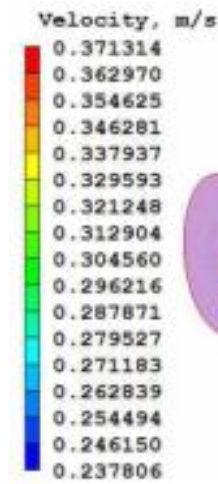

Figura 4.44 - Campo de velocidades para o escoamento turbulento $(k-\varepsilon)$, vazão de 12 L.min ${ }^{-1}$, utilizando a malha 2 , para o tubo reto cilíndrico.

\subsubsection{Distribuição do Tempo de Residência (DTR)}

Para as simulações realizadas citadas na Tabela 4-10, as curvas de distribuição de tempos de residência foram obtidas.

\subsubsection{Validação do Comprimento do Tubo}

Para a definição exata do comprimento do domínio que deveria ser utilizado para simular as reações de actinometria, alguns comprimentos de tubos foram simulados para comparação das curvas de distribuição de tempo de residência com 
a do o hairpin, conforme as condições expressas na Tabela 4-14.Essa análise comparativa para o caso laminar está ilustrada na Figura 4.45 e para o caso turbulento, na Figura 4.46.

Tabela 4-14 - Resumo das simulações realizadas para o tubo reto cilíndrico visando comparar diferentes comprimentos do domínio.

\begin{tabular}{ccc}
\hline Dado & $\mathbf{L}=\mathbf{5 , 0 9 7 7} \mathbf{~ m}$ & $\mathbf{L}=\mathbf{6 . 0 9 7 7} \mathbf{~ m}$ \\
\hline Vazão $\left(\mathrm{L} \cdot \mathrm{min}^{-1}\right)$ & 8,00 & 8,00 \\
Densidade $\left(\mathrm{kg} \cdot \mathrm{m}^{-1}\right)$ & 1000 & 1000 \\
Diâmetro dos tubos $(\mathrm{m})$ & 0,0292 & 0,0292 \\
Viscosidade $(\mathrm{Pa} \cdot \mathrm{s})$ & 0,001 & 0,001 \\
Vazão $\left(\mathrm{m}^{3} \cdot \mathrm{s}^{-1}\right)$ & $1,33 \mathrm{E}-04$ & $1,33 \mathrm{E}-04$ \\
Velocidade $\left({\left.\mathrm{m} . \mathrm{s}^{-1}\right)}^{\text {Nel }}\right)$ & 0,1991 & 0,1991 \\
Número de Reynolds & 5814 & 5814 \\
Modelo de Escoamento & Laminar & $\mathrm{k}-\varepsilon$ \\
Passo de Tempo & $1 \mathrm{~s}$ & $1 \mathrm{~s}$ \\
\hline
\end{tabular}

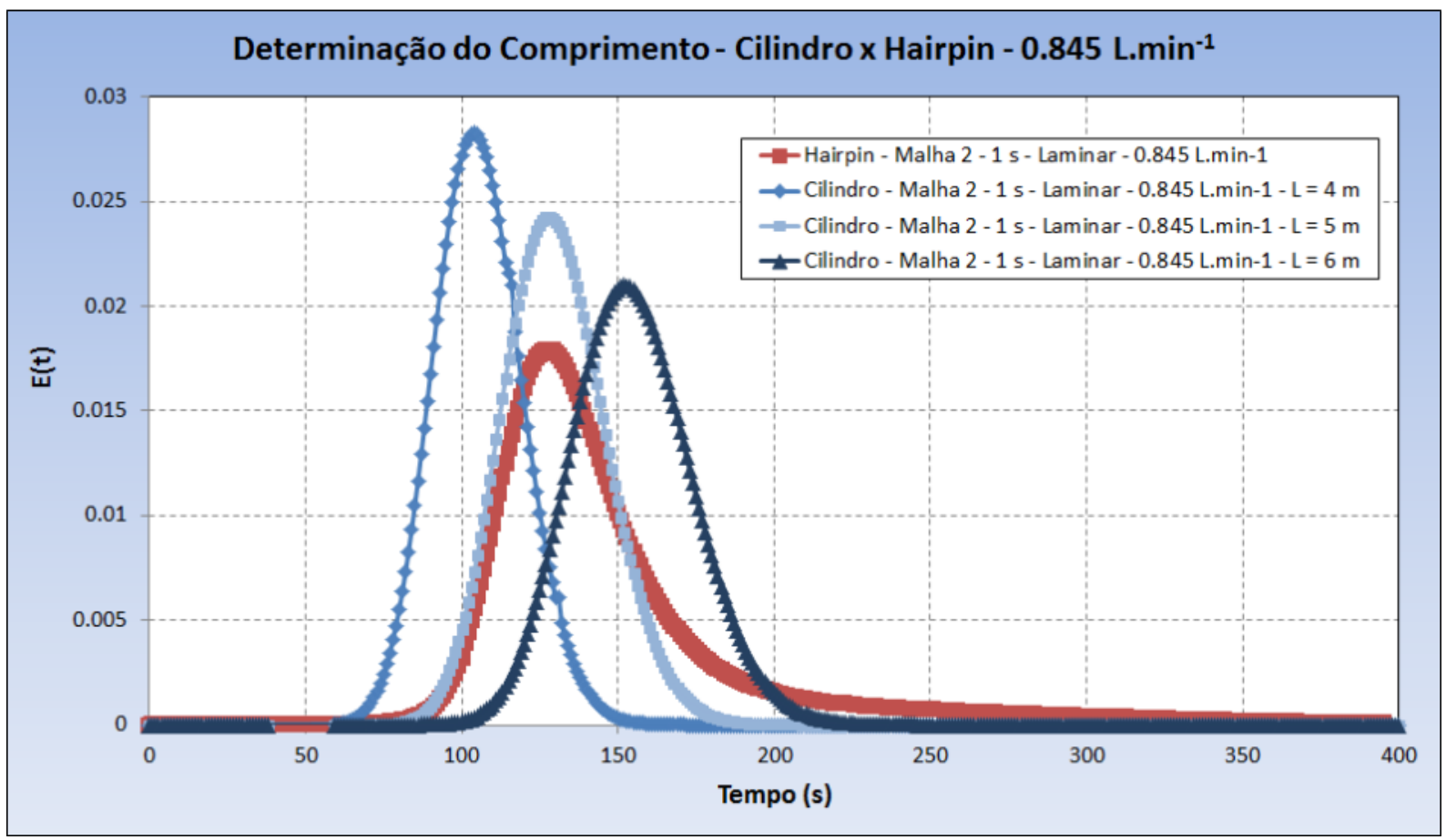

Figura 4.45 - Comparativo das curvas de distribuição do tempo de residência obtidas para escoamento laminar no tubo reto cilíndrico, para diferentes comprimentos do domínio, e a curva selecionada para o hairpin. 


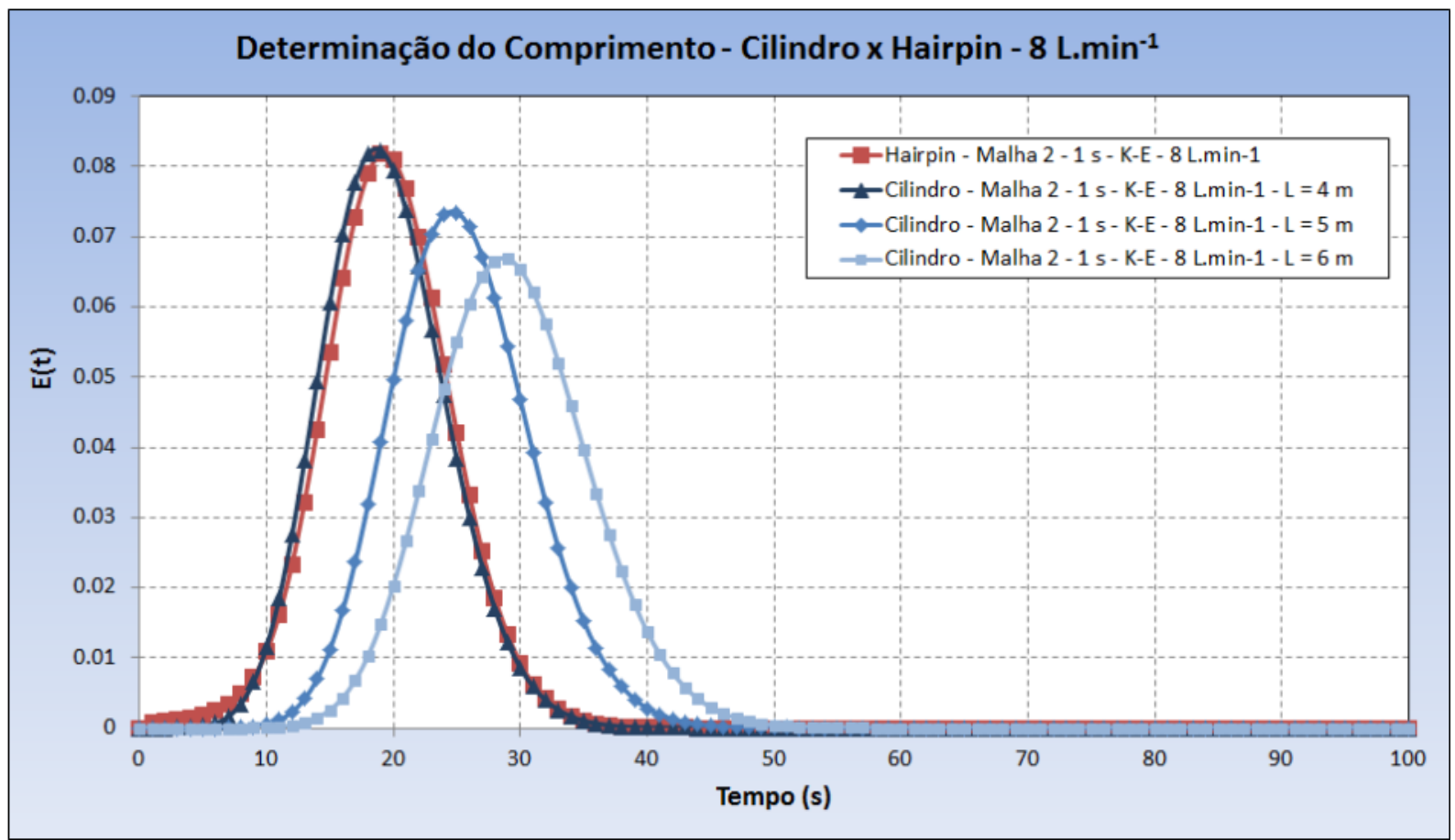

Figura 4.46 - Comparativo das curvas de distribuição do tempo de residência obtidas para escoamento turbulento $(k-\varepsilon)$ no tubo reto cilíndrico, para diferentes comprimentos do domínio, e a curva selecionada para o hairpin.

\subsubsection{DTR Selecionada}

A curva de distribuição de residência selecionada para o modelo laminar foi com a malha $2, \Delta t=1 \mathrm{~s} \mathrm{e} L=5 \mathrm{~m}$.

A mesma análise do item 4.1.5.3 foi feita para o escoamento laminar. A curva selecionada foi comparada com dois modelos teóricos de distribuição de tempo de residência em reatores: o modelo de dispersão de Taylor e o modelo de escoamento laminar (segregado). 


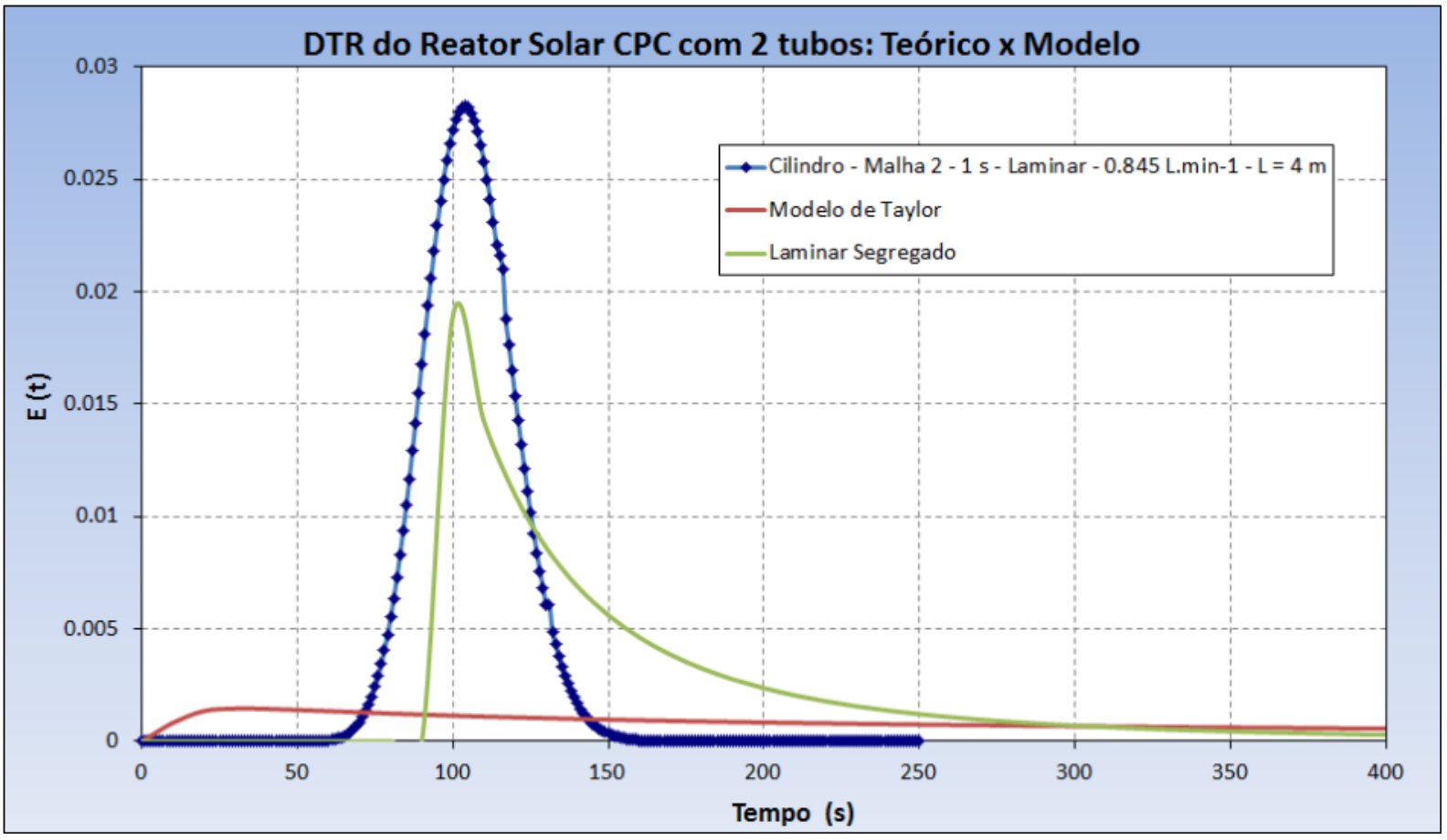

Figura 4.47 - Comparativo das curvas de distribuição do tempo de residência para o escoamento laminar no tubo reto cilíndrico: modelos teóricos e a curva selecionada do modelo.

A curva de distribuição de residência selecionada para o modelo turbulento foi com a malha 2 e $\Delta t=1 \mathrm{~s}$.

A curva experimental foi ajustada para um modelo semi-teórico, com parâmetros ajustados. Pelo modelo de tanques em série (Levenspiel, 2000), obtiveram-se: $\mathrm{Nt}=17,2$ e $\tau=19,86$ s. Essa comparação pode ser vista na Figura 4.48. 


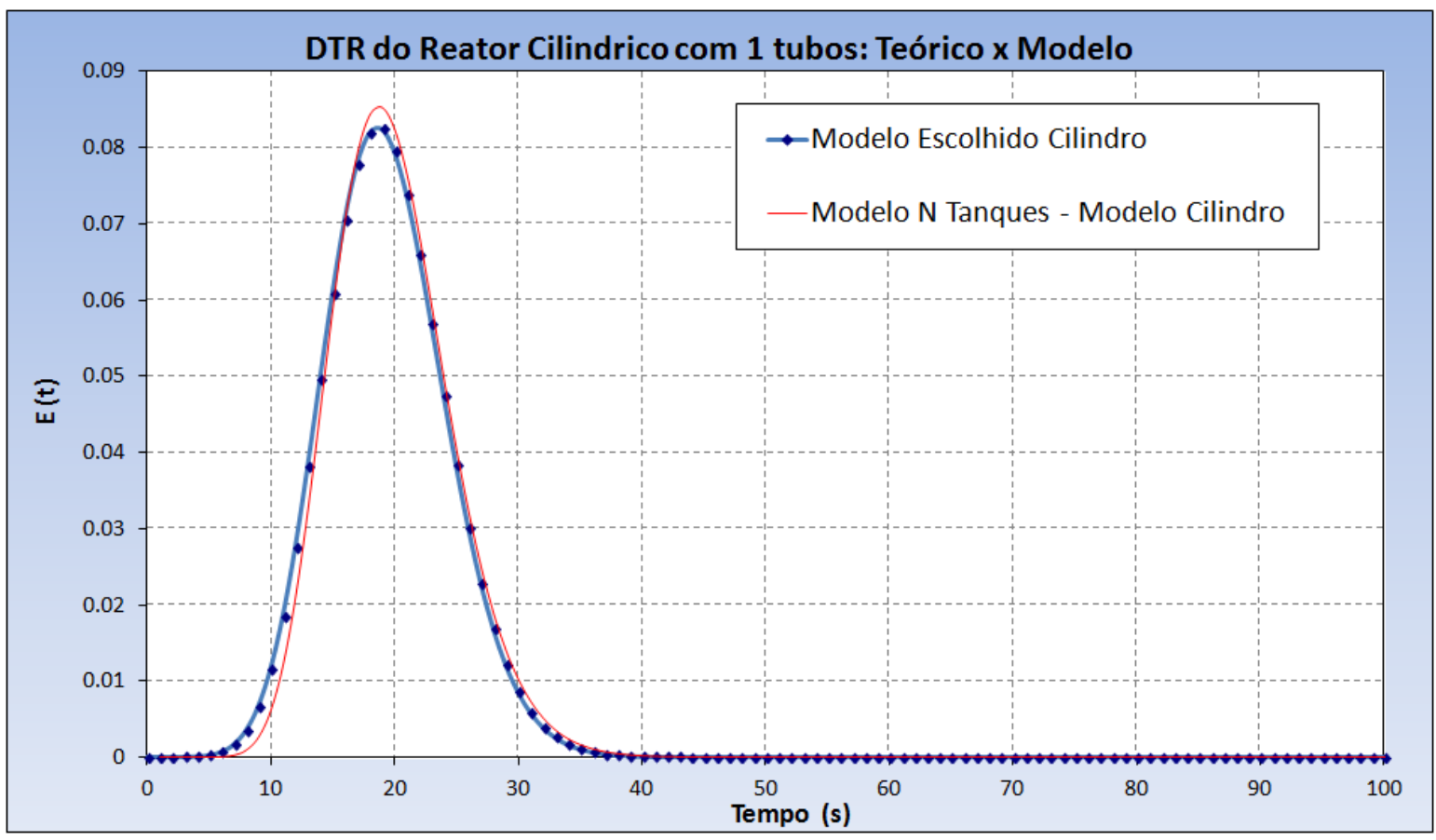

Figura 4.48 - Comparativo das curvas de distribuição do tempo de residência para o escoamento turbulento $(\mathrm{K}-\varepsilon)$ no tubo reto cilíndrico entre a curva do modelo semi-teórico e a curva selecionada do modelo.

\subsubsection{Discussão de resultados - Tubo cilíndrico}

Comparando-se os resultados de DTR para o Cilindro e para o Hairpin, podese concluir que a geometria pode ser aproximada para o tubo cilíndrico, conforme a Figura 4.49, desde que seja utilizado o modelo laminar, para a vazão de 0,845 L.min ${ }^{1}$, com comprimento de tubo igual a $5 \mathrm{~m}$ e passo de tempo de $1 \mathrm{~s}$. 


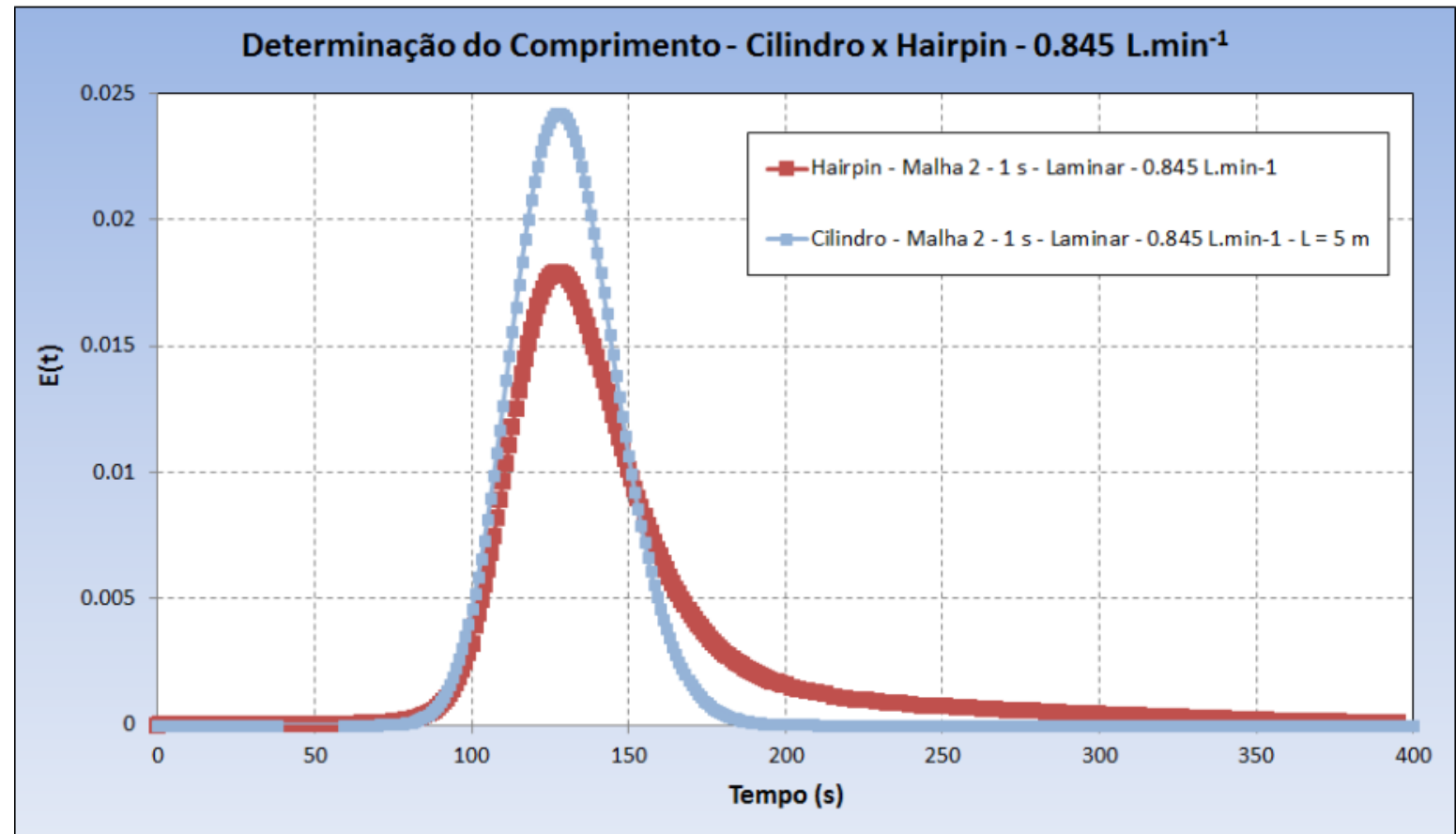

Figura 4.49 - Comparativo das curvas de distribuição do tempo de residência para o escoamento laminar no tubo reto cilíndrico e no hairpin.

Comparando-se os resultados de DTR para o Cilindro e para o Hairpin, para a vazão de $8 \mathrm{~L} \cdot \mathrm{min}^{-1}$, pode-se concluir que a geometria pode ser aproximada para o tubo cilíndrico, conforme a Figura 4.50, desde que seja utilizado o modelo $k-\varepsilon$, o comprimento de tubo igual a $4 \mathrm{~m}$ e passo de tempo de $1 \mathrm{~s}$. Pelo modelo de tanques em série, os valores de $\mathrm{Nt}$ para o hairpin $(\mathrm{Nt}=17,2)$ e o tubo cilíndrico de $4 \mathrm{~m}$ foram muitos próximos $(\mathrm{Nt}=17,2)$. 


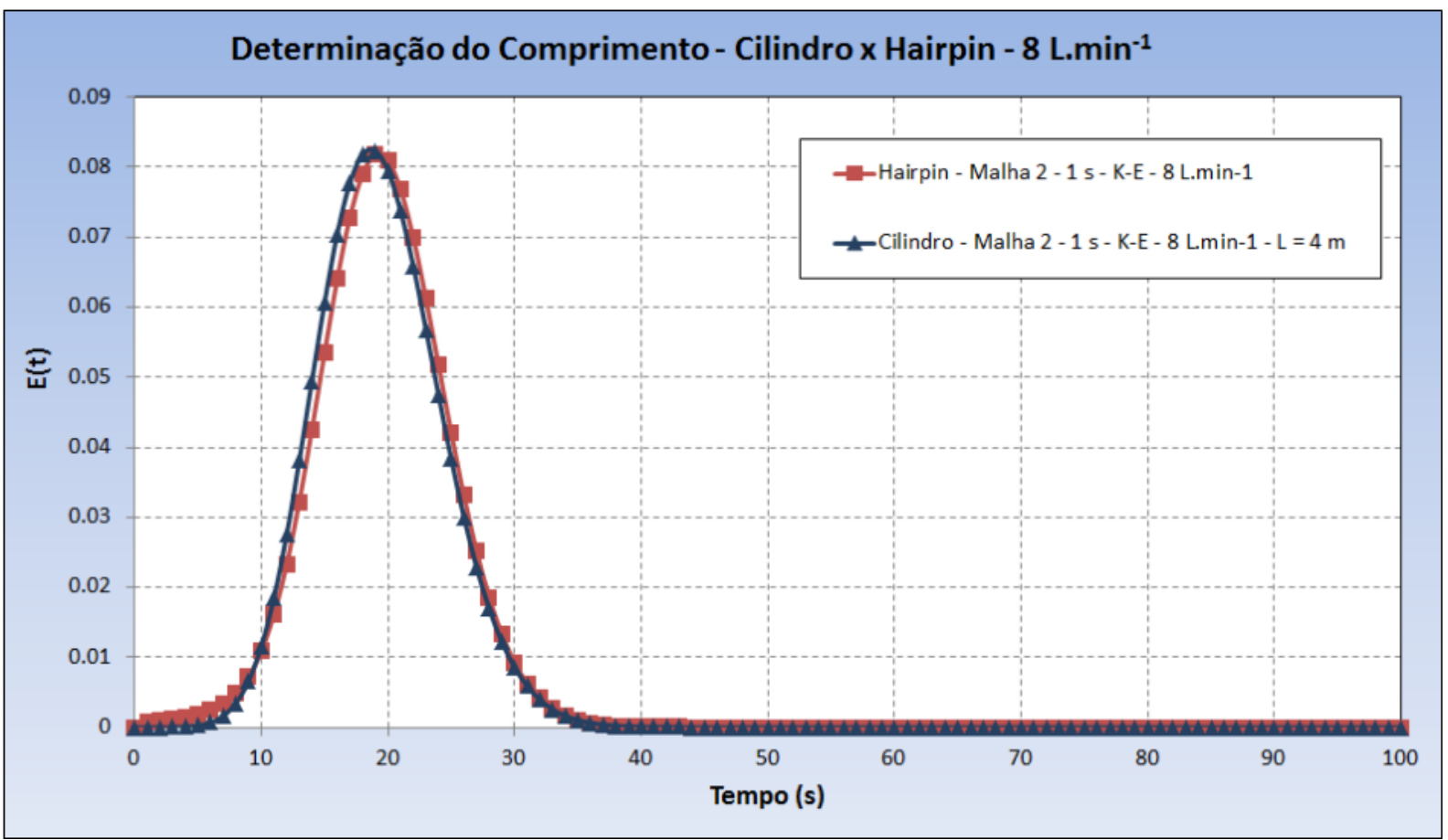

Figura 4.50 - Comparativo das curvas de distribuição do tempo de residência para o escoamento turbulento $(k-\varepsilon)$ no tubo reto cilíndrico e no hairpin. 


\section{RESULTADOS DA MODELAGEM MATEMÁTICA DO REATOR FOTOQUÍMICO - ACTINOMETRIA}

Este capítulo apresenta os resultados da modelagem matemática descrita no item 3.4, referente ao cálculo da radiação incidente. Neste capítulo, para uma melhor visualização dos campos de radiação e das concentrações ao longo do reator cilíndrico, as figuras apresentadas utilizam um fator de aumento de 100 vezes na direção radial.

\subsection{MODELO CINÉTICO}

\subsubsection{Dados Experimentais}

De acordo com o item 3.4, dados experimentais de actinometria obtidos por RIBEIRO et al (2009) foram utilizados para o cálculo da radiação incidente no reator. As condições e os resultados experimentais estão apresentados na Tabela 5-1 e Figura 5.1, respectivamente.

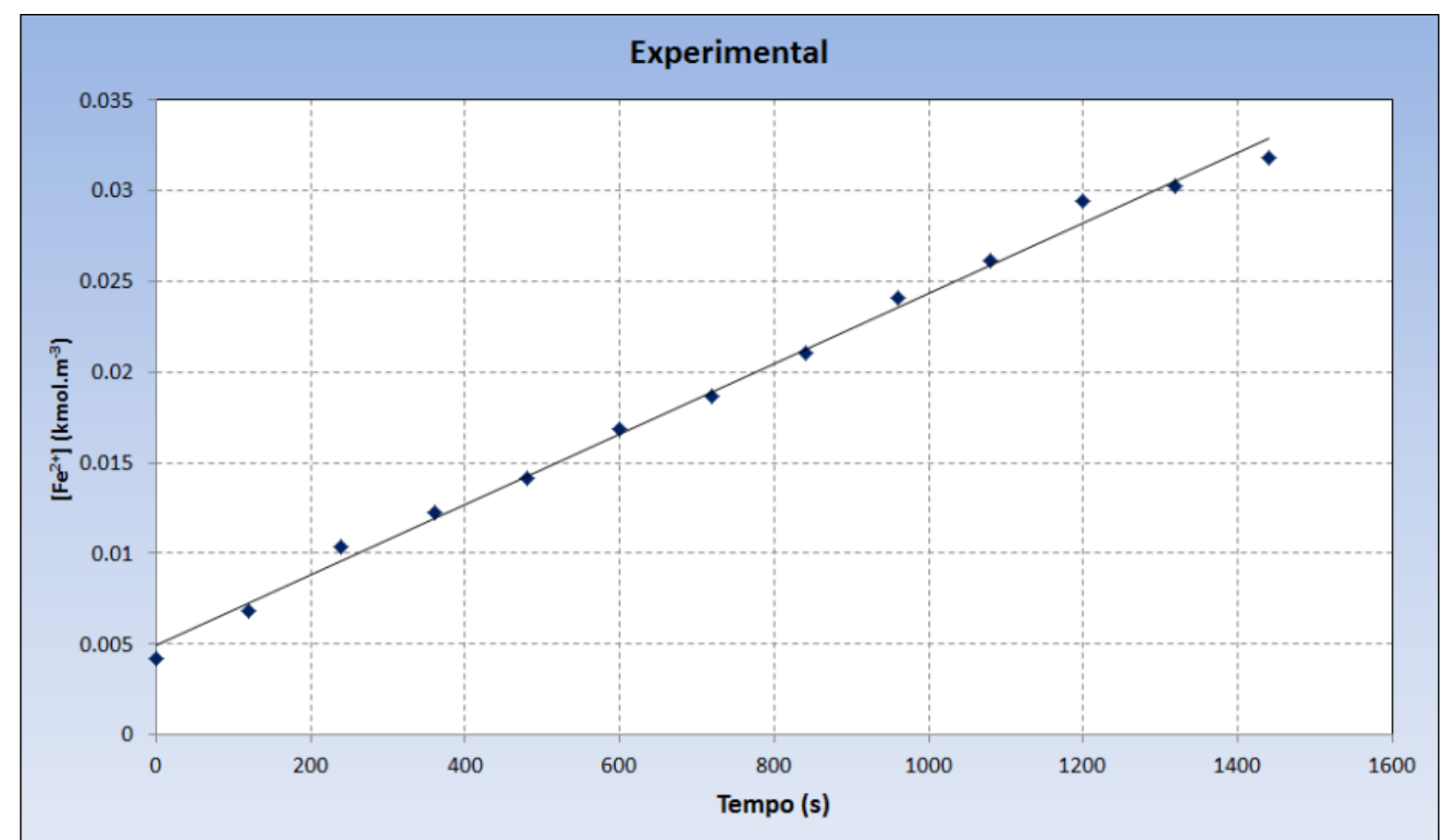

Figura 5.1 - Curva obtida experimentalmente por RIBEIRO et al 2009, mostrando a concentração de $\mathrm{Fe}^{2+}$ em função do tempo. 
Os dados experimentais utilizados estão mostrados na Tabela 5-1.

Tabela 5-1 - Dados experimentais utilizados no modelo implementado no PHOENICS.(RIBEIRO , 2009).

\begin{tabular}{ccc}
\hline Variável & Valor & Unidade \\
\hline$\left[\mathrm{Fe}^{3+}\right]_{t=0}$ & 0,15 & $\mathrm{kmol} . \mathrm{m}^{-3}$ \\
{$\left[\mathrm{Fe}^{2+}\right]_{t=0}$} & $4,242 \cdot 10^{-3}$ & $\mathrm{kmol} \cdot \mathrm{m}^{-3}$ \\
$V_{T}$ & $2,29 \cdot 10^{-3}$ & $\mathrm{~m}^{3}$ \\
$G_{v}$ Incidente & $6,0509 \cdot 10^{-4}$ & einstein. $\mathrm{s}^{-1} \cdot \mathrm{m}^{-2}$ \\
\hline
\end{tabular}

\subsubsection{Modelo e Condições de Contorno}

Os campos de pressão e velocidades utilizados para as simulações dos modelos cinéticos foram os apresentados no item 4.3.5. No entanto, foi necessário e emprego de uma malha mais refinada para a simulação do modelo cinético e de radiação, de forma a satisfazer o critério: $\alpha \cdot \Delta y \cdot\left[\mathrm{Fe}^{3+}\right]<1$.

Por outro lado, esta malha mais refinada não é adequada para a simulação do campo de pressões e velocidades, principalmente, devido à lei de parede. Sendo assim, a simulação foi realizada a partir dos resultados dos campos de velocidade obtidos no item 4.3.5, que são, então, transpostos para a malha refinada a partir de uma sub-rotina de interpolação destes campos. Portanto, a malha destas simulações não foi definida a partir de um teste de malha como nos itens anteriores, e, sim, selecionada a partir de restrições do modelo cinético do item 3.4.1. Apresentam-se, na Tabela 5-3, os dados referentes às condições básicas da simulação e características da malha empregada. Os outros dados de entrada utilizados na simulação estão apresentados na Tabela 5-1.

Tabela 5-2 - Condições de contorno e dados de entrada das simulações do modelo cinético.

\begin{tabular}{ccc}
\hline Variável & Valor & Unidade \\
\hline$\alpha$ & $5,17 \cdot 10^{3}$ & $\mathrm{~m}^{2} \cdot \mathrm{kmol}^{-1}$ \\
$\Phi_{A c}$ & $1,04 \cdot 10^{-4}$ & $\mathrm{kmol}^{-}$einstein \\
IX & 2 & - \\
IY & 100 & - \\
IZ & 120 & - \\
Número de Elementos & 24000 & - \\
$\Delta \mathrm{t}$ & 30 & $\mathrm{~s}$ \\
$\mathrm{y}$ & $1,46.10^{-4}$ & $\mathrm{~m}$ \\
$v_{z_{z}=0}$ & 0,1991 & $\mathrm{~m} \cdot \mathrm{s}^{-1}$ \\
$\dot{q}$ & $1,33 \cdot 10^{-4}$ & $\mathrm{~m}^{3} \cdot \mathrm{s}^{-1}$ \\
\hline
\end{tabular}




\subsubsection{Simulações Realizadas}

Para o estudo dos modelos cinéticos, as simulações foram realizadas com as variáveis de entrada da Tabela 5-2, variando-se o ajuste matemático do modelo cinético, ou seja, foram executadas três simulações, a saber: modelo cinético $1^{\underline{a}}$. ordem, modelo cinético de 4⿳亠丷a . ordem e modelo cinético exponencial.

O desenvolvimento do modelo cinético, assim como, os ajustes necessários para a implementação do modelo, foram apresentados no item 3.4.1.

\subsubsection{Discussão dos Resultados}

O campo de radiação, no caso do modelo de incidência radial, aqui adotado, varia intensamente com a posição radial. Sendo, porém, atenuado devido à absorção. A Figura 5.2 apresenta o campo de radiação radial teórico calculado pelo programa de simulação, para a região interna do reator, mas na ausência de absorção da radiação, para uma dada radiação, $\mathrm{G}_{v}$, incidente na parede externa do reator.
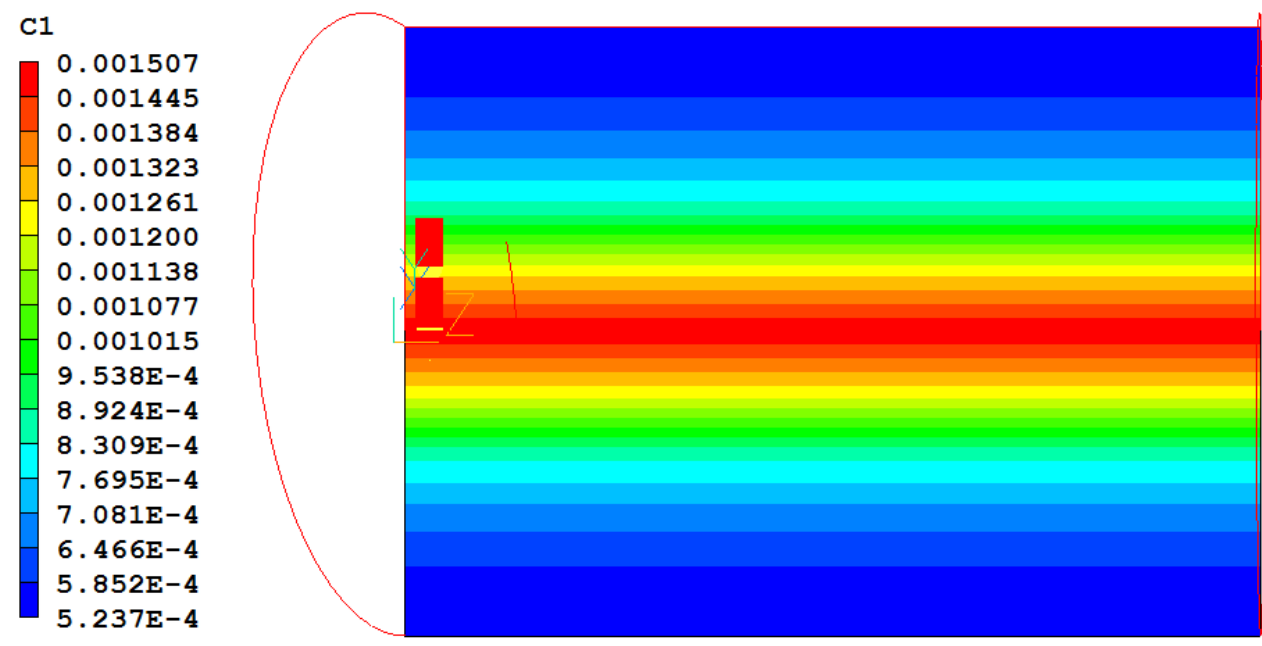

Figura 5.2 - Campo de radiação para o modelo de incidência radial, para $G_{v}=6,0509 \cdot 10^{-4}$ einstein.s ${ }^{1} \cdot \mathrm{m}^{-2}$, sem absorção da radiação.

Investigaram-se os modelos matemáticos considerados, cujos erros no balanço de massa estão apresentados na Figura 5.4. Este erro é um importante indicativo da qualidade dos resultados obtidos por simulação. Ressalta-se, que este erro está expresso como a diferença entre a concentração total calculada, $\left[\mathrm{Fe}^{2+}\right]+$ $\left[\mathrm{Fe}^{3+}\right]$, e o seu valor estequiométrico $0,154 \mathrm{kmol} \cdot \mathrm{m}^{-3}$, que deve ser constante ao longo de toda a simulação. 
A partir desta análise, optou-se pela utilização do modelo linear, acoplado a uma malha mais refinada, que apresentou um baixo erro no balanço de massa e um campo de radiação bastante próximo do modelo exponencial, como pode ser observado na Figura 5.3 e na Figura 5.4.
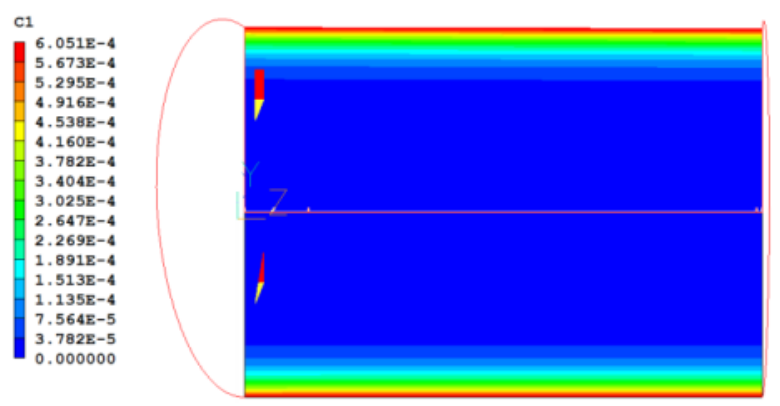

(a)

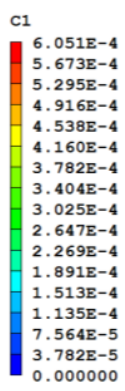

$0.782 \mathrm{E}-5$

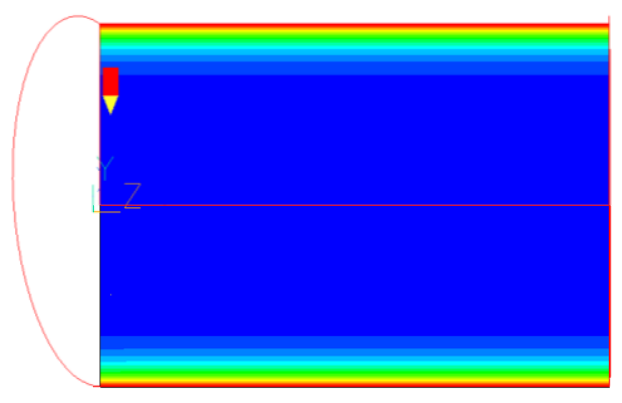

(b)

Figura 5.3 - Comparativo do campo de radiação para o: (a) Modelo cinético de 1a. ordem e (b) Modelo cinético exponencial.

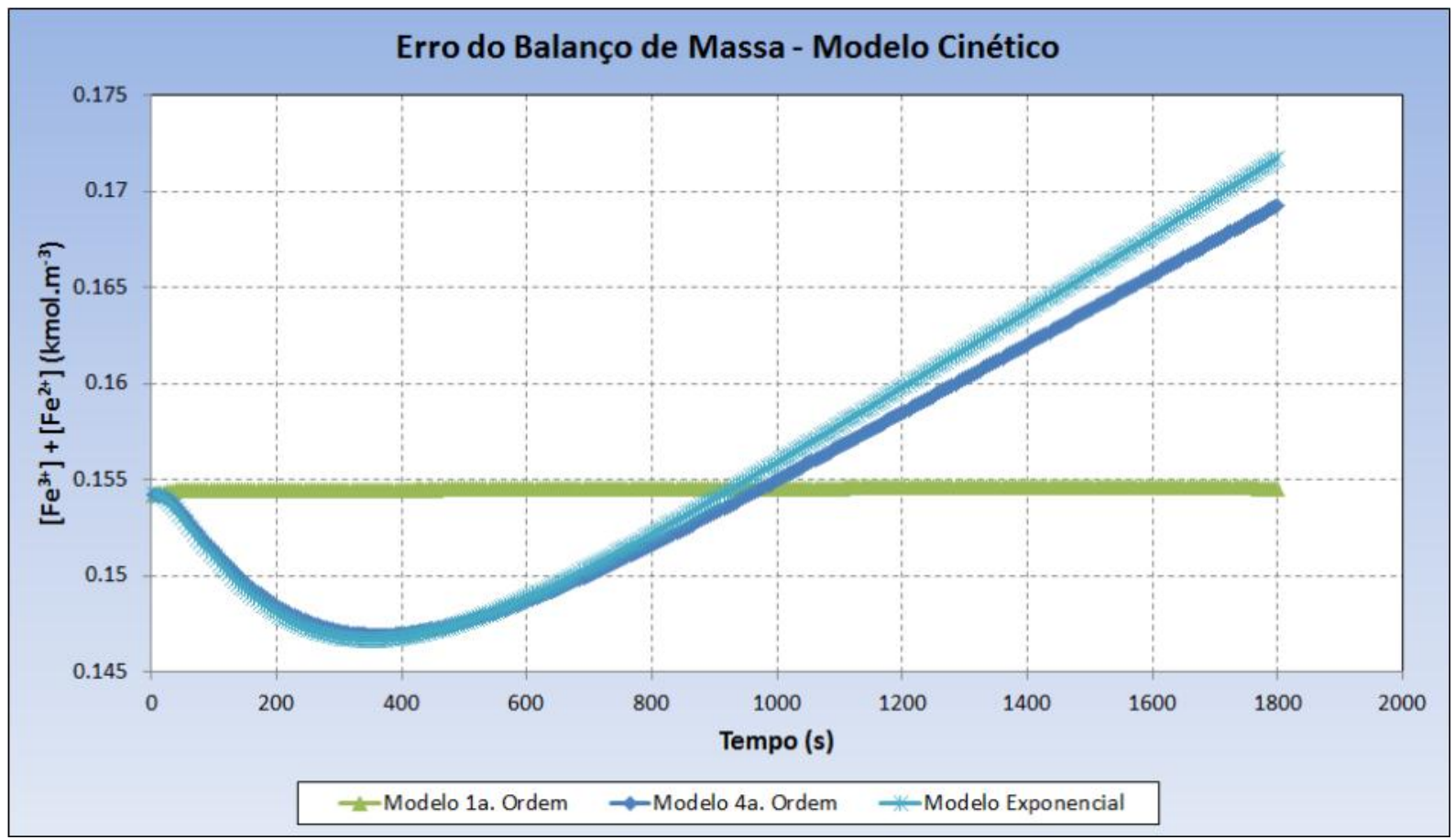

Figura 5.4 - Comparação dos erros do balanço de massa para os diferentes modelos cinéticos ajustados.

\subsection{DETERMINAÇÃO DA RADIAÇÃO INCIDENTE $G_{v}$}

\subsubsection{Modelo e Condições de Contorno}

Os campos de pressão e velocidades utilizados para as simulações dos modelos cinéticos foram os apresentados no item 4.3.5. 
No entanto, conforme discutido no item 5.1.3.1, foi necessário o emprego de uma malha ainda mais refinada para a simulação do modelo cinético e de radiação.

Por outro lado, esta malha mais refinada também não é adequada para a simulação do campo de pressões e velocidades. Então, foi empregado o mesmo procedimento descrito no item 5.1.2. Portanto, a malha destas simulações não foi definida a partir de um teste de malha como nos itens anteriores. A malha foi selecionada a partir de restrições do modelo cinético do item 3.4.1. Apresentam-se, na Tabela 5-3 os dados referentes às condições básicas da simulação e características da malha empregada. Os outros dados de entrada utilizados na simulação são os apresentados na Tabela 5-1.

Tabela 5-3 - Condições de contorno e dados de entrada das simulações para determinação do $G_{v}$.

\begin{tabular}{ccc}
\hline Variável & Valor & Unidade \\
\hline$\alpha$ & $5,17 \cdot 10^{4}$ & $\mathrm{~m}^{2} \cdot \mathrm{kmol}^{-1}$ \\
$\Phi_{A c}$ & $1,04 \cdot 10^{-4}$ & $\mathrm{kmol}^{-1}$ einstein \\
IX & 2 & - \\
IY & 200 & - \\
IZ & 120 & - \\
Número de Elementos & 48000 & - \\
$\Delta \mathrm{t}$ & 30 & $\mathrm{~s}$ \\
$\mathrm{y}$ & $7,3.10^{-5}$ & $\mathrm{~m}$ \\
$v_{z_{z=0}}$ & 0,1991 & $\mathrm{~m}^{-1} \mathrm{~s}^{-1}$ \\
$\dot{q}$ & $1,33 \cdot 10^{-4}$ & $\mathrm{~m}^{3} \cdot \mathrm{s}^{-1}$ \\
\hline
\end{tabular}

\subsubsection{Cálculo da Radiação Incidente Gv}

Neste item, realizaram-se simulações nas condições descritas no item 5.2.1, para o cálculo da radiação incidente no reator, considerando-se a reação de actinometria. Adotando-se diferentes valores para a radiação incidente, a cada simulação, calculou-se a curva de concentração de $\mathrm{Fe}^{+2}$ no tanque de recirculação, em função do tempo. Os resultados obtidos foram então comparados com os resultados experimentais obtidos por RIBEIRO (2009). O procedimento foi repetido até a obtenção do melhor ajuste, determinando-se, assim, a radiação incidente.

Apresentam-se, na Figura 5.5, as curvas de concentração de $\mathrm{Fe}^{+2}$ no tanque de recirculação, em função do tempo, para diferentes valores de $G_{v}$, partindo-se do valor inicial $6,0509 \cdot 10^{-4}$ einstein. $\mathrm{s}^{-1} \cdot \mathrm{m}^{-2}$. O valor calculado, pela inclinação da reta de melhor ajuste aos dados experimentais, foi $G_{v}=3,1054.10^{-4}$ einstein. $\mathrm{s}^{-1} \cdot \mathrm{m}^{-2}$. 
Os resultados para o campo de radiação são apresentados na Figura 5.6, para $\mathrm{G}_{v}=6,0509 \cdot 10^{-4}$ einstein. $\mathrm{s}^{-1} \cdot \mathrm{m}^{-2}$. Na Figura 5.7 , são ilustrados os resultados das concentrações de $\mathrm{Fe}^{+3}$ e $\mathrm{Fe}^{+2}$ calculadas, para este caso. Constata-se que praticamente toda a radiação é absorvida em região muito próxima da parede, onde efetivamente ocorre a reação de consumo de $\mathrm{Fe}^{+3} \mathrm{e}$ formação $\mathrm{Fe}^{+2}$. Com o decorrer do tempo, apesar do aumento da concentração de $\mathrm{Fe}^{+2}$, nota-se que o perfil desta apresenta praticamente o mesmo padrão ao longo do reator.

De forma similar, a Figura 5.8 e Figura 5.9 apresentam os resultados obtidos para uma radiação incidente $G_{v}=3,1054 \cdot 10^{-4}$ einstein. $\mathrm{s}^{-1} \cdot \mathrm{m}^{-2}$. Observa-se que o comportamento é muito parecido com o caso $G_{v}=6,0509 \cdot 10^{-4}$ einstein. $\mathrm{s}^{-1} \cdot \mathrm{m}^{-2}$, mas, obviamente com valores inferiores à este.

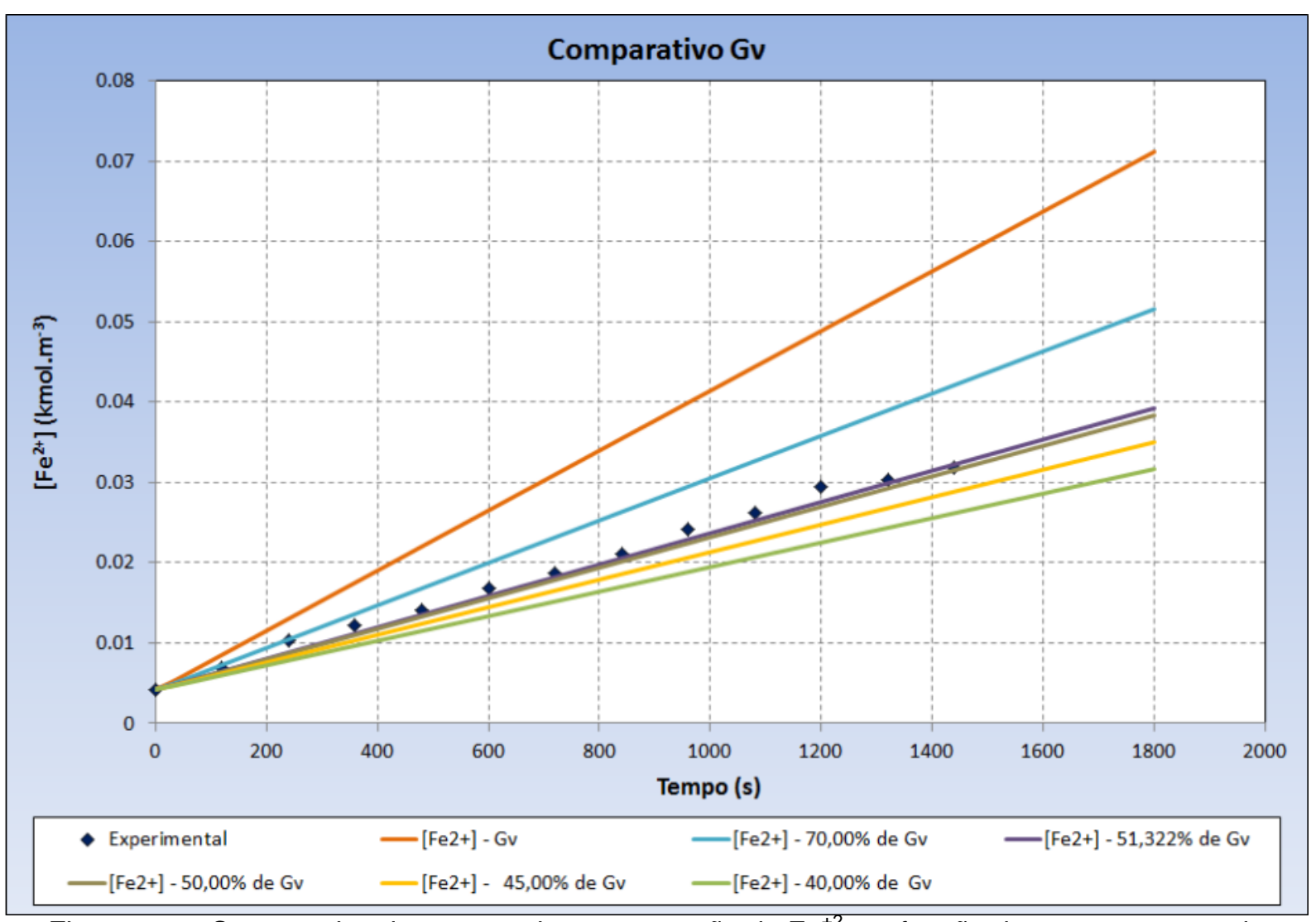

Figura 5.5 - Comparativo das curvas de concentração de $\mathrm{Fe}^{+2}$ em função do tempo, mostrando resultados experimental e calculados para diferentes valores de $G_{v}$. 

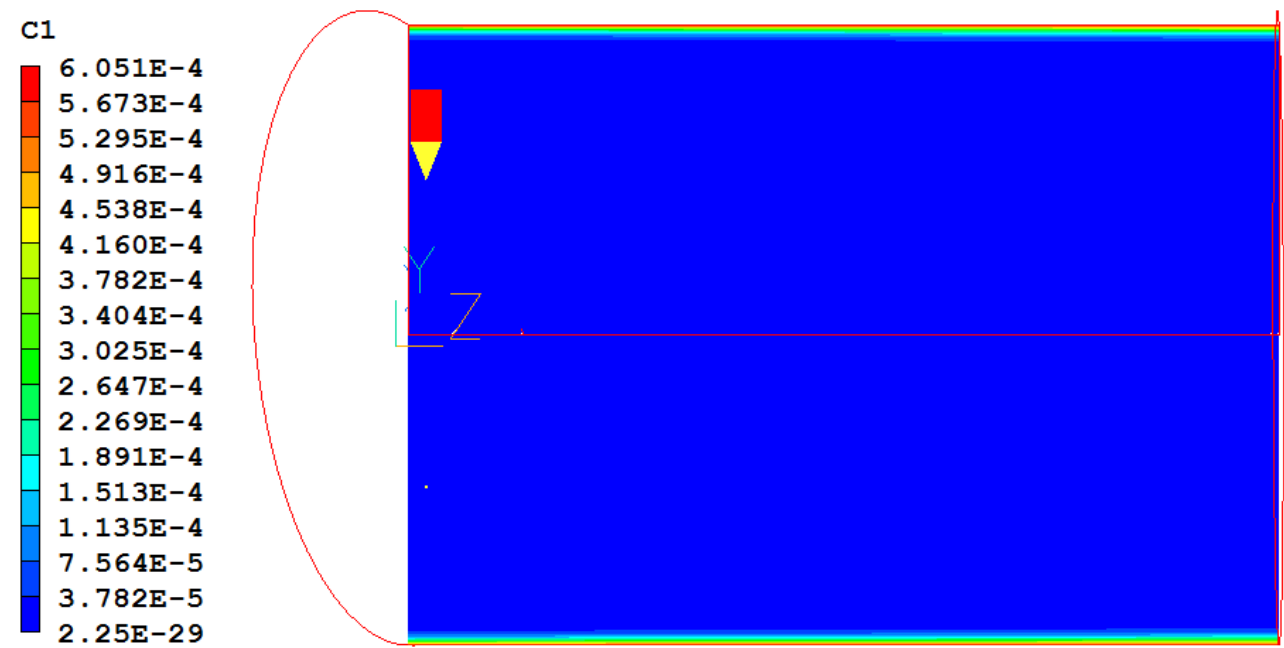

Figura 5.6 - Campo de radiação obtido para $G_{v}=6,0509 \cdot 10^{-4}$ einstein $\cdot \mathrm{s}^{-1} \cdot \mathrm{m}^{-2}$, no instante $\mathrm{t}=1800 \mathrm{~s}$.
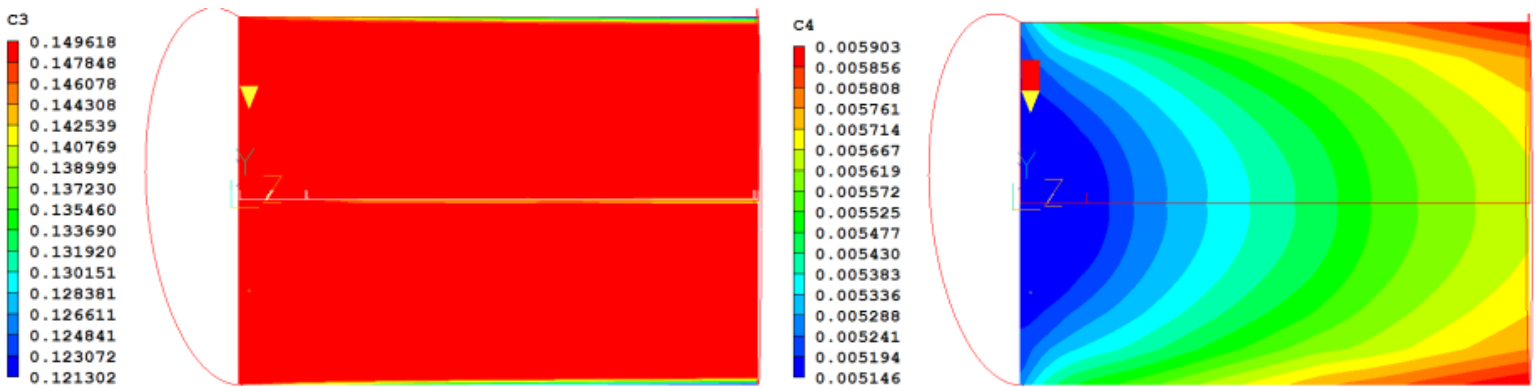

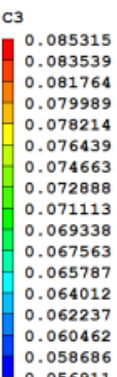

(a)

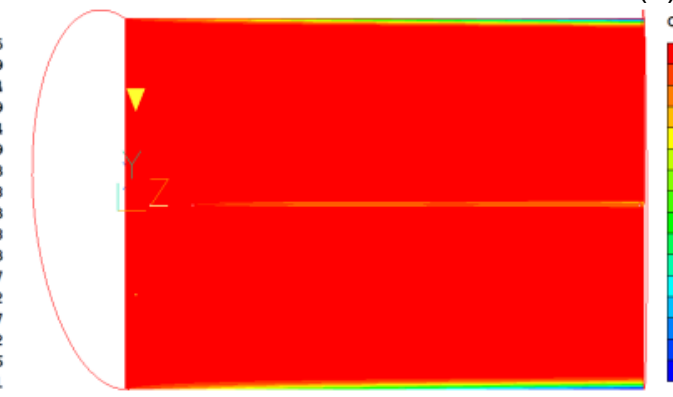

C4
0.071990
0.071936
0.071883
0.071829
0.071775
0.071721
0.071667
0.071614
0.071560
0.071506
0.071452
0.071399
0.071345
0.071291
0.071237
0.071183
0.071130

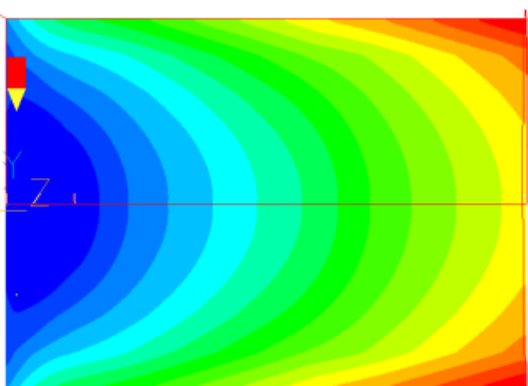

(b)

Figura 5.7 - Concentração de $C 3=F e^{3+}$ e $C 4=F e^{2+}$ para $G_{v}=6,0509 \cdot 10^{-4}$ einstein. $\mathrm{s}^{-1} \cdot \mathrm{m}^{-2}$, nos instantes: (a) $t=30 \mathrm{se}(\mathrm{b}) \mathrm{t}=1800 \mathrm{~s}$. 

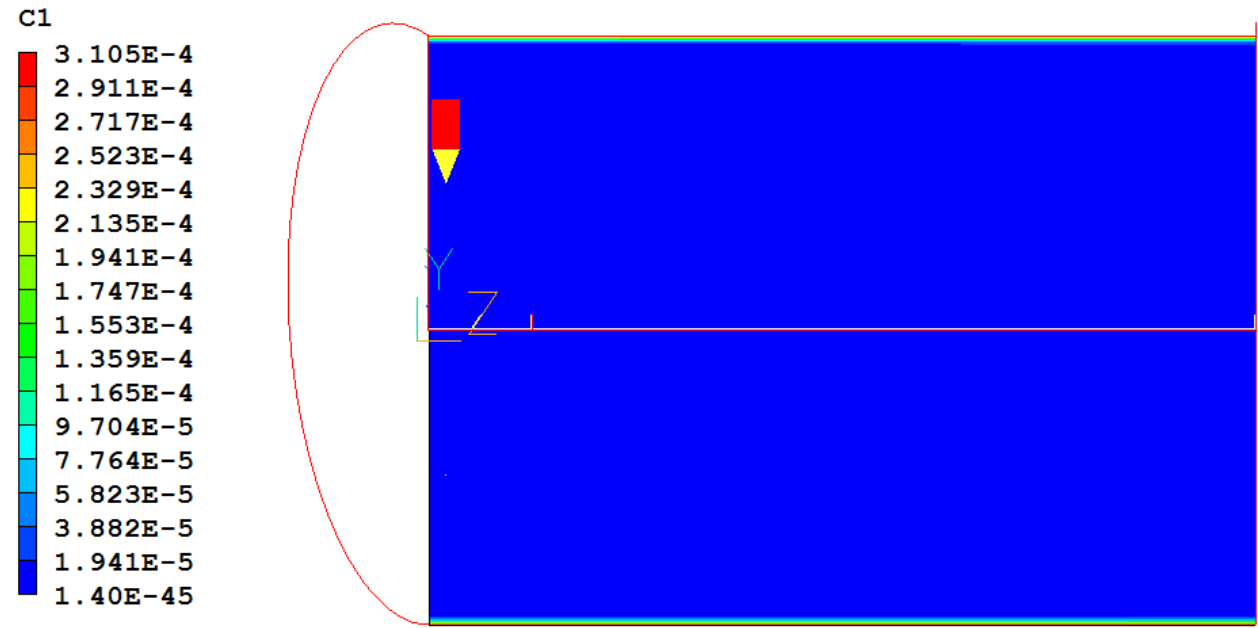

Figura 5.8 - Campo de radiação obtido para $G_{v}=3,1054 \cdot 10^{-4}$ einstein $\cdot \mathrm{s}^{-1} \cdot \mathrm{m}^{-2}$, no instante $\mathrm{t}=1800 \mathrm{~s}$.
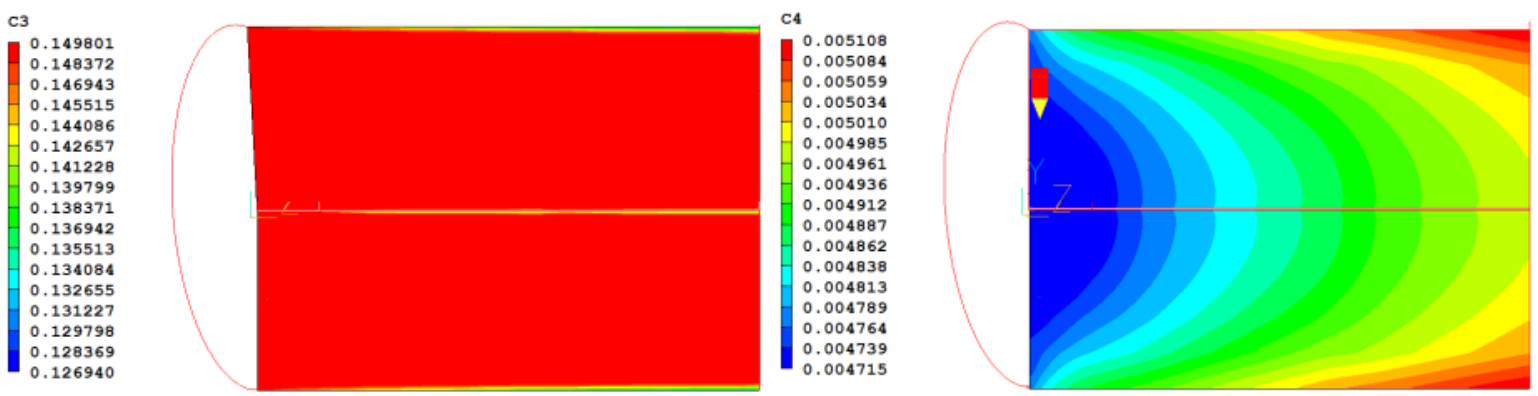

(a)
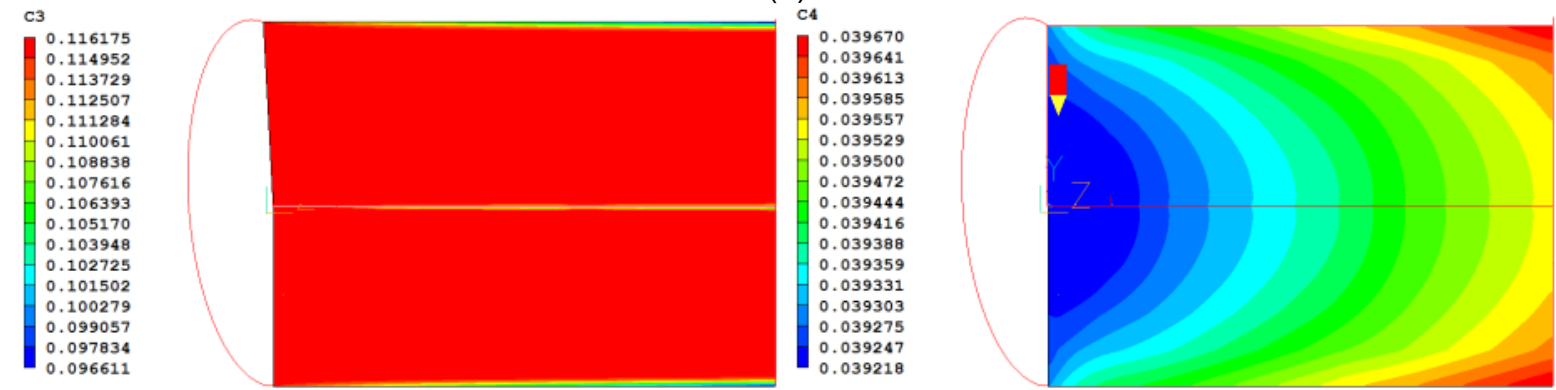

(b)

Figura 5.9 - Concentração de $C 3=F e^{3+}$ e $C 4=F e^{2+}$ para $G_{v}=3,1054 \cdot 10^{-4}$ einstein..$^{-1} \cdot \mathrm{m}^{-2}$, nos instantes: (a) $t=30$ s e (b) $t=1800$ s.

\subsection{ANÁLISE PARAMÉTRICA}

Após a determinação da radiação incidente, $G_{v}=3,1054 \cdot 10^{-4}$ einstein. $\mathrm{s}^{-1} \cdot \mathrm{m}^{-2}$, uma análise paramétrica foi feita para analisar a influência dos seguintes aspectos do processo:

- Coeficiente neperiano de absorção molar;

- Modelo de Incidência de radiação;

- Modelo de escoamento. 


\subsubsection{Coeficiente Neperiano de Absorção Molar}

Realizaram-se as simulações nas condições descritas no item 5.3.1.1, para analisar a influência do coeficiente neperiano de absorção molar no modelo da actinometria.

\subsubsection{Modelo e Condições de Contorno}

Consideraram-se os mesmos campos de pressão e velocidades do item 4.3.5, e a malha utilizada foi a mesma do item 5.2.1. Apresentam-se, na Tabela 5-4 os dados referentes às condições básicas da simulação. Os demais dados de entrada utilizados na simulação são os apresentados na Tabela 5-1.

Tabela 5-4 - Condições de contorno e dados de entrada das simulações para a análise da influência do coeficiente neperiano de absorção molar.

\begin{tabular}{ccc}
\hline Variável & Valor & Unidade \\
\hline$\Phi_{A c}$ & $1,04.10^{-4}$ & kmol.einstein $^{-1}$ \\
IX & 2 & - \\
IY & 200 & - \\
IZ & 120 & - \\
Número de Elementos & 48000 & - \\
$\Delta \mathrm{t}$ & 30 & $\mathrm{~s}$ \\
$\mathrm{y}$ & $1,46.10^{-4}$ & $\mathrm{~m}$ \\
$v_{z_{Z}=0}$ & 0,1991 & $\mathrm{~m}^{-1}$ \\
$\dot{q}$ & $1,33 \cdot 10^{-4}$ & $\mathrm{~m}^{3} \cdot \mathrm{s}^{-1}$ \\
\hline
\end{tabular}

\subsubsection{Simulações Realizadas}

Alguns valores de coeficiente neperiano de absorção molar foram investigados, sendo executadas quatro simulações:

Tabela 5-5 - Simulações realizadas para a análise da influência do coeficiente neperiano de absorção molar.

\begin{tabular}{cc}
\hline $\begin{array}{c}\text { Absorção molar } \\
\left(\mathbf{m}^{2} \cdot \mathbf{k m o l}^{-1}\right)\end{array}$ & $\begin{array}{c}\text { Valor em relação } \\
\mathbf{a} \alpha\end{array}$ \\
\hline $5,17 \cdot 10^{4}$ & $\alpha$ \\
$5,17 \cdot 10^{6}$ & $100 \alpha$ \\
$5,17 \cdot 10^{5}$ & $10 \alpha$ \\
$5,17 \cdot 10^{3}$ & $0,1 \alpha$ \\
\hline
\end{tabular}




\subsubsection{Discussão dos Resultados}

Apresentam-se, na Figura 5.10, as curvas de concentração de $\mathrm{Fe}^{+2}$ no tanque de recirculação, em função do tempo, para diferentes valores de $\alpha$. Os resultados para o campo de radiação são apresentados na Figura 5.11, para $\mathrm{G}_{v}=3,1054.10^{-4}$ einstein. $\mathrm{s}^{-1} \cdot \mathrm{m}^{-2}$ e diferentes valores de $\alpha$. Na Figura 5.12 , são ilustrados os resultados das concentrações de $\mathrm{Fe}^{+3}$ e $\mathrm{Fe}^{+2}$ calculadas, para cada caso. Para valores de $\alpha$ maiores, nota-se que a radiação é absorvida na região bem próxima a parede e há um consumo maior de $\mathrm{Fe}^{3+}$, conforme o esperado. Os perfis de concentrações obtidos são bem parecidos.

Por outro lado, para um valor de $\alpha$ menor, observa-se que a radiação tem uma penetração radial maior e os perfis das concentrações de $\mathrm{Fe}^{+3}$ e $\mathrm{Fe}^{+2}$ apresentam uma diferença em relação aos anteriores. Mostrando que o coeficiente de absorção molar possui uma influência no modelo apenas quando há uma mudança de ordem de grandeza. Para variações pequenas no valor de $\alpha$, não se observa uma influência significativa nos resultados do modelo de actinometria. 


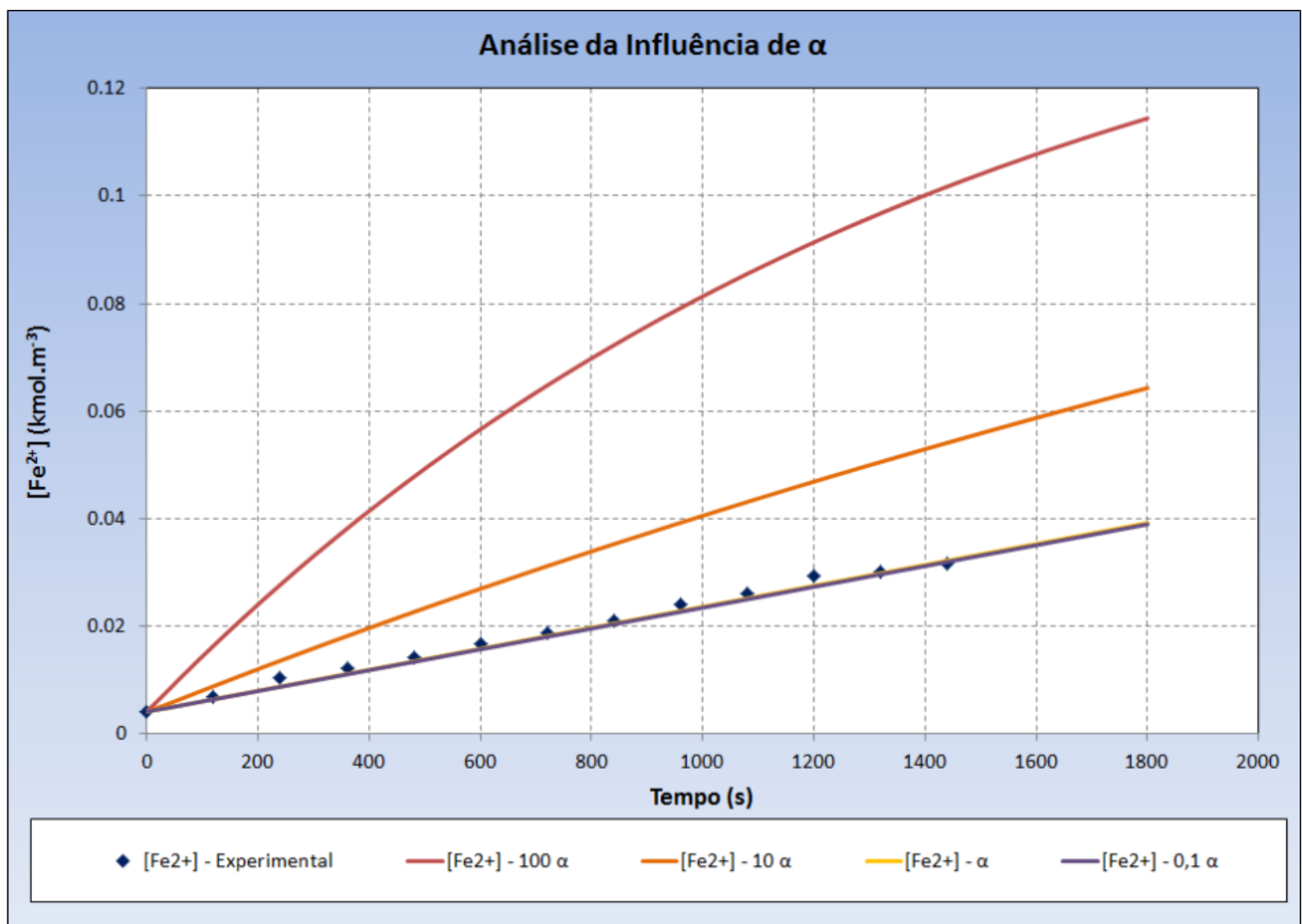

Figura 5.10 - Comparação das curvas de concentração $\mathrm{Fe}^{+2}$ em função do tempo para: os resultados experimentais e os calculados para diferentes valores $\alpha$.

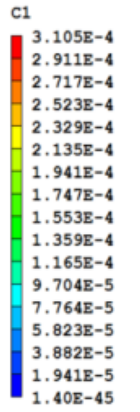

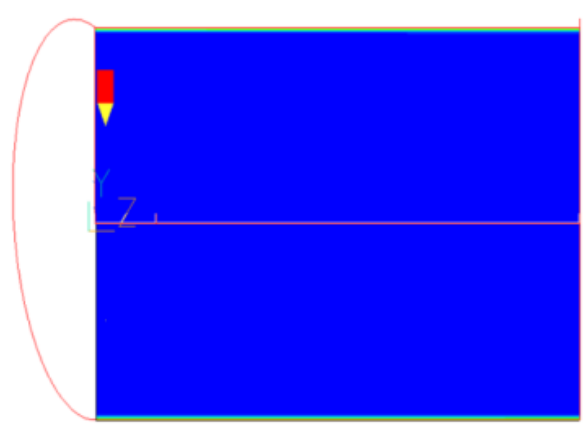

(a)

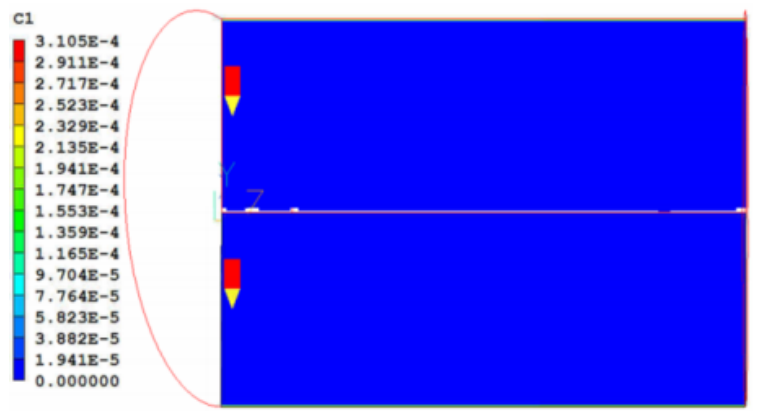

(b)

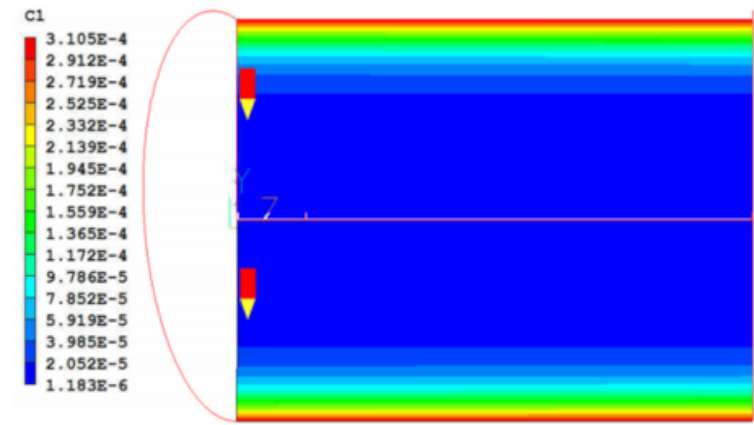

(c)

Figura 5.11 - Comparação do campo de radiação para $G_{v}=3,1054 \cdot 10^{-4}$ einstein. $\mathrm{s}^{-1} \cdot \mathrm{m}^{-2} \mathrm{e} \mathrm{t}=1800 \mathrm{~s}$, para diferentes valores de $\alpha$ : (a) $\alpha=5,17 \cdot 10^{4} \mathrm{~m}^{2} \cdot \mathrm{kmol}^{-1}$, (b) $10 \cdot \alpha=5,17 \cdot 10^{5} \mathrm{~m}^{2} \cdot \mathrm{kmol}^{-1} \mathrm{e}(\mathrm{c}) \alpha / 10=$ $5,17 \cdot 10^{3} \mathrm{~m}^{2} \cdot \mathrm{kmol}^{-1}$. 

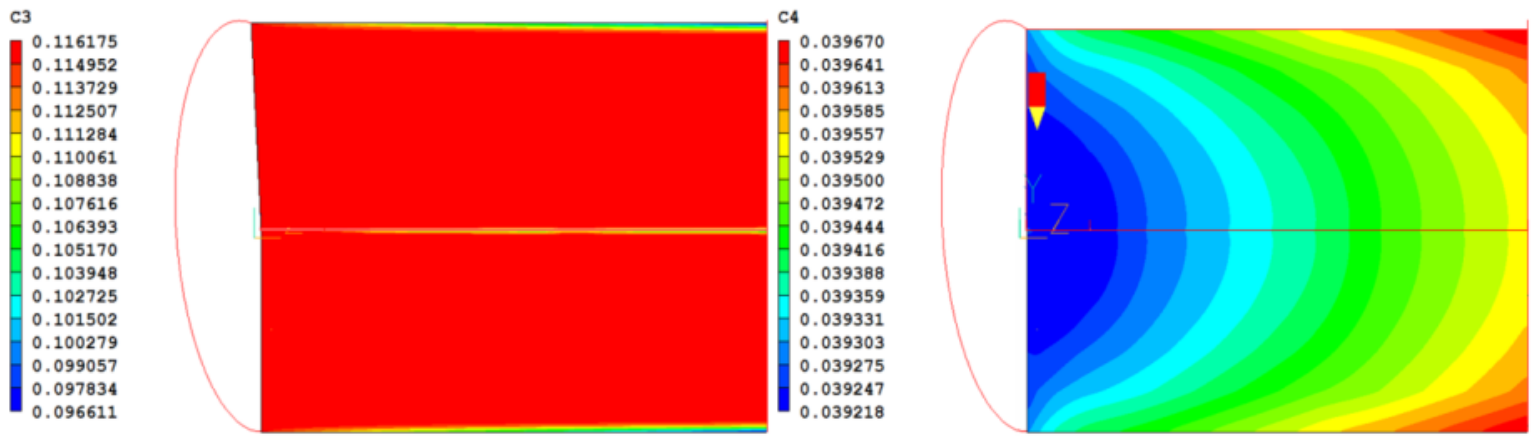

(a)

0.091742
0.087678
0.083614
0.079550

0.075485

0.071421
0.067357

0.067357
0.063293

0.063293
0.059228

0.055164

0.051100

0.047036

0.042972

0.038907
0.034843

0.034843

0.030779

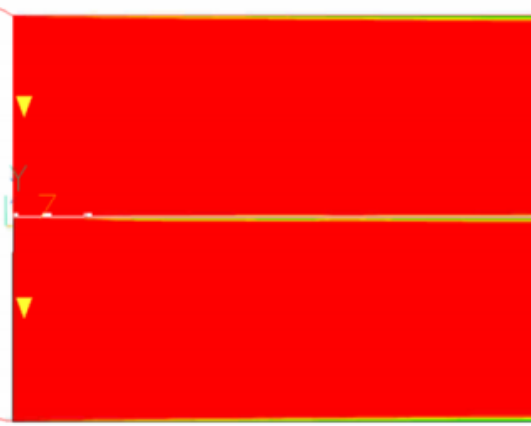

C4 0.064919

0.06488

0.064843
0.064805

0.064805
0.064766

0.064728

0.064690

.064576

0.064538

0.064500

0.0645062
0.064423

0.064385

.064347

0.064309

(b)

C3
0.116084
0.115870
0.115657
0.115443
0.11529
0.115015
0.114801
0.114587
0.114373
0.114160
0.113946
0.113732
0.113518
0.113304
0.113090
0.112877
0.112663
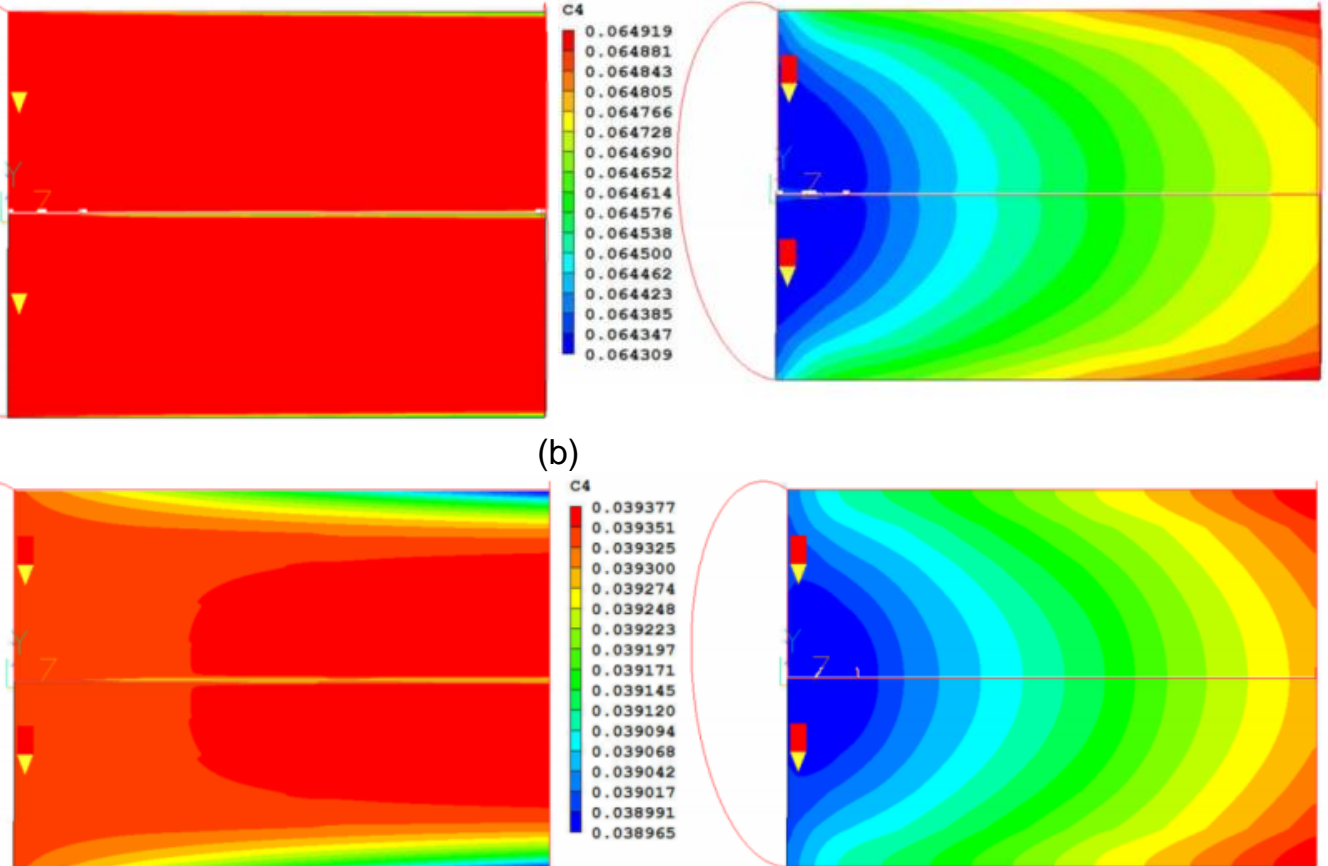

(c)

Figura 5.12 - Comparação das concentrações de $C 3=F e^{3+}$ e $C 4=F e^{2+}$, para $G_{v}=3,1054.10$ ${ }^{4}$ einstein $\cdot \mathrm{s}^{-1} \cdot \mathrm{m}^{-2} \mathrm{e} \mathrm{t}=1800 \mathrm{~s}:$ (a) $\alpha=5,17 \cdot 10^{4} \mathrm{~m}^{2} \cdot \mathrm{kmol}^{-1}$, (b) $10 \cdot \alpha=5,17 \cdot 10^{5} \mathrm{~m}^{2} \cdot \mathrm{kmol}^{-1}$ e (c) $\alpha / 10=$ $5,17.10^{3} \mathrm{~m}^{2} \cdot \mathrm{kmol}^{-1}$.

\subsubsection{Modelos de Radiação}

\subsubsection{Modelo e Condições de Contorno}

Consideraram-se os mesmos campos de pressão e velocidades do item 4.3.5, e a malha utilizada foi a mesma do item 5.2.1. Apresentam-se, na Tabela 5-6, os dados referentes às condições básicas da simulação e características da malha empregada para a análise dos modelos de incidência de radiação. Os outros dados de entrada utilizados na simulação são os mesmos apresentados na Tabela 5-1. 
Tabela 5-6 - Condições de contorno e dados de entrada das simulações para a análise da influência do tipo de modelo de radiação.

\begin{tabular}{ccc}
\hline Variável & Valor & Unidade \\
\hline$\alpha$ & $5,17.10^{4}$ & $\mathrm{~m}^{2} \cdot \mathrm{kmol}^{-1}$ \\
$\Phi_{A c}$ & $1,04 \times 10^{-4}$ & $\mathrm{kmol}^{-e i n s t e i n}{ }^{-1}$ \\
IX & 2 & - \\
IY & 200 & - \\
IZ & 120 & - \\
Número de Elementos & 48000 & - \\
$\Delta \mathrm{t}$ & 30 & $\mathrm{~s}$ \\
$\mathrm{Y}$ & $1,46.10^{-4}$ & $\mathrm{~m}$ \\
$v_{z_{Z=0}}$ & 0,1991 & $\mathrm{~m}^{-1}$ \\
$\dot{q}$ & $1,33 \cdot 10^{-4}$ & $\mathrm{~m}^{3} \cdot \mathrm{s}^{-1}$ \\
\hline
\end{tabular}

\subsubsection{Simulações Realizadas}

Visando analisar qual a influência do modelo de radiação utilizado na actinometria, as simulações foram realizadas variando-se o tipo de modelo radiação descritos no item 3.4.2, ou seja, foram executadas quatro simulações com:

- Modelo de incidência de radiação radial com $\alpha=5,17.10^{4} \mathrm{~m}^{2} \cdot \mathrm{kmol}^{-1}$;

- Modelo de incidência de radiação radial $\operatorname{com} \alpha / 10=5,17 \cdot 10^{3} \mathrm{~m}^{2} \cdot \mathrm{kmol}^{-1}$;

- Modelo de incidência de radiação difusa com $\alpha=5,17.10^{4} \mathrm{~m}^{2} \cdot \mathrm{kmol}^{-1}$;

- Modelo de incidência de radiação difusa com $\alpha / 10=5,17 \cdot 10^{3} \mathrm{~m}^{2} \cdot \mathrm{kmol}^{-1}$.

\subsubsection{Discussão dos Resultados}

Para analisar os diferentes modelos de radiação descritos no item 3.4.2, foram feitas as simulações descritas no item 5.3.2.2.

$\mathrm{Na}$ Figura 5.13 pode-se observar uma comparação das curvas de concentração de $\mathrm{Fe}^{+2}$ no tanque de recirculação, em função do tempo, para os modelos de incidência radial e difusa, sendo: $\mathrm{G}_{v}=3,1054 \cdot 10^{-4}$ einstein. $\mathrm{s}^{-1} \cdot \mathrm{m}^{-2}$ e $\alpha=$ $5,17.10^{4} \mathrm{~m}^{2} \cdot \mathrm{kmol}^{-1}$. Constata-se que não há uma diferença significativa entre as curvas.

Os resultados para o campo de radiação são apresentados na Figura 5.14. E, na Figura 5.15, são ilustrados os resultados das concentrações de $\mathrm{Fe}^{+3}$ e $\mathrm{Fe}^{+2}$ calculadas, para estas simulações. Nestas figuras, também, não se observa 
nenhuma influência significativa, pois a radiação incidente é consumida em uma região muito próxima a parede, não tendo o campo de radiação uma influência significativa no consumo de $\mathrm{Fe}^{3+}$. Trata-se de um caso bem particular, que é característico da actinometria (absorção praticamente total).

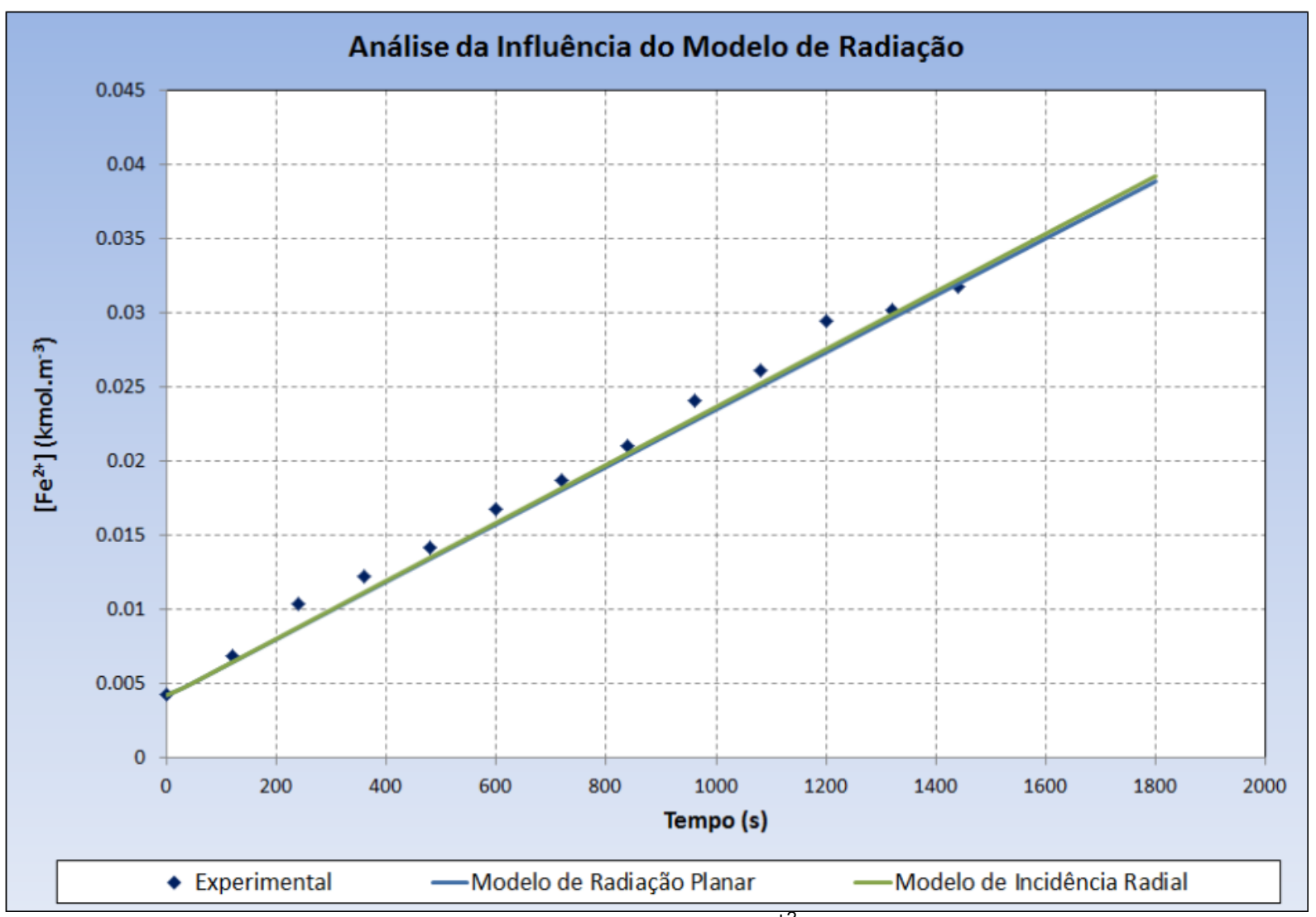

Figura 5.13 - Comparação das curvas de concentração $\mathrm{Fe}^{+2}$ em função do tempo para modelos de incidência de radiação.

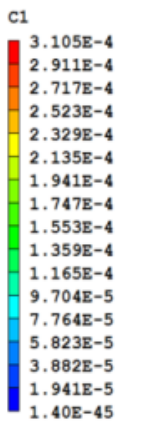

$3.105 \mathrm{E}-4$
$2.911 \mathrm{E}-4$
$2.717 \mathrm{E}-4$
$2.523 \mathrm{E}-4$
$2.329 \mathrm{E}-4$
$2.135 \mathrm{E}-4$
$1.941 \mathrm{E}-4$
$1.747 \mathrm{E}-4$
$1.553 \mathrm{E}-4$
$1.359 \mathrm{E}-4$
$1.165 \mathrm{E}-4$
$9.704 \mathrm{E}-5$
$7.764 \mathrm{E}-5$
$5.823 \mathrm{E}-5$
$3.882 \mathrm{E}-5$
$1.941 \mathrm{E}-5$
$1.40 \mathrm{E}-45$

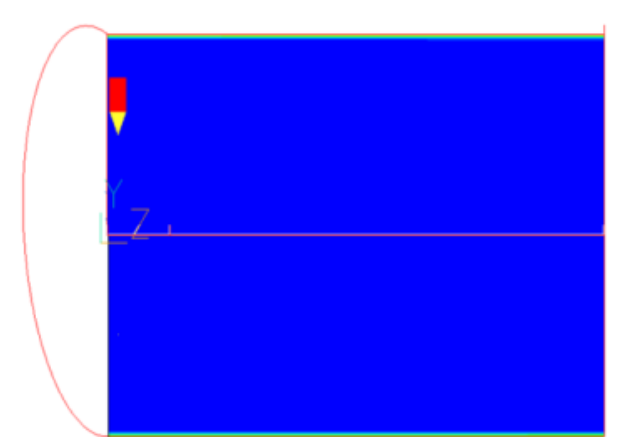

(a)

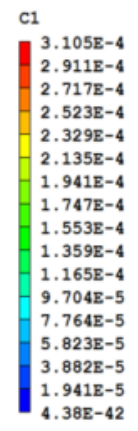

$38 \mathrm{E}-42$

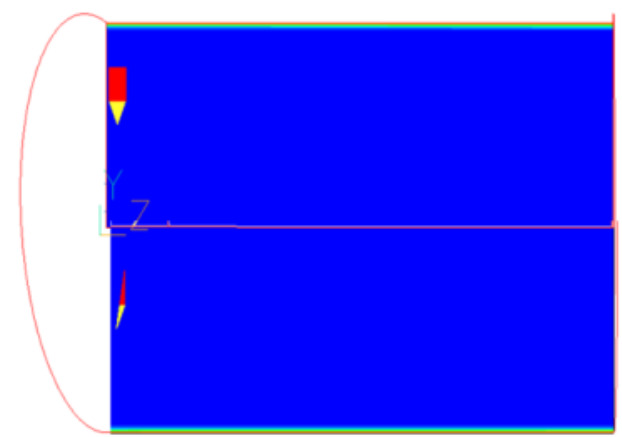

(b)

Figura 5.14 - Comparação do campo de radiação para $G_{v}=3,1054 \cdot 10^{-4}$ einstein. $\mathrm{s}^{-1} \cdot \mathrm{m}^{-2}$ e $\mathrm{t}=1800 \mathrm{~s}$ : (a) Modelo de Incidência Radial e (b) Modelo de Incidência Difusa. 

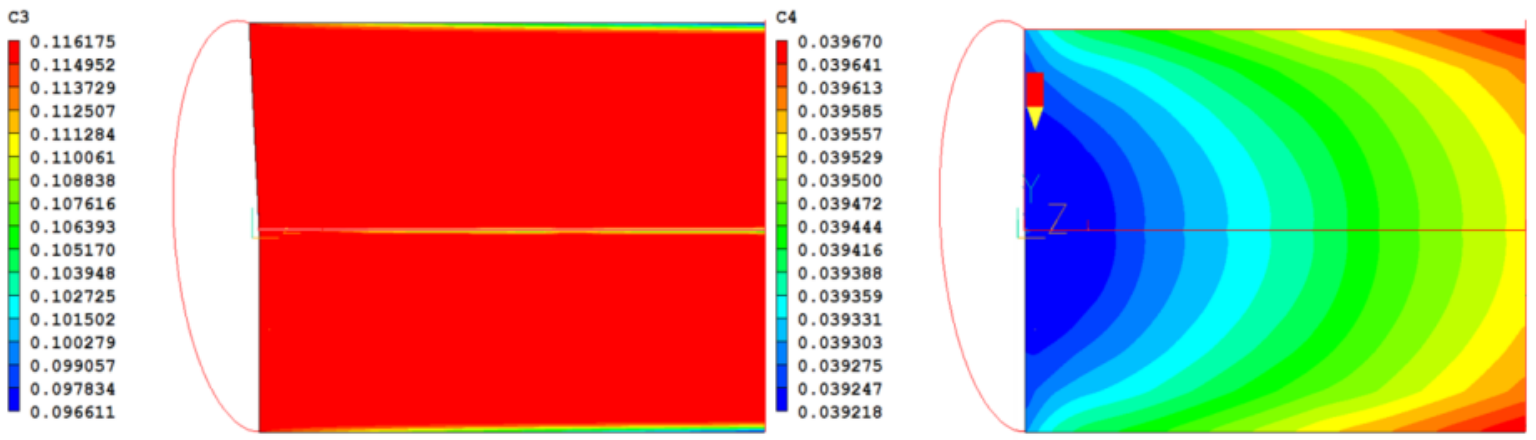

C3
$\begin{array}{ll}0.116517 \\ 0.115291 \\ 0.114064 \\ 0.112838 \\ 0.111612 \\ 0.110386 \\ 0.109160 \\ 0.107933 \\ 0.106707 \\ 0.105481 \\ 0.104255 \\ 0.103029 \\ 0.101802 \\ 0.100576 \\ 0.099350 \\ 0.098124 \\ 0.096898\end{array}$
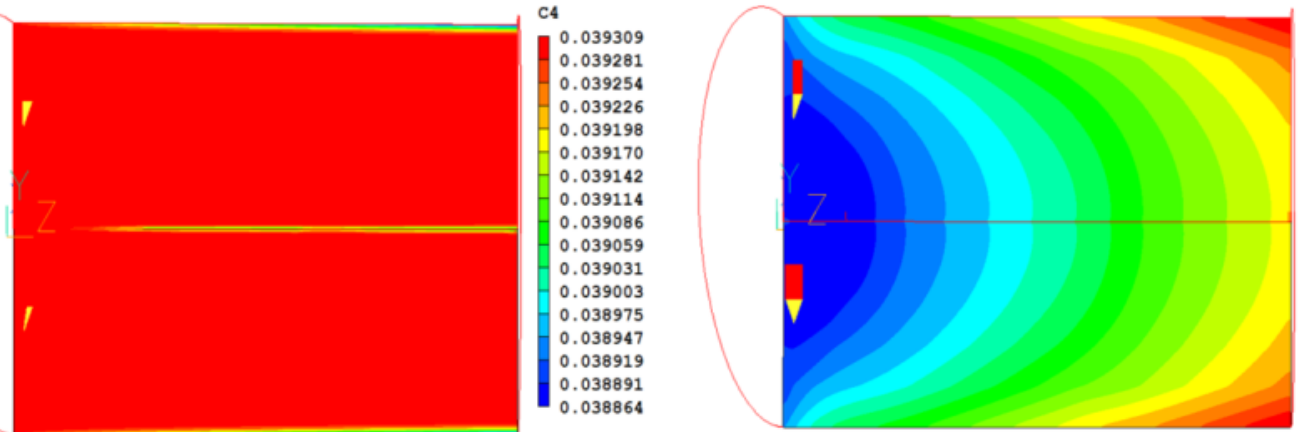

(b)

Figura 5.15 - Comparação das concentrações de $C 3=F e^{3+}$ e $C 4=F e^{2+}$, para $G_{v}=3,1054 \cdot 10^{-4}$ einstein. $\mathrm{s}^{-1} \cdot \mathrm{m}^{-2}$ e t=1800s: (a) Modelo de Incidência Radial e (b) Modelo de Incidência Difusa.

Visando analisar se, para um coeficiente de absorção menor haveria uma diferença entre os modelos de radiação, diminuiu-se o valor de $\alpha$ para $\alpha=5,17.10^{3}$ $\mathrm{m}^{2} . \mathrm{kmol}^{-1}$. Os resultados para o campo de radiação são apresentados na Figura 5.16. Na Figura 5.17, são ilustrados os resultados das concentrações de $\mathrm{Fe}^{+3} \mathrm{e} \mathrm{Fe}^{+2}$ calculados, para estas simulações. A partir destas figuras, pode-se concluir que no modelo de incidência difusa, o campo de radiação é menos intenso ao longo do raio, indicando um consumo menor de $\mathrm{Fe}^{3+}$.

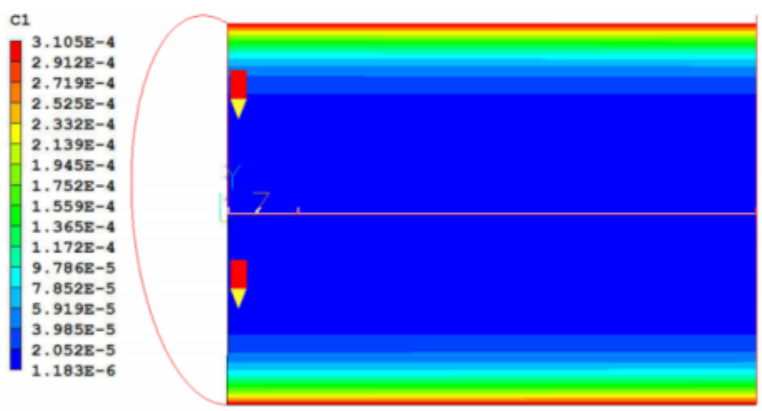

(a)

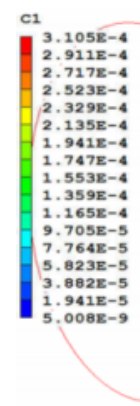

(b)

Figura 5.16 - Campo de radiação para $G_{v}=3,1054 \cdot 10^{-4}$ einstein $\cdot \mathrm{s}^{-1} \cdot \mathrm{m}^{-2}, \alpha / 10=5,17 \times 10^{3} \mathrm{~m}^{2} \cdot \mathrm{kmol}^{-1} \mathrm{e} \mathrm{t}$ $=1800 \mathrm{~s}$ : (a) Modelo de Incidência Radial e (b) Modelo de Incidência Difusa. 

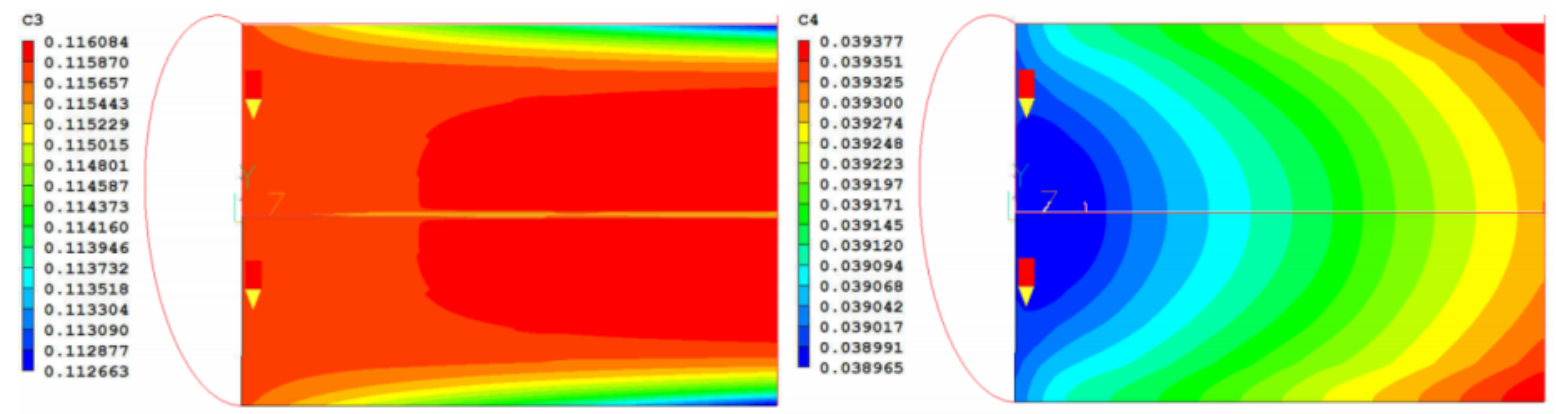

(a)
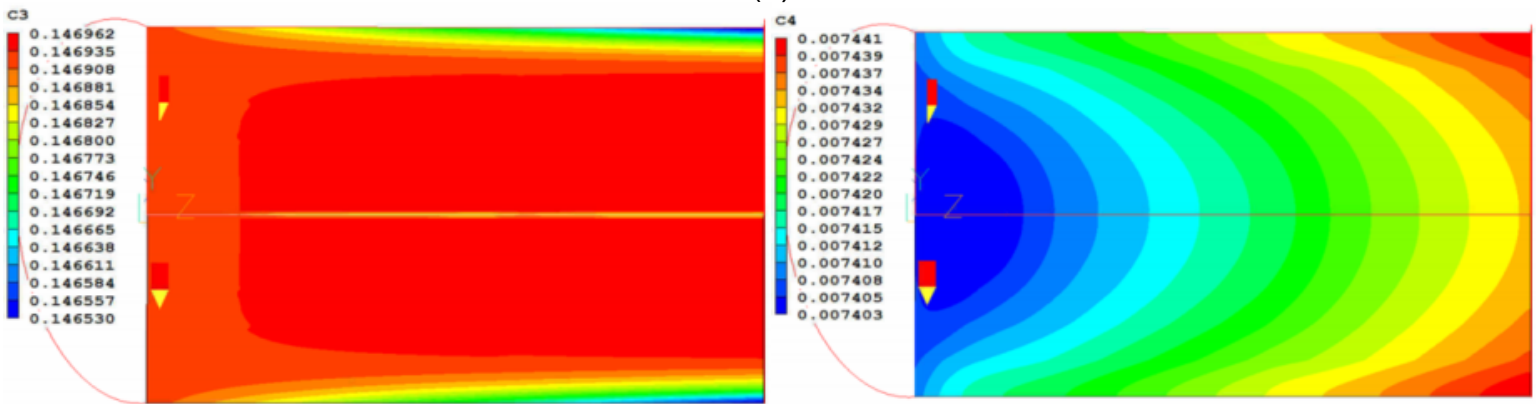

(b)

Figura 5.17 - Comparação das concentrações de $C 3=F e^{3+}$ e $C 4=F e^{2+}$, para $G_{v}=3,1054.10^{-4}$ einstein. $\mathrm{s}^{-1} \cdot \mathrm{m}^{-2}, \alpha / 10=5,17 \times 10^{3} \mathrm{~m}^{2} \cdot \mathrm{kmol}^{-1} \mathrm{e} \mathrm{t}=1800 \mathrm{~s}$ : (a) Modelo de Incidência Radial e (b) Modelo de Incidência Difusa.

\subsubsection{Modelo de Escoamento}

Visando estudar a influência do escoamento na simulação da actinometria, foram realizadas dois tipos de análise. A primeira para o tipo de modelo de escoamento e a segunda, para a influência da vazão.

\subsubsection{Influência do Tipo de Modelo}

\subsection{Modelo e Condições de Contorno}

Os campos de pressão e velocidades utilizados para as simulações dos modelos cinéticos foram os apresentados no item 4.3.5, segundo os respectivos modelos de escoamento. A malha utilizada foi a mesma do item 5.2.1. Apresentamse, na Tabela 5-7, os dados referentes às condições básicas da simulação e características da malha empregada para a análise dos modelos de escoamento. Os outros dados de entrada utilizados na simulação são os apresentados na Tabela 5-1. 
Tabela 5-7 - Condições de contorno e dados de entrada das simulações para a análise do tipo de escoamento.

\begin{tabular}{ccc}
\hline Variável & Valor & Unidade \\
\hline$\alpha$ & $5,17.10^{4}$ & $\mathrm{~m}^{2} \cdot \mathrm{kmol}^{-1}$ \\
$\Phi_{A c}$ & $1,04 \times 10^{-4}$ & $\mathrm{kmol}^{-e i n s t e i n}{ }^{-1}$ \\
IX & 2 & - \\
IY & 200 & - \\
IZ & 120 & - \\
Número de Elementos & 48000 & - \\
$\Delta \mathrm{t}$ & 30 & $\mathrm{~s}$ \\
$\mathrm{y}$ & $1,46.10^{-4}$ & $\mathrm{~m}$ \\
$v_{z_{Z=0}}$ & 0,1991 & $\mathrm{~m}^{-1}$ \\
$\dot{q}$ & $1,33 \cdot 10^{-4}$ & $\mathrm{~m}^{3} \cdot \mathrm{s}^{-1}$ \\
\hline
\end{tabular}

Foram realizadas três simulações para esta análise, a saber: a primeira para o modelo turbulento $(\mathrm{k}-\varepsilon)$, a segunda para o modelo plug flow e a última para o modelo laminar.

\subsubsection{Discussão dos Resultados}

A partir das simulações dos diferentes tipos de escoamento, obtiveram-se as curvas de concentração de $\mathrm{Fe}^{2+}$, no tanque de recirculação, em função do tempo, que podem ser vistas na Figura 5.18. A influência dos tipos de modelo é dificilmente percebida a partir da análise deste gráfico. Analisando-se os campos de radiação, mostrados na Figura 5.19, nota-se que o campo de radiação é independente do escoamento. No entanto, os perfis de concentrações para o $\mathrm{Fe}^{3+}$ e para o $\mathrm{Fe}^{2+}$, ilustrados na Figura 5.20, mostram que para o modelo turbulento e plug-flow, tem-se certa uniformidade para a concentração de $\mathrm{Fe}^{2+}$, o que não se observa para o modelo laminar. Estes comportamentos devem estar relacionados diretamente aos diferentes mecanismos de transporte: turbilhonar, no caso do escoamento turbulento, e difusão pura, no caso laminar. 


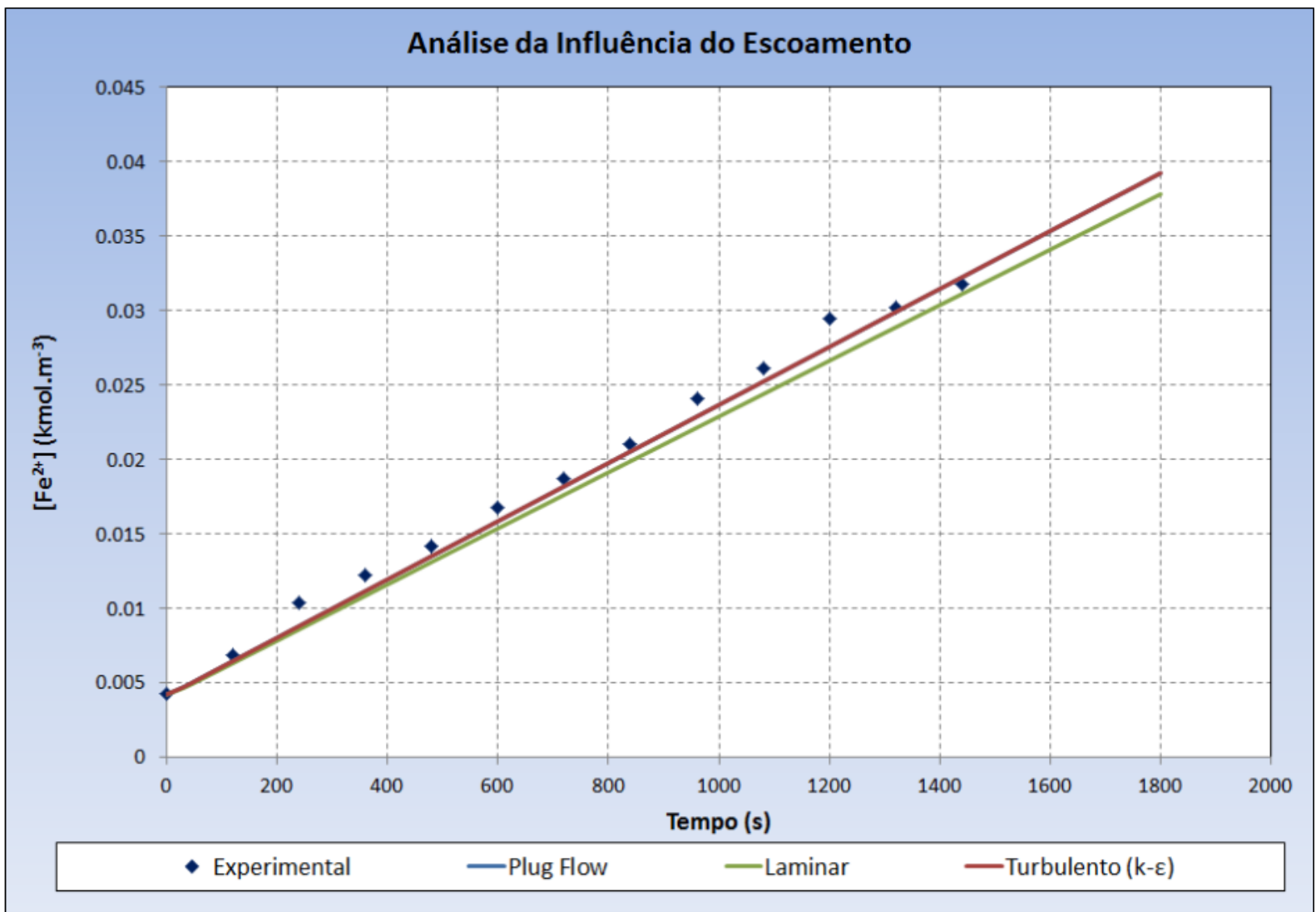

Figura 5.18 - Comparação das curvas de concentração $\mathrm{Fe}^{+2}$ em função do tempo para análise da influência de diferentes modelos de escoamento.

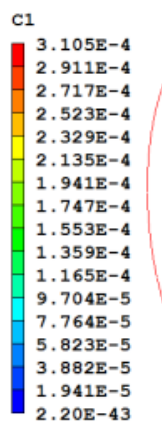

$2.20 \mathrm{E}-43$

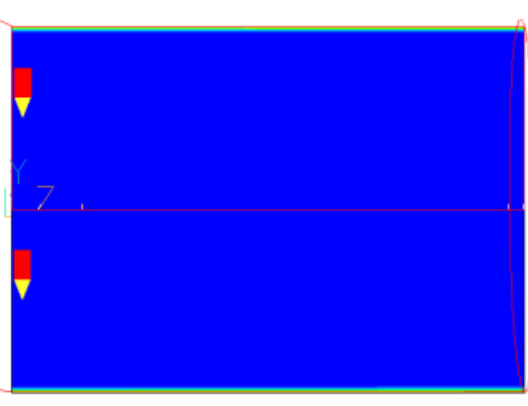

(a)

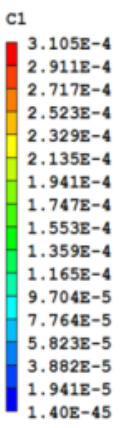

$C 1$
$3.105 \mathrm{E}-4$
$2.911 \mathrm{E}-4$
$2.717 \mathrm{E}-4$
$2.523 \mathrm{E}-4$
$2.329 \mathrm{E}-4$
$2.135 \mathrm{E}-4$
$1.941 \mathrm{E}-4$
$1.747 \mathrm{E}-4$
$1.553 \mathrm{E}-4$
$1.359 \mathrm{E}-4$
$1.165 \mathrm{E}-4$
$9.704 \mathrm{E}-5$
$7.764 \mathrm{E}-5$
$5.823 \mathrm{E}-5$
$3.882 \mathrm{E}-5$
$1.941 \mathrm{E}-5$
$6.01 \mathrm{E}-41$

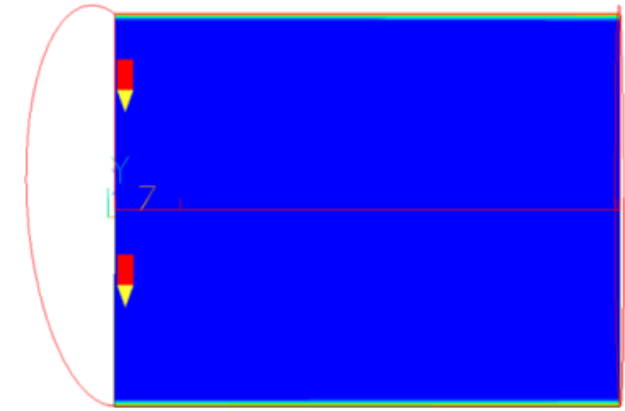

(c)

Figura 5.19 - Comparação do campo de radiação, para $G_{v}=3,1054 \cdot 10^{-4}$ einstein. $\mathrm{s}^{-1} \cdot \mathrm{m}^{-2} \mathrm{e} \mathrm{t}=1800 \mathrm{~s}$ : (a)

Plug Flow, (b) Turbulento (k- $-\varepsilon$ e (c) Laminar. 

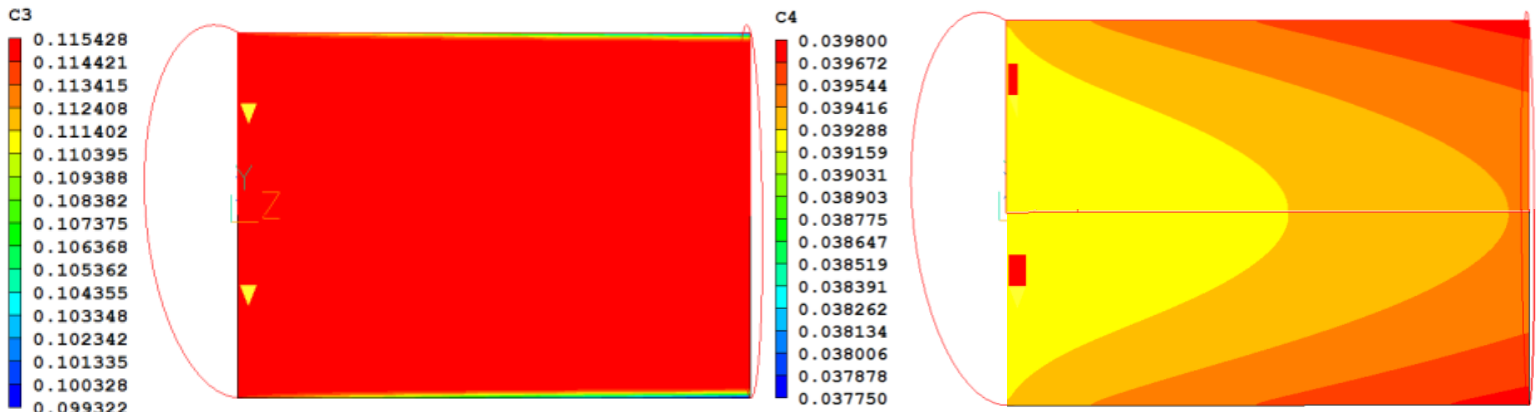

c3

(a)
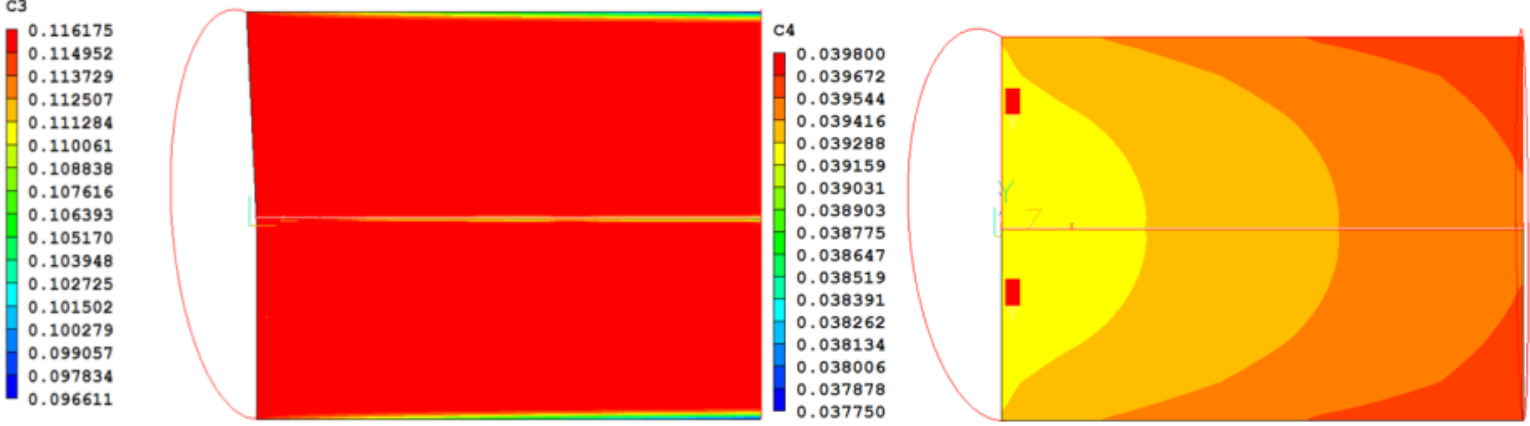

(b)
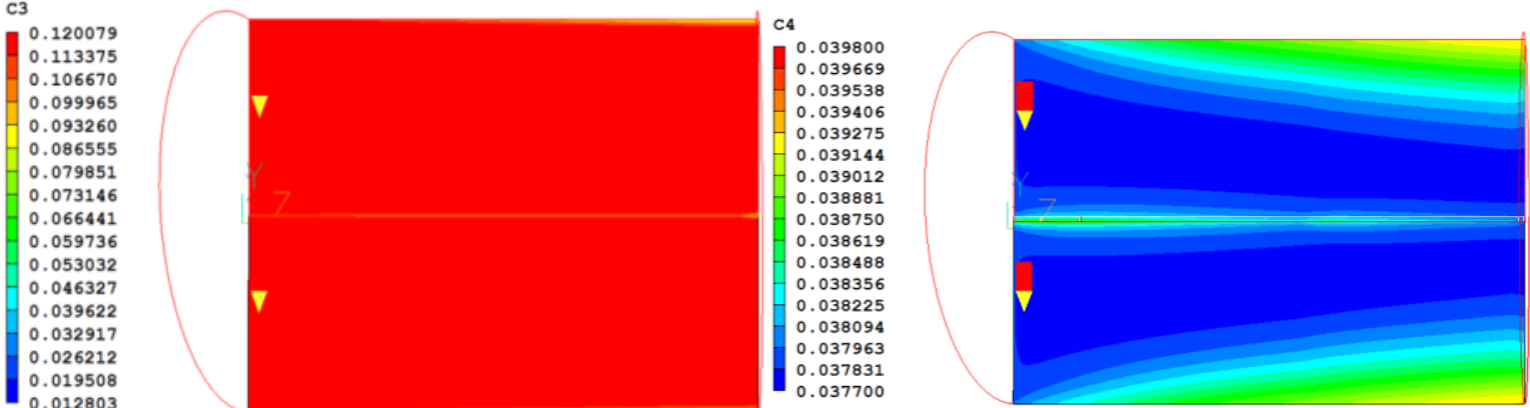

(c)

Figura 5.20 - Comparação das concentrações de $C 3=\mathrm{Fe}^{3+}$ e $C 4=\mathrm{Fe}^{2+}$, para $G_{v}=3,1054.10^{-4}$ einstein. $s^{-1} \cdot m^{-2}$ e $t=1800 s$ : (a) Plug Flow, (b) Turbulento (k- $\varepsilon$ ) e (c) Laminar.

\subsubsection{Influência da Vazão}

\subsection{Modelo e Condições de Contorno}

Os campos de pressão e velocidades utilizados para as simulações dos modelos cinéticos foram os apresentados no item 4.3.5. A malha utilizada foi a mesma do item 5.2.1. Apresentam-se, na Tabela 5-8, os dados referentes às condições básicas da simulação e características da malha empregada para a análise dos modelos de escoamento. Os outros dados de entrada utilizados são os apresentados na Tabela 5-1. 
Tabela 5-8 - Condições de contorno e dados de entrada das simulações para a análise da influência da vazão.

\begin{tabular}{ccc}
\hline Variável & Valor & Unidade \\
\hline$\alpha$ & $5,17.10^{4}$ & $\mathrm{~m}^{2} \cdot \mathrm{kmol}^{-1}$ \\
$\Phi_{A c}$ & $1,04 \times 10^{-4}$ & $\mathrm{kmol}^{-e i n s t e i n}{ }^{-1}$ \\
IX & 2 & - \\
IY & 200 & - \\
IZ & 120 & - \\
Número de Elementos & 48000 & - \\
$\Delta \mathrm{t}$ & 30 & $\mathrm{~S}$ \\
$\mathrm{Y}$ & $1,46.10^{-4}$ & $\mathrm{~m}$ \\
\hline
\end{tabular}

Foram realizadas três simulações para esta análise, a saber: a primeira para vazão de 8 L.min ${ }^{-1}$, a segunda para uma vazão 50\% maior e a última para uma vazão $50 \%$ menor. Todos os escoamentos simulados foram em regime turbulento.

\subsection{Discussão dos Resultados}

As simulações para diferentes vazões forneceram como resultado as curvas de concentração de $\mathrm{Fe}^{2+}$, no tanque de recirculação, em função do tempo, mostradas na Figura 5.21. Nota-se que, quanto maior a vazão, tem-se um incremento suave na quantidade de $\mathrm{Fe}^{2+}$ produzida globalmente. Observando-se os campos de radiação e os perfis de concentrações para $\circ \mathrm{Fe}^{3+}$ e para $\circ \mathrm{Fe}^{2+}$, ilustrados na Figura 5.22 e na Figura 5.23, nota-se que a vazão não influencia significativamente estes resultados. 


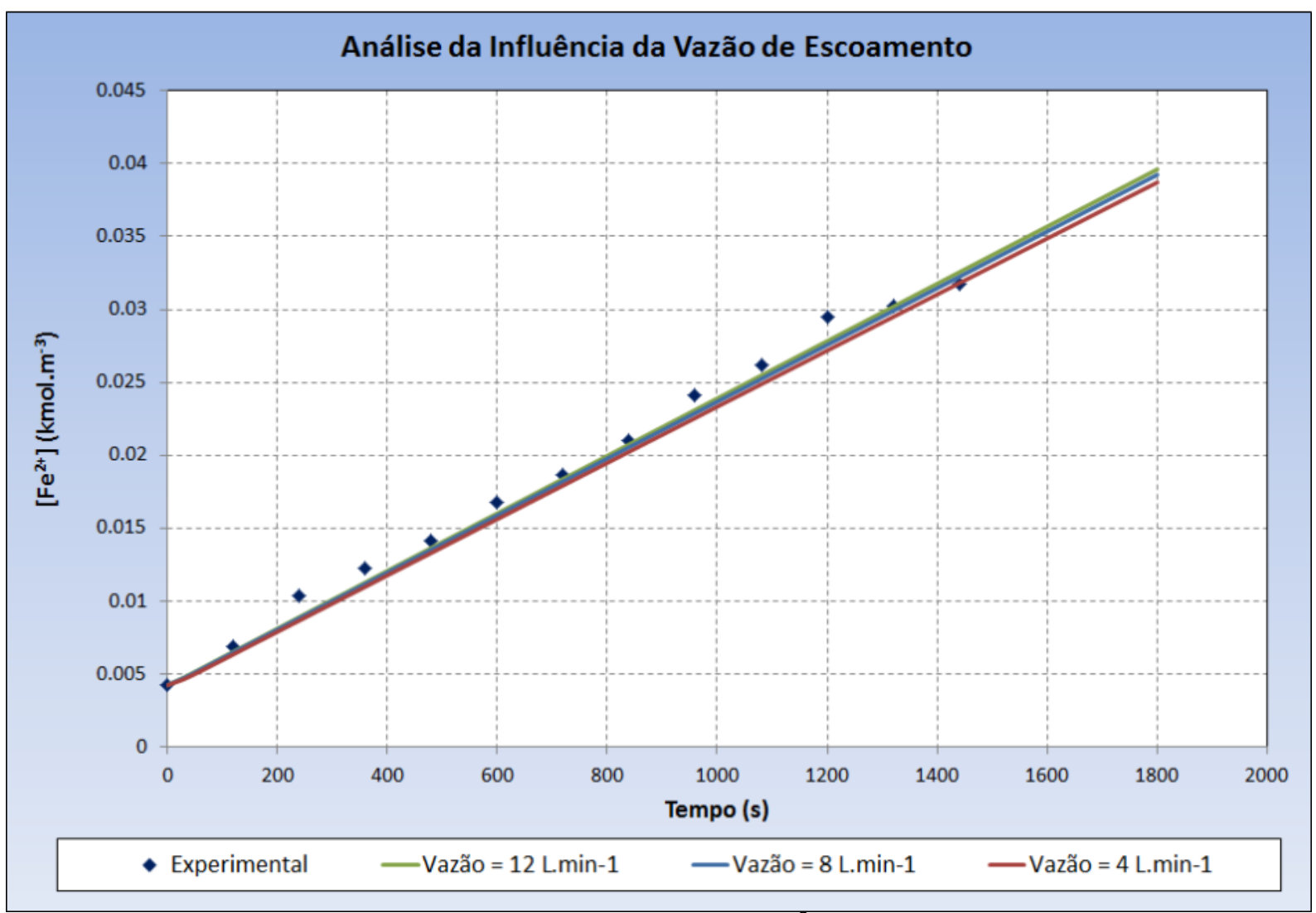

Figura 5.21 - Comparação das curvas de concentração $\mathrm{Fe}^{+2}$ em função do tempo para análise da influência de diferentes vazões.

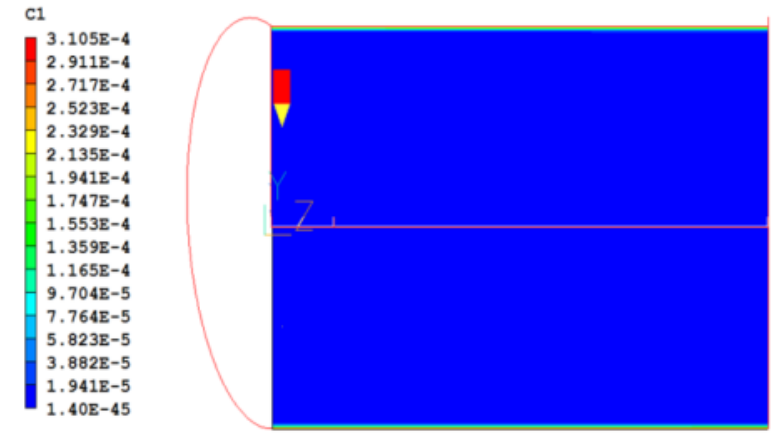

(a)

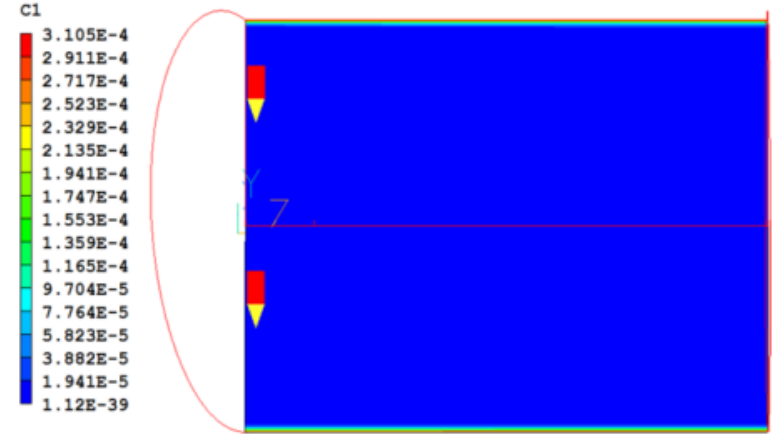

(b)

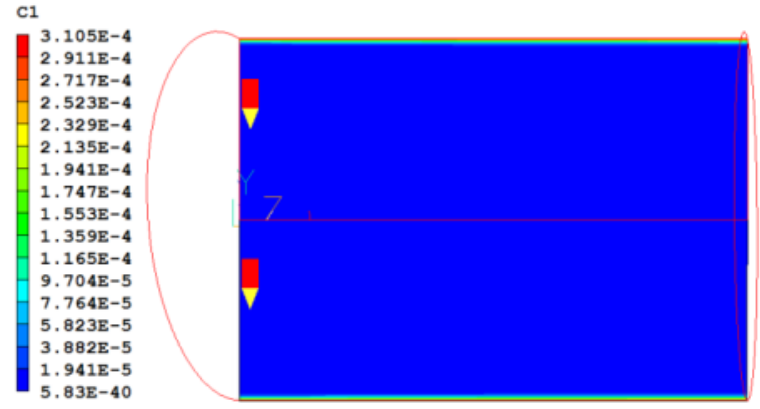

(c)

Figura 5.22 - Comparação do campo de radiação para $G_{v}=3,1054.10^{-4}$ e $\mathrm{t}=1800 \mathrm{~s}$, para: (a) Vazão = 8 L.min ${ }^{-1}$, (b) Vazão = 12 L. $\min ^{-1}$ e (c) Vazão $=4$ L.min ${ }^{-1}$ 
C3

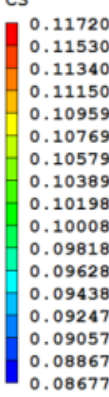

0.116175

0.114952

0.112507

0.111284

0.108838

0.107616

0.106393

0.105170
0.103948

0.102725

0.101502

0.100279

0.099057
0.097834

0.099057
0.097834
0.096611
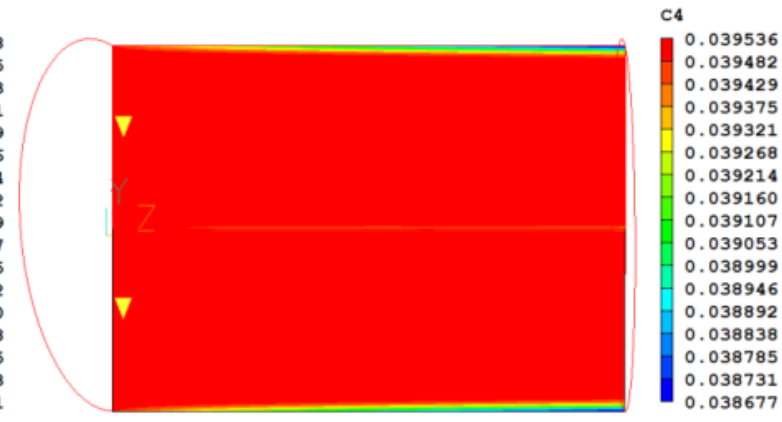

(a)

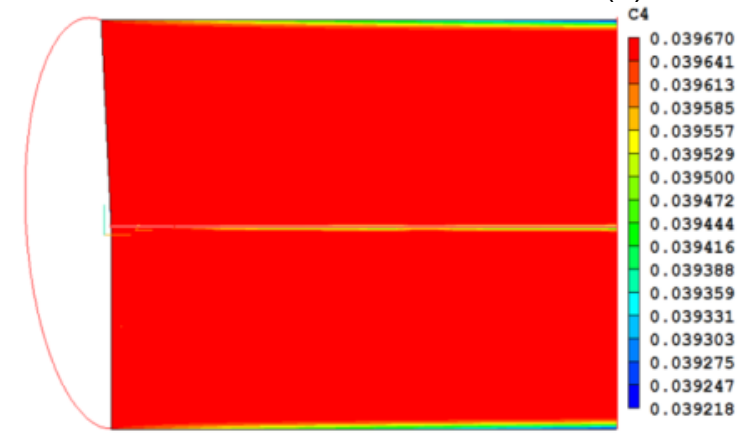

(b)

C3
0.11568
0.113201
0.11071
0.10822
0.105739
0.10325
0.10076
0.098277
0.095789
0.093302
0.090815
0.08832
0.085840
0.08335
0.080866
0.07837
0.075891

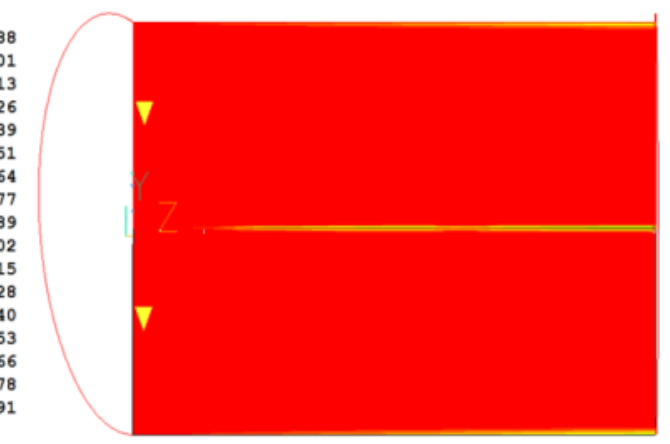

0.039670

0.039903
0.039884
0.039865
0.039846
0.039826
0.039807
0.039788
0.039769
0.039750
0.039731
0.039712
0.039693
0.039674
0.039654
0.039635
0.039616
0.039597
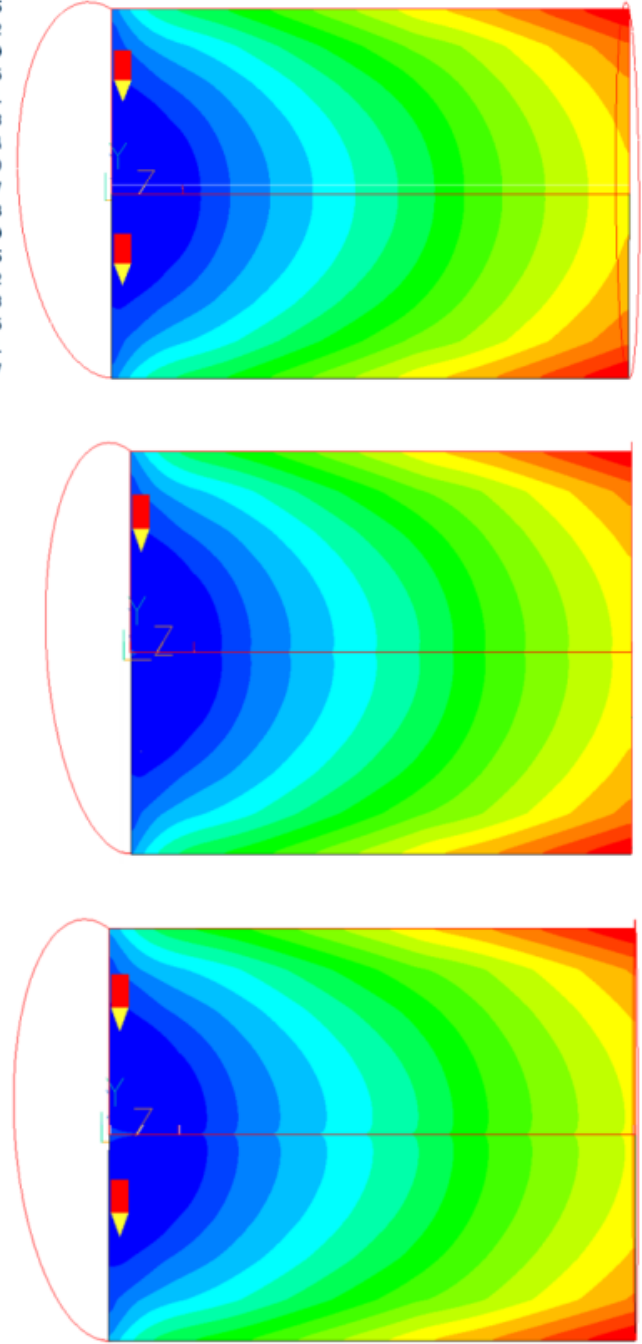

(c)

Figura 5.23 - Comparação das concentrações de $C 3=\mathrm{Fe}^{3+}$ e $C 4=\mathrm{Fe}^{2+}$, para $G_{v}=3,1054.10^{-4}$ einstein. $\mathrm{s}^{-1} \cdot \mathrm{m}^{-2}$ e t $=1800 \mathrm{~s}$ : (a) Vazão $=4 \mathrm{~L} \cdot \mathrm{min}^{-1}$, (b) Vazão $=8 \mathrm{~L} \cdot \mathrm{min}^{-1} \mathrm{e}$ (c) Vazão $=12 \mathrm{~L} \cdot \mathrm{min}^{-1}$ 


\section{CONSIDERAÇÕES FINAIS}

\subsection{CONCLUSÕES}

Este trabalho apresenta um modelo em fluidodinâmica computacional (CFD) aplicado a um reator solar, utilizado para Processos Oxidativos Avançados (POA). Desenvolveu-se um modelo, que foi implementado no código PHOENICS, que considera o escoamento, o campo de radiação e a cinética da reação de actinometria química, em regime transiente.

Para a geometria completa do reator solar, determinou-se a distribuição de tempo de residência, a partir da definição da malha cartesiana e o intervalo de tempo de integração. Os resultados obtidos da simulação apresentaram boa concordância com os dados experimentais obtidos por RIBEIRO (2009).

Constatou-se que o hairpin, no qual se realizou a reação de actinometria, pode ser representado por um tubo cilíndrico reto, equivalente, que apresentou DTR muito próxima da simulado para o hairpin.

Estimou-se a taxa de fótons incidentes na parede do reator, a partir da simulação do modelo de fluidodinâmica com radiação e reação e comparação com os resultados experimentais de actinometria química obtidos por RIBEIRO (2009).

Através de simulação computacional do modelo implementado, foram feitos alguns estudos para análise dos seguintes aspectos: coeficiente de absorção molar, modelo de incidência de radiação e modelo de escoamento. A influência do coeficiente de absorção só é perceptível para grandes variações desta. Para a reação de actinometria, o modelo de radiação incidente radial e o de radiação incidente difusa apresentaram desempenhos muito próximos. Observa-se que o modelo de escoamento (plug flow, turbulento e laminar) afeta de forma significativa o campo de concentrações dos íons de ferro, ao longo do reator. 


\subsection{SUGESTÕES DE CONTINUIDADE}

Expandir o modelo desenvolvido de forma a incluir outras reações fotoquímicas e implementá-lo para o reator solar completo.

Obtenção de dados experimentais da radiação solar incidente efetiva e cálculo da radiação absorvida pelo reator, para obtenção do desempenho do coletor solar.

O modelo implementado foi desenvolvido para os valores médios de coeficiente de absorção e de rendimento quântico, para uma dada faixa do espectro. No entanto, considera-se importante o equacionamento discretizado, no comprimento de onda. Sugere-se, portanto, a sofisticação do modelo neste sentido.

Sugere-se, também , o estudo do modelo de radiação dependente do ângulo de incidência ao longo do perímetro do reator, que representaria de forma mais realista o coletor solar estudado. 


\section{REFERÊNCIAS BIBLIOGRÁFICAS}

ALFANO, O.M. Radiation Field Modeling in Photoreactors - I. Homogeneous Media. Chemical Engineering Science, 1986. Vol.41, No.03, pp.421-444.

ALFANO, O. M.; BAHNEMANN, D.; CASSANO, A. E.; DILLERT, R.; GOSLICH, R. Photocatalysis in Water Environments using Artificial and Solar Light. Cat. Today, 2000. Vol.58, No.02, pp. 199.

BRAUN, A.M.; MAURETTE, M.T.; OLIVEROS, E. Photochemical Technology. Chischester: John Wiley, 1991.

CASSANO, A.E.; MARTÍN, C.A.; BRANDI, R.J; ALFANO, O.M. Photoreactor Analysis and Design: Fundamentals and Applications. Ind. Eng. Chem. Res, 1996. Vol. 34, pp. 2155-2201

CONAMA, CONSELHO NACIONAL DO MEIO AMBIENTE, Resolução №.357de17 de março de 2005. Dispõe sobre a classificação dos corpos de água e diretrizes ambientais para o seu enquadramento, bem como estabelece as condições e padrões de lançamento de efluentes e dá outras providências.

Disponível em: http://www.mma.gov.br/conama/res/res05/res35705.pdf.

DECRETO, Decreto 8468 de 08 de Setembro de 1976, revisão de 2004. Padrões de Emissão Lançamento Ar Água Licenciamento Ambiental e RIA, RIMA. Poluição do Solo Poluição Sonora. Resíduos. Zoneamento. Penalidades. Classificação Corpos Receptores.

FOGLER, H.S. Elementos de Engenharia das Reações Químicas. 3ª . Edição. Ed. LTC, Rio de Janeiro, 2002.

JARANDEHEI, A.; VISSCHER, A. Three-Dimensional CFD Model for a Flat Plate Photocatalytic Reactor: Degradation of TCE in a Serpentine Flow Field. AIChE Journal, 2009. Vol. 55, No.02, pp. 312-320.

KAYS, W.M.; CRAWFORD, M.E. Convective Heat and Mass Transfer. 3a. Edição. Ed. McGraw-Hilll, Singapura, 1993.

LAUNDER, B.E.; SPALDING, D.B. The numerical computational of turbulent fluid flows. Comput. Methods Appl. Mech. Eng,1974. Vol. 3, pp. 269-289.

LAUNDER, B.E.; REECE, G.J.; RODI, W. Progress in the development of a Reynolds-stress turbulence closure. J. Fluid. Mech. 1975, vol. 68, Pt 3, pp.537-566.

LEAIST, D.G. The effects of aggregation, counterion binding, and added $\mathrm{NaCl}$ on diffusion of aqueous methylene blue. J. Chem, 1988. Vol. 66, pp. 2452-2457. 
MALISKA, C.R. Transferência de calor e mecânica dos fluidos computacional. $2^{\mathrm{a}}$. Edição. Ed. LTC, Rio de Janeiro, 2004.

MÁRQUEZ, J.C. Radiation Absorption and Optimization of Solar Photocatalytic Reactors for Environmental Applications. Environ. Sci. Technol., 2010. Vol. 44, pp. 5112-5120.

MARTÍN, C.A.; BALTANÁS, M.A.; CASSANO, A.E. Photocatalytic Reactors.II.Quantum Efficiencies Allowing for Scattering Effects. An Experimental Approximation. J.Photochemistry and Photobiology A: Chemistry, 1996. Vol. 94, pp. 173-189.

MUKHERJEE, R. Fundamentals of Photochemistry. New Age International Limited, Publishers. Calcutta, Índia, 1991.

RIBEIRO, K. Estudo experimental e modelagem matemática de reator solar híbrido para degradação de fenol em solução aquosa pelo processo foto-fenton. Tese de Doutorado em Engenharia Química. Escola Politécnica da Universidade de São Paulo, 2009.

PATANKAR, S. V.; SPALDING, D. B. A calculation procedure for heat, mass and momentum transfer in three-dimensional parabolic flows. Int. Journal of Heat Mass Transfer, 1972. Vol. 5, pp. 1787-1806.

PATANKAR, S. V. Numerical Heat Transfer and Fluid Flow. Ed. Hemisphere Publishing Corporation, New York, 1980.

SHERWOOD, T. K.; PIGFORD, R. L.; WILKE, C. R. Mass Transfer. Ed.Mc Graw-Hill, New York, 1975.

SILVA, D.P.C.,Estudo para otimização do projeto de um sistema de reatores para o tratamento fotoquímico de efluentes industriais. Dissertação de Mestrado em Engenharia Química. Escola Politécnica da Universidade de São Paulo, 2012.

SILVARES, A.F.M. Modelagem matemática de reatores fotoquímicos aplicados ao tratamento de efluentes. Dissertação de Mestrado em Engenharia Química. Escola Politécnica da Universidade de São Paulo, 2001.

SILVARES, A.F.M.Desenvolvimento experimental e simulação matemática do processo de pré-polimerização fotoiniciada do metacrilato de metila (MMA).Tese de Doutorado em Engenharia Química. Escola Politécnica da Universidade de São Paulo, 2006.

SOUZA, V. C. Bicos dispersores da Indústria do petróleo - Análise bidimensional aplicando à fluido dinâmica Computacional. Dissertação de Mestrado em Engenharia Química. Universidade Estadual de Campinas, 2001. 
SOUZA, V. C. Dissipadores térmicos de placas paralela com influxo de topo. Tese de Doutorado em Engenharia Mecânica. Universidade de Campinas, 2005.

SPALDING, D. B. A single formula for the law of the wall. Journal Applied Mechanics, 1961. Vol. 28, pp.455-457.

SPALDING, D. B. A novel finite-difference formulation for differential expressions involving both first and second derivatives. Int. Journal Numerical Methods in Engineering, 1972. Vol 4, pp. 551.

SPALDING, D. B. Mathematical modelling of fluid-mechanics, heat-transfer and chemical-reaction processes. CFDU Report HTS/80/1. Imperial College, London, 1980.

SPALDING, D. B. The PHOENICS Encyclopedia. CHAM Ltd, London, UK, 2011.

SPARROW, E. M.; CESS, R. D. Radiation Heat Transfer. Brooks/Cole Publishing Company, California, 1996.

TAMBANI, P. C. Estudo da degradação de fenol e seus intermediários pelo processo UV/ $\mathrm{H}_{2} \mathrm{O}$.Dissertação de Mestrado em Engenharia Química. Escola Politécnica da Universidade de São Paulo, 2011.

TURRO, N. J. Modern Molecular Photochemistry. University Science Books, Sausalito, CA, 1991.

VERSTEEG, H.K.; MALALASEKERA, W. An introduction to Computational Fluid Dynamics - The Finite Volume Method. Ed. Longman, London, 1995.

WHITE, F.M. Viscous Fluid Flow. 2a. Edição. Ed. McGraw-Hill, New York, 1991.

WOODWARD, R. B.; HOFFMANN, R. Die Erhaltung der Orbitalsymmetrie. Verlag Chemie. Weinheim, 1970.

ZALAZAR, C.S.; LABAS, M.D; MARTÍN, C.A.; BRANDI, R.J.; ALFANO, O.M.; CASSANO, A.E. The Extended Use of Actinometry in the Interpretation of Photochemical Reaction Engineering Data. Chemical Engineering Journal, 2005. Vol. 109, pp. 67-81 


\section{APÊNDICE A - Q1}

$<$ html $><$ head $><$ title $>$ Q1 $</$ title $>$

$<$ link rel="stylesheet" type="text/css"

href="/phoenics/d_polis/polstyle.css" $>$

$</$ head $><$ body $><$ pre $><$ strong $>$

$\mathrm{TALK}=\mathrm{T} ; \operatorname{RUN}(1,1)$

Q1 created by VDI menu, Version 2010, Date 18/08/10

CPVNAM $=$ VDI ; SPPNAM $=$ Core

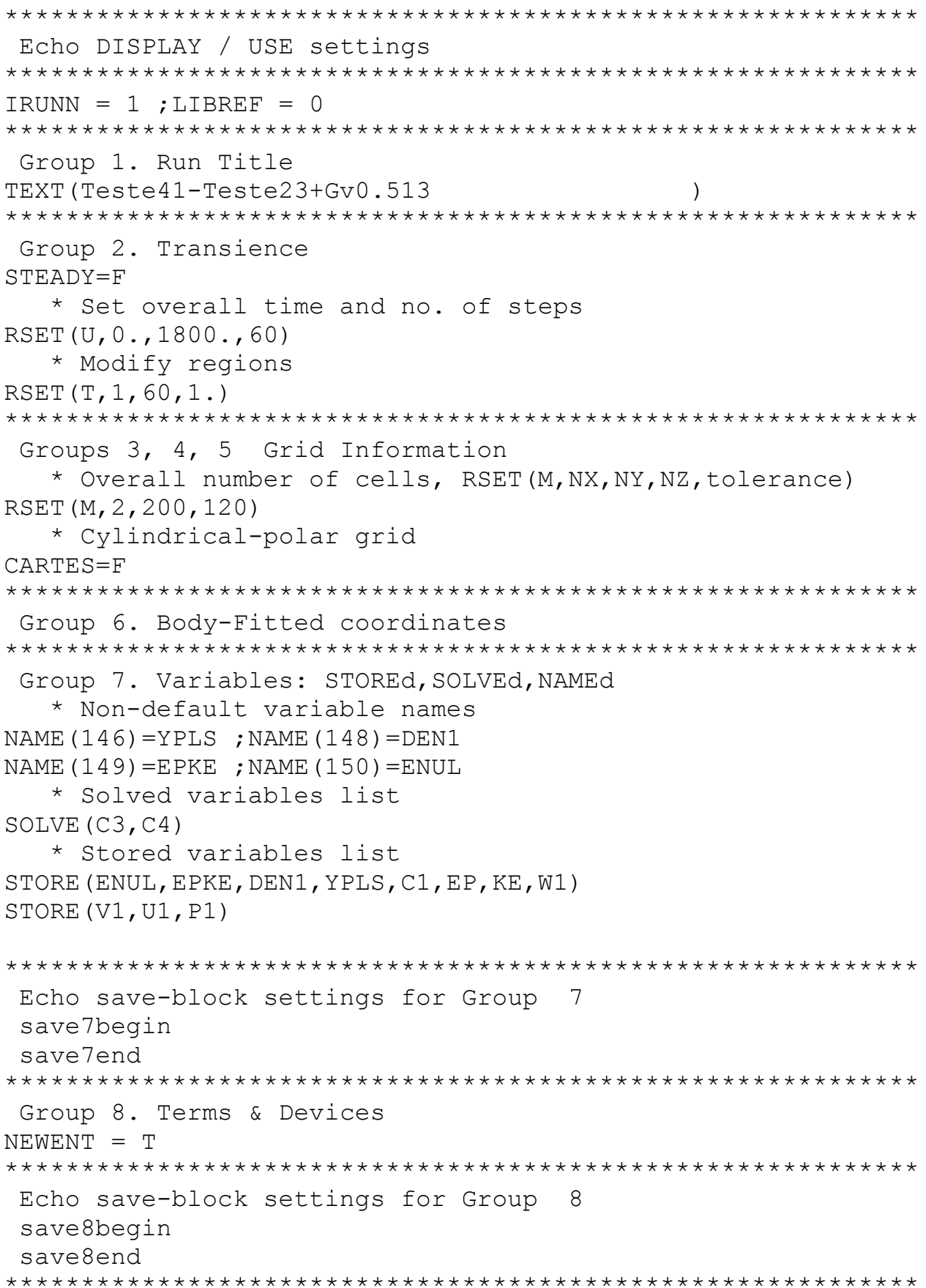




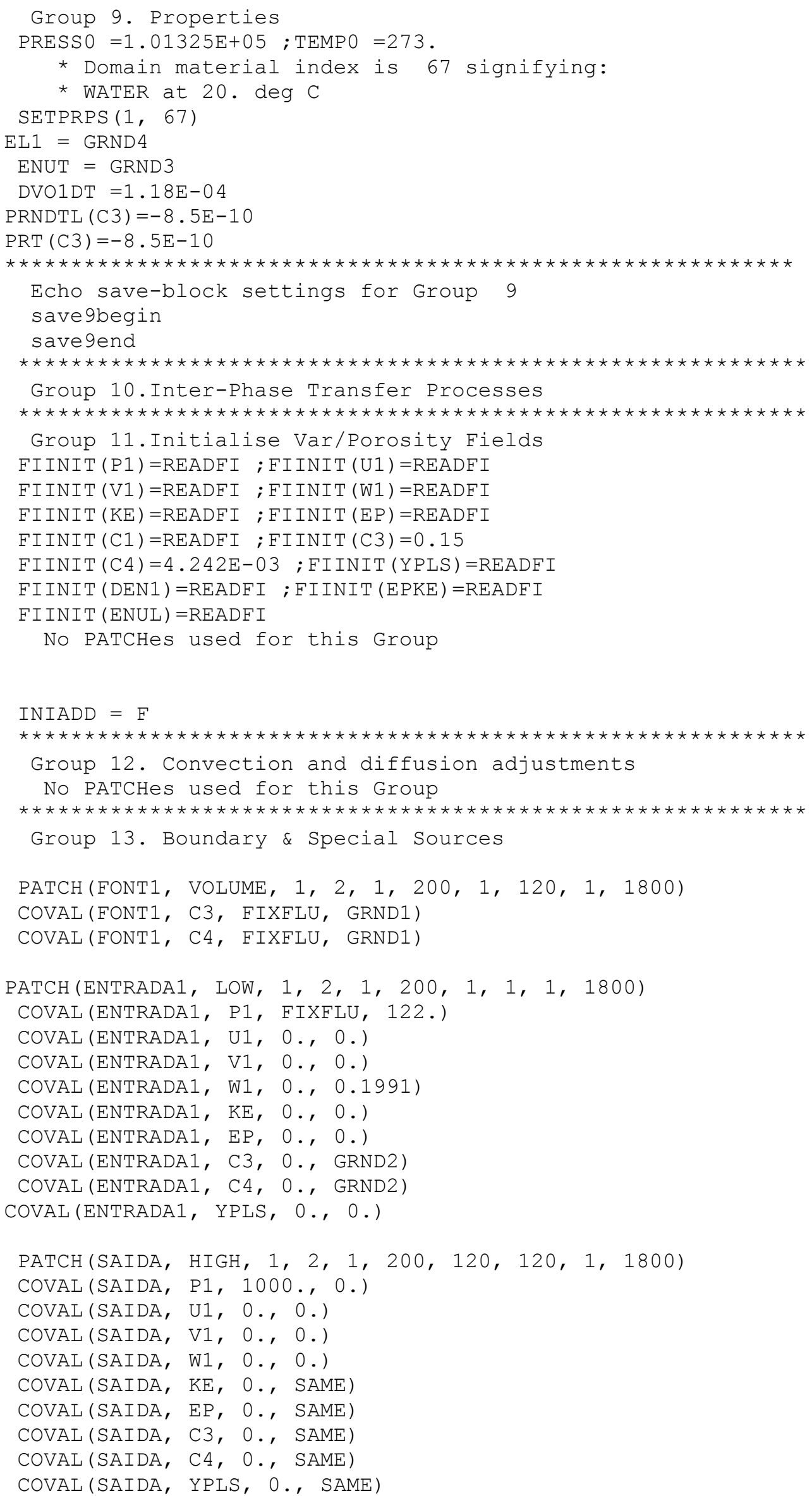




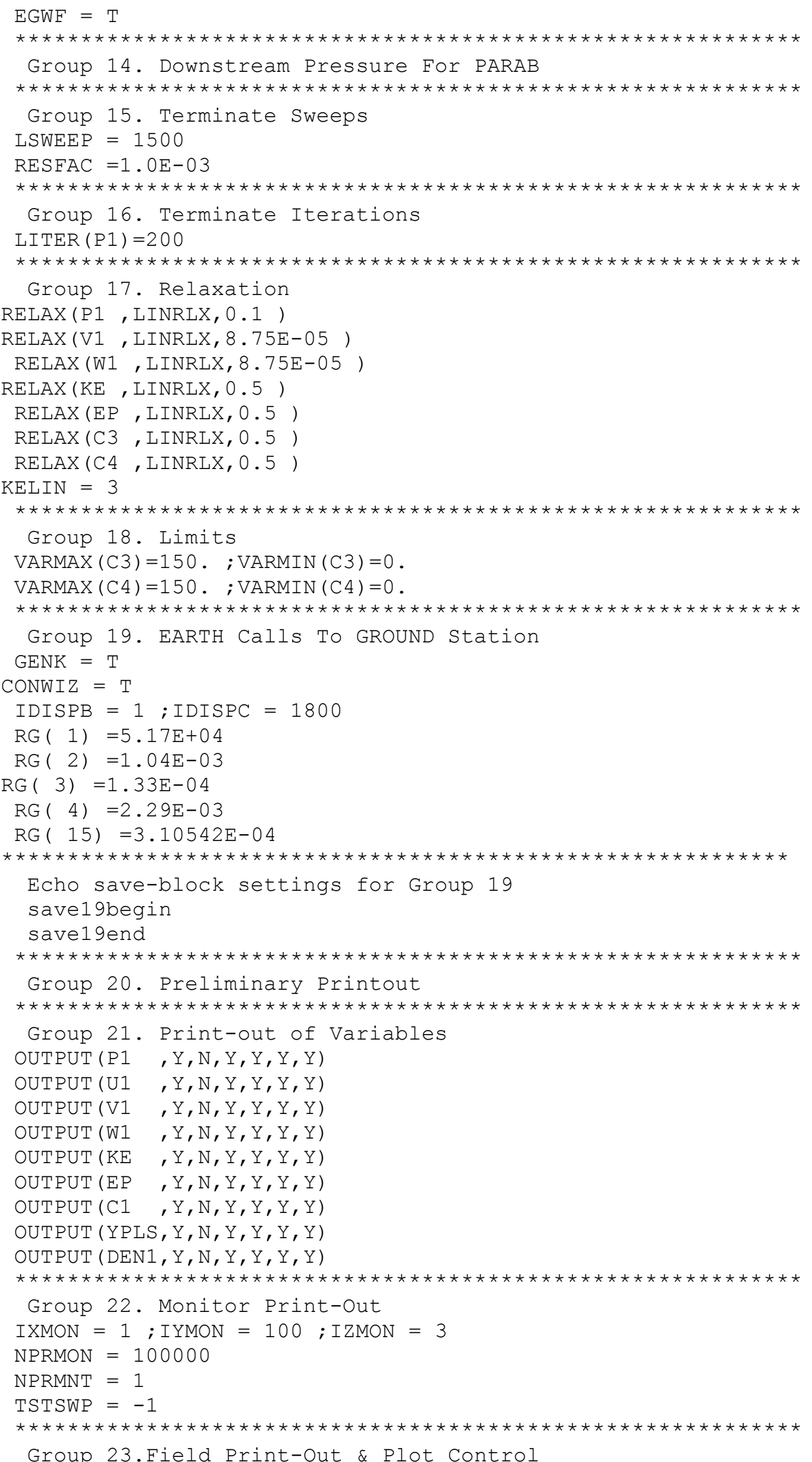

Group 23.Field Print-Out \& Plot Control 


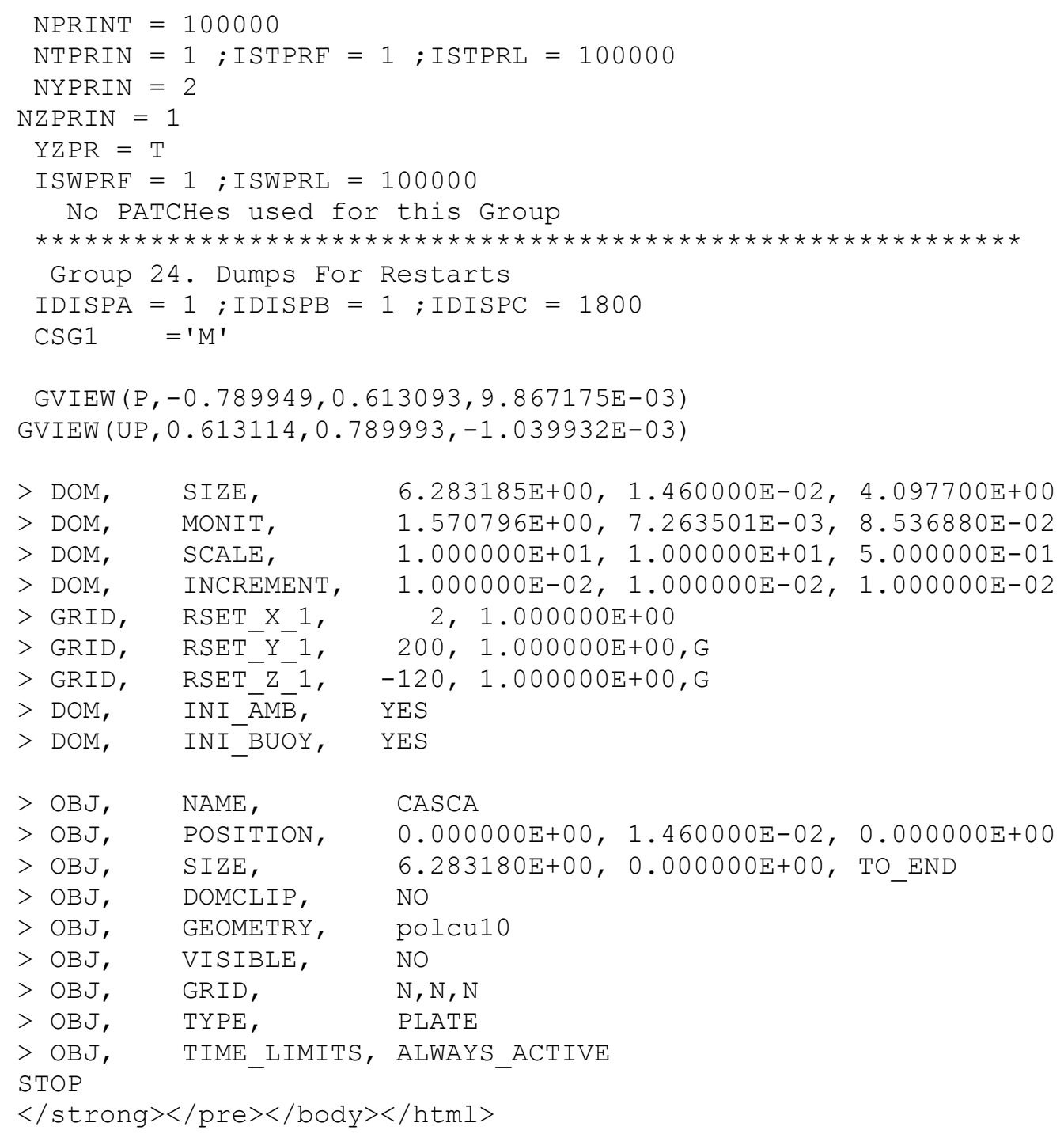




\section{APÊNDICE B - GROUND}

\section{B.1. Modelo cinético de 1‥ ordem e modelo de incidência radial}

$\mathrm{C}<\mathrm{html}><$ body $><$ pre $><$ strong $><$ ! -- - - >

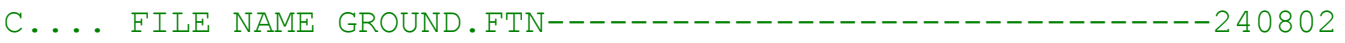

SUBROUTINE GROUND

INCLUDE' / phoenics/d includ/farray'

INCLUDE'/phoenics/d_includ/satear'

INCLUDE' / phoenics/d_includ/grdloc'

INCLUDE ' / phoenics/d includ/satgrd'

INCLUDE' / phoenics/d includ/grdear'

INCLUDE' / phoenics/d includ/grdbfC'

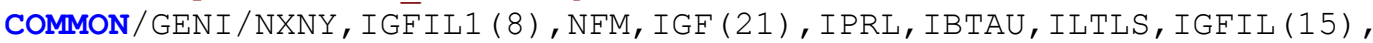

1 ITEM1, ITEM2, ISPH1, ISPH2, ICON1, ICON2, I PRPS, IRADX, IRADY, IRADZ, IVFOL COMMON/DRHODP / ITEMP, IDEN/DVMOD / I DVCGR

COMMON/HBASE/ IHO1, IH02, KH01, KH01H, KH01L, KHO2, KHO2H, KH02L, LOHO 2 CXXXXXXXXXXXXXXXXXXXXXXXXXXXXXXXXXXXXXXX USER SECTION STARTS:

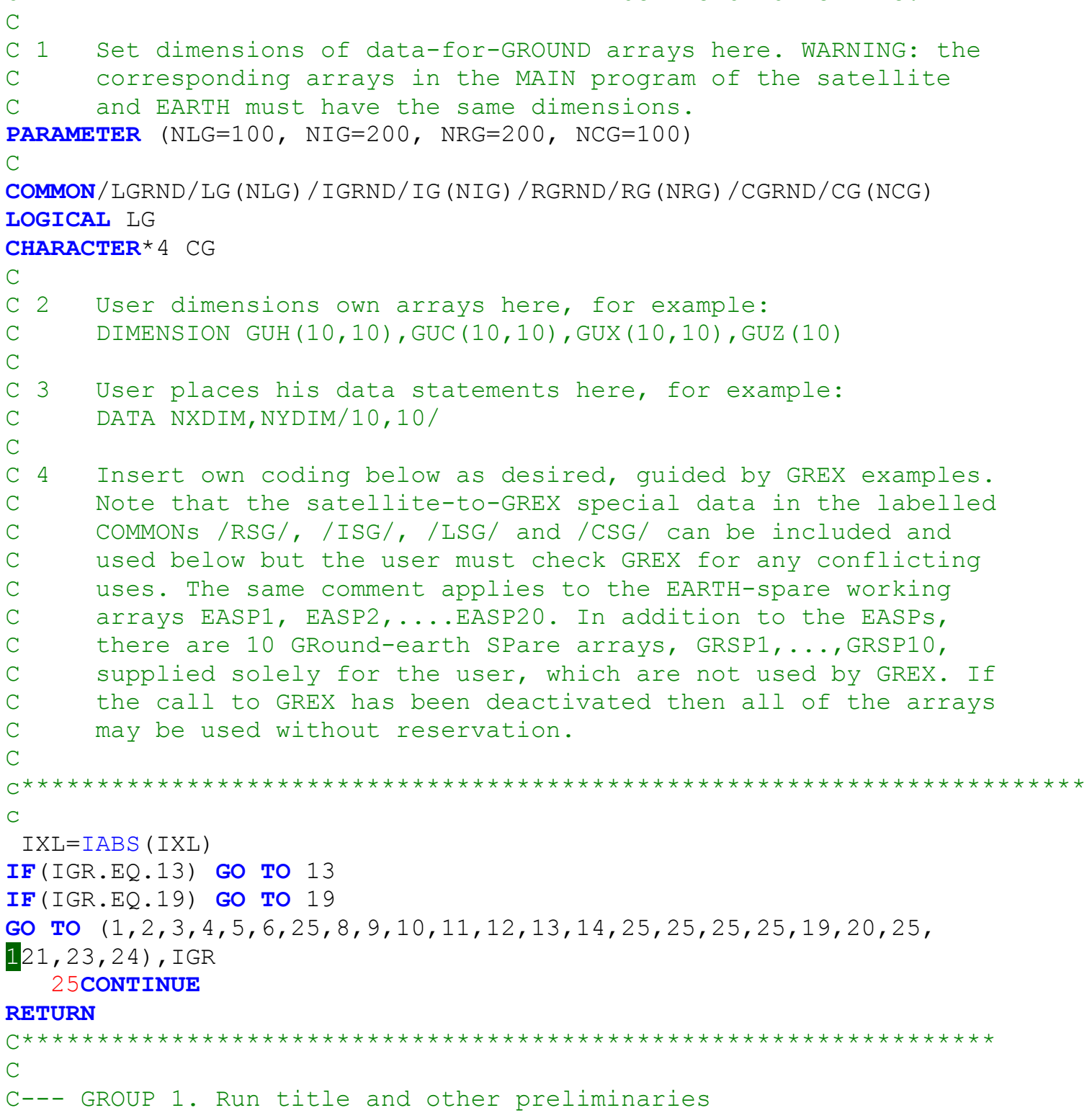


C

1GO TO $(1001,1002,1003)$, ISC

C

CALL MAKE (RV2D)

CALL MAKE (DYV2D)

CALL MAKE (RG2D)

1001 CONTINUE

C

C * - ----------GROUP 1 SECTION 3

C---- Use this group to create storage via MAKE, GXMAKE etc which it is

C essential to dump to PHI (or PHIDA) for restarts

C User may here change message transmitted to the VDU screen

IF (.NOT.NULLPR)

1CALL WRYT40('GROUND file is GROUND.F of: 140796 ')

\section{RETURN}

C * - - - - - - ---GROUP 1 SECTION 3 - - - - - - - - - - - - - - - - - - - - -

C---- Use this group to create storage via GXMAKE which it is not

C necessary to dump to PHI (or PHIDA) for restarts

1003 CONTINUE

GO TO 25

1002 CONTINUE

\section{RETURN}

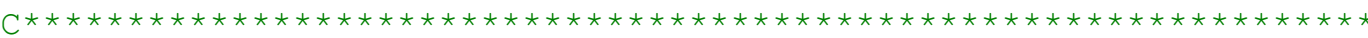

$\mathrm{C}$

C--- GROUP 2. Transience; time-step specification

C

\section{CONTINUE}

\section{RETURN}

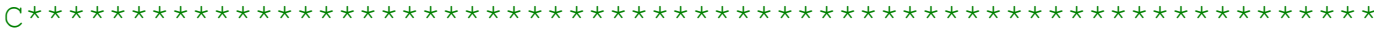

$\mathrm{C}$

C--- GROUP 3. X-direction grid specification

C

\section{CONTINUE}

\section{RETURN}

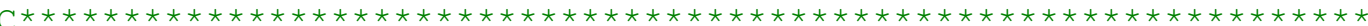

$\mathrm{C}$

C--- GROUP 4. Y-direction grid specification

$\mathrm{C}$

\section{CONTINUE}

RETURN

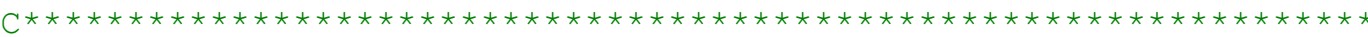

$\mathrm{C}$

C--- GROUP 5. Z-direction grid specification

C

5 CONTINUE

\section{RETURN}

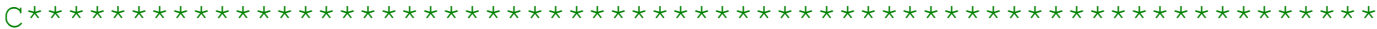

$\mathrm{C}$

C--- GROUP 6. Body-fitted coordinates or grid distortion

C

\section{CONTINUE}

\section{RETURN}

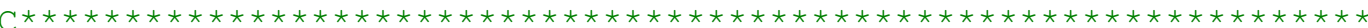

C * Make changes for this group only in group 19.

C--- GROUP 7. Variables stored, solved \& named 


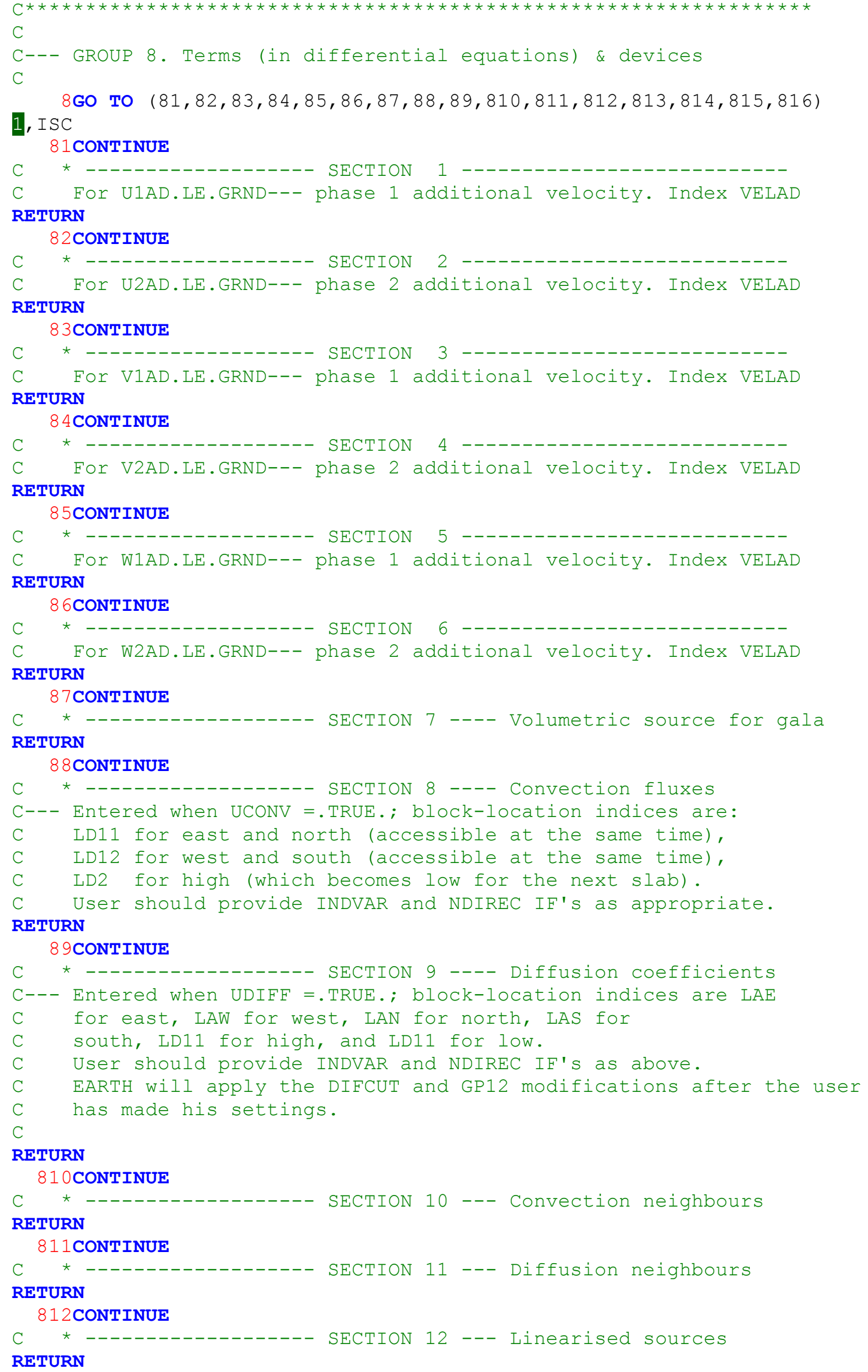




\section{CONTINUE}

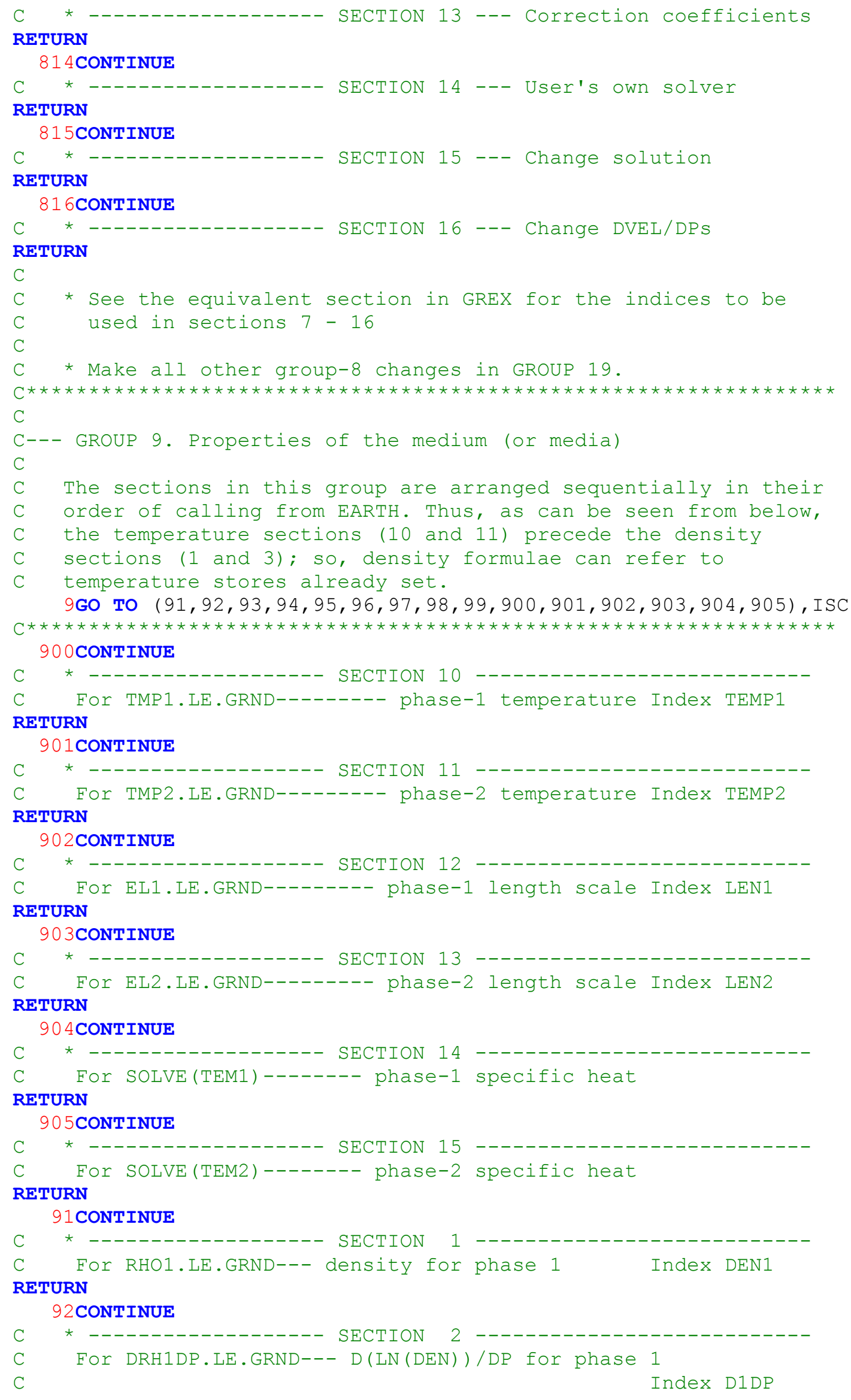




\section{RETURN}

93 CONTINUE

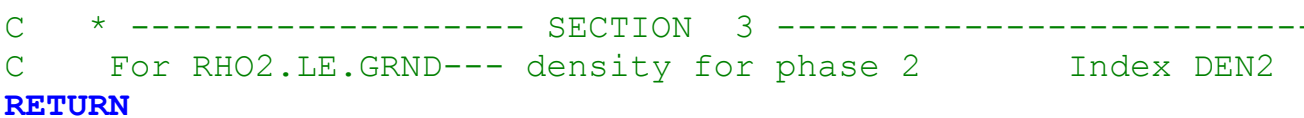

94 CONTINUE

C $\quad *-1$
C FOr DRH2DP.LE.GRND--- D(LN (DEN)) /DP for phase 2

C

RETURN

95 CONTINUE

$\mathrm{C} *------------------$ SECTION $5---------------------------$

C For ENUT.LE.GRND--- reference turbulent kinematic viscosity

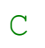




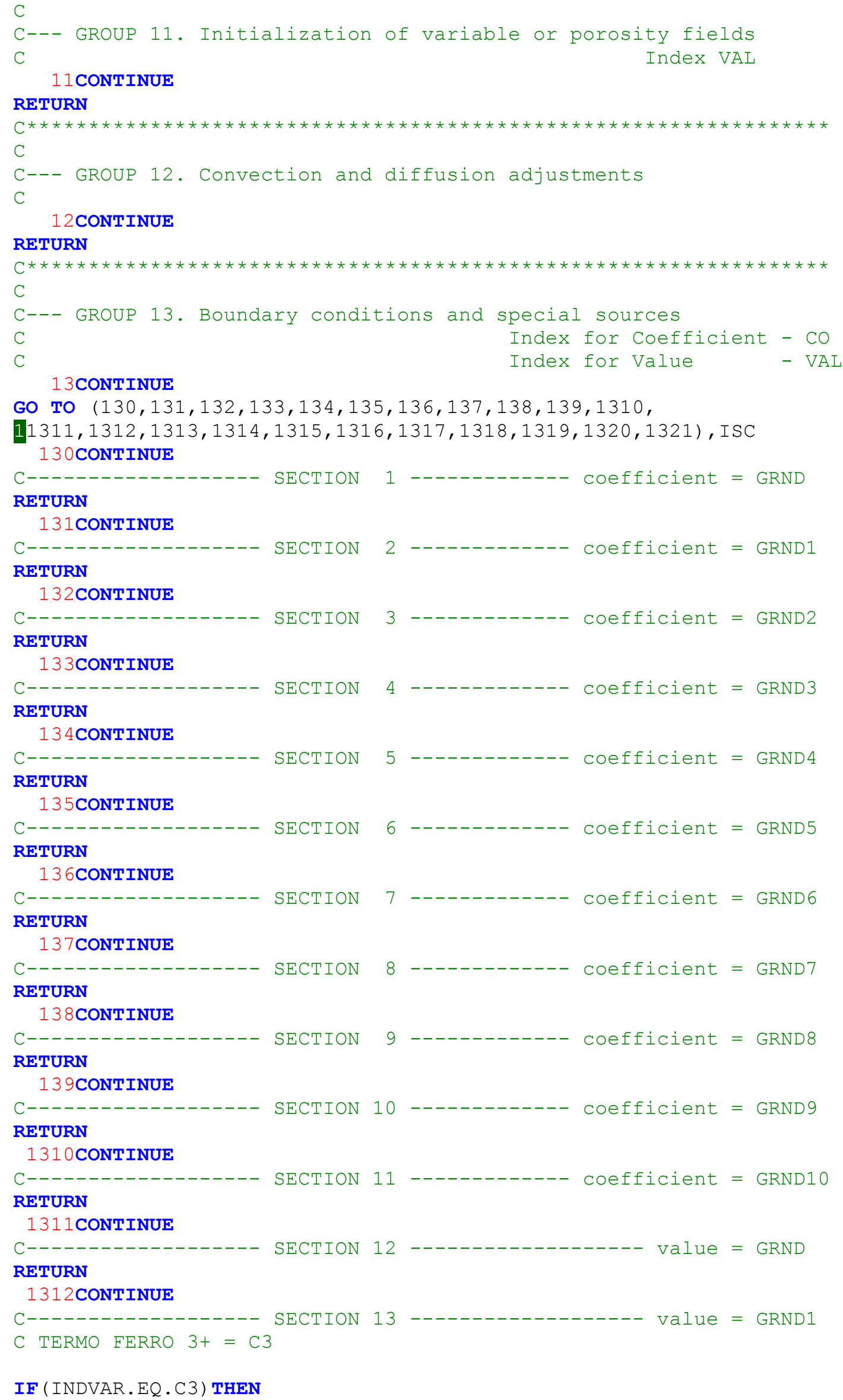




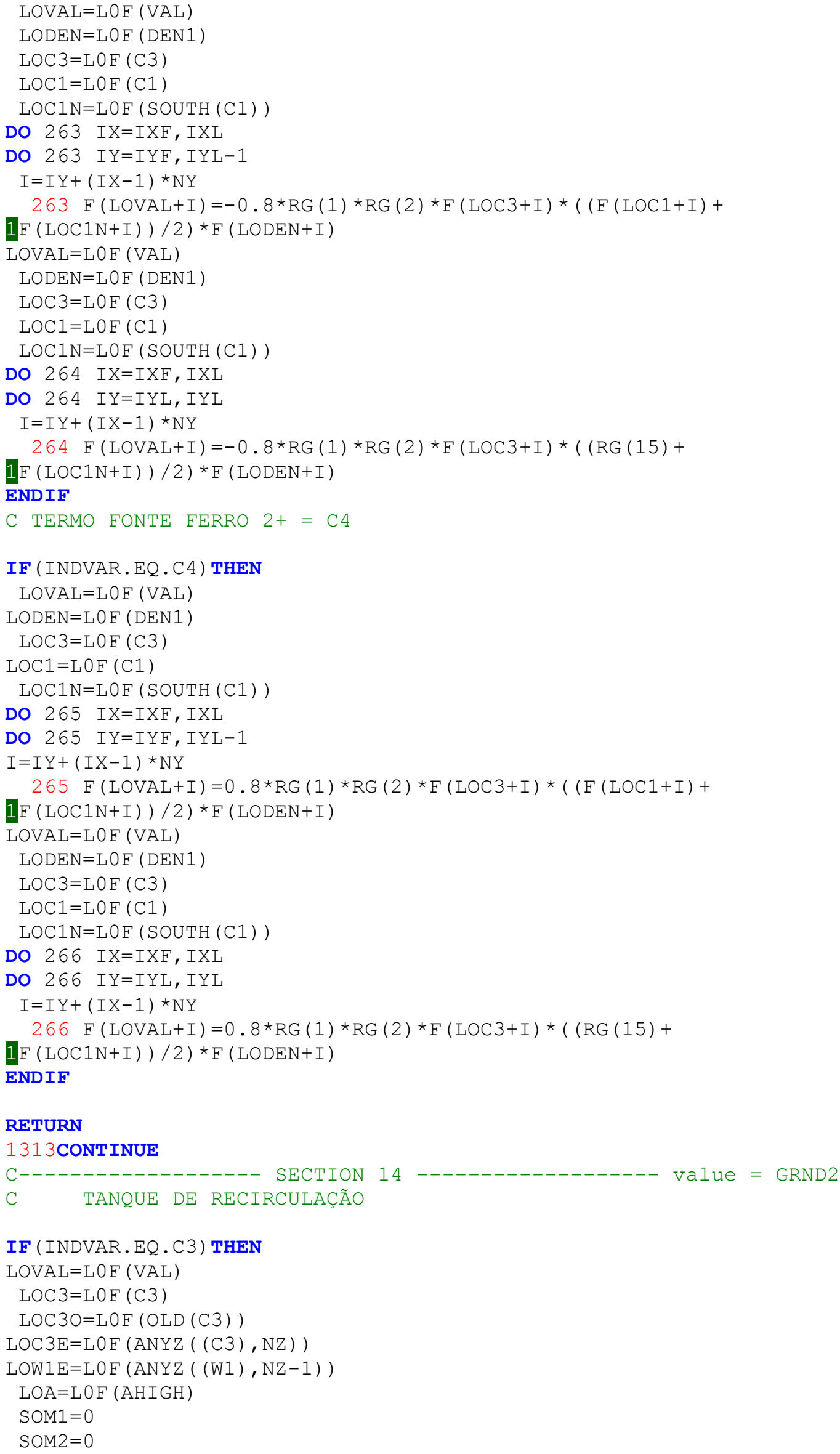




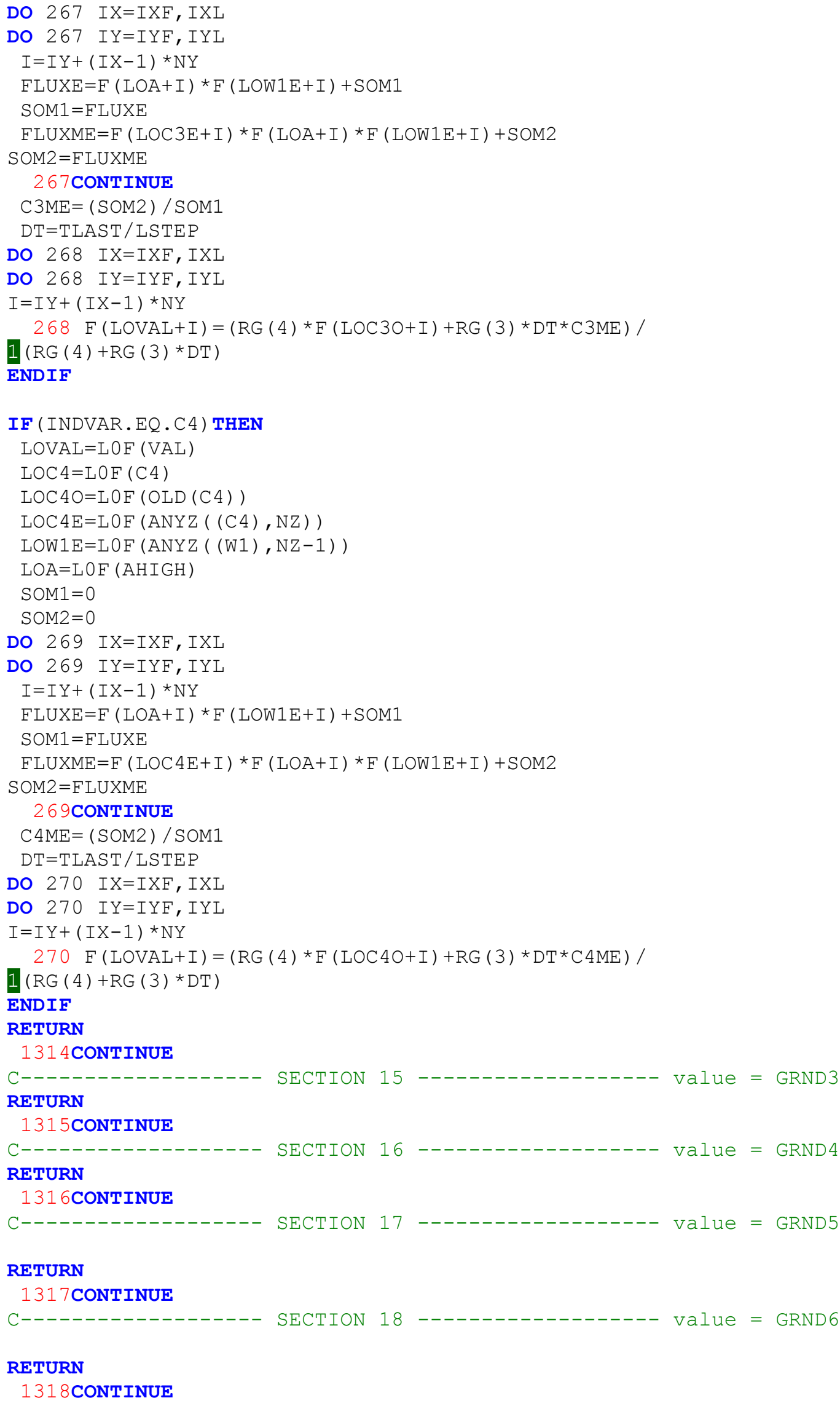




\section{RETURN}

1319 CONTINUE

C------------------ SECTION $20-------------------$ value $=$ GRND8

\section{RETURN}

1320 CONTINUE

C------------------- SECTION $21-------------------$ value $=$ GRND9

\section{RETURN}

1321 CONTINUE

C---------------- SECTION $22----------------$ value = GRND10

\section{RETURN}

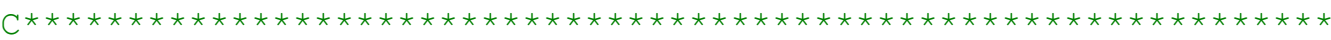

C

C--- GROUP 14. Downstream pressure for PARAB=.TRUE.

C

14 CONTINUE

\section{RETURN}

C* $\mathrm{C}^{*}$ Make changes to data for GROUPS 15, 16, 17, 18 GROUP 19.

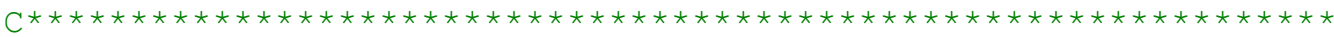

$\mathrm{C}$

C--- GROUP 19. Special calls to GROUND from EARTH

$\mathrm{C}$

19 GO TO $(191,192,193,194,195,196,197,198,199,1910,1911)$, ISC

191 CONTINUE

$\mathrm{C}$ SECTION 1 ---- Start of time step.

\section{RETURN}

192 CONTINUE

C

$\mathrm{LOC1}=\mathrm{LOF}((\mathrm{C} 1))$

LOC 1 N=LOF (NORTH (C1))

$\mathrm{LOC} 3 \mathrm{~N}=\mathrm{LOF}(\mathrm{NORTH}(\mathrm{C} 3))$

$\mathrm{LOC} 3=\mathrm{LOF}((\mathrm{C} 3))$

LOY $=\mathrm{LOF}(\mathrm{RV} 2 \mathrm{D})$

LOYIN=LOF (NORTH (RV2D))

DO 273 IX=IXE, IXI

DO 273 IY=IYF, IYL-1

$I=I Y+(I X-1) * N Y$

$273 \mathrm{~F}(\mathrm{LOC} 1+\mathrm{I})=\mathrm{F}(\mathrm{LOC} 1 \mathrm{~N}+\mathrm{I})$ * $(\mathrm{F}(\mathrm{LOYIN}+\mathrm{I}) / \mathrm{F}(\mathrm{LOY}+\mathrm{I}))$ *EXP $(-\mathrm{RG}(1) * \mathrm{~F}(\mathrm{LOC} 3+\mathrm{I})$ *

$1(\mathrm{~F}(\mathrm{LOYIN}+\mathrm{I})-\mathrm{F}(\mathrm{LOY}+\mathrm{I})))$

$\mathrm{LOC} 1=\mathrm{L} 0 \mathrm{~F}((\mathrm{C1}))$

LOC1N=L0F (NORTH (C1))

$\mathrm{LOC} 3 \mathrm{~N}=\mathrm{LOF}(\mathrm{NORTH}(\mathrm{C} 3))$

$\mathrm{LOC} 3=\mathrm{L} 0 \mathrm{~F}($ (C3) $)$

$\mathrm{LOY}=\mathrm{LOF}(\mathrm{RV} 2 \mathrm{D})$

LOYIN=LOF (NORTH (RG2D))

DO 274 IX=IXE, IXI

DO 274 IY=IYL, IYL

$I=I Y+(I X-1) * N Y$

$274 \mathrm{~F}(\mathrm{LOC} 1+\mathrm{I})=\mathrm{RG}(15)$

RETURN

193CONTINUE

$\mathrm{C} *-------$

$\mathrm{LOC1}=\mathrm{L} 0 \mathrm{~F}((\mathrm{C} 1))$

LOC1N=L0F (NORTH (C1))

LOC3N=LOF (NORTH (C3))

$\mathrm{LOC3}=\mathrm{LOF}((\mathrm{C} 3))$ 


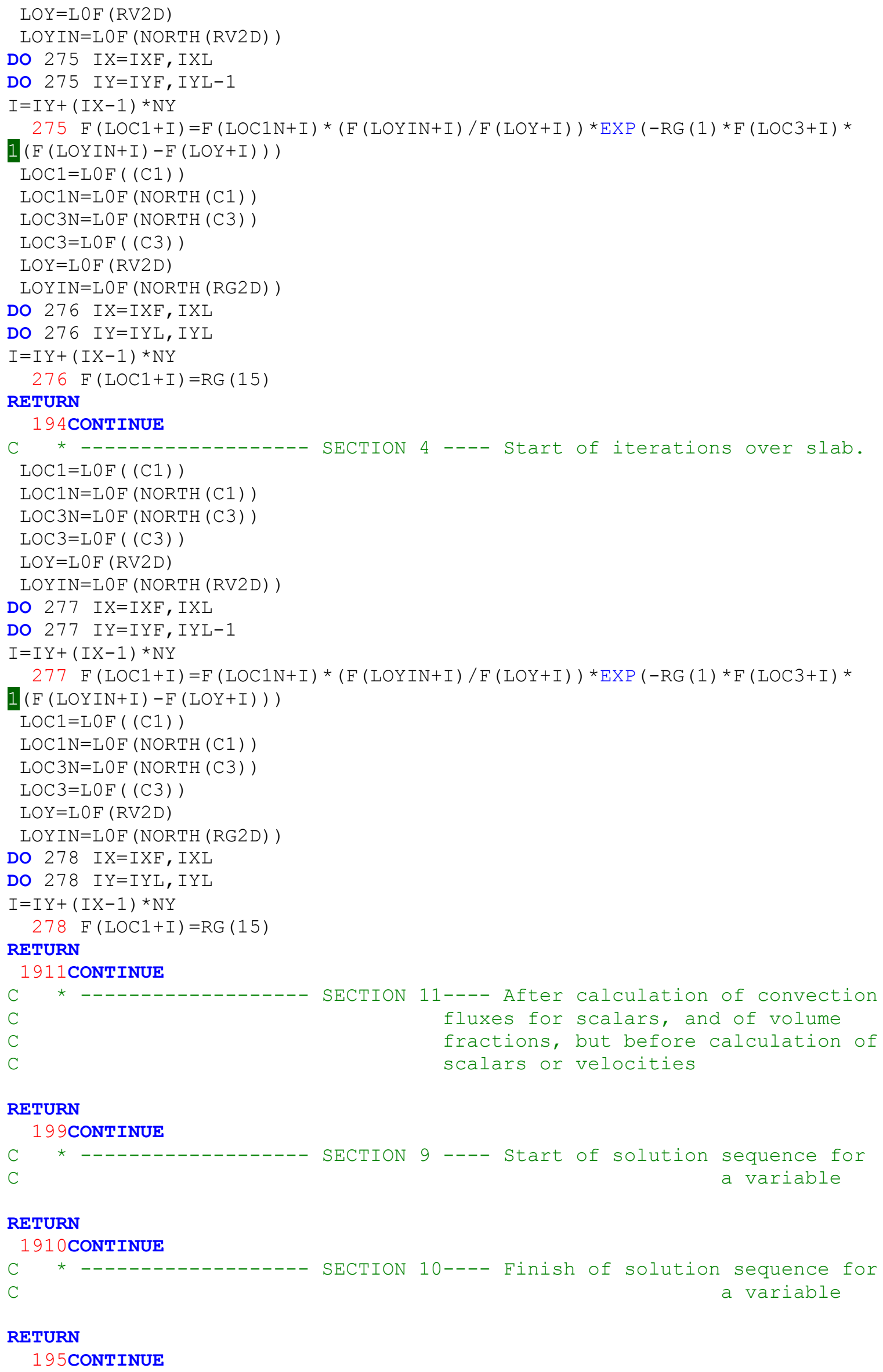




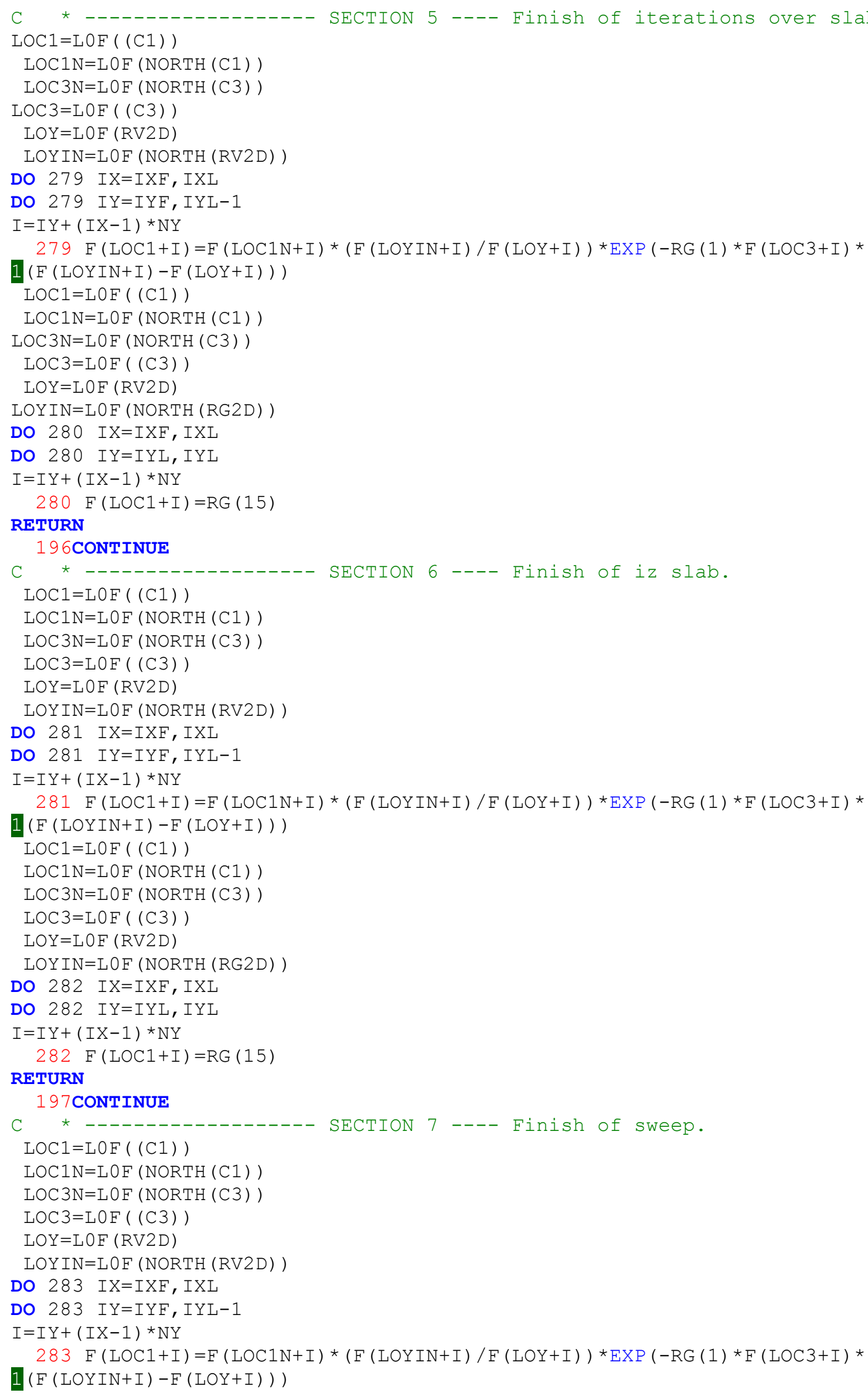




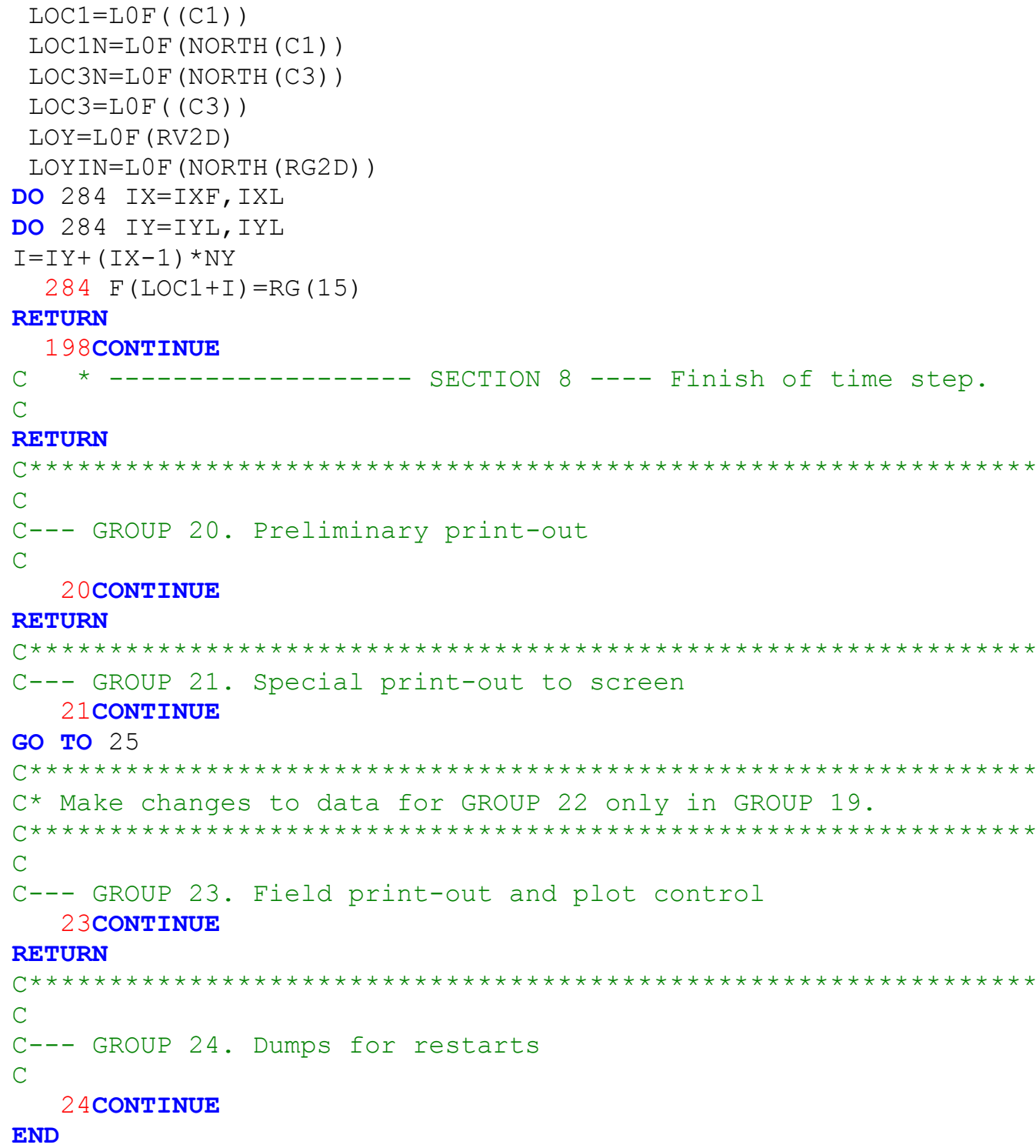

\section{B.2. Modelo de incidência difusa}

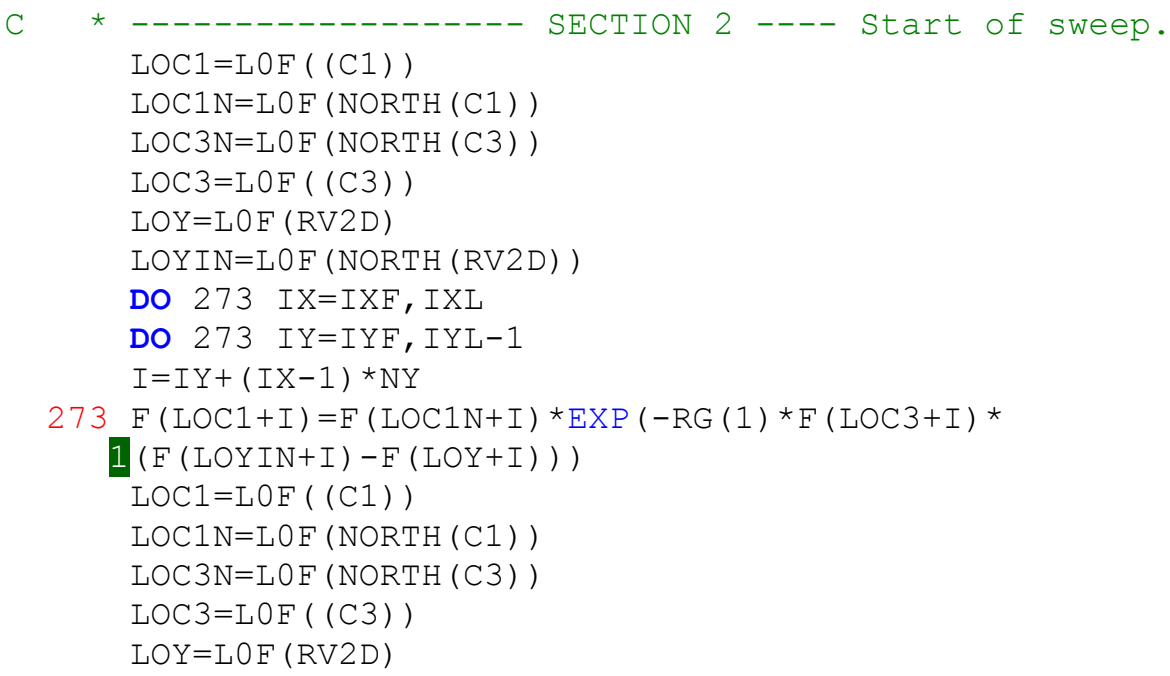




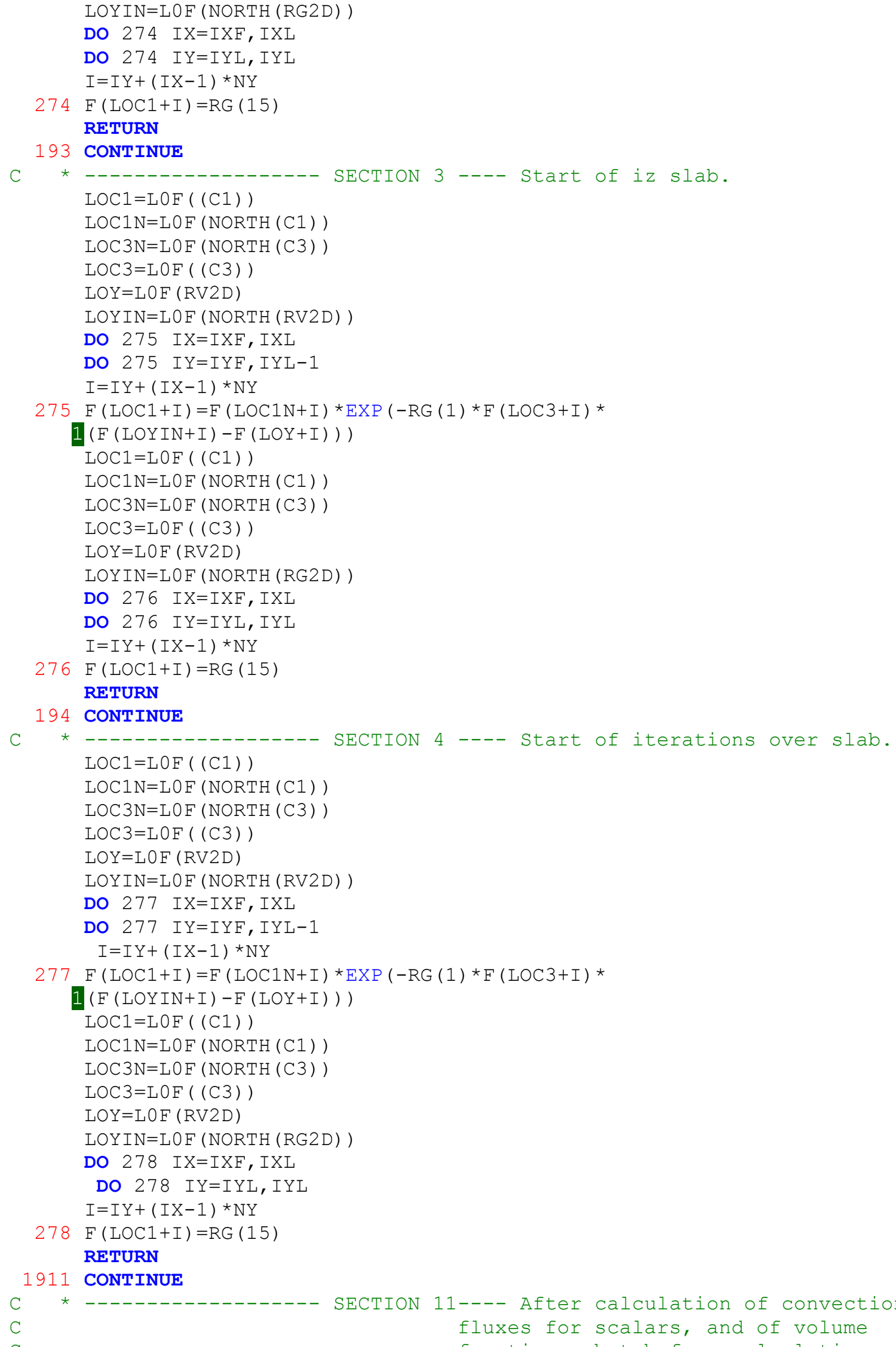

\section{CONTINUE} SECTION 4 ---- Start of iterations over slab. 


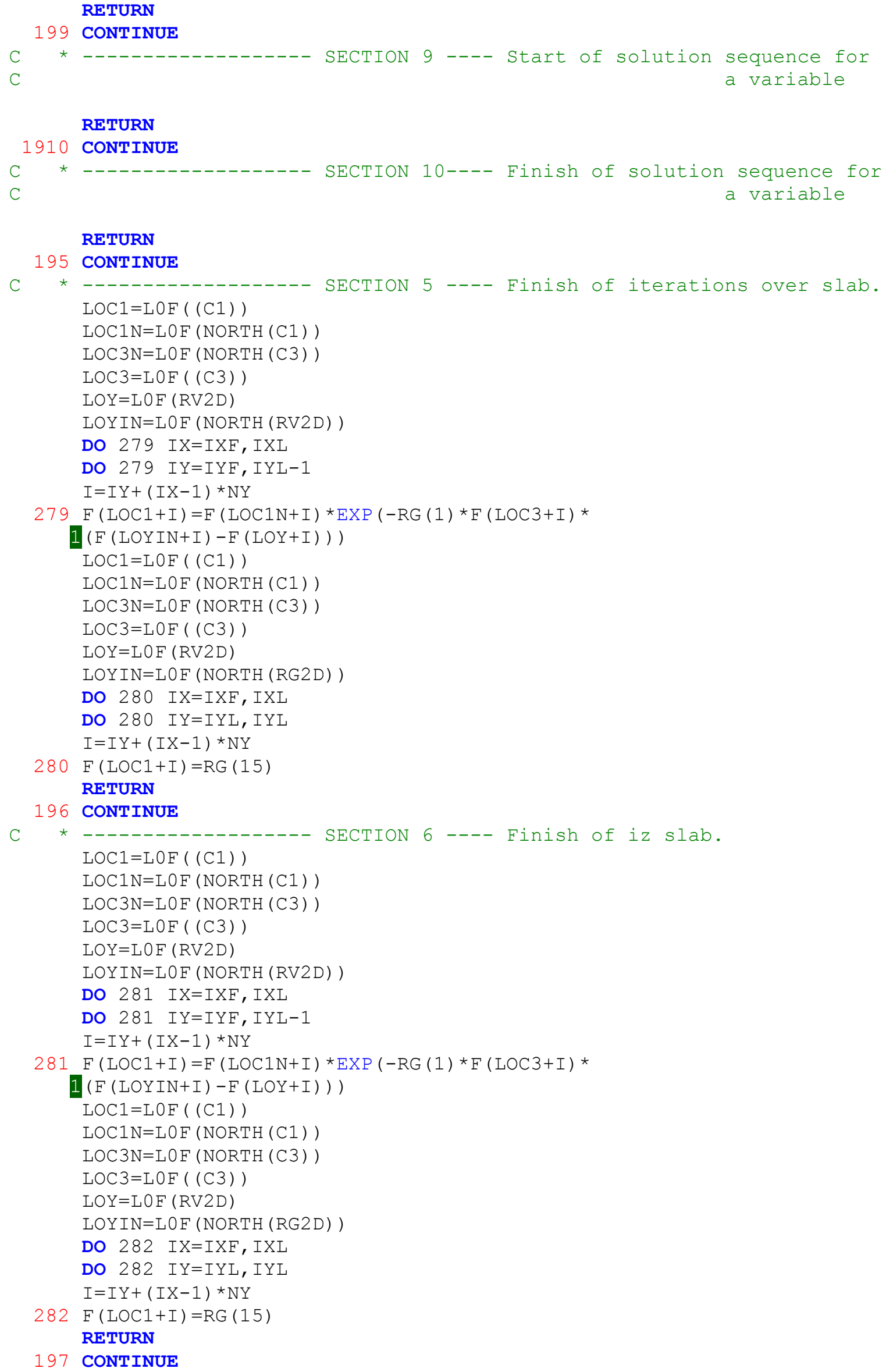




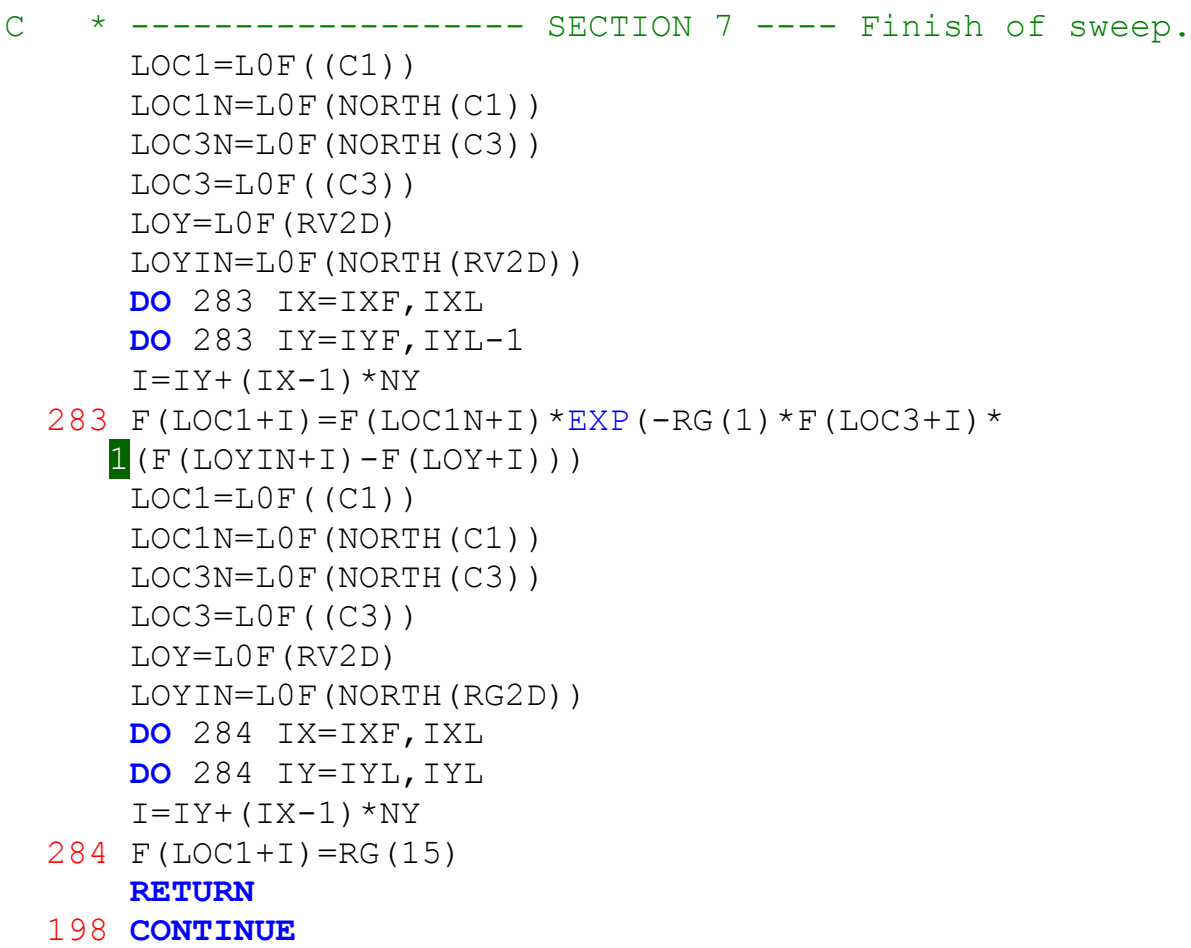

\section{B.3. Modelo cinético exponencial}

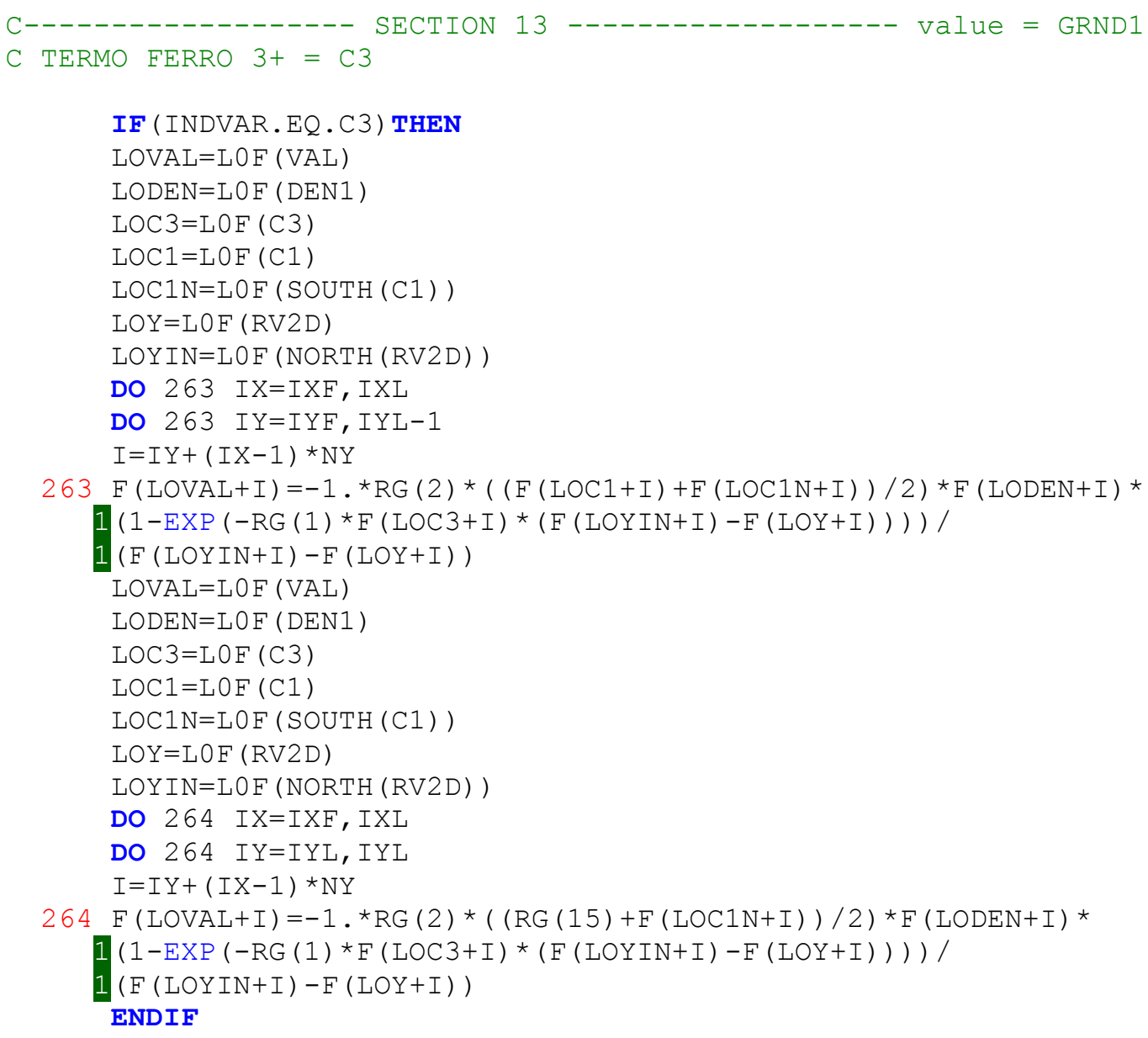


C TERMO FONTE FERRO $2+=\mathrm{C} 4$

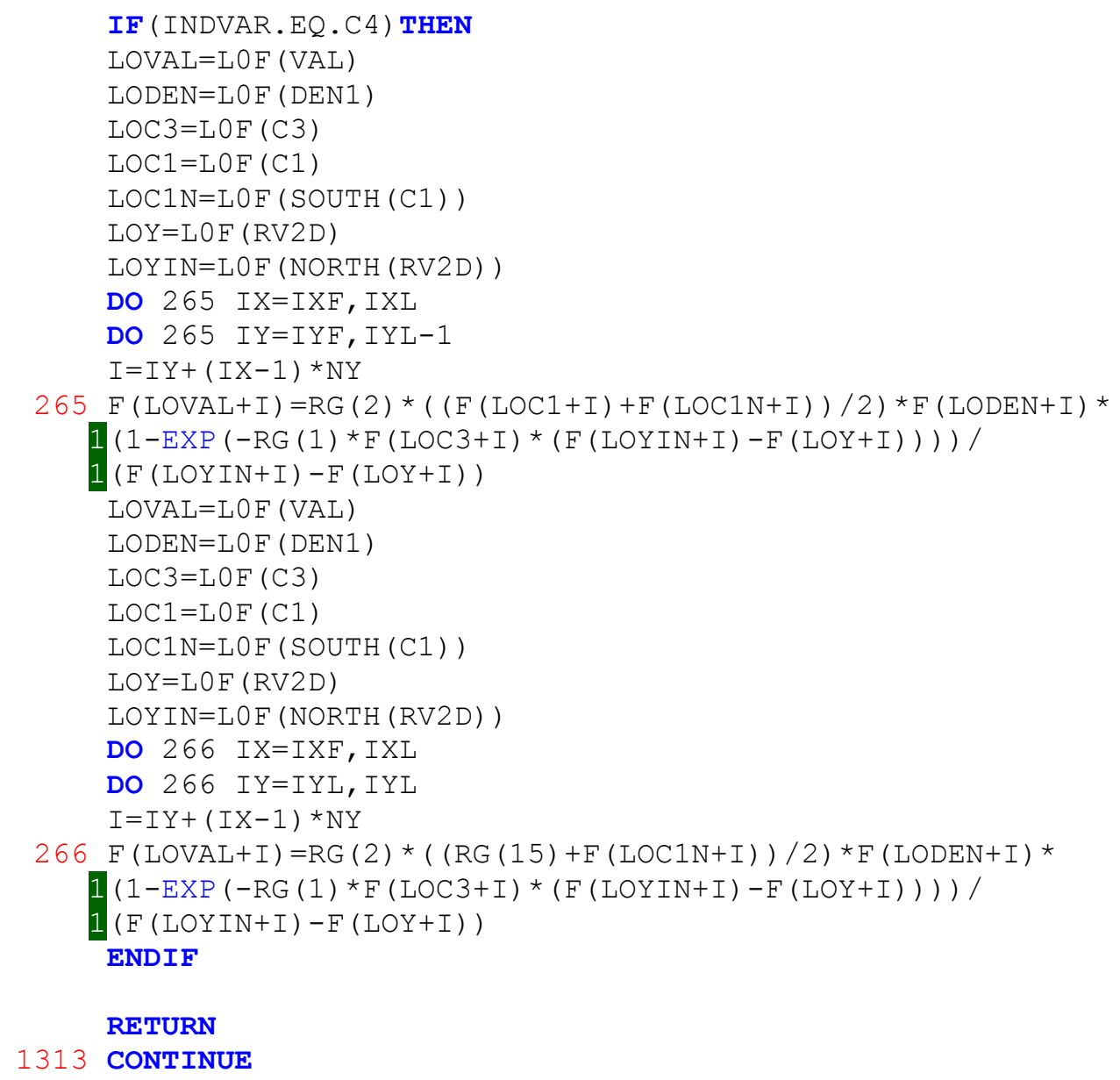

\section{B.4. Modelo cinético de 4ª ordem}

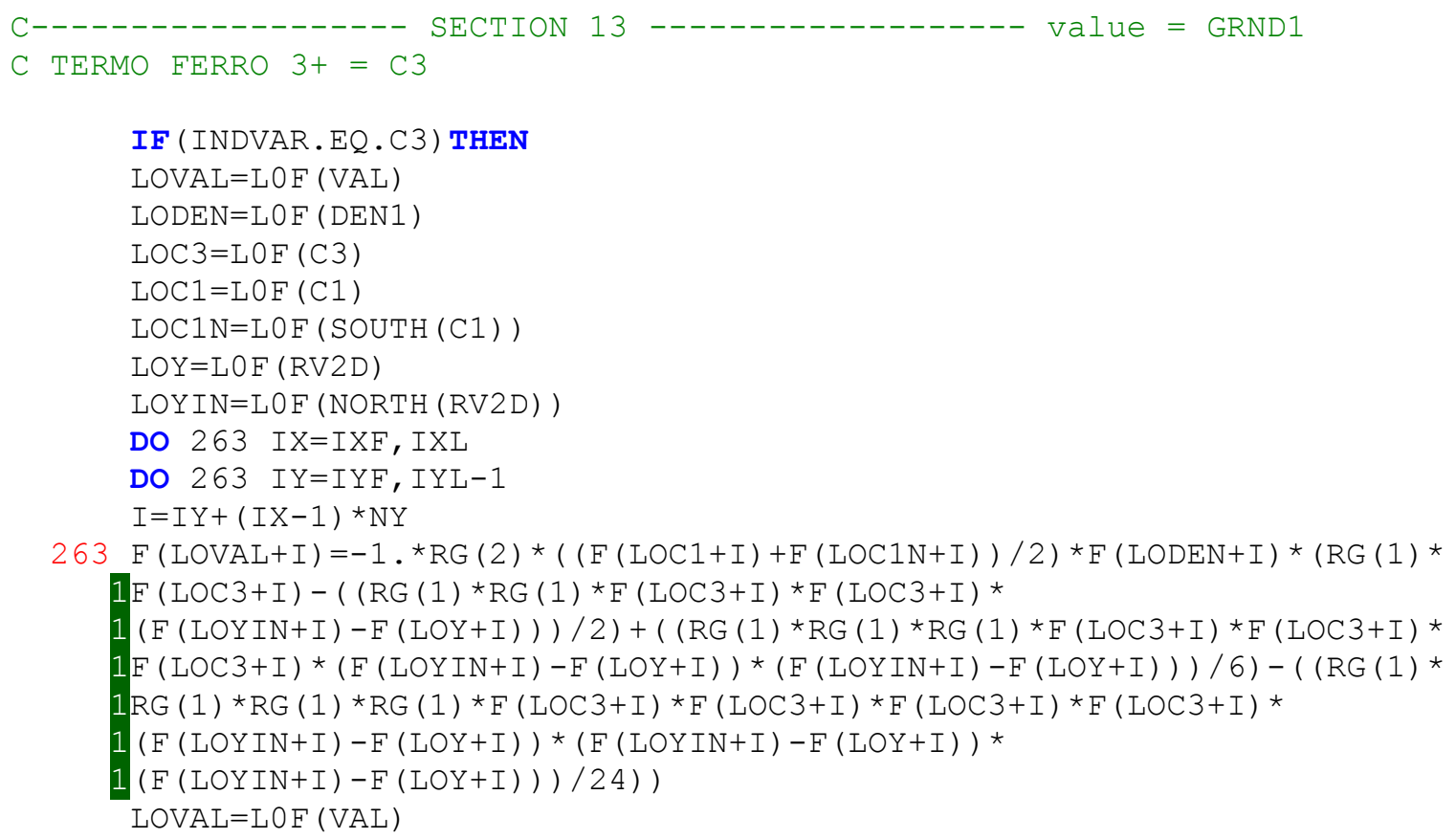




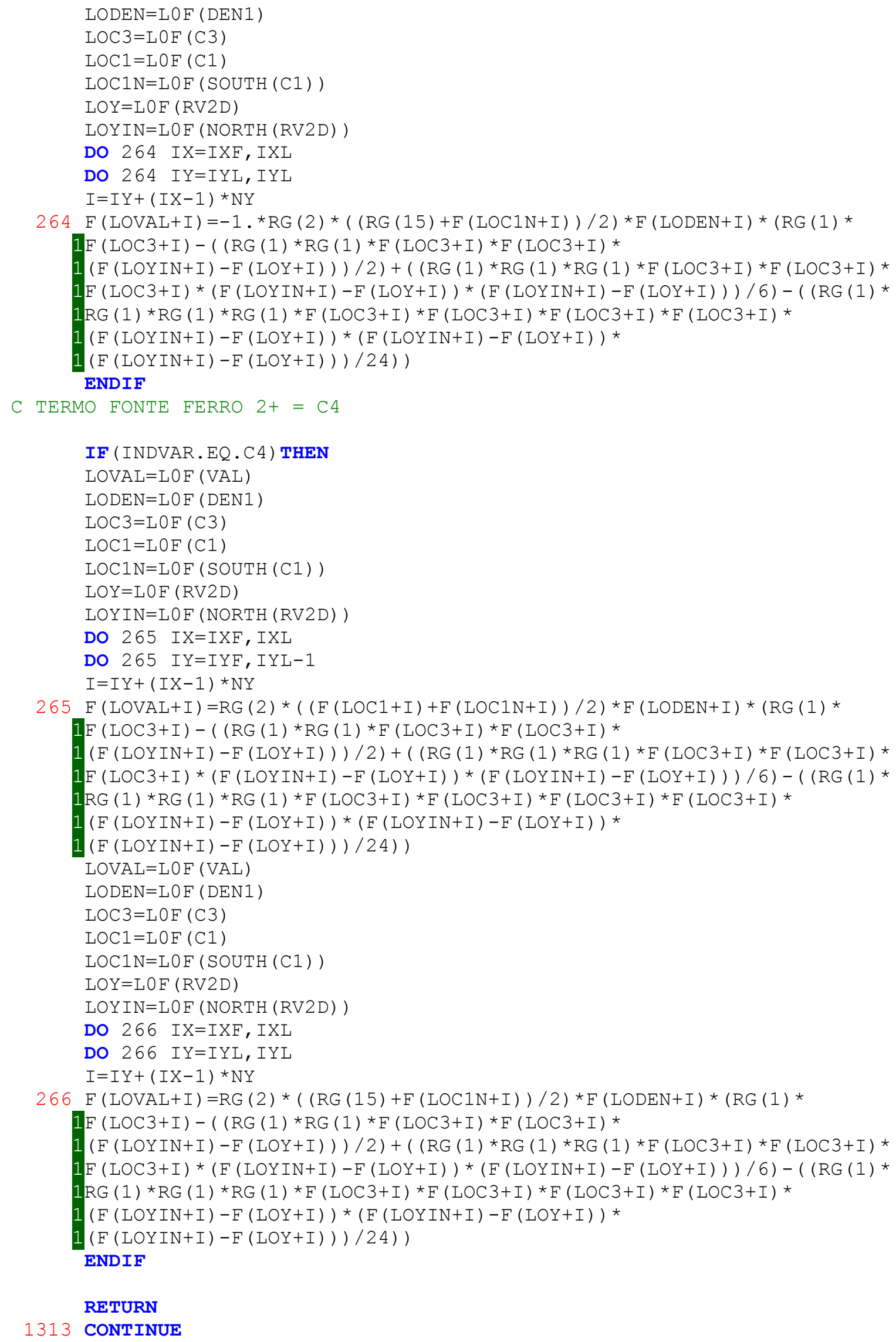




\section{APÊNDICE C - GXMONI DA SIMULAÇÃO DO $G_{v}$ ESCOLHIDO}

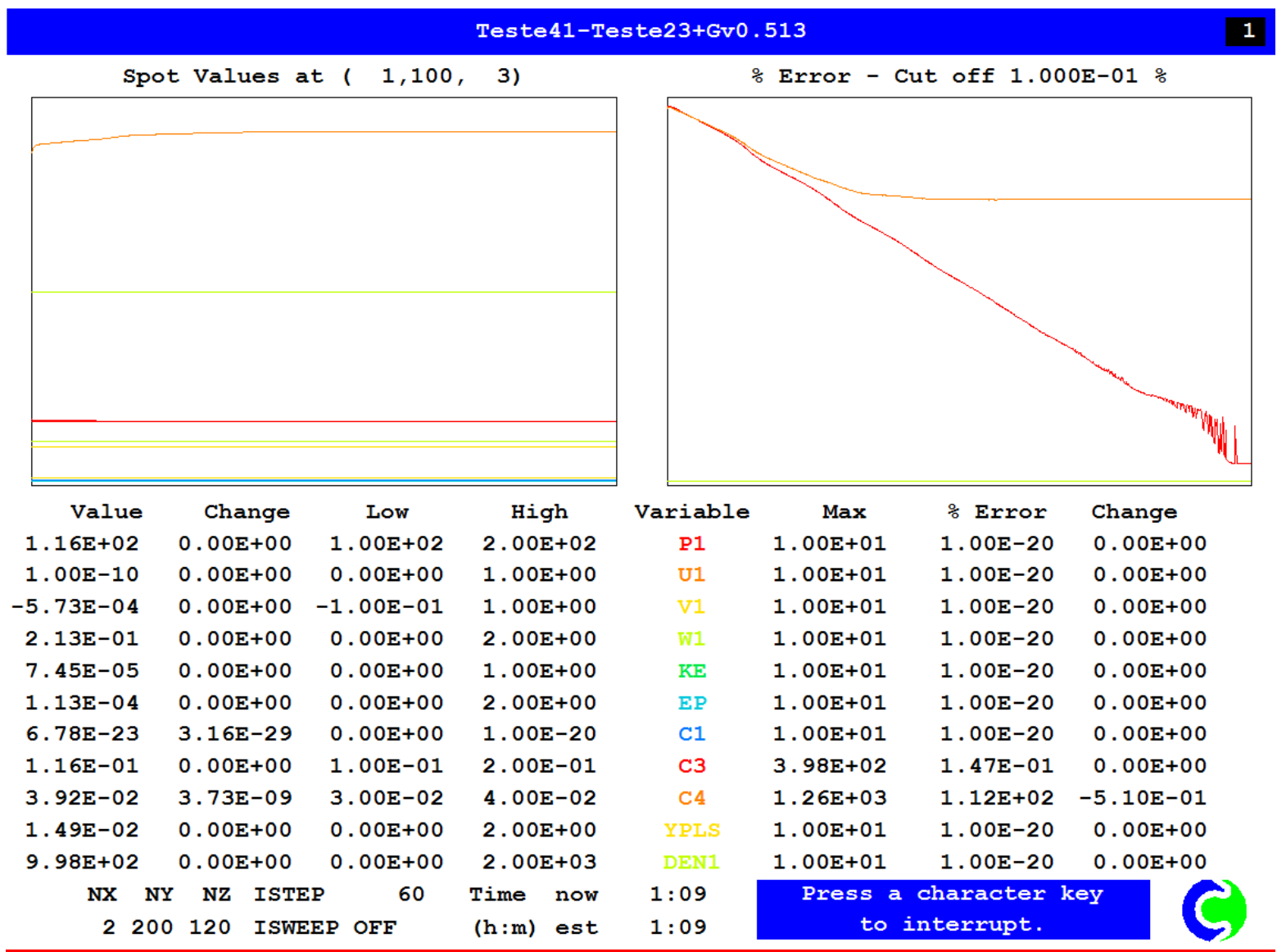

